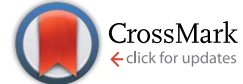

Cite this: Nat. Prod. Rep., 2015, 32, 116

\title{
Marine natural products
}

John W. Blunt, ${ }^{\star a}$ Brent R. Copp, ${ }^{\text {b }}$ Robert A. Keyzers, ${ }^{c}$ Murray H. G. Munro ${ }^{a}$ and Michèle R. Prinsep ${ }^{d}$

Covering: 2013. Previous review: Nat. Prod. Rep., 2014, 31, 160-258
Received 4th November 2014

DOI: $10.1039 / c 4 n p 00144 c$

www.rsc.org/npr
This review covers the literature published in 2013 for marine natural products (MNPs), with 982 citations (644 for the period January to December 2013) referring to compounds isolated from marine microorganisms and phytoplankton, green, brown and red algae, sponges, cnidarians, bryozoans, molluscs, tunicates, echinoderms, mangroves and other intertidal plants and microorganisms. The emphasis is on new compounds (1163 for 2013), together with the relevant biological activities, source organisms and country of origin. Reviews, biosynthetic studies, first syntheses, and syntheses that lead to the revision of structures or stereochemistries, have been included.
Introduction

Reviews

Marine microorganisms and phytoplankton

3.1 Marine-sourced bacteria (excluding from mangroves)

3.2

3.3

3.4

3.5

3.6

3.7

3.8

3.9

3.10

4

5

6

7

\section{8}

\section{9}

\section{0}

\section{1}

12

13

14

15

Marine-sourced fungi (excluding from mangroves)

Fungi from mangroves

Cyanobacteria

Dinoflagellates

Microalgae

Synthetic aspects

Assorted bioactivities

o Biosynthesis

Green algae

Brown algae

Red algae

Sponges

Cnidarians

Bryozoans

Molluses

Tunicates (ascidians)

Echinoderms

Mangroves

Miscellaneous

Conclusion

${ }^{a}$ Department of Chemistry, University of Canterbury, Christchurch, New Zealand. E-mail: john.blunt@canterbury.ac.nz

${ }^{b}$ School of Chemical Sciences, University of Auckland, Auckland, New Zealand ${ }^{c}$ Centre for Biodiscovery, and School of Chemical and Physical Sciences, Victoria University of Wellington, Wellington, New Zealand

${ }^{d}$ Chemistry, School of Science, University of Waikato, Hamilton, New Zealand

\section{Acknowledgements \\ 17 References}

\section{Introduction}

This review is of the literature for 2013 and describes 1163 new compounds from 379 articles, a 6\% decrease in the number of compounds reported in 2012. ${ }^{1}$ As in previous reviews, the structures are shown only for new compounds, or for previously reported compounds where there has been a structural revision or a newly established stereochemistry. Previously reported compounds for which first syntheses or new bioactivities are described are referenced, but separate structures are generally not shown. Where the absolute configuration has been determined for all stereocentres in a compound, the identifying diagram number is distinguished by addition of the $\dagger$ symbol.

\section{Reviews}

A selection of the many reviews on various aspects of MNP studies is listed here. A comprehensive review of MNPs reported in 2011 has appeared, ${ }^{2}$ as well as the highlights of compounds reported in 2012. ${ }^{3}$ Marine pharmacology papers for 2009-2011 have been collated, ${ }^{4}$ two reviews summarise natural products (NPs), including from marine sources, as drug leads, ${ }^{5,6}$ while another paper describes recent advances in marine drug research. ${ }^{7}$ A synopsis of the project BAMMBO for the sustainable production of biologically active molecules of marine based origin has appeared. ${ }^{8}$ General classes of compounds have been reviewed in papers on marine triterpenoids as anticancer 
agents, ${ }^{9}$ alkaloids from corals, ${ }^{\mathbf{1 0}}$ meroterpenes from marine invertebrates, ${ }^{\mathbf{1 1}}$ 'head-to-sidechain' cyclodepsipeptides, ${ }^{\mathbf{1 2}}$ marine alkaloids containing an 1-(indol-3-yl)ethane-1,2diamine fragment, ${ }^{13}$ tetrahydrofuran-containing macrolides, ${ }^{\mathbf{1 4}}$

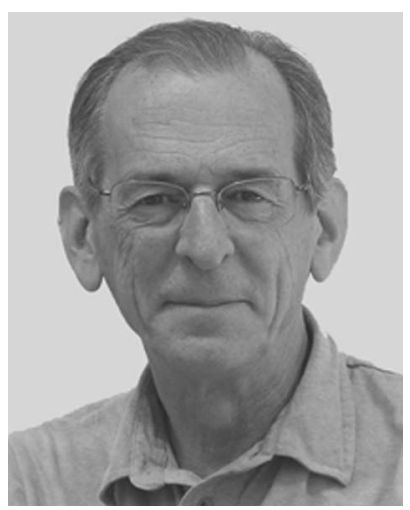

John Blunt obtained his BSc (Hons) and PhD degrees from the University of Canterbury, followed by postdoctoral appointments in Biochemistry at the University of Wisconsin-Madison, and with Sir Ewart Jones at Oxford University. He took up a lectureship at the University of Canterbury in 1970, from where he retired as an Emeritus Professor in 2008. His research interests are with natural products, the application of NMR techniques to structural problems, and the construction of databases to facilitate natural product investigations.

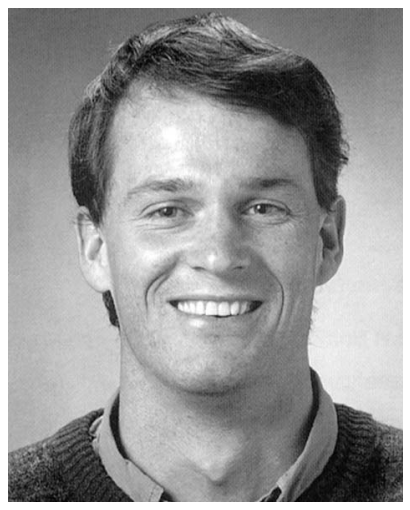

Brent Copp received his BSc (Hons) and PhD degrees from the University of Canterbury, where he studied the isolation, structure elucidation and structureactivity relationships of biologically active marine natural products under the guidance of Professors Blunt and Munro. He undertook postdoctoral research with Jon Clardy at Cornell and Chris Ireland at the University of Utah. 1992-93 was spent working in industry as an isolation chemist with Xenova Plc, before returning to New Zealand to take a lectureship at the University of Auckland, where he is currently an Associate Professor.

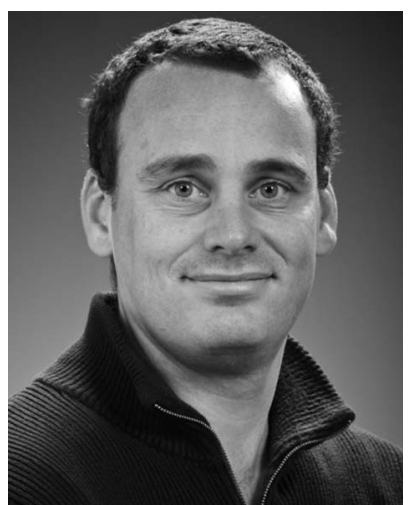

Rob Keyzers carried out his BSc(Hons) and PhD studies at Victoria University of Wellington. His thesis research, carried out under the guidance of Assoc. Prof. Peter Northcote, a former contributor to this review, focused on spectroscopy-guided isolation of sponge metabolites. He then carried out post-doctoral research with Mike Davies-Coleman (Rhodes University, South Africa) and Raymond Andersen (University of British Columbia, Canada) before a short role as a flavour and aroma chemist at CSIRO in Adelaide, Australia. He was appointed to the faculty at his alma mater in 2009 where he is currently a Senior Lecturer. terpenes from Sarcophyton sp., ${ }^{\mathbf{1 5 , 1 6}}$ antimicrobial peptides from proteobacteria, ${ }^{17}$ diarrhetic shellfish toxins in Washington State. ${ }^{18}$ di- and sesquiterpenes from Cystosiera sp. ${ }^{19}$ and halogenated compounds from Rhodomelaceae. ${ }^{20}$ Some general reviews on various classes of compounds include data on marine compounds - anticancer steroids, ${ }^{21}$ sesterterpenoids, ${ }^{22}$ NPs containing a nitrogen-nitrogen bond, ${ }^{23}$ and muscarine, imidazole, oxazole and thiazole alkaloids. ${ }^{24}$ Reviews on various aspects of specific compounds include lamellarins $\mathrm{N}$ and $\mathrm{L},{ }^{25}$ STX, ${ }^{26}$ lyngbouilloside and related macrolides, ${ }^{27}$ thiomarinol and related dithiolopyrrolone compounds, ${ }^{28}$ okadaic acid,${ }^{29}$ and the marinopyrroles. ${ }^{30}$ There have been many reviews covering a variety of groups of marine organisms, including bioprospecting of plankton, ${ }^{31}$ actinomycetes, ${ }^{32,33}$ S. China Sea opisthobranch molluscs, ${ }^{34}$ actinobacteria, ${ }^{35,36}$ filamentous marine cyanobacteria, $^{37}$ and microbes in general. $^{38-40}$ Reviews on specific organisms include Australian Dicathais orbita, ${ }^{\mathbf{4 1}}$ metabolites from Osmundaria spp., ${ }^{42}$ Aspergillus spp., ${ }^{43}$ and Bacillus spp. ${ }^{\mathbf{4 4}}$ A focus on bioactivities is made in reviews on anti-inflammatory compounds, ${ }^{45,46}$ trypanocidal products, ${ }^{47}$ neuroprotective compounds, ${ }^{48}$ antitumour/anticancer

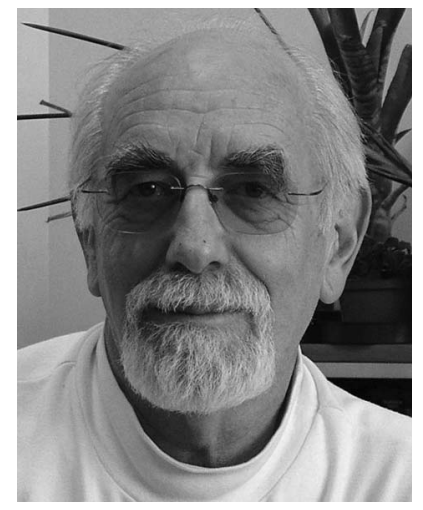

Murray Munro, Emeritus Professor in Chemistry at the University of Canterbury, has worked on natural products right through his career. This started with diterpenoids (PhD; Peter Grant, University of Otago), followed by alkaloids during a postdoctoral spell with Alan Battersby at Liverpool. A sabbatical with Ken Rinehart at the University of Illinois in 1973 led to an interest in marine natural products with a particular focus on bioactive compounds which has continued to this day. In recent years his research interests have widened to include terrestrial/marine fungi and actinomycetes.

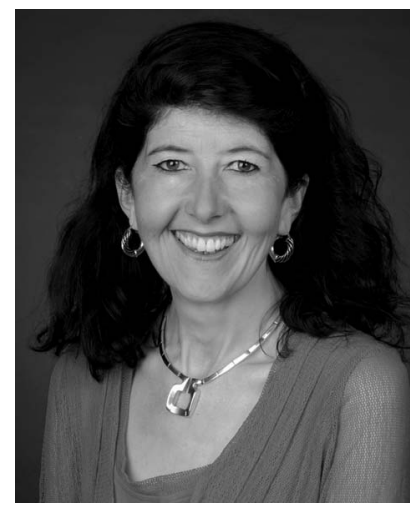

Michèle Prinsep received her BSc (Hons) and PhD degrees from the University of Canterbury, where she studied the isolation and structural elucidation of biologically active secondary metabolites from sponges and bryozoans under the supervision of Professors Blunt and Munro. She undertook postdoctoral research on cyanobacteria with Richard Moore at the University of Hawaii before returning to New Zealand to take up a lectureship at the University of Waikato, where she is currently a Senior Lecturer. 
agents, ${ }^{49-52}$ kinase inhibitors, ${ }^{53}$ anti-Herpes simplex agents, ${ }^{54}$ anti-HIV actives, ${ }^{55}$ angiogenesis inhibitors, ${ }^{56}$ cardioprotective peptides, ${ }^{57}$ antithrombotic peptides, ${ }^{58}$ antimicrobial peptides, ${ }^{59}$ therapeutics for Gram-negative sepsis, ${ }^{60}$ and bioactives from Antarctic and Arctic organisms. ${ }^{61}$ The chemical ecology of plankton $^{62}$ and the possible ecological roles of cyanotoxins ${ }^{63}$ have been reviewed. The eighth in a companion series providing an overview of synthetic aspects of MNPs has appeared with coverage of publications from 2010. ${ }^{64}$ Further reviews of syntheses of specific compounds include marine alkyl purines, ${ }^{65}$ tetrodotoxin, ${ }^{66}(+)$-spirastrellolide A methyl ester, ${ }^{67}$ and 'upenamide, the structure of which still remains elusive. ${ }^{68} \mathrm{~A}$ number of papers which, while not necessarily being reviews, are useful to reference here as they describe advances in techniques or approaches to discovery that are relevant to MNP studies. These include papers on novel extraction technologies for bioactives from marine algae, ${ }^{69}$ dereplication of marine actinomycetes by LCHRMS profiling, ${ }^{70} \mathrm{X}$-ray analysis on the nanogram to microgram scale using porous complexes, ${ }^{71,72}$ rapid screening of bioactive compounds by integrating 5channel parallel chromatography coupled with on-line mass spectrometry and microplate based assays, ${ }^{73}$ molecular networking as a dereplication strategy, ${ }^{74}$ NMR-based metabolomic analysis of macroalgae,$^{75}$ biogeography and biodiscovery hotspots of macroalgal compounds, ${ }^{76}$ and coral aquaculture to support drug discovery. ${ }^{77}$ The MarinLit database has been updated and was used as the literature source for the preparation of this present review. This database has now been transferred to the Royal Society of Chemistry from where it is available as a web-accessible version. ${ }^{78}$

\section{Marine microorganisms and phytoplankton}

MNP research effort is being increasingly directed towards marine microorganisms with 491 new compounds reported in 2013, an increase of 14\% from 2012 (see 15 Conclusion). Unless otherwise stated, compounds described in this section were obtained from cultures of the named microorganisms.

\subsection{Marine-sourced bacteria (excluding from mangroves)}

The chlorinated pyrones halomadurone A 1 and B 2 were isolated from Actinomadura sp. (ascidian Ecteinascidia turbinata, Florida Keys, U.S.A.) and with increased concentration of potassium bromide in the growth media produced the brominated analogues halomadurone C 3 and D 4. The halomadurones A-D activated the nuclear factor E2-related antioxidant response element, an indication of potential for treatment of neurodegenerative diseases. ${ }^{79}$ Discoipyrroles A-D 5-8 are alkaloids isolated from Bacillus hunanensis (sediment, Galveston Bay, Texas, U.S.A.) that inhibit the signaling pathway of the tyrosine kinase, discoidin domain receptor 2 . They were each obtained as racemates and feeding experiments with several substituted benzaldehyde precursors indicated formation through a nonenzymic process, which led to a one-pot total synthesis of discoipyrrole A $\mathbf{5 . 8 0}$

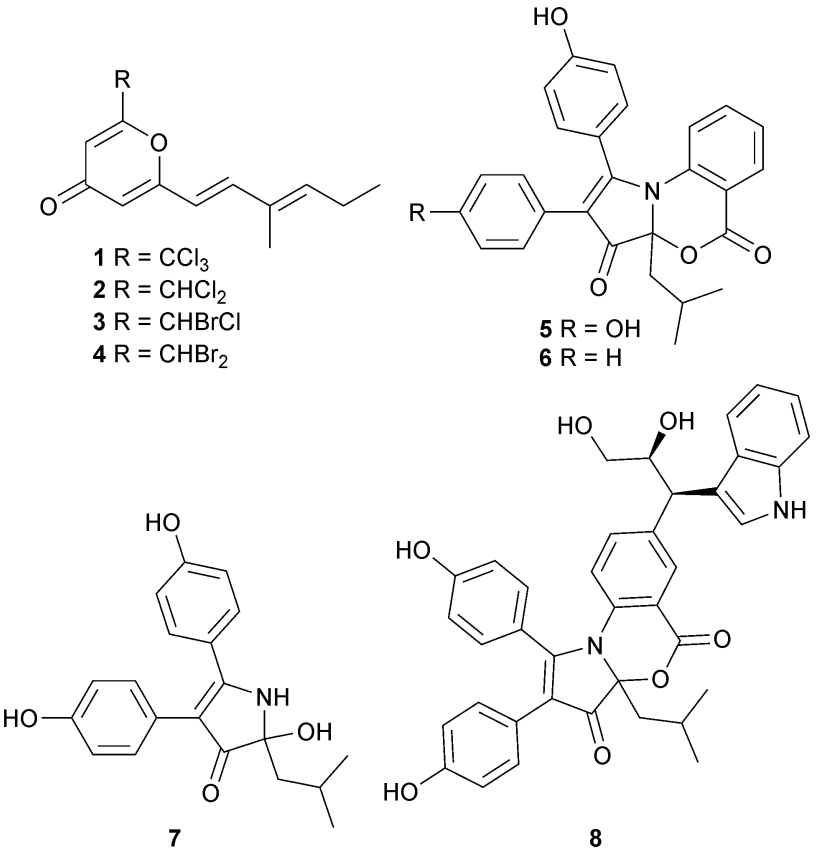

Three glycosylated methoxy-macrolactins 9-11 were isolated from Bacillus subtilis (B. subtilis) (sediment, Gageocho, S. Korea) and all displayed inhibition of Gram-positive and Gram-negative bacterial strains, in addition to modest antifungal activity. ${ }^{\mathbf{8 1}}$ A strain of B. subtilis (sponge Haliclona simulans, Gurraig Sound, Galway, Ireland) yielded subtilomycin, a partially characterised 32-amino acid compound that was partly responsible for the observed broad spectrum antimicrobial activity of the bacterium. ${ }^{82}$

Bacillus sp. (sediment, Ieodo Reef, $\mathrm{S}$. Korea) ${ }^{\mathbf{8 3}}$ produced the 24-membered macrolactones macrolactin $X-Z \quad$ 12-14 and the unsaturated fatty acids linieodolide A 15 and B 16, all with modest antibacterial and antifungal activity. ${ }^{84}$

Two separate isolates of the myxobacterium Enhygromyxa salina yielded antibiotics. Salimyxins A 17 and B 18 were obtained from one strain (sediment, Santa Barbara, California, U.S.A.) whilst the geometric isomers enhygrolide A 19 and B 20 were isolated from another strain (sediment, Prerow, Germany). Salimyxins A $\mathbf{1 7}$ and B $\mathbf{1 8}$ are structurally very similar to demethylincisterol obtained from the sponge Homaxinella sp., ${ }^{85}$ whilst enhygrolides A 19 and B 20 are structurally related to the nostoclides, first obtained from a Nostoc species of cyanobacterium. ${ }^{86}$ Salimyxin B 18 and enhygrolide A 19 were moderate growth inhibitors of the Gram-positive bacterium Arthrobacter cristallopoietes. ${ }^{87}$ The obligatory marine myxobacterium Enhygromxya salina (sediment, Prerow Is., Germany) was the source of the tetracyclic salimabromide $\mathbf{2 1}$ which was a moderate inhibitor of Arthrobacter cristallopoietes. ${ }^{\mathbf{8}}$

Kocuria palustris (sponge Xestospongia muta, Key Largo, Florida) ${ }^{89}$ produced a thiazolyl peptide kocurin 22 with antibacterial activity including strong inhibition of methicillinresistant Staphylococcus aureus (MRSA). ${ }^{90}$ A molecule with the same planar structure as $\mathbf{2 2}$ was previously isolated from Kocuria sp. in Southeast Spain ${ }^{91}$ as baringolin and is also 


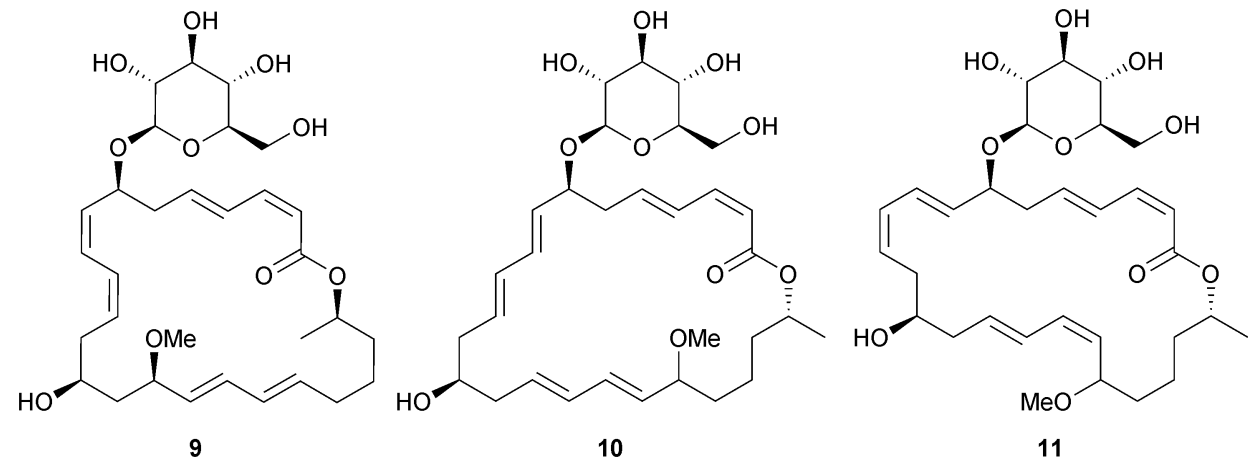

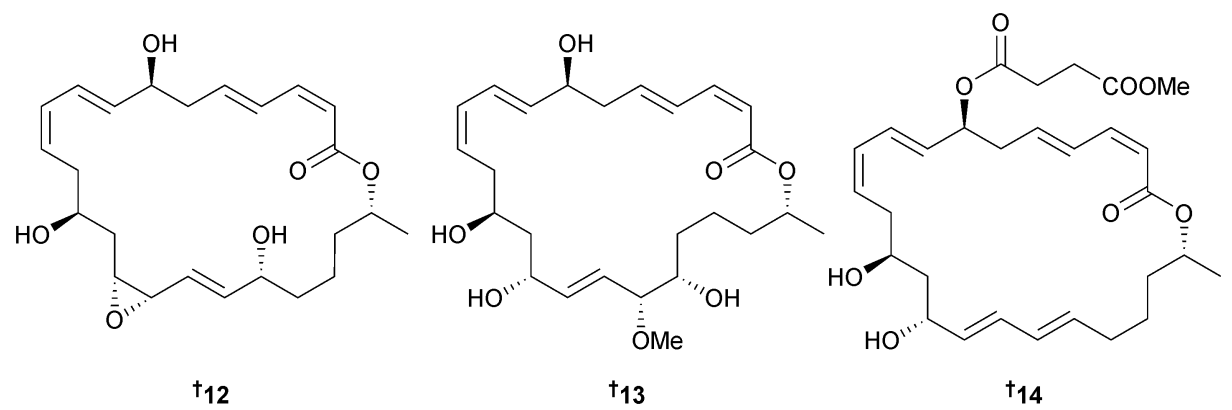<smiles>CC(=O)CC(O)C[C@@H](O)C[C@@H](O)/C=C/C=C/CCCC(C)O</smiles>

15<smiles>C[C@H](O)CCC/C=C/C=C/[C@@H](O)C[C@H](O)C/C=C/C=C/C(=O)O</smiles>

16

believed to be a correction of the structure previously assigned to PM181104, ${ }^{92}$ (also obtained from a Kocuria sp.) mentioned in a patent. ${ }^{90}$ Kocurin, also produced by Kocuria marina and a Micrococcus sp. (Florida Keys), ${ }^{93}$ has been synthesised by a convergent strategy in good overall yield. ${ }^{94}$ The macrolide juvenimicin C $\mathbf{2 3}$ was obtained from Micromonospora sp. (sediment, Palau) and enhanced the activity of the enzymes quinone reductase I, glutathione reductase and glutathione peroxidase, suggesting potential as a cancer chemopreventive agent. ${ }^{95}$ Levantilide C 24 is a 20 -membered macrolide isolated from a Micromonospora strain (Golfo Corcovaclo, Chiloe Is., Chile) with moderate antiproliferative activity against human tumour cancer cell lines (HTCLs). ${ }^{96}$ Two strains of Micromonospora (sediment, North Carolina coast, U.S.A.) yielded the polyene macrolactam micromonolactam 25, a constitutional isomer of salinilactam $\mathrm{A}^{97}$ but with a different polyene pattern and a $(Z)$-double bond,<smiles>C[C@H](/C=C/[C@@H](C)C(C)(C)O)[C@H]1CC[C@H]2C3=CC(=O)O[C@@]3(O)CC[C@@]21C</smiles>

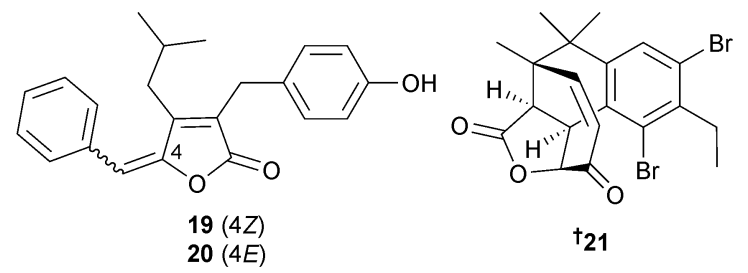

in contrast to the all $(E)$-structure of salinilactam A. Genome sequencing of one of the strains determined that 25 was derived from eleven polyketide units and a modified glutamate starter unit.98 ${ }^{\mathbf{9 8}}$ Nocardiopsis alba (deep-sea sediment, Indian Ocean) produced several diketopiperazines, including the new C-6 epimers nocazine D 26 and E 27 and the known synthetic compounds $(S, Z)$-3-benzylidene-6methylpiperazine-2,5-dione and (S,Z)-3-benzylidene-6-isopropylpiperazine-2,5-dione, ${ }^{99}$ both isolated for the first time 


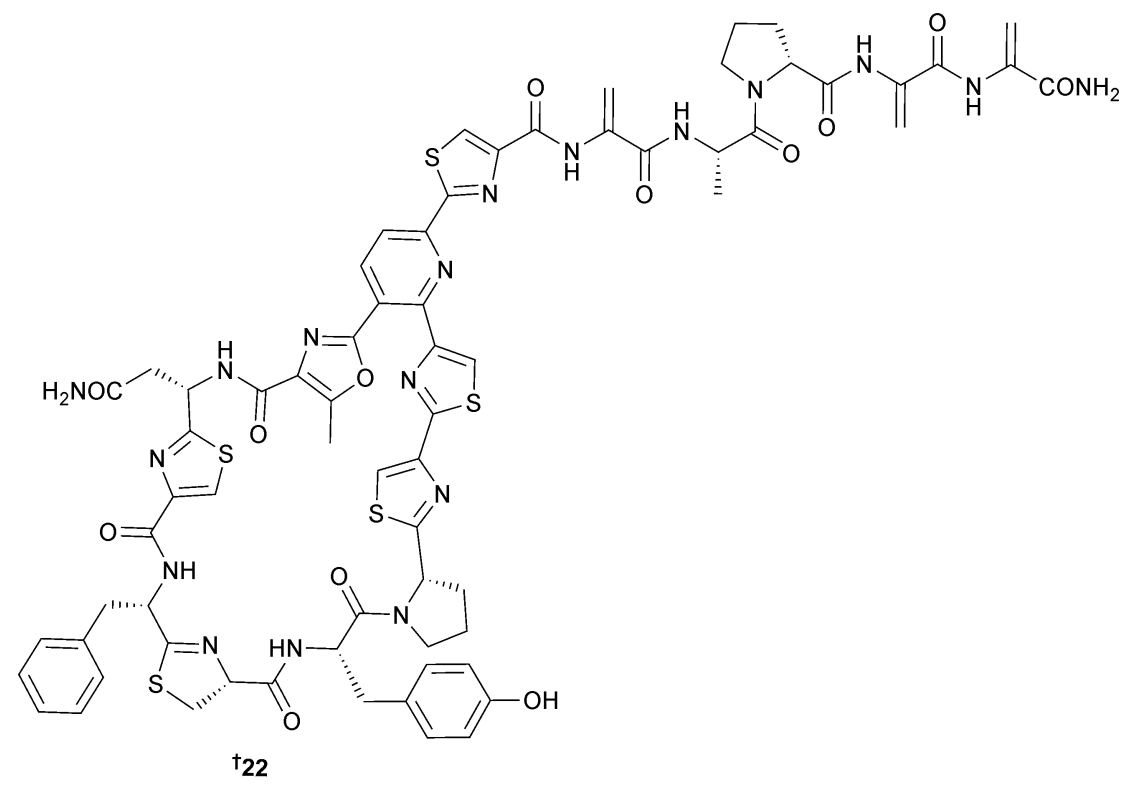

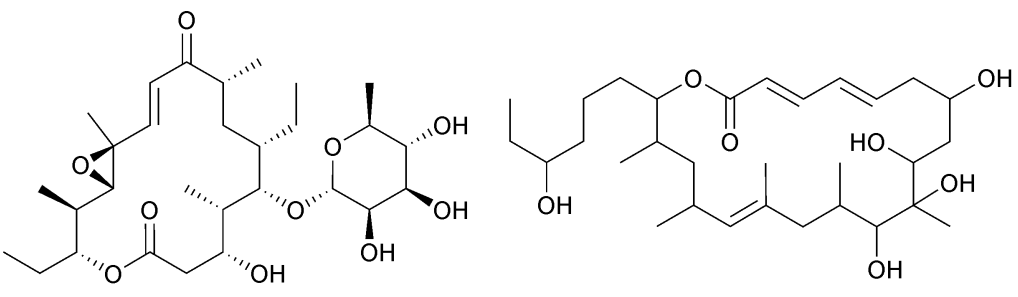

$t_{23}$<smiles>C/C=C/C=C\CC(C)NC(=O)/C=C/C=C/C=C/C(C)C(O)C(O)CC(O)/C=C/C=C/C(C)=C/C</smiles>

25

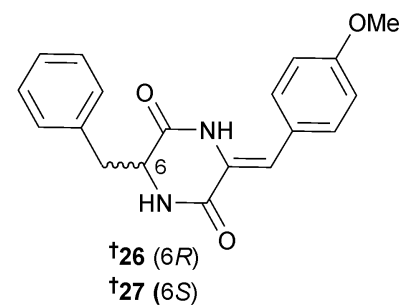

as NPs. Methoxyneihumicin was also isolated. This is a structure that had been previously reported in a conference poster $^{\mathbf{1 0 0}}$ but not in the chemical literature. Both methoxyneihumicin and the known bacterial metabolite XR334 (ref. 101) (first time marine isolate) were modestly active against HTCLs. ${ }^{102}$

Three different groups of researchers have isolated metabolites from Nocardiopsis species and all have named them nocapyrones. To avoid confusion they are presented here in order of publication. Firstly, symbiotic Nocardiopsis alba (cone snail Conus rolani, Mactan Is., Philippines) produced the $\gamma$-pyrones nocapyrone $\mathrm{H}-\mathrm{Q}$ 28-39. Of these, nocapyrone $\mathrm{N} \mathrm{35/36}$ was isolated as a mixture of enantiomers in a 10:1 ratio and nocapyrone $M$ 33/34 occurred as an inseparable mixture of diastereoisomers. Both nocapyrone $\mathrm{H}$ 28 and the co-isolated nocapyrone B, previously obtained from a sponge-associated Nocardiopsis strain, ${ }^{\mathbf{1 0 3}}$ modulated nerve cell depolarisation and were active against a wide range of dorsal root ganglion neuronal cell types. Nocapyrones B and $\mathrm{H}$ were moderately cytotoxic to cancer cell lines. ${ }^{\mathbf{1 0 4}}$ Secondly, three 3,6-disubstituted $\alpha$-pyrones 40-42 were isolated from Nocardiopsis sp. (sediment, Ulleung Basin, Eastern sea, Korea) and named nocapyrones H-J. "Nocapyrone H" 40 inhibited pro-inflammatory factors such as nitric oxide (NO), prostaglandin E2 (PGE2) and interleukin-1 $\beta$ (IL-1 $\beta$ ) (potential neuroprotective effects). ${ }^{105}$ Lastly, Nocardiopsis dassonvillei subsp. dassonvillei (sediment, Lianyungang, China) also produced $\alpha$-pyrones named "nocapyrones $\mathrm{H}-\mathrm{N}$ ". Of these "nocapyrone $\mathrm{H}$ " had the same structure as 40, "nocapyrone $\mathrm{K}$ " was identical to 41 , while the balance, 43-47, were unique. "Nocapyrone I" 43 and "M" 46 displayed inhibition of quorum sensing (QS) controlled gene expression in Chromobacterium violaceum CV026 and Pseudomonas aeruginosa QSIS-lasI biosensors. ${ }^{106}$ 
<smiles>[R2]C(C)CCCC[C@@H]([R1])c1oc(OC)c(C)c(=O)c1C</smiles>

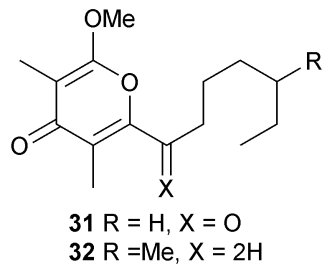

$t_{29} R_{1}=H, R_{2}=O H$

$\mathrm{t}_{30 \mathrm{R}_{1}}=\mathrm{OH}, \mathrm{R}_{2}=\mathrm{H}$<smiles>[R3]C(CCC[C@@H]([R8])C([R])O)c1oc(OC)c(C)c(=O)c1C</smiles>
$33 \mathrm{R}_{1}=\mathrm{OH} . \mathrm{R}_{2}=\mathrm{Me}, \mathrm{R}_{3}=\cdots \cdot \mathrm{Me}$ $34 \mathrm{R}_{1}=\mathrm{OH} . \mathrm{R}_{2}=\mathrm{Me}, \mathrm{R}_{3}=-\mathrm{Me}$ ${ }^{+} 35 \mathrm{R}_{1}=\mathrm{R}_{2}=\mathrm{H}, \mathrm{R}_{3}=\cdots \cdot \mathrm{Me}$ $\dagger_{36} R_{1}=R_{2}=H, R_{3}=-M e$<smiles>COc1oc(C(=O)CCCC(C)C)c(C)c(=O)c1C</smiles>

38
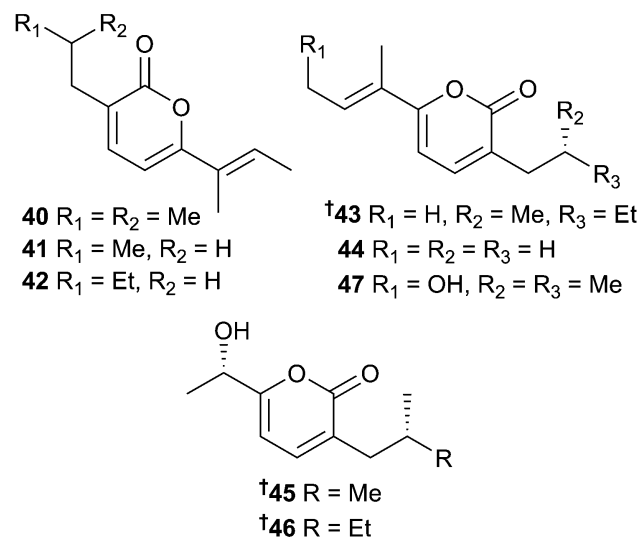

Very clearly the naming of these metabolites needs revision. Saline culture of Nocardiopsis sp. (sediment, S. Molle Is., Queensland, Australia) previously yielded norcardioazines A and $\mathrm{B}^{107}$ whilst non-saline culture of the same strain yielded nocardiopsins A and B. ${ }^{108}$ Further investigation of the strain cultivated under non-saline conditions has resulted in the isolation of the prolinyl-macrolactam polyketides nocardiopsin C 48 and D 49 and the highly substituted $\alpha$-pyrone polyketide, nocardiopyrone A $\mathbf{5 0 .}{ }^{109}$ It should be noted that the name nocardiopyrone A has coincidentally been given to a metabolite isolated from a terrestrial species, Nocardiopsis alkaliphila, ${ }^{\mathbf{1 1 0}}$ and that the same CAS number appears to have been given to both compounds in error on the Scifinder database, with the terrestrial compound structure showing as corresponding to that CAS number.

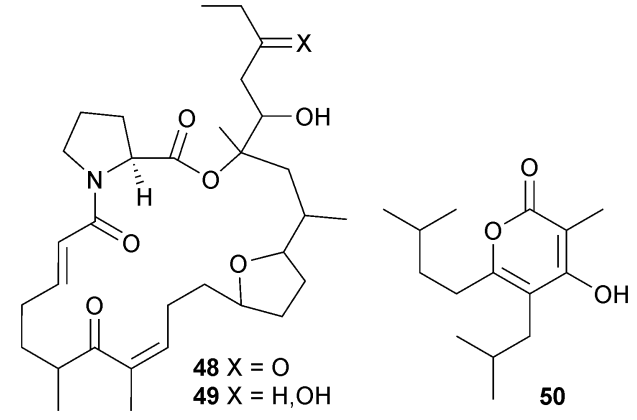

The cyclic hexapeptides nocardiamide A 51 and B 52 were isolated from Nocardiopsis sp. (La Jolla Canyon, San Diego, California, U.S.A.) and then synthesised via solid-phase peptide synthetic methods. ${ }^{111}$ A microorganism, nominally Paenibacillus profundus sp. nov., (sediment, Sea of Japan) yielded a linear glyceryl acid derived heptapeptide $\mathbf{5 3}$ with strong antibacterial inhibition and moderate inhibition of SK-MEL-28 cells, ${ }^{\mathbf{1 1 2}}$ while a species of Photobacterium, closely related to $P$. halotolerans (mussel, Solomon Is., Pacific Ocean), was the source of the cyclodepsipeptides ngercheumicin F-I 54-57 that inhibited quorum sensing in Staphylococcus aureus. ${ }^{\mathbf{1 1 3}}$

A Pseudoalteromonas sp. (oil-contaminated surface water, Gulf of Mexico after the Deepwater Horizon oil spill) yielded the siderophores lystabactin A-C 58-60 which contained the unusual nonproteinogenic amino acid 4,8-diamino-3hydroxyoctanoic acid (LySta). Since lystabactin C is 29-methoxy lystabactin A, it may have been an artefact of isolation. ${ }^{114}$

Cyanosporasides A and B are chloro- and cyano-cyclopenta[a] indene glycosides originally isolated from a Palauan Salinispora pacifica strain, ${ }^{\mathbf{1 1 5}}$ while cyanosporasides C-E 61-63 came from investigation of another $S$. pacifica strain (sediment, Palau) and cyanosporasides D-F 62-64 from a Streptomyces sp. (sediment, Bahamas). Cloning, sequencing, and mutagenesis of cyanosporaside biosynthetic gene clusters from both bacteria demonstrated that the cyanosporasides are enediyne polyketides and a two-gene operon was identified which was implicated in the nitrile functionalisation of these metabolites. ${ }^{116}$ Further investigation of the strain of $S$. pacifica (USDA Agricultural Research Service) that produced lomaiviticins C$\mathrm{E}^{\mathbf{1 1 7}}$ resulted in the isolation of (-)-homoseongomycin 65 . Synthesis of an isotopically-labelled derivative, homoseongomycin- $d_{5}$, clarified aspects of the biosynthetic pathway. ${ }^{\mathbf{1 1 8}}$

The alkaloid 66 was obtained from Serinicoccus profundi sp. nov. (deep-sea sediment, Indian Ocean) (weak activity against Staphylococcus aureus (S. aureus) $)^{119}$ and Staphylococcus sp. (red alga, Corallina officinalis, Nagasaki Shitsu Coast, Japan) provided the diketopiperazine derivatives staphyloamide A 67 and B 68. ${ }^{120}$ Streptomyces antibioticus (sediment, source not given) yielded the indanomycin-related antibiotics 69-71 as moderate growth inhibitors of $S$. aureus. ${ }^{\mathbf{1 2 1}}$

The alkaloids nitrosporeusine A 72 and B 73 with an unprecedented skeleton (benzenecarbothioc cyclopenta $[c]$ pyrrole-1,3-dione) were isolated from $S$. nitrosporeus (sediment, Arctic Chukchi Sea). Both nitrosporeusines inhibited the H1N1 virus in infected MDCK cells. ${ }^{\mathbf{1 2 2}}$ Some sesquiterpenoid 


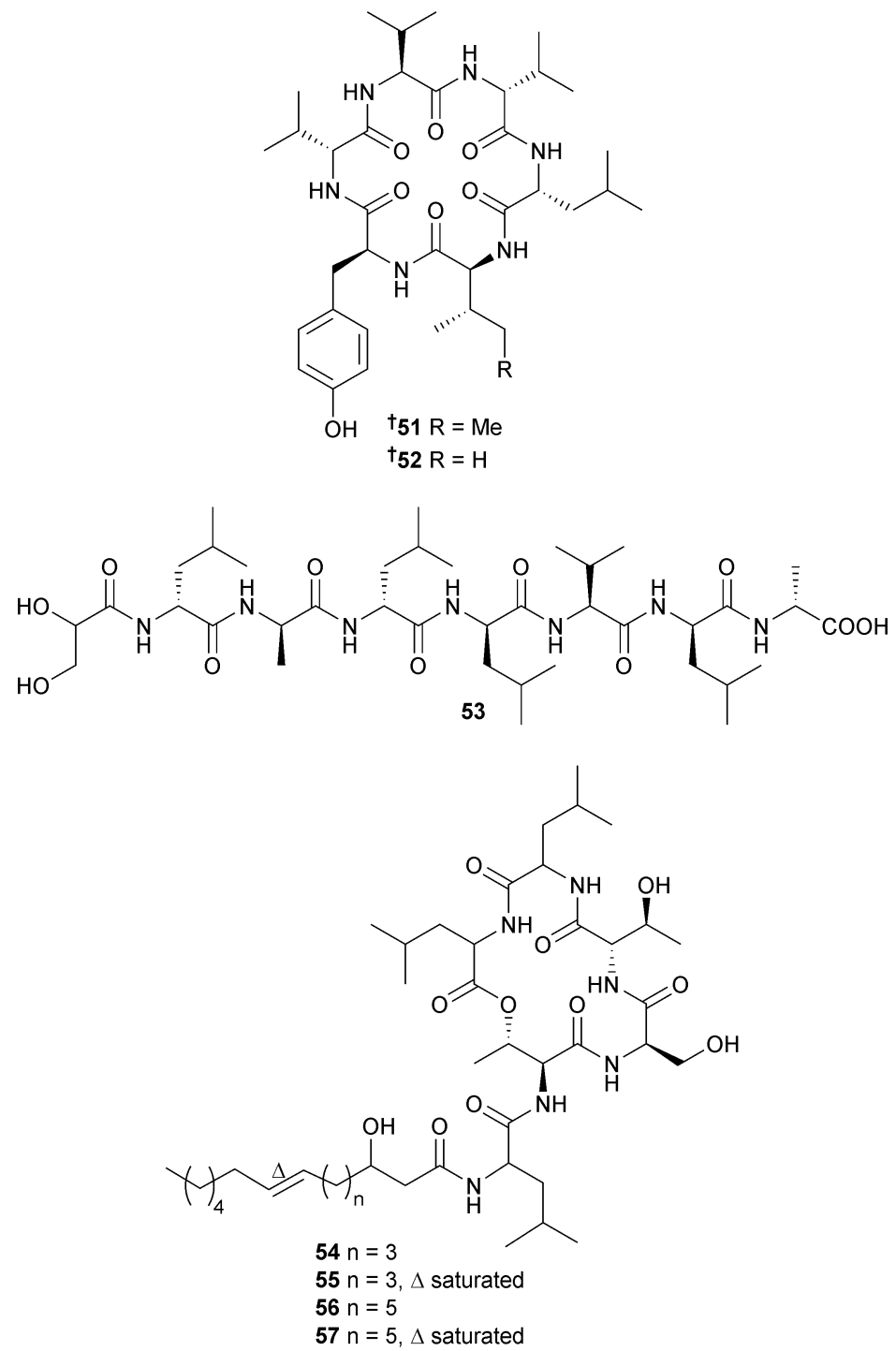

naphthoquinones marfuraquinocin A-D 74-77 and the geranylated phenazines phenaziterpene A 78 and B 79 were isolated from $S$. niveus (sediment, S. China Sea). Marfuraquinocins A 74 and C 76 were growth inhibitors of NCI-H460 cancer cells (moderate) whilst marfuraquinocins A, C and D 77 were moderate growth inhibitors of $S$. aureus, with marfuraquinocins C and D also inhibitors of methicillin-resistant Staphylococcus epidermidis. ${ }^{123}$

Tetroazolemycins A 80 and B 81 are oxazole/thiazole derivatives obtained from $S$. olivaceus (deep-sea water, southwest Indian Ocean), both of which showed binding affinity for the metal ions $\mathrm{Fe}^{3+}, \mathrm{Cu}^{2+}$ and $\mathrm{Zn}^{2+} \cdot{ }^{124} S$. seoulensis (shrimp gut Penasus orientalis, Qingdao, China) yielded the neuraminidase inhibitors streptoseolactone 82, limazepine G 83 and a known synthetic compound ${ }^{\mathbf{1 2 5 , 1 2 6}}$ isolated for the first time as an NP, and named limazepine $\mathrm{H}^{\mathbf{1 2 7}}$ Endophytic S. sundarbansensis (brown alga Fucus sp., Bejaia, Algeria) provided the polyketide chromanone $\mathbf{8 4}$ (modest but selective activity against MRSA). ${ }^{\mathbf{1 2 8}}$
S. tateyamensis (sponge Haliclona sp., Tateyama City, Japan $)^{129}$ was the source of JBIR-107 85, ${ }^{130}$ while the phenoxazine-based alkaloids venezueline A-E 86-90 and the aminophenols venezueline F 91 and G 92 were obtained from $S$. venezuelae (sediment, Guam) with the known analogues exfoliazone, ${ }^{131}$ chandrananimycin $\mathrm{D}^{\mathbf{1 3 2}}$ and carboxyexfoliazone, ${ }^{133}$ all previously obtained from terrestrial Streptomyces species but now first time marine isolates. Venezueline B $\mathbf{8 7}$ was moderately cytotoxic towards a panel of HTCLs. ${ }^{134}$

Double mutation of a strain of $S$. xiamenensis (sediment, Eastern Pacific Ocean) led to production of two benzopyran derivatives xiamenmycin C 93 and D 94, which both inhibited proliferation of human lung fibroblasts (WI26), ${ }^{\mathbf{1 3 5}}$ and Streptomyces sp. (unidentified soft coral, Weizhou Is., Guangki Province, China) was the source of the chlorinated polyketides strepchloritide A 95 and B 96 cytotoxic against MCF-7 cells (modest). ${ }^{136}$ Chlorizidine A 97, comprised of a chlorinated 2,3dihydropyrrolizine ring attached to an unprecedented chlorinated $5 H$-pyrrolo[2,1- $a]$ isoindol-5-one, was isolated from a 
<smiles>[R2]OC(=O)[C@H](CCCN(O)C=O)NC(=O)[C@H](CC(N)=O)NC(=O)[C@H](CCCN(O)C=O)NC(=O)[C@H](CO)NC(=O)C[C@H](O)[C@@H](N)CCCCNC(=O)c1cccc(O)c1O</smiles><smiles>CN(O)CCC[C@H](NC(=O)[C@H](COC(=O)[C@H](CCCN(C)O)NC(=O)C[C@H](O)[C@H](N)CCCCNC(=O)c1cccc(O)c1O)NC(=O)[C@H](CC(N)=O)NC(=O)[C@H](O)C=O)C(N)=O</smiles>

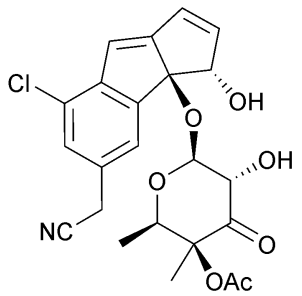

$\dagger_{61}$<smiles>[R]O[C@H]1C=CC2=Cc3c(Cl)cc(CC#N)cc3[C@]21O</smiles>

$t_{62} \mathrm{R}=\mathrm{Ac}$

$t_{63} \mathrm{R}=\mathrm{H}$<smiles>C[C@@H]1O[C@H](O[C@@H]2C=CC3=Cc4ccc(CC#N)c(Cl)c4[C@]32O)[C@H](SCCNC(N)=O)C[C@@H]1O</smiles><smiles>CCc1cc(O)c2c(c1)C(SC[C@H](NC(C)=O)C(=O)O)=C1C(=O)c3c(O)cccc3C(O)=C12</smiles>

$\dagger^{6} 6$
Streptomyces strain (sediment, San Clemente, California, U.S.A.) and was moderately cytotoxic to a panel of HTCLs. ${ }^{137}$ The biosynthetic gene cluster of chlorizidine A $\mathbf{9 7}$ was identified and whole pathway heterologous expression and genetic manipulations were utilised to show that it is assembled by a polyketide synthase (PKS) that uniquely incorporates a fatty acid synthasederived dichloropyrrolyl extender unit into the pyrroloisoindolone enzymic product. ${ }^{138}$

The diketopiperazine derivatives 98-102 were obtained from Streptomyces sp. (sediment, Huanghai Beach, Dalian, China)

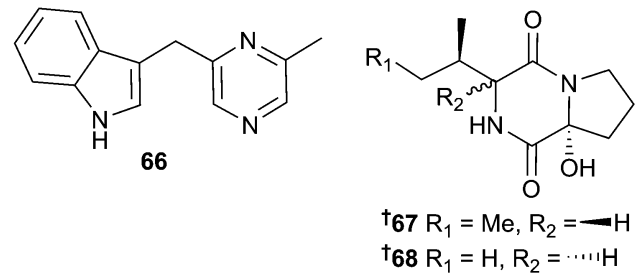

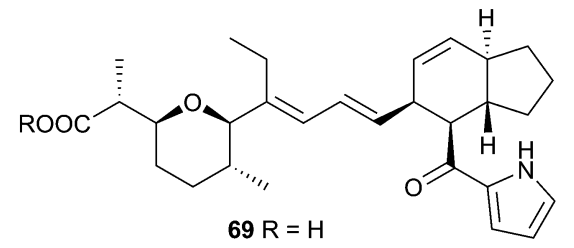<smiles>CC/C(=C\C=C\C1C=C[C@H]2CCC[C@@]2(C)C1C(=O)c1ccc[nH]1)[C@H]1O[C@H]([C@@H](C)C(C)=O)CC[C@H]1C</smiles>

70<smiles>O=C1NC(=O)C2(C(=O)Sc3ccc(O)cc3)CCC(O)C12</smiles><smiles>O=C(SC12CCC(O)C1C(=O)NC2=O)c1ccc(O)cc1</smiles>

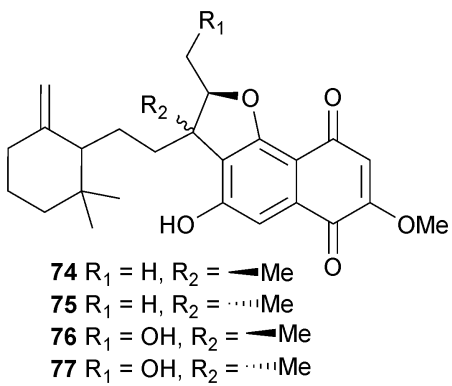<smiles>CC(C)=CCC/C=C(/C)COc1cccc2nc3c(O)cccc3nc12</smiles>

and 100 displayed modest activity against the influenza $\mathrm{A}$ (H1N1) virus, whilst the co-isolated fungal metabolites $(3 Z, 6 S)$ 3-benzylidene-6-isobutylpiperazine-2,5-dione ${ }^{139}$ and albomoursin ${ }^{140}$ displayed potent inhibition of the virus and were first time marine isolates. ${ }^{141}$

Streptomyces sp. (sediment, S. China Sea) yielded the spirotetronate lobophorin G 103, a potent inhibitor of both $\mathrm{Myco}$ bacterium bovis Bacillus Calmette-Guerin (BCG) and B. subtilis and a moderate inhibitor of Mycobacterium tuberculosis ( $M$. tuberculosis) ${ }^{142}$ Sungsanpin 104 isolated from a Streptomyces sp. (deep-sea sediment, Jeju Is., S. Korea) is an example of a socalled lasso peptide, a ribosomally synthesised peptide of between 16 and 23 amino acids with an N-terminal eight- or nine-residue ring with a linear C-terminus threaded through the ring. ${ }^{143}$ Sungsanpin inhibited A549 cells in a cell invasion assay. ${ }^{144}$ 


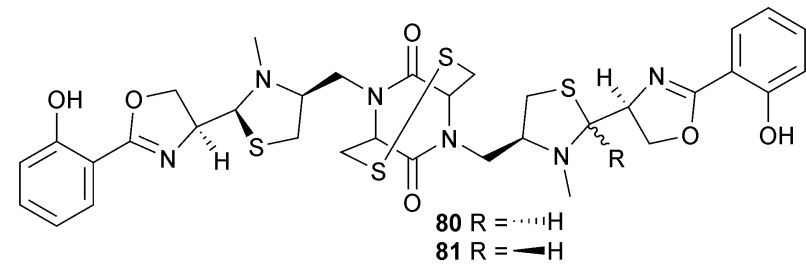

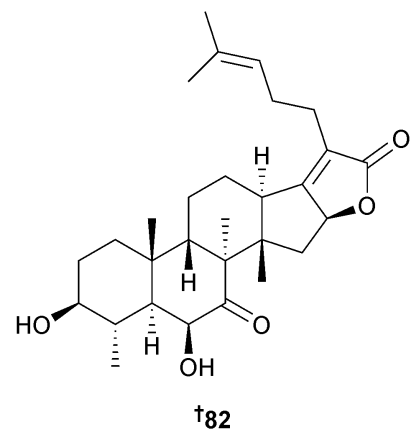<smiles>C/C=C/C1=CN2C(=O)c3ccc(C)c(O)c3NC(=O)[C@@H]2C1</smiles><smiles>CCCC1(O)CC(=O)c2c(Cc3cc(=O)cc(O)o3)cccc2O1</smiles><smiles>CCCCC(Cc1ccc(N(C)CC(=O)Cc2ccccc2)cc1)C(=O)CCC(=O)O</smiles><smiles>CCNc1cc2nc3cc(CO)c(Cc4ccc(O)c(NC(C)=O)c4)cc3oc-2cc1=O</smiles><smiles>Nc1cc2c(cc1OC(=O)CO)Oc1ccc(CO)cc1N2</smiles>

Investigation of two different Streptomyces strains identified six new napyradiomycin analogues. The Streptomyces strain CNQ-329 (sediment, San Diego, California, U.S.A.) produced napyradiomycins A-E 105-109, while strain CNH-070 (sediment, San Elijo Lagoon, Encinitas, California, U.S.A.) produced napyradiomycin F $\mathbf{1 1 0 .}$

Four of the napyradiomycins A, D-F were cytotoxic (moderate) to HCT-116 cells whilst napyradiomycins A and B inhibited MRSA (moderate).

Also isolated were napyradiomycins B2-B4; B3 (ref. 145) and B4 (ref. 146) as first time marine isolates. ${ }^{147}$ Three napyradiomycins, 4-dehydro-4a-dechloronapyradiomycin A1 111, 3dechloro-3-bromonapyradiomycin A1 112 and 3-chloro-6,8-<smiles>O=C(CO)Nc1cc2c(cc1OC(=O)CO)Oc1ccc(CO)cc1N2</smiles>

89<smiles>CCCCNc1cc2nc3cc(COC(=O)C(C)C)ccc3oc-2cc1=O</smiles><smiles>C=CNc1cc(COCc2ccc(O)c(NCC)c2)ccc1O</smiles><smiles>CCNc1cc(COC)ccc1O</smiles>

92<smiles>[R][R9]([H])(Cl)c1cc(O)cc(/C(O)=C/C(=O)C([R])(Cl)Cl)c1</smiles><smiles>[R]C(C)/C=c1\c(=O)[nH]/c(=C\c2ccccc2)c(=O)n1C</smiles><smiles>CC[C@H](C)[C@H]1NC(=O)/C(=C/c2ccccc2)NC1=O</smiles> 


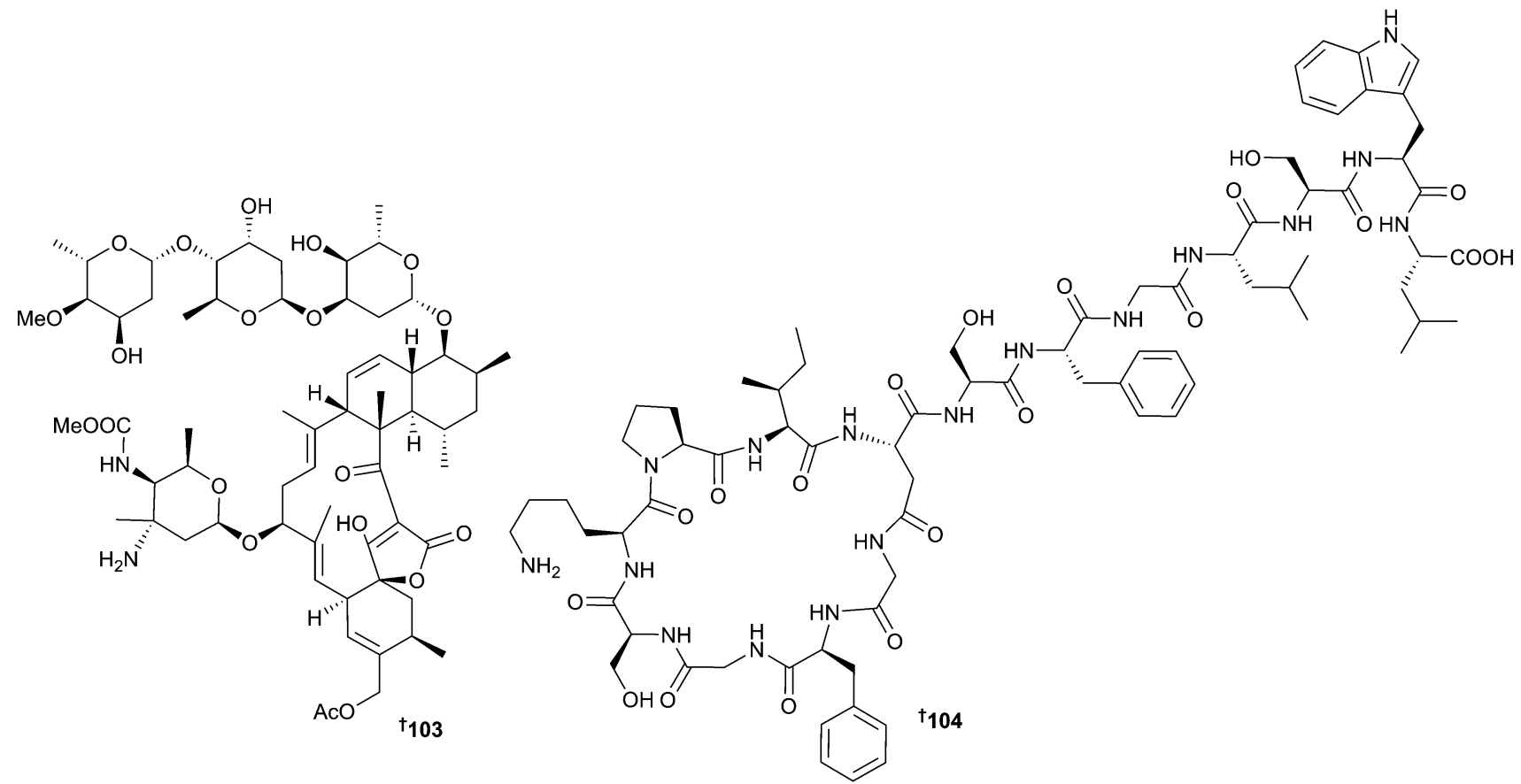

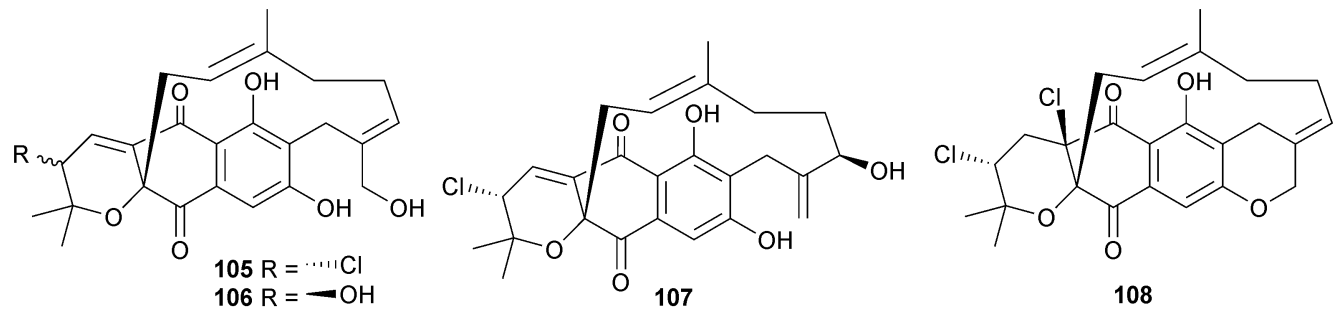<smiles>C=C1CCC(Br)C(C)(C)[C@H]1C[C@]12OC(C)(C)[C@@H](Cl)C=C1C(=O)c1c(O)cc(O)cc1C2=O</smiles>

dihydroxy-8- $\alpha$-lapachone $\mathbf{1 1 3}$ isolated from a Streptomyces species (sediment, Xieyang Is., Beihai, Guangxi Province, China) displayed moderate inhibition of several Gram-positive bacteria while 3-dechloro-3-bromonapyradiomycin A1 112 was moderately active against several HTCLs. ${ }^{\mathbf{1 4 8}}$ A Streptomyces sp. (sediment, Santa Barbara, California, U.S.A.) yielded the antibiotic anthracimycin 114, significantly active against Bacillus anthracis. Early in vivo results indicated that $\mathbf{1 1 4}$ also provided significant protection against MRSA cell lines. The planar structure of anthracimycin $\mathbf{1 1 4}$ may have been published in a
2011 patent $^{\mathbf{1 4 9}}$ but insufficient detail was given to permit a full comparison. ${ }^{150}$

Surugamides A-E 115-119, cyclic octapeptides with four Damino acid residues, were obtained from Streptomyces sp. (deep-sea sediment, Kinko Bay, Japan) and were modest inhibitors of the protease enzyme bovine cathepsin B. ${ }^{151}$ Three strains of $S$. champavatii (sediment, Gotland Deep and Kiel Bight, Baltic Sea and Urania Basin, Eastern Mediterranean) produced the octapeptide champacyclin 120, an inhibitor of the bacterium Erwinia amylovora, the causative agent of fire blight disease in certain plants. Champacyclin $\mathbf{1 2 0}$ has the same 
<smiles>CC(C)=CCCC(C)=C[C@H]1C(=O)c2cc(O)cc(O)c2C(=O)C2=C[C@H](Cl)C(C)(C)O[C@@]21C/C=C(\C)CCC=C(C)C</smiles>

planar structure as surugamide A $\mathbf{1 1 5}$ but different configurations at two amino acid residues. Champacyclin was also prepared by solid-phase peptide synthesis. ${ }^{152}$

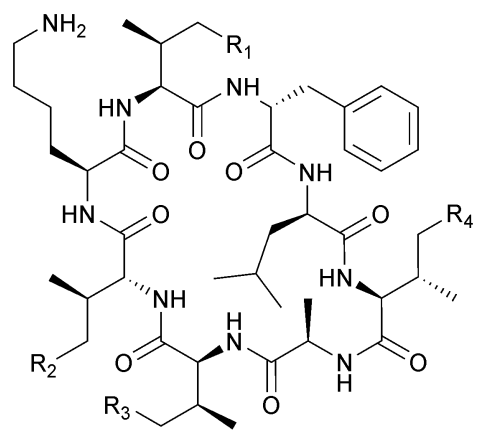

$$
\begin{aligned}
& t_{115} R_{1}=R_{2}=R_{3}=R_{4}=M e \\
& t_{116} R_{1}=R_{3}=R_{4}=M e, R_{2}=H \\
& t_{117} R_{1}=H, R_{2}=R_{3}=R_{4}=M e \\
& t_{118} R_{1}=R_{2}=R_{4}=M e, R_{3}=H \\
& t_{119} R_{1}=R_{2}=R_{3}=M e, R_{4}=H
\end{aligned}
$$

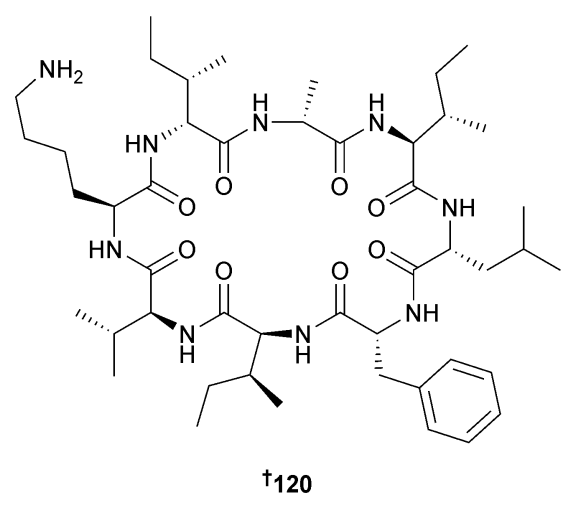

Streptomyces sp. (sediment, S. China Sea) yielded the pregnene steroid 3219A 121 with a rare $\Delta^{8,9}$-double bond in the skeleton, ${ }^{153}$ and the polyketide nahuoic acid A 122 was obtained from a Streptomyces sp. (sediment, Padana Nahua, Papua New Guinea) as a selective SAM-competitive inhibitor of the histone methyltransferase enzyme SETD8. ${ }^{154}$ A meroterpenoid actinoranone $\mathbf{1 2 3}$ was isolated from a bacterium, likely a Streptomyces species (sediment, San Diego, California, U.S.A. $)^{155}$ as a moderate cytotoxin of HCT-116 ${ }^{156}$ and Streptomyces sp. (sediment, Marsa Matruh city, Egypt) was the source of maroxazinone 124, moderately cytotoxic to several HTCLs. ${ }^{157}$<smiles>CC(=O)[C@]1(C)CC[C@H]2C3=C(CC[C@]21C)[C@@]1(C)CC[C@@H](O)C[C@H]1CC3</smiles>

Farnesides A 125 and B 126, linear sesquiterpenoids connected by ether linkages to a ribose dihydrouracil nucleoside, came from Streptomyces sp. (sediment, Nacula Is., Yasawa Is., Fiji) with farneside A modestly active against Plasmodium falciparum (P. falciparum). ${ }^{158}$<smiles>CC(C)=CCCC1(C)OC1CC/C(C)=C/COC[C@H]1O[C@@H](N2CCC(=O)NC2=O)[C@H](O)[C@@H]1O</smiles>

A PCR-based genetic screening experiment targeting the dTDP-glucose-4,6-dehydratase gene was used to identify that 


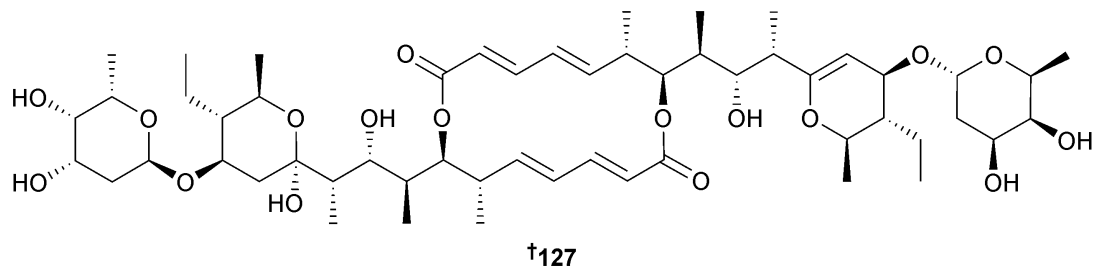

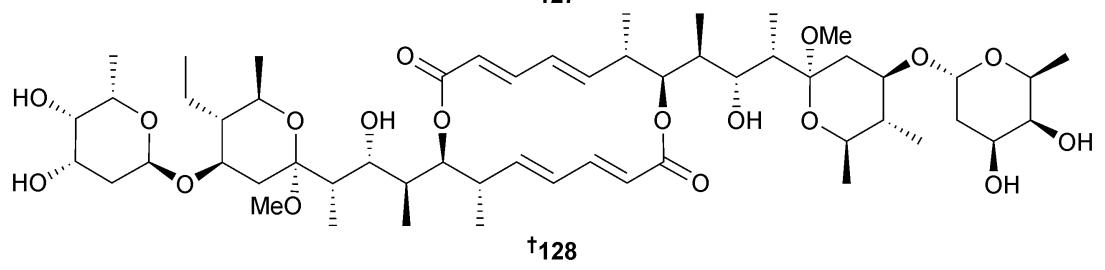

a Streptomyces sp. (sediment, Heishijiao Bay, Dalian, China) could potentially produce glycosidic antibiotics. Further investigation of this strain yielded the 6-deoxyhexose-containing antibiotics, $11^{\prime}, 12^{\prime}$-dehydroelaiophylin 127 and 11,11'$O$-dimethyl-14'-deethyl-14'-methylelaiophylin 128, of which 127 was an inhibitor of MRSA and vancomycin-resistant Enterococci pathogens. The elaiophylin derivative 128 might be an artefact resulting from methanolysis during the isolation procedure. ${ }^{159}$

The cyclic peptides ohmyungsamycin A 129 and B 130 were isolated from a Streptomyces sp. (sand, Shinyang Beach, Jeju Is., S. Korea). During determination of configurations a new method to determine the absolute configuration of $\mathrm{N}, \mathrm{N}$-dimethylvaline was developed which utilises phenylglycine methyl ester derivatisation coupled with chromatographic analysis and provides a general and convenient method for determination of the configurations of amino acids with fully substituted amine groups. Ohmyungsamycins A 129 and B 130 inhibited growth of several HTCLs and of Gram-positive and Gram-negative bacteria with ohmyungsamycin A 129 being much more potent than B 130. ${ }^{160}$

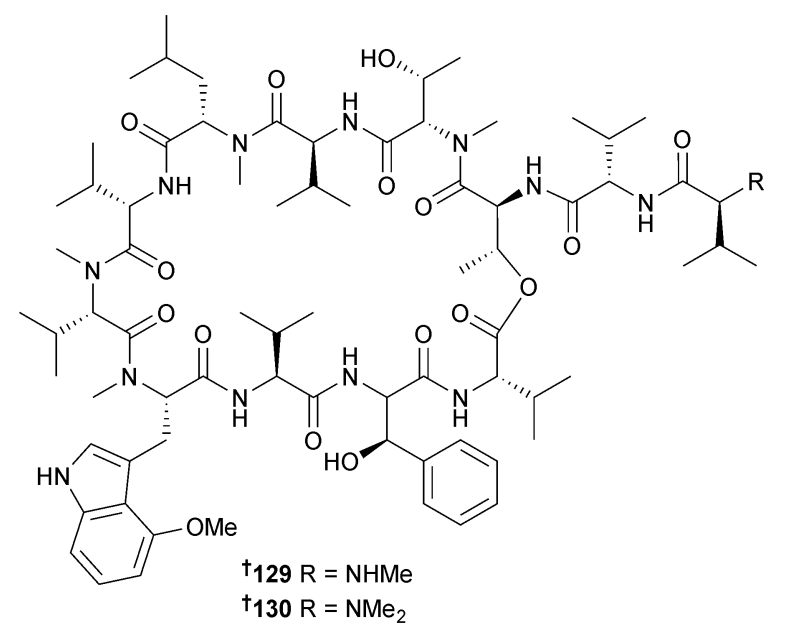

Separacenes A-D 131-134 are polyene polyols obtained from Streptomyces sp. (sediment, Jeju Is., S. Korea).
Separacenes A 131 and B 132 are C-3 epimers whilst separacenes C 133 and D 134 are C-12 epimers. Separacene A 131 was a modest inhibitor of Candida albicans (C. albicans) isocitrate lyase and two HTCLs. ${ }^{161}$

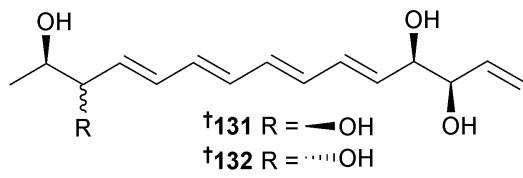<smiles>[R]C(/C=C/C=C/C=C/[C@@H](O)[C@@H](O)[C@H](O)C=C)[C@H](O)/C=C\C</smiles>

Streptomyces sp. (deep-sea sediment, S. China Sea) was the source of lobophorins H 135 and I 136 of which lobophorin H 135 exhibited significant inhibition of $B$. subtilis and moderate inhibition of $S$. aureus while lobophorin I $\mathbf{1 3 6}$ was much less active. ${ }^{162}$

The polycyclic polyketide akaeolide 137 was isolated from a Streptomyces sp. (sediment, Miyazaki Harbour, Japan) as a modest cytotoxin to $3 \mathrm{Y} 1$ rat fibroblasts. ${ }^{163}$ Strepsesquitriol 138, a caged sesquiterpene isolated from Streptomyces sp. (sediment, Bay of Bengal, Indian Ocean), was a moderate inhibitor of lipopolysaccharide-induced TNF $\alpha$ production in RAW264.7 macrophages, ${ }^{164}$ while cycloheximide acid A 139 was obtained from Streptomyces sp. (seawater, E. China Sea, Wenzhou, Zhejiang Province, China). ${ }^{165}$

The immunosuppressant cyclic lipopeptides thalassospiramides A and B were originally obtained from the $\alpha$ proteobacterium Thalassospira sp. ${ }^{166}$ Reinvestigation of the original producer, a second strain of Thalassospira (source not given), Tistrella mobilis (Red $\mathrm{Sea}^{167}$ ) and Tistrella bauzanensis (Pacific Ocean ${ }^{167}$ ) led to the isolation of fourteen analogues thalassospiramides A1-A5 140-144, C 145 and C1 146, E 147 and E1 148, B1 149 and B2 150, D 151 and D1 152 and thalassospiramide $\mathrm{F} \mathbf{1 5 3}$ that have been subdivided into six structural classes with variations in the length and composition of the acyl peptide side chain. The planar 


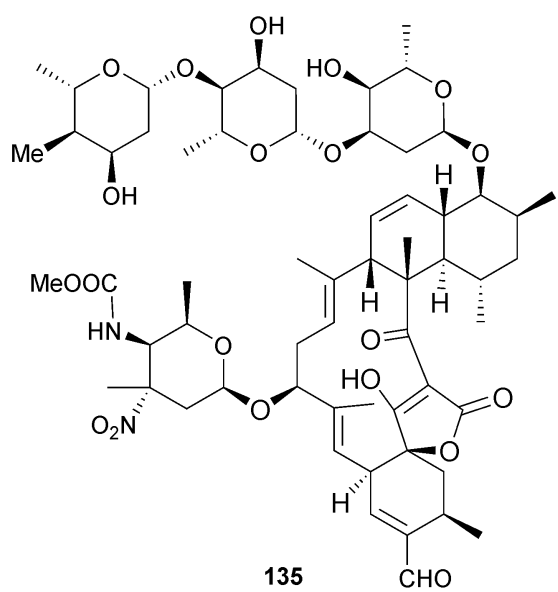<smiles>CCC[C@H]1C(=O)[C@H](CC[C@@]2(C)C[C@H](C)[C@H]([C@H](O)/C=C(\C)C(=O)C[18F])O2)C(=O)O[C@H]1C</smiles><smiles>C[C@@H]1C[C@H](O)[C@]23CC1CC[C@]2(O)C3(C)C</smiles><smiles>CC(=O)CC(C)C/C(=C\CC1CC(=O)NC(=O)C1)C(=O)O</smiles>

structures of 149 and 152 were described in a patent as metabolites of another $\alpha$-proteobacterium, Oceanospirillum sp. ${ }^{168}$ and potent inhibitors of the cysteine protease calpain 1. In the current study selected thalassospiramides (A, A1, B, C, D1 and E1) were tested and all displayed potent activity against calpain 1 . Biosynthetic gene clusters for all four bacterial strains were characterised revealing some atypical NRPS biochemical features such as intrasynthetase trans A domain activation, module skipping and multimodule iteration which likely yield the structural diversity. ${ }^{\mathbf{1 6 9}}$ Thalassospira sp. (brown alga Rosenvingea sp., Bahamas) yielded a further member of the thalassospiramide family of peptides, thalassospiramide G 154. The co-isolated thalassospiramides $\mathrm{A}^{\mathbf{1 6 6}}$ and $\mathrm{D}^{\mathbf{1 6 9}}$ were moderate inhibitors of NO production in lipopolysaccharide (LPS)-stimulated mouse macrophage RAW 264.7 cells. $^{170}$

The 18-membered macrolide macplocimine A 155 was obtained from the filamentous sulfur bacterium Thioploca sp. (benthic microbial mat, Chile). ${ }^{171}$ Verrucosispora sp. (deep-sea sediment, S. China Sea) was the source of three further abyssomicin polyketides abyssomicin J-L 156-158. Abyssomicin $\mathrm{C}^{\mathbf{1 7 2}}$ was also isolated and converted to abyssomicin $\mathrm{J}$ 156. In vitro and cell-based analytical studies were then used to show that abyssomicin J 156 can act as a prodrug which, upon oxidative

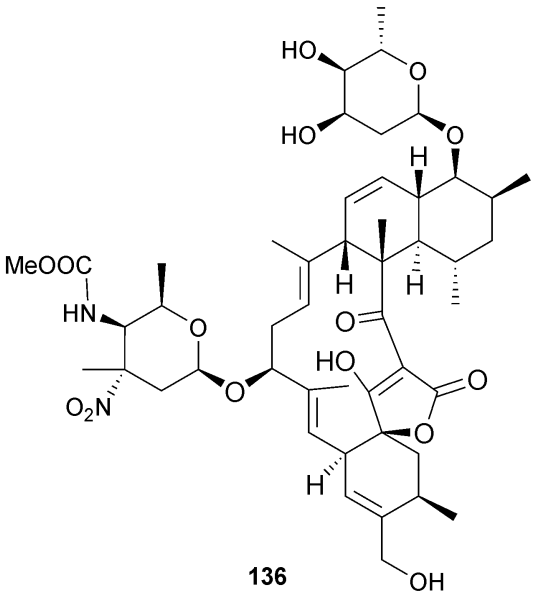

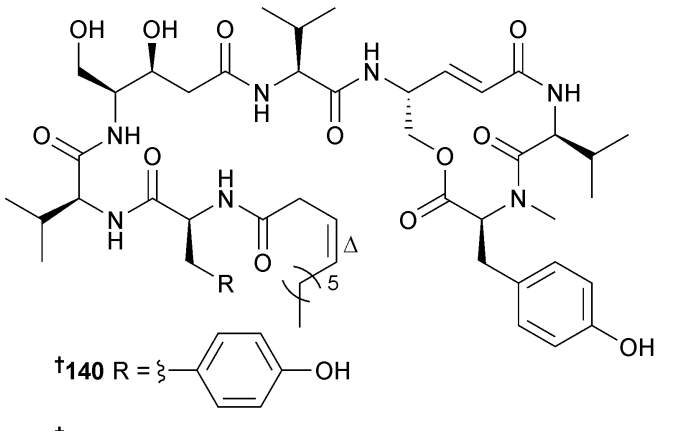

$\mathrm{t}_{141 \mathrm{R}}=\mathrm{OH}, \Delta$ saturated<smiles>[14CH3][14CH2]c1ccc(O)cc1</smiles>

$t_{143} R=i P r$

$\mathrm{t}_{144 \mathrm{R}}=\mathrm{Ph}$

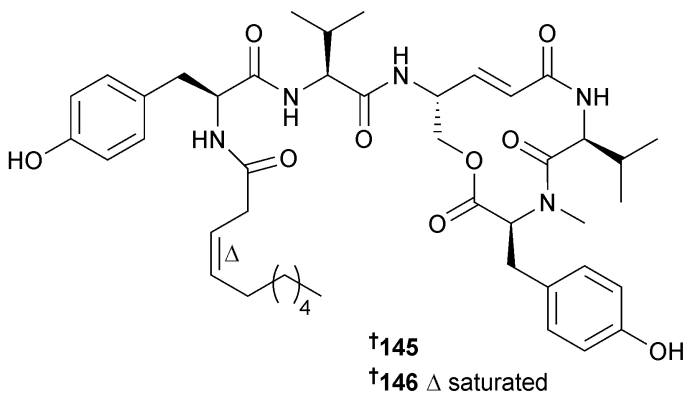

activation, will be selectively transformed to atrop-abyssomicin C, ${ }^{173}$ an anti-TB antibiotic. ${ }^{174}$

Heronamide A, a polyketide macrolactam originally obtained from an Australian, sediment-derived Streptomyces sp. ${ }^{175}$ was reisolated from a Streptomyces sp. (sediment, Uranouchi Bay, Kochi Prefecture, Japan). Detailed NMR analysis of heronamide A and derivatives resulted in configurational reassignment of heronamide A to $\mathbf{1 5 9}$ and the suggestion that 


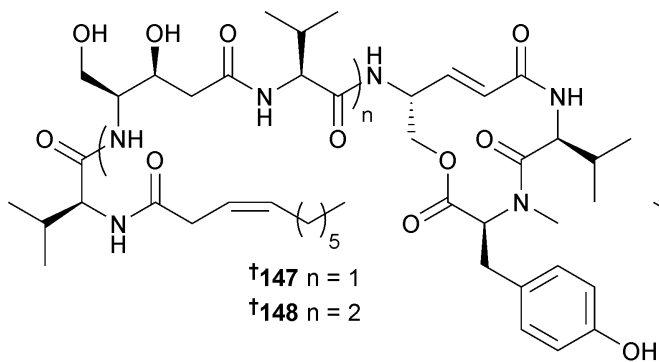

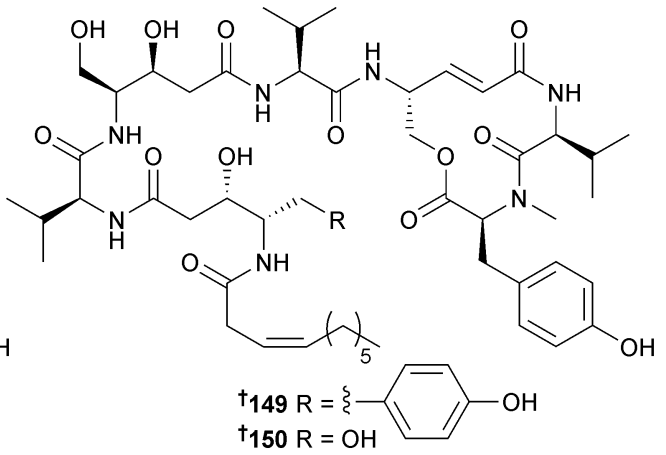

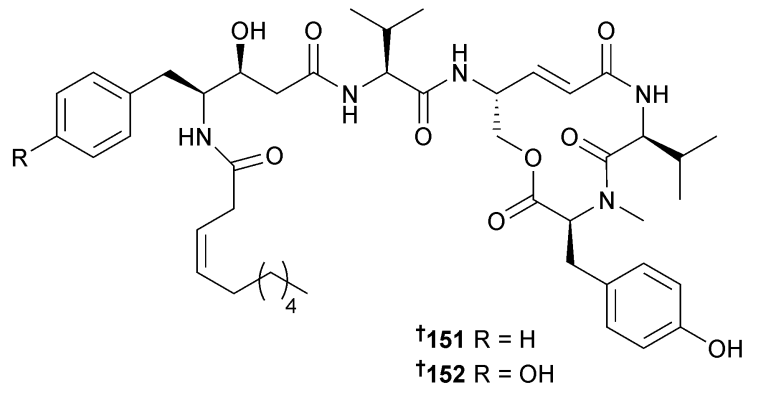

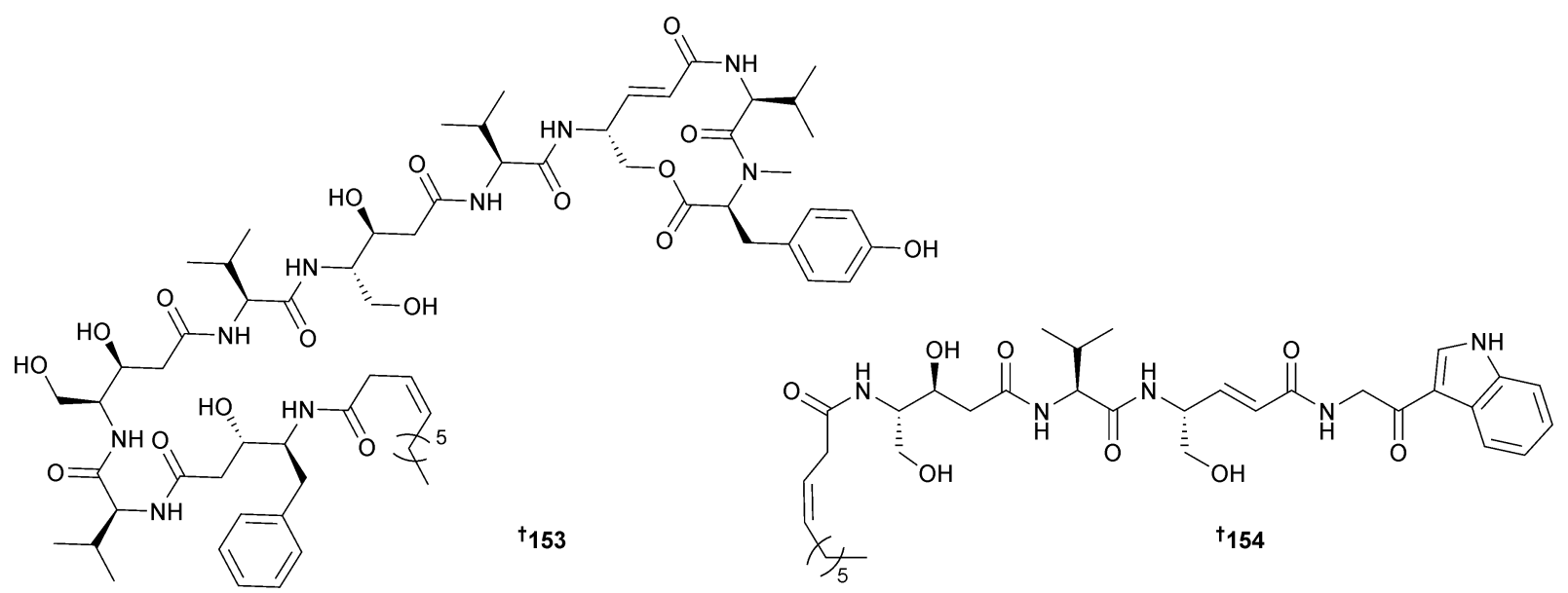

the configurations of heronamides $\mathrm{B}^{\mathbf{1 7 5}}$ and $\mathrm{C}^{\mathbf{1 7 5}}$ should be reinvestigated. ${ }^{\mathbf{1 7 6}}$

The configuration of the $\alpha$-methylserine residue in the tetrapeptides JBIR-34 and JBIR-35 and in the trichostatin analogue JBIR-111, originally obtained from a sponge-derived Streptomyces $\mathrm{sp}^{\mathbf{1 7 7 , 1 7 8}}$ have been corrected from $(R)$ to $(S) .^{\mathbf{1 7 9 , 1 8 0}}$ Tenacibaculum mesophilum (unidentified sponge, Republic of Palau) yielded a siderophore bisucaberin B. This is an open form of the known macrocyclic dimer bisucaberin ${ }^{181,182}$ that has been reported as a degradation product of desferrioxamine $\mathrm{B}^{\mathbf{1 8 3}}$ but not as a product of de novo biosynthesis. ${ }^{\mathbf{1 8 4}}$

\subsection{Bacteria from mangroves}

Bacillus hunanensis (sediment, Trinity Bay, Galveston Texas, U.S.A.) yielded hunanamycin A 160, the first NP with a pyrido [1,2,3-de]quinoxaline-2,3-dione core, which also displayed modest inhibition of Salmonella enterica. ${ }^{\mathbf{1 8 5}}$ Hunanamycin A was subsequently synthesised via a simple and scaleable method from 6,7-dimethyl-1,4-dihydroquinoxaline-2,3-dione. ${ }^{186}$ An indole alkaloid 161 was obtained from Pantoea agglomerans (mangrove Ceriops tagal, Zhanjiang, Guangdong, China) along with two phenylethylamine derivatives, 3-( $p$-hydroxy)benzoyl indole $^{187}$ and 1,2-di(1H-indol-3-yl)ethane, ${ }^{188}$ both known synthetic compounds but now isolated for the first time as MNPs. ${ }^{189}$ 
<smiles>Cc1cc(O)cc(O)c1OC(=O)C(CC(O)C/C=C\C(O)CC[C@H](C)CCCO)n1cc(C)c(=O)[nH]c1=O</smiles>

155

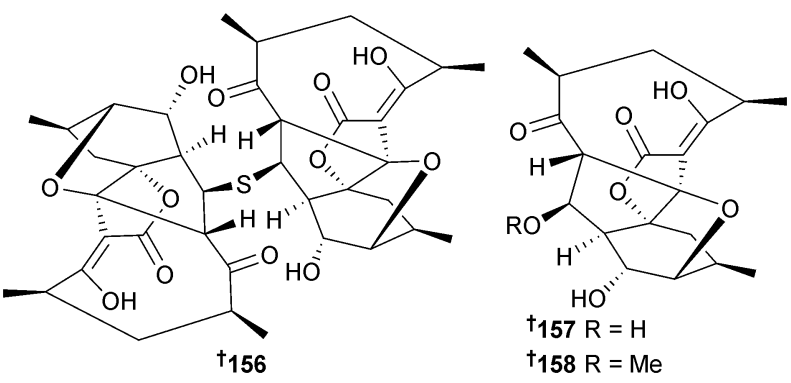

$\mathrm{HO}$

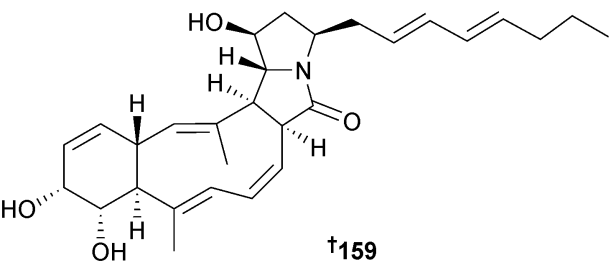<smiles>Cc1cc2c3c(c1C)C(C)(C)CCn3c(=O)c(=O)n2C[C@H](O)[C@H](O)[C@H](O)CO</smiles><smiles>O=C(Cc1c[nH]c2ccccc12)NCCc1ccc(O)cc1</smiles>

Streptomyces sp. (mangrove rhizosphere soil Heritiera globosa, Wenchang, China) ${ }^{\mathbf{1 9 0}}$ was the source of a series of azalomycin $\mathrm{F}$ analogues 162-168 which were all broad-spectrum antimicrobials and inhibitors of HCT-116 cells. ${ }^{191}$ The di-O-prenylated flavone 169 was isolated from an endophytic Streptomyces sp. (mangrove root Myoporum bontioides, Leizhou Peninsula, Guangdong Province, China) and was a moderate inhibitor of the plant pathogenic fungi, Colletotrichum musae, Gibberella zeae and Penicillium citrinum. ${ }^{192}$

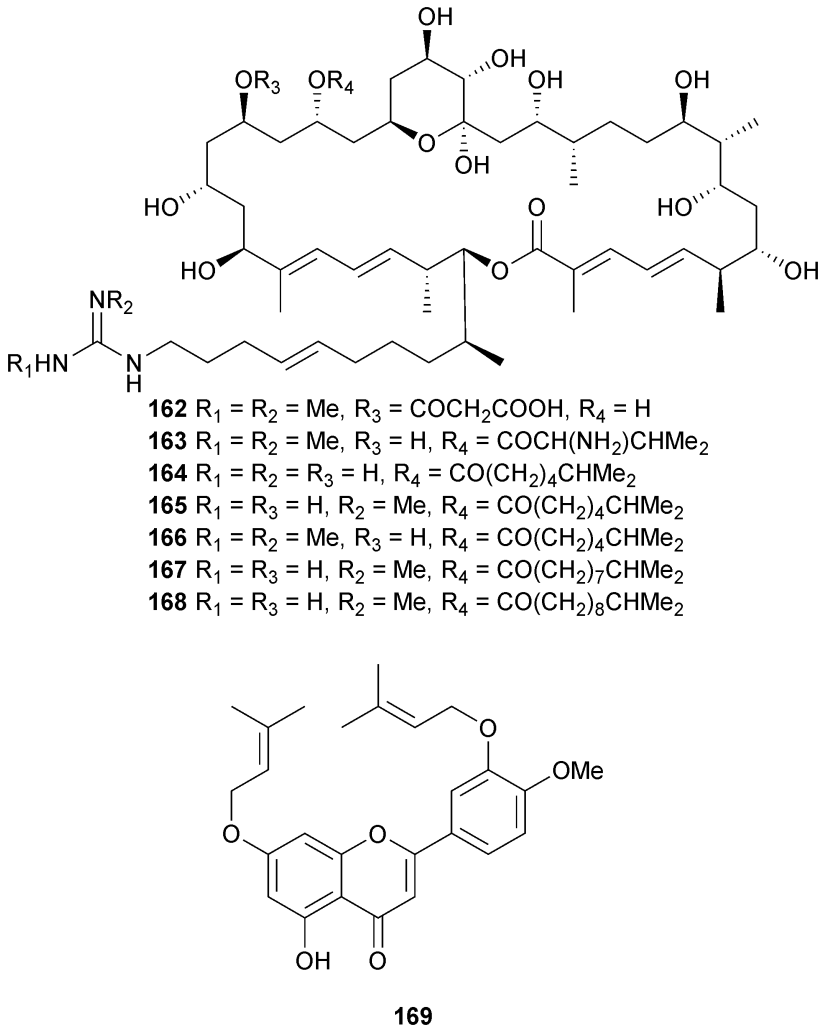

\subsection{Marine-sourced fungi (excluding from mangroves)}

Several acremine metabolites, 5-chloroacremine A 170, 5chloroacremine $\mathrm{H} 171$ and acremines O-R 172-175, together with the known terrestrial fungal metabolite acremine $\mathrm{F},{ }^{193}$ were isolated from Acremonium persicinum (sponge Anomoianthella rubra, Gneering Reef, S. E. Queensland, Australia). The configuration of acremine $\mathrm{F}$ was determined as $\mathbf{1 7 6}$ and this was the first isolation as an MNP. ${ }^{194}$<smiles>CCC[18O][C@@]1(C)C(=O)C=C(/C=C/C(C)(C)O)[C@@H](O)[C@H]1Cl</smiles><smiles>[Y17]C1=C(Cl)C(=O)[C@]2(CC1=O)C[C@H](O)C(C)(C)O2</smiles>

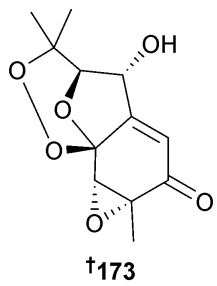

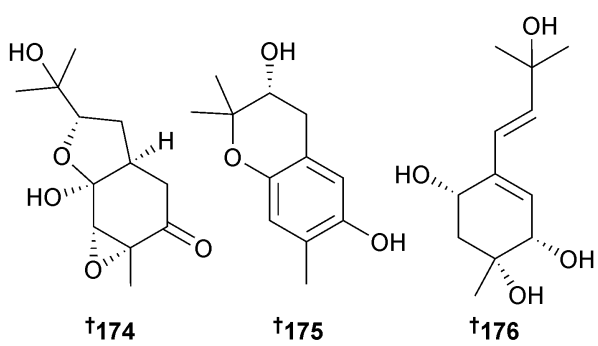

Alternaria sp. (sponge Callyspongia sp., Sanya, Hainan Is., China) was the source of a variety of meroterpenoids including tricycloalternarene A 177, the hydrogenated benzofurans, bicycloalternarene A-D 178-181, the hydrogenated chromans, 
<smiles>CC(C)=CCC[C@@H](C)[C@H]1CCC(O)(O)[C@]12CC1=C(O[C@H](O)CC1)C2=O</smiles><smiles>CC(C)=CCCC(C)(O)[C@H](O)CC[C@@H](O)[C@H]1CC2=C(CC[C@@H](O)C2=O)O1</smiles>

bicycloalternarene E 182 and F 183, and the hydrogenated cyclopenta- $[b]$-chromans, tricycloalternarene $\mathrm{B} \mathbf{1 8 4}$ and $\mathrm{C}$ 185. Four additional monocyclic meroterpenoids monocycloalternarene $\mathrm{A}^{\mathbf{1 9 5}} \mathbf{1 8 6}$ and monocycloalternarene B-D 187-

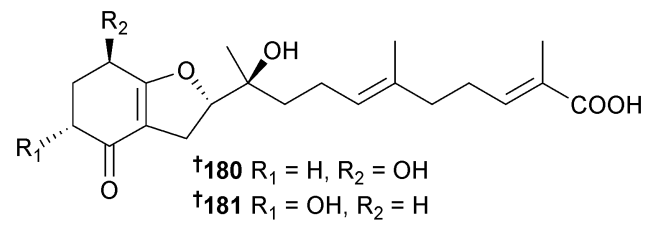

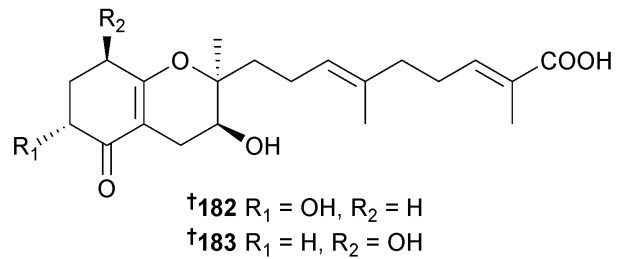

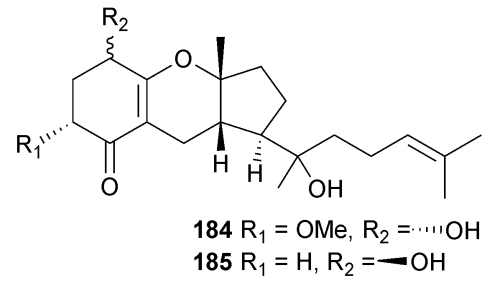

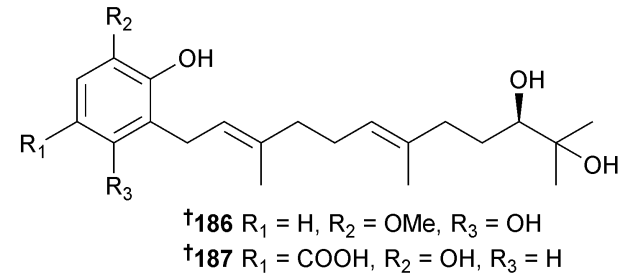<smiles>CO[C@H]1C[C@@H](O)C(O)=C(C/C=C(/[15NH2])CC/C=C(\C)CC/C=C(\C)C(=O)O)C1=O</smiles>

189 were obtained when the putative precursors sodium 3,4dihydroxybenzoic acid or shikimic acid were fed to the fungus, reinforcing the proposed shikimate-isoprenoid hybrid biosynthetic pathway. All the metabolites except bicycloalternarenes $\mathrm{E}$ 182 and $\mathrm{F} 183$ were weak to moderate inhibitors of NF- $\kappa \mathrm{B}$ in RAW264.7 cells. ${ }^{196}$

The sesquiterpene ascotrichic acid 190 was isolated from Ascotricha sp. (coastal mud, Fenghua County, Zhejiang, China). ${ }^{197}$ The benzoquinone derivatives aculeatusquinone A-D 191-194 were isolated from Aspergillus aculeatus (sediment, Langqi Is., Fujian, China) and of these aculeatusquinones B and D were moderately cytotoxic to several HTCLs. ${ }^{198}$<smiles>C/C(=C\CCC(C)(O)[C@H]1CC[C@@](C)(O)[C@@H]1C)C(=O)O</smiles><smiles>CC1=C(O)C(=O)C(Oc2cc(C)cc(O)c2C)=C(C)C1=O</smiles><smiles>CO[C@]1(C)C(=O)C(O)=C(C)C(=O)[C@@H]1Oc1cc(C)cc(O)c1C</smiles><smiles>CO[C@]1(C)[C@@H](O)C(O)=C(C)C(=O)[C@H]1Oc1cc(C)cc(O)c1C</smiles><smiles>CO[C@]1(C)C(=O)C(O)=C(C)C(=O)[C@]12Oc1c(C)c(O)cc(C(C)(C)C)c1C2=O</smiles>

An oxepin-containing alkaloid 195, a quinazolinone-containing alkaloid 196 and a dihydrobenzofuran derivative 197 were obtained from A. carneus (brown alga Laminaria sachalinensis, Kunachir Is., Russia). ${ }^{199}$ Clavatustides A 198 and B 199, cyclodepsipeptides with an unusual anthranilic acid dimer and a D-phenyllactic acid residue, were isolated from A. clavatus (hydrothermal vent crab Xenograpsus testudinatus, Kueishantao, Taiwan) and suppressed proliferation of HTCLs. ${ }^{200}$

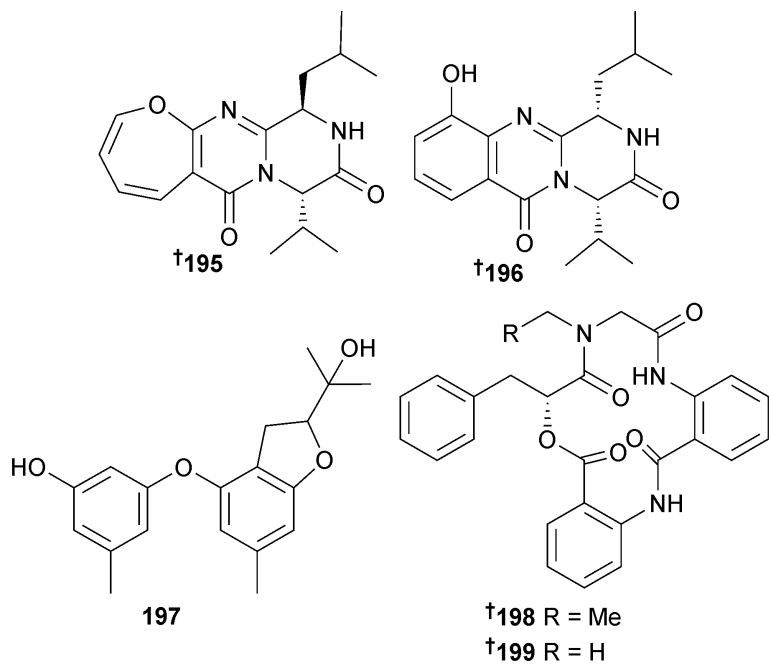


A. elegans (soft coral Sarcophyton sp., Weizhou coral reef, S. China Sea) produced the phenylalanine derivative 4 -methoxyasperphenamate 200 and the cytochalasins aspochalasin A1 201 and cytochalasin Z24 202, in addition to a number of known cytochalasin analogues. 4'-Methoxyasperphenamate 200 was modestly active against Staphylococcus epidermidis while the known cytochalasins aspochalasin $\mathrm{I}^{201} \mathrm{~J},{ }^{201} \mathrm{D}^{202,203}$ and $\mathrm{H}^{204}$ displayed strong antifouling activity against larval settlement of the barnacle Balanus amphitrite (B. amphitrite). Aspochalasins I, $\mathrm{J}$ and $\mathrm{H}$, previously isolated from terrestrial Aspergillus species, are first time MNPs. ${ }^{205}$<smiles>COc1ccc(C[C@H](COC(=O)[C@H](Cc2ccccc2)NC(=O)c2ccccc2)NC(=O)c2ccccc2)cc1</smiles><smiles>CC1=C[C@@H]([C@H](C)CC(C)C)/C=C(\C)CCC(=O)O[C@@]2(CCC(=O)[C@H](O)CCC(=O)O2)[C@H](C)C(C)=C[C@H]1C</smiles>

201

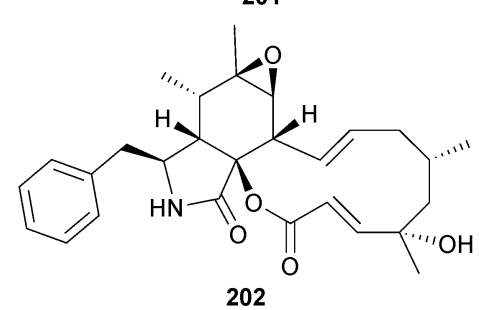

Of the tris-pyrogallol ethers sydowiol A-C 203-205 from A. sydowii (sediment, E. China Sea), sydowiols A 203 and C 205 inhibited M. tuberculosis protein tyrosine phosphatase A (PTPA). ${ }^{206}$ A. terreus, var. boedijnii (Blochwitz) (red alga Laurencia ceylanica, Arugam Bay, Sri Lanka) produced a new butyrolactone 206 which was a strong inhibitor of the enzyme $\beta$-glucuronidase.<smiles>Cc1cc(O)c(Oc2cc(C)cc(O)c2Oc2c(O)cc(C)cc2Oc2c(O)cc(C)cc2Oc2c(O)cc(C)cc2Oc2c(O)cc(C)cc2Oc2c(O)cc(C)cc2Oc2cc(C)cc(O)c2O)c(O)c1</smiles><smiles>CC(=O)C1(Cc2ccc(O)c(C=O)c2)OC(=O)C(O)=C1c1ccc(O)cc1</smiles>

A number of known compounds were also isolated which included $(+)$-asterrelenin, ${ }^{207}$ a moderate inhibitor of $\beta$-glucuronidase, $(3 R, 4 R)$-6,7-dimethoxy-4-hydroxymellin ${ }^{208}$ and (+)-territonin $\mathrm{A}^{207}$ all reported as first time MNPs. ${ }^{209}$ The cyclic tetrapeptide asperterrestide A 207, the alkaloid terremide C 208 and an aromatic butenolide aspernolide E 209 were obtained from A. terreus (gorgonian Echinogorgia aurantiaca, Sanya, Hainan Province, China). Asperterrestide A 207 inhibited influenza virus strains $\mathrm{H} 1 \mathrm{~N} 1$ and $\mathrm{H} 3 \mathrm{~N} 2$ and was cytotoxic to HTCLs. ${ }^{210}$<smiles>CCC(C)[C@H](NC(=O)[C@H](C)NC(=O)c1ccccc1NC(=O)[C@@H]([C@@H](O)c1ccccc1)N(C)C(=O)[C@H](C)NC(=O)c1ccccc1)C(=O)[OH2+]</smiles><smiles>COC(=O)[C@]1(Cc2ccc3c(c2)C=CC(C)(C)O3)OC(=O)C(O)=C1c1ccc(O)cc1</smiles>

Cultivation of A. unguis (unidentified sponge, Tub-La-Mu Bay, Pang-nga Province, Thailand) in media containing different halogen salts led to the production of "unnatural natural" depsidones. Growth in media containing $\mathrm{KBr}$ produced the brominated depsidones aspergillusidone D-F 210-212 and the orcinol derivatives aspergillusidone A 213 and B 214, whilst culture in KI produced another new depsidone 2,4dichlorounguinol 215. Of these, aspergillusidones D-F 210-212 inhibited aromatase, a therapeutic target for breast cancer treatment. ${ }^{211}$<smiles>[R]c1c(C)c2c(c([R2])c1O)Oc1c(c(C)c(O)c([R3])c1/C(C)=C/C)OC2=O</smiles><smiles>[Y]C=C(C)c1cc(O)c(C)c(O)c1[R]</smiles>

$210 \mathrm{R}_{1}=\mathrm{R}_{3}=\mathrm{Br}, \mathrm{R}_{2}=\mathrm{H}$ $211 \mathrm{R}_{1}=\mathrm{Br}, \mathrm{R}_{2}=\mathrm{R}_{3}=\mathrm{H}$ $212 \mathrm{R}_{1}=\mathrm{H}, \mathrm{R}_{2}=\mathrm{R}_{3}=\mathrm{Br}$ $215 R_{1}=R_{2}=\mathrm{Cl}, \mathrm{R}_{3}=\mathrm{H}$
$213 \mathrm{R}=\mathrm{H}$ $214 \mathrm{R}=\mathrm{Br}$ 
A large number of terpenes were sourced from A. ustus (green alga Codium fragile, Zhoushan Is., Zhejiang Province, China) and included the meroterpene 1,2-dihydroterretonin F 216, the sesterterpenes (6 $\alpha$ )-21-deoxyophiobolin G 217, $(6 \alpha)$-16,17-dihydro-21-deoxyophiobolin G 218, ophiobolins $U-W$ 219-221 and the diasteroisomeric sesquiterpenes, (6-strobilactone-B) esters of (E,E)-6,7-epoxy2,4-octadienoic acids 222 and 223 as new compounds. Ophiobolin $\mathrm{F}^{\mathbf{2 1 2}}$ was obtained from the marine environment for the first time. Ophiobolin U 219 and the co-isolated known $(5 \alpha, 6 \alpha)$-ophiobolin $\mathrm{H}^{213}$ moderately inhibited growth of E. coli. ${ }^{214}$

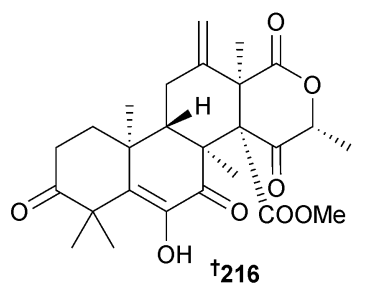

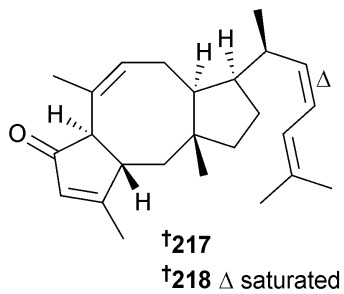<smiles>[Z10][C@H]1CC(=O)C2=C1C[C@]1(C)CC[C@H]([C@H](C)/C=C\C=C(C)C)[C@H]1C/C=C\2CO</smiles><smiles>CC(C)=C/C=C\[C@@H](C)[C@H]1CC[C@@]2(C)C[C@H]3C(C)=CC(=O)/C3=C(\CO)CC[C@@H]12</smiles>

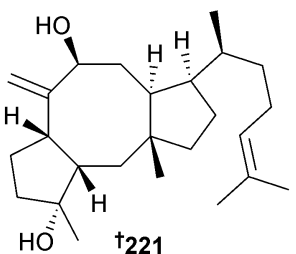<smiles>CC1OC1/C=C/C=C/C(=O)O[C@H]1C=C2COC(=O)[C@]2(C)[C@@]2(C)CCCC(C)(C)[C@H]12</smiles>

Anthcolorins A-F 224-229, tetrahydropyran diterpene metabolites containing an oxoindoline moiety were isolated from A. versicolor (sea urchin Anthocidaris crassispana, Tanabe Bay, Wakayama, Japan), as three sets of epimeric pairs with moderate growth inhibition (P388) noted for anthcolorins B-D 225-227. 215,216

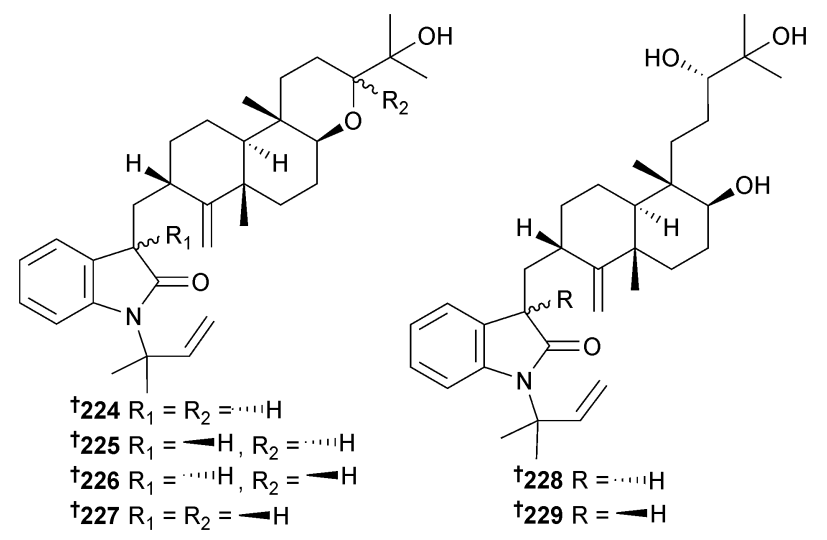

Aspeverin 230 isolated from A. versicolor (green alga Codium fragile, Dalian, China) was a moderate growth inhibitor of the phytoplankton Heterosima akashiwo. ${ }^{217}$ Four prenylated diphenyl ethers diorcinol B-E 231-234 were obtained from $A$. versicolor (mud, Yellow Sea), ${ }^{218}$ of which two, diorcinols D and $\mathrm{E}$ were toxic to HTCLs. ${ }^{219}$

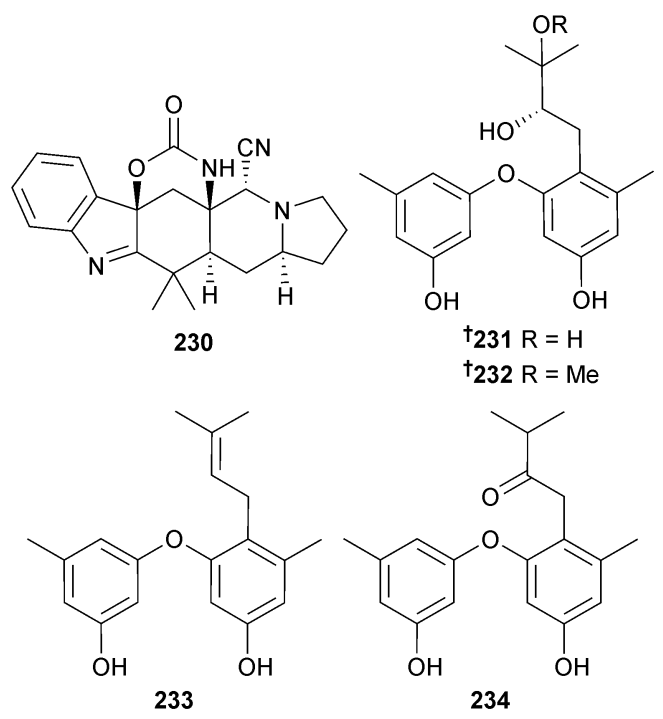

Endophytic A. wentii (brown alga Sargassum sp., no location specified) produced wentiquinone A 235, along with another secoanthraquinone derivative which was claimed as new and named wentiquinone B. A compound of this structure had already been isolated as guepinone from the terrestrial fungus Pestalotiopsis guepinii, ${ }^{220}$ but this was the first isolation from the marine environment. ${ }^{221}$ The xanthone derivatives yicathin A-C 236-238 were isolated from endophytic A. wentii (red alga Gymnogongrus flabelliformis, Pingtan Is., China). Yicathins B and $\mathrm{C}$ had antimicrobial activities. ${ }^{222}$<smiles>COc1cc(O)c2c(=O)c3c(O)cc(C)cc3oc(=O)c2c1</smiles>

235

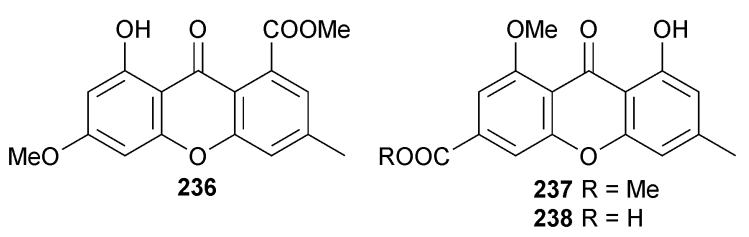

A. westerdijkiae (deep-sea sediment, S. China Sea) was the source of the benzodiazepine alkaloids circumdatin K 239 and $\mathrm{L}$ 240, the prenylated indole alkaloids 5-chlorosclerotiamide 241 and 10-epi-sclerotiamide $\mathbf{2 4 2}$ and the amide aspergilliamide B 243 (ref. 223) whilst Aspergillus sp. (mussel Mytilus edulis, Toyama Bay, Japan Sea $)^{224}$ produced himeic acids E-G 244246. ${ }^{225}$ 
<smiles>CC1NC(=O)c2ccccc2-n2c1nc1c(c2=O)C=CC=CO1</smiles>

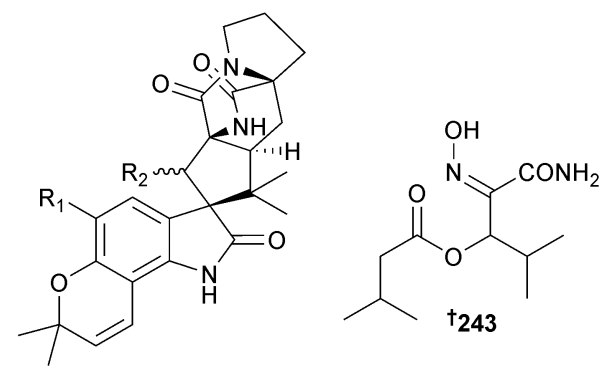

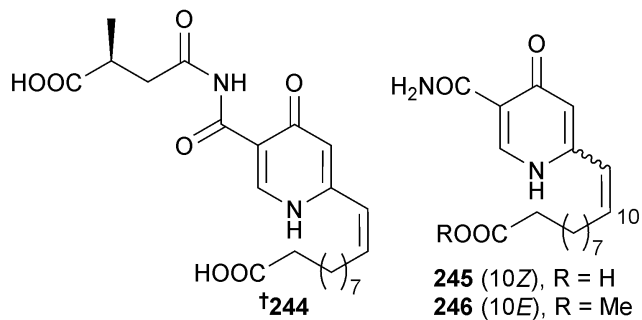

The cyclic tetrapeptides aspergillipeptide A-C 247-249 and asteltoxin B 250 were isolated from Aspergillus sp. (gorgonian Melitodes squamata, Sanya, Hainan province, China) with aspergillipeptide C 249 showing strong antifouling activity against Bugula neritina (B. neritina) larvae settlement. ${ }^{226}$

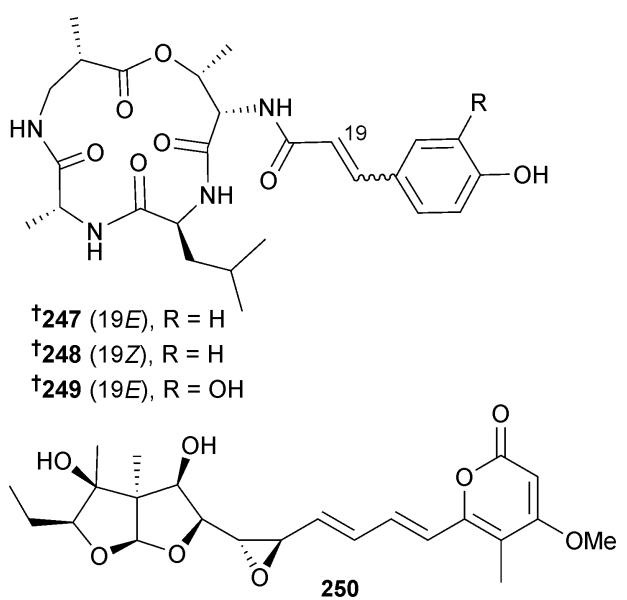

Aspergillus sp. (sponge Tethya aurantium, Limski canal, N. Adriatic Sea, Croatia) produced seven new alkaloids, tryptoquivaline K 251 and fumiquinazolines K-P 252-257, the latter group containing the rare 1-aminocyclopropane-1-carboxylic acid residue. ${ }^{227}$

The prenylated indole alkaloids 17-epi-notoamide Q 258 and M 259 and the phenyl ether derivative cordyol D 260 were obtained from Aspergillus sp. (gorgonian Dichotella gemmacea, Xisha Is., S. China Sea). A further phenyl ether was isolated and claimed as new but had already been reported from the mangrove-associated fungus Penicillium expansum. ${ }^{228}$ The synthetic compound dehydronotoamide $\mathrm{C}^{229}$ was obtained for the first time as an NP and the fungal metabolite notoamide $\mathrm{C}^{230}$ was also reisolated and the absolute configuration previously proposed $^{231}$ for this metabolite proven as $261 .^{232}$ As a consequence the configurations of the Aspergillus-derived notoamides $\mathrm{J},{ }^{233} \mathrm{Q}^{234}$ and $\mathrm{M}^{235}$ have been corrected from $(3 S)$ to $(3 R)$ for notoamide $\mathrm{J}^{235,236}$ and from $(3 R)$ to $(3 S)$ for notoamides Q and $\mathrm{M}^{237,238}$

Aspergillide D 262, a 16-membered macrolide, was isolated from Aspergillus sp. (gorgonian Melitodes squamata, Sanya, Hainan Province, China). ${ }^{239}$ Co-isolated were two known sesquiterpenoid nitrobenzoyl esters, $9 \alpha, 14$-dihydroxy-6 $\beta-p$ nitrobenzoylcinnamolide ${ }^{240}$ and $7 \alpha, 14$-dihydroxy-6 $\beta$ - $p$-nitrobenzoylconfertifolin, ${ }^{240}$ moderate inhibitors of H1N1.239 Two aspergillic acid group toxins aspergilliamide 263 and ochratoxin A butyl ester 264 were obtained from Aspergillus sp. (gorgonian Melitodes squamata, Sanya, Hainan Province, China), both modestly toxic to brine shrimp (Artemia salina). Co-isolated was the known neoaspergillic $\operatorname{acid}^{241}$ and, surprisingly, the aluminium and zirconium salts of the acid. ${ }^{242}$

A racemic mixture of a $\gamma$-lactone derivative 265 was isolated from Aspergillus sp. (gorgonian Melitodes squamata, Sanya, Hainan Province, China) with significant toxicity to brine shrimp. ${ }^{243}$ A lactam derivative was also obtained and the structure proposed as a dehydrated pyrrolyl 1-isoquinoline alkaloid, ${ }^{243}$ a structure originally proposed for marinamide, but which was subsequently revised to that of the dehydrated quinoline alkaloid penicinoline (in section 3.4 below this same problem is addressed with respect to two unidentified microorganisms grown in co-culture). ${ }^{244,245}$ While it might be possible that these two compounds have very similar NMR data, X-ray crystallography of this new marinamide is required to resolve the doubt.

Bartalinia robillardoides (sponge Tethya aurantium, Limsky Channel, Croatia) was the source of the chloroazaphilone helicusin E 266 and the pentaketide bartanolide 267. Isochromophilones $\mathrm{X}^{246}$ and $\mathrm{XI}^{246}$ were also isolated and claimed as new but are known terrestrial fungal metabolites. Isochromophilone $\mathrm{XI}^{246}$ along with other known fungal metabolites helicusin $\mathrm{A}^{247}$ and deacetylsclerotiorin, ${ }^{248}$ had a variety of moderate to weak antimicrobial activities. ${ }^{249}$

Calcarisporium sp. (seawater, Wadden Sea, Germany) generated macrocyclic and linear polyesters including calcarides A-E 268-272, out of which calcarides A-C 268-270 and the co-isolated analogues $15 \mathrm{G} 256 \alpha$ and $15 \mathrm{G} 256 \beta$, previously obtained from the marine fungus Hypoxylon oceanicum, ${ }^{250}$ inhibited growth of Staphylococcus epidermidis and Xanthomonas campestris while the linear ester 15G256 $\pi$ inhibited growth of Propionibacterium acnes. ${ }^{251}$

Two lanostanes 273 and 274, with the latter previously reported in the patent literature as a metabolite of the mushroom Fomitopsis pinicola, ${ }^{252}$ were obtained from endophytic Ceriporia lacerate (starfish Acanthaster planci, Hainan Sanya National Coral Reef Reserve, China). ${ }^{253}$ Although a further lanostane, $3 \beta$-acetoxy-15 $\alpha$-hydroxylanosta-8,24-dien-21-oic acid 


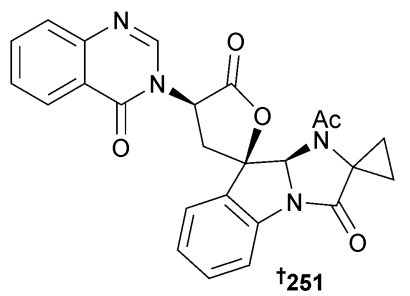

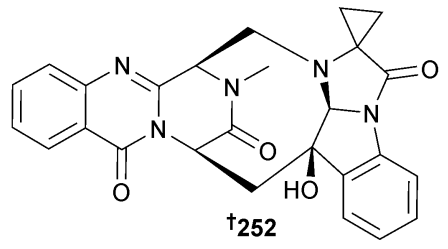

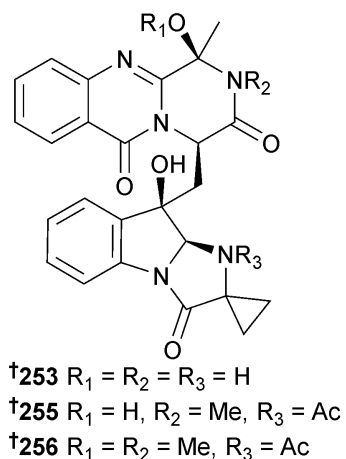<smiles>Cc1c(O)c(C(=O)O)c(O)c2c1[C@H](C)[C@@H](C)O[C@H]2/C=C1\NC(=O)[C@@H](C[C@@]2(O)c3ccccc3N3C(=O)C4(CC4)N[C@@H]32)n2c1nc1ccccc1c2=O</smiles><smiles></smiles><smiles>[R]C12CCCN1C(=O)C(C[C@@]1(C(C)(C)C=C)C(=O)Nc3c1ccc1c3C=CC(C)(C)O1)C(=O)N2</smiles><smiles>COc1cc(C)cc(Oc2cc(C)cc(OC)c2O)c1O</smiles><smiles></smiles>
262<smiles>CC(C)CC(=O)NC(=O)/C(CC(C)C)=N\O</smiles><smiles>CCOC(=O)C(Cc1ccccc1)NC(=O)c1cc(Cl)c2c(c1O)C(=O)O[C@H](C)C2</smiles>

was also claimed as new, it had previously been isolated from a fungal endophyte of a traditional Chinese medicinal plant Huperzia serrata. ${ }^{254}$

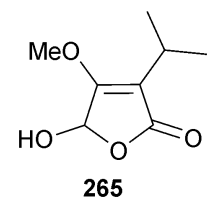

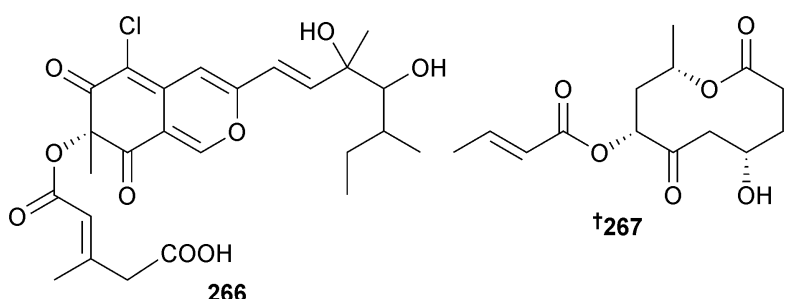

Chondrostereum sp. (soft coral Sarcophyton tortuosum, Hainan Sanya National Coral Reef Reserve, China), previously the source of chondrosterins $\mathrm{A}-\mathrm{E},{ }^{255}$ produced further chondrosterins $\mathrm{F}-\mathrm{H}$ 275-277. The terrestrial fungal metabolites incarnal $^{256}$ and arthrosporone, ${ }^{257}$ and the plant metabolite $(2 E)$ decene-4,6,8-triyn-1-ol, ${ }^{258}$ were also all isolated for the first time as MNPs. ${ }^{259}$ The benzolactone metabolites chrysoarticulin A-C 278-280 were isolated from Chrysosporium articulatum, (unidentified dictyoceratid sponge, Gagu-do, S. Korea) with chrysoarticulin $\mathrm{C} \mathbf{2 8 0}$ active against the bacterial transpeptidase enzyme sortase A. $^{260}$ 


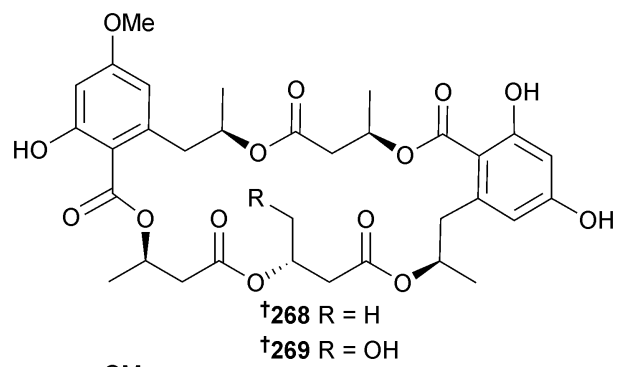<smiles>COc1cc(O)c(C(=O)O[C@@H](C)CC(=O)OCCCC(=O)O[C@@H](C)Cc2cc(O)cc(O)c2C(=O)OC(C)CC(=O)OC(C)Cc2cc(O)cc(O)c2)c(O)c1</smiles><smiles>[R]C[C@H](O)CC(=O)O[C@H](C)Cc1cc(O)cc(O)c1C(=O)O[C@H](C)CC(=O)O[C@@H](C)Cc1cc(OC)cc(O)c1C(=O)O[C@@H](C)CC(=O)O</smiles>

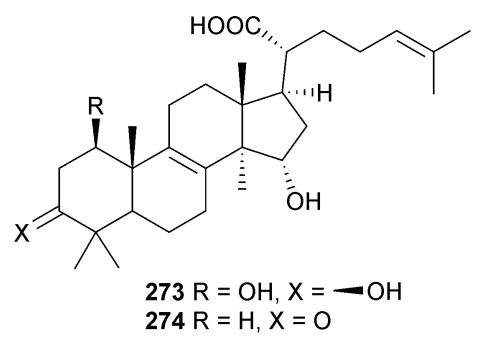

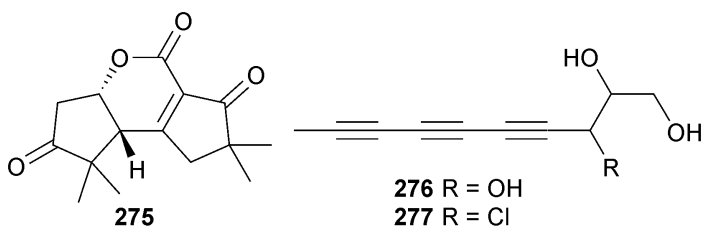<smiles>[R]Cc1cc(C)c2c(c1O)C(=O)O[C@H]([C@H](C)CC)[C@H]2O</smiles><smiles>CC[C@H](C)[C@H](O)[C@H]1OC(=O)c2c(O)c(C)cc(C)c21</smiles>

Dendrodochium sp. (sea cucumber Holothuria nobilis, S. China Sea) produced the 12-membered macrolides dendrodolide A-M 281-293 (dendrodolides A-E, G-I, K and L had

modest inhibitory activity against two HTCLs), ${ }^{261}$ while the polyketides 294 and 295 were obtained from Eutypella scoparia (sediment, S. China Sea). ${ }^{262}$
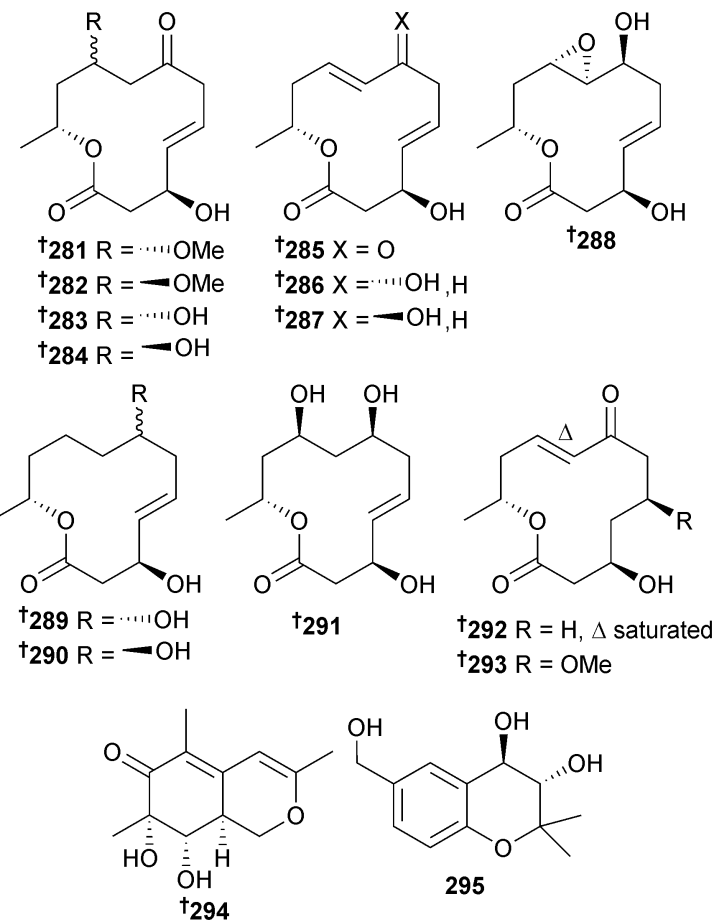

Gymnascella dankaliensis (sponge Halichondria japonica, Osaka Bay, Japan $)^{263}$ provided dankastatin C 296, a polyketide tyrosine derivative with potent growth inhibition of P388 cells. ${ }^{264}$ Hypocreales sp. (sponge Gelliodes carnosa, S. China Sea) was the source of the cadinane-type sesquiterpenes hypocreaterpene A 297 and B 298. The known terrestrial plant metabolites, $\quad(1 R, 6 R, 7 R, 10 S)$-10-hydroxy-4(5)-cadinen-3-one ${ }^{265}$ and $(R)$-5,6-dihydro-6-pentyl-2H-pyran-2-one ${ }^{266}$ were also isolated for the first time as MNPs and both had moderate antiinflammatory activity (inhibition of NO production). ${ }^{267}$ Oxirapentyn E 299, a highly oxidised chromene was isolated from Isaria felina (sediment, Vietnam) as a growth stimulant of corn (Zea mays L.) and barley (Hordeum vulgare L.) rootlets. ${ }^{268}$<smiles>CCCCCC[C@@H](C)/C=C(C)/C=C/C(=O)N[C@H]1C[C@@]2(O)[C@H](OC)[C@@H](Cl)C(=O)[C@H](Cl)[C@H]2O[C@H]1OC</smiles>

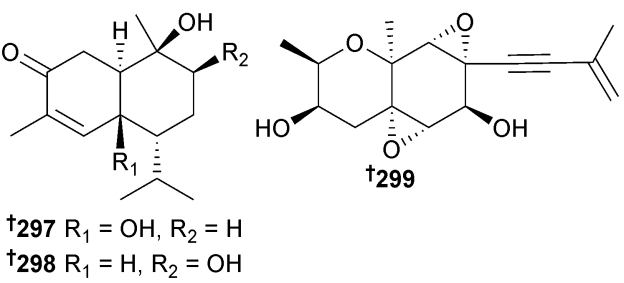


Metarhizium anisopliae (unidentified sponge, Naozhou Is., Guangxi, China) generated two naphtho- $\gamma$-pyrone glycosides indigotide $\mathrm{G} 300$ and $\mathrm{H}$ 301. The known compounds isochaetochromin B2 (ref. 269) and ustilaginoidin $\mathrm{D}^{270}$ were obtained for the first time from a marine source and displayed modest inhibition of Mycobacterium phlei. ${ }^{271}$<smiles>CO[C@@H]1[C@@H](O)[C@@H](O)[C@H](Oc2cc(O)cc3cc4c(c(O)c23)C(=O)[C@H](C)[C@@H](C)O4)O[C@@H]1CO</smiles><smiles>CO[C@@H]1[C@@H](C)[C@@H](O)[C@H](Oc2cc(O)c3c(O)c4c(cc3c2)O[C@H](C)[C@@H](C)C4=O)O[C@@H]1CO</smiles>

Sartorypyrone B 302, a moderate inhibitor of HTCLs, was obtained from Neosartorya tsunodae (sponge Aka coralliphaga, Similan Is., Phagna Province, Thailand), ${ }^{272}$ while tryptoquivalines $\mathrm{R} \mathbf{3 0 3}$ and $\mathrm{S} \mathbf{3 0 4}$ are indole alkaloids obtained from Neosartorya sp. (intertidal mud, Hainan Province, China), ${ }^{273}$ previously the producer of tryptoquivalines $\mathrm{P}$ and $\mathrm{Q} .{ }^{274}$

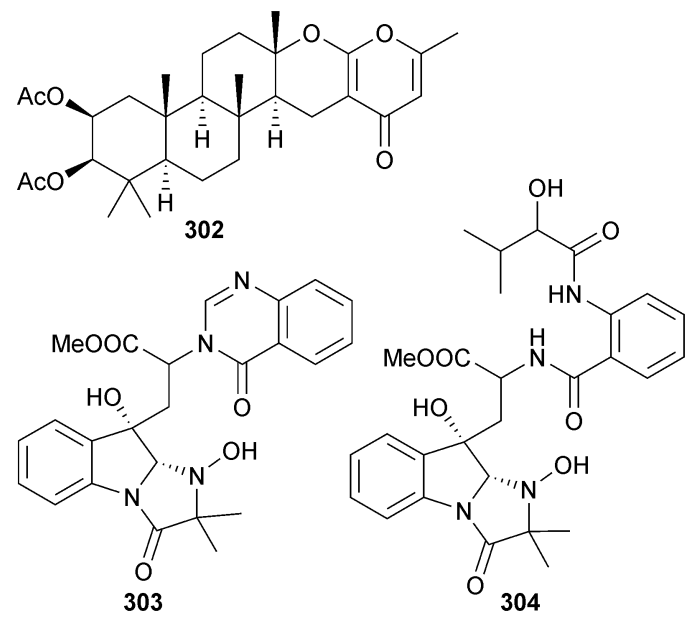

Paecilomyces sp., (unspecified sponge, Tinggi Is., Malaysia) was the source of the dione $\mathbf{3 0 5},{ }^{275}$ while the chrysotriazoles A 306 and B $\mathbf{3 0 7}$ were obtained from endophytic Penicillium chrysogenum (brown alga Sargassum palladium, Fujian, China). ${ }^{276}$ P. oxalicum (sediment, Bohai Bay, Liaoning Province, China) produced decaturins E 308 and F 309, ${ }^{277}$ and 2-(4-hydroxybenzoyl) quinazolin-4(3H)-one $\mathbf{3 1 0}$ was isolated from $P$. oxalicum (strain 0312F1, Genbank accession no. EU926977) as a moderate inhibitor of tobacco mosaic virus (TMV) and the human gastric cancer cell line SGC-7901. ${ }^{278}$

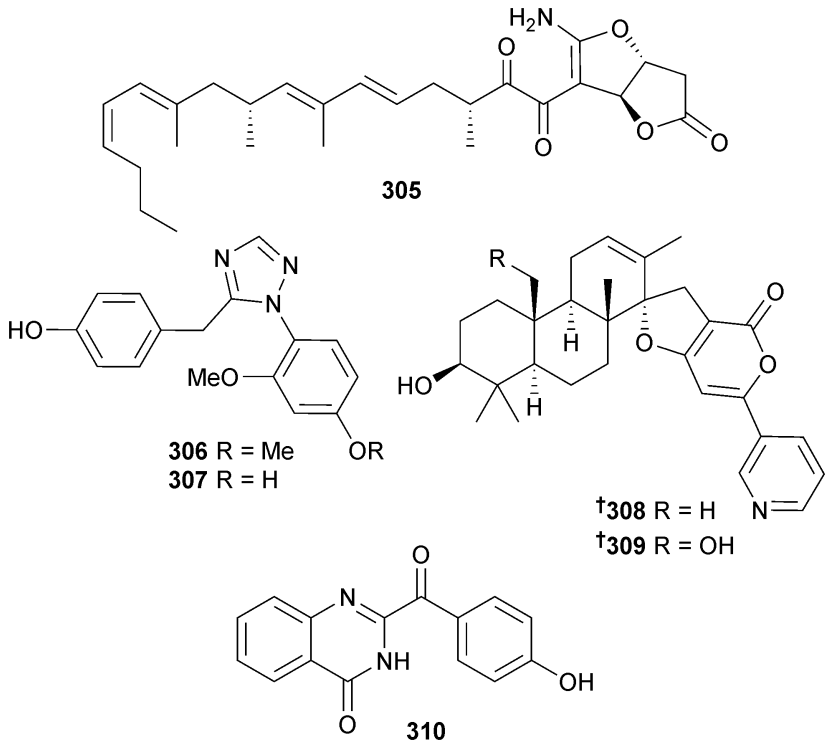

The dihydrothiophene-condensed chromones oxalicumone A 311 and B 312 were obtained from P. oxalicum (gorgonian Muricella flexuosa, Sanya, China) with oxalicumone A 311 moderately cytotoxic to HTCLs. ${ }^{279}$ A further chromone was also claimed as new and named as oxalicumone $\mathrm{C}$ but while isolated from a natural source for the first time, is a known reaction product of chloromonilicin, a metabolite of the cherry rot fungus Monilinia fructicola. ${ }^{280}$<smiles>CC(=O)CC(O)C(C)(CC(O)C(C)=O)[C@H]1Cc2c(oc3cc(C)cc(O)c3c2=O)S1</smiles>

The anthranilic acid derivatives penipacid A-C 313-315, E 316 and $\mathrm{G} 317$ were isolated from $P$. paneum (sediment, S. China Sea) together with a known analogue, 2-[(1-methyl-2oxopropylidene)aminobenzoic acid, ${ }^{281}$ previously synthesised but now isolated as an NP. Penipacids A 313 and E 316 inhibited human colon cancer RKO cells and 2-[(1-methyl-2-oxopropylidene)aminobenzoic acid was cytotoxic to HeLa cells. ${ }^{282}$<smiles>[R]OC(=O)N=C(C)Nc1cc(S([R])(C)[R1]([R])([H])C)ccc1C(=O)O</smiles>

P. pinophilum (sediment, Pearl River Estuary, S. China Sea) yielded pinodiketopiperazine A 318 and 6,7-dihydroxy-3methoxy-3-methylphthalide $\mathbf{3 1 9}$ and the known synthetic 
compounds, alternariol 2,4-dimethyl ether ${ }^{283,284}$ and L-5-oxoproline methyl ester ${ }^{285}$ as first time NPs. The phthalide 319 displayed potent cytotoxicity to brine shrimp and pinodiketopiperazine A 318, alternariol 2,4-dimethyl ether ${ }^{283,284}$ and the coisolated known metabolites $N$-methylphenyldehydroalanyl-Lproline-anhydride ${ }^{286}$ and rubralide $\mathrm{C}^{287}$ all exhibited moderate inhibition of E. coli growth. ${ }^{288}$<smiles>CO[C@]1(C)OC(=O)c2c1ccc(O)c2O</smiles>

The chlorinated sesquiterpenoid ligerin $\mathbf{3 2 0}$ came from a Penicillium strain (seawater, La Prée, Loire Atlantique, France) and strongly inhibited the osteosarcoma cell line POS1, ${ }^{289}$ while another Penicillium sp. (sediment, Jiaozhou Bay, China) yielded prenpenicillide 321 and prenxanthone $322 .{ }^{290}$

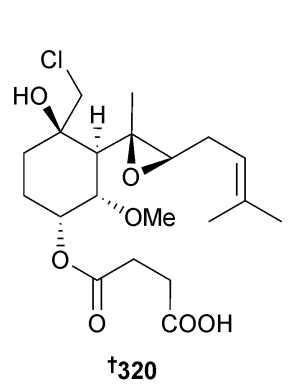<smiles>COc1c(CC=C(C)C)ccc2c1C(=O)OCc1cc(C)cc(O)c1Oc1ccc(CC=C(C)CO)c(O)c1C2=O</smiles>

The polyaromatic metabolites herqueiazole 323 , herqueioxazole 324 and herqueidiketal 325 were obtained from Penicillium sp. (sediment, Gagu-do, S. Korea). Herqueidiketal 325 was moderately cytotoxic to A549 cells and significantly inhibitory against sortase A. ${ }^{291}$ Penicillium sp. (gorgonian Dichotella gemmacea, Sanya, Hainan Province, China) produced the indolyl diketopiperazine penilloid A $\mathbf{3 2 6}$ in addition to a number of known indole alkaloids.

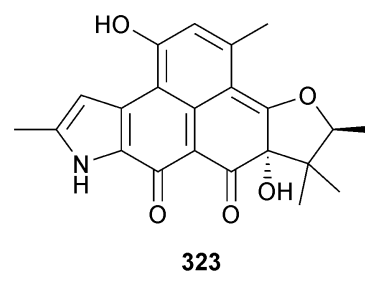<smiles></smiles><smiles>COc1c(O)c2c(c3c1O[C@]1(O)C(C)(C)[C@@H](C)O[C@]1(O)[C@H]3O)C(=O)C(C)=CC2=O</smiles>
325
Aspergillus sydowii (gorgonian Verrucella umbraculum, Sanya, Hainan Province, China) also yielded additional known indole alkaloids including fumiquinazoline $\mathrm{D},{ }^{292}$ cyclotryprostatin $\mathrm{B}^{293}$ and fumiquinazoline $\mathrm{G},{ }^{294}$ which in addition to $(E)-3-(1 H$-imidazol-4-ylmethylene)-6-(1H-indol-3ylmethyl)-2,5-piperazinedione, ${ }^{295}$ meleagrin, ${ }^{296}$ roquefortine $\mathrm{C}^{297}$ and $11 \alpha$-methoxy roquefortine $\mathrm{C}^{298}$ from the Penicillium sp. exhibited significant antifouling activity towards B. amphitrite and/or B. neritina larvae. Meleagrin also exhibited moderate activity against the larvae settlement-inducing bacterium Micrococcus luteus. ${ }^{299}$ Penstyrylpyrone 327 and the known terrestrial fungal metabolite anhydrofulvic acid (first time MNP) ${ }^{\mathbf{3 0 0}}$ were obtained from Penicillium sp. (unidentified sponge. Jeju Is., S. Korea) as inhibitors of protein tyrosine phosphatase 1B (PTP1B) activity. Furthermore, penstyrylpyrone 327 suppressed production of pro-inflammatory mediators via the NF- $\mathrm{B}$ pathway through expression of the antiinflammatory enzyme, heme oxygenase. ${ }^{301}$<smiles>COc1cc(/C=C/c2ccccc2)oc(=O)c1C</smiles>

Penicillium sp. (gorgonian coral Dichotella gemmacea, Sanya, Hainan, China) was the source of the polyketides 328 and paecilin $\mathrm{C}$ 329, and some known analogues. 6,8,5', $6^{\prime}$-Tetrahydroxy-3'-methylflavone 328 , emodin, ${ }^{302}$ citreorosein ${ }^{302}$ and isorhodoptilometrin ${ }^{303}$ exhibited significant antifouling activity against $B$. amphitrite larvae settlement while penicillixanthone $\mathrm{A}^{304}$ was moderately antibacterial..$^{305}$<smiles>Cc1cc(O)c(O)c(-c2cc(=O)c3cc(O)cc(O)c3o2)c1</smiles><smiles>CC(=O)C1Oc2c(-c3ccc(O)c4c3OC(C(C)=O)([C@H]3OC(=O)C[C@H]3C)CC4=O)ccc(O)c2C(=O)C1[C@H]1OC(=O)C[C@H]1C</smiles>

Endophytic Penicillium sp. (unidentified sponge, Weizhou, S. China Sea) was the source of the hydroisocoumarins penicimarin A-C 330-332, the isocoumarins penicimarin D-F 333335 and the benzofurans penicifuran A-D 336-339, out of which only penicifuran A 336 was cytotoxic to Staphylococcus albus (moderate)..$^{306}$ 


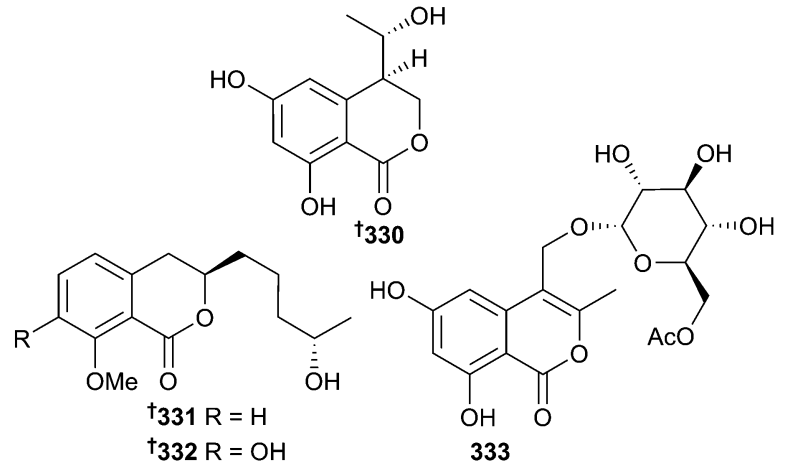<smiles>[R20]Cc1c([R2])oc(=O)c2c(O)cc(O)cc12</smiles>

Co-cultivation of Penicillium sp. (sponge Mycale angulosa, Toque-Toque Is., Brazil) ${ }^{307}$ and Trichoderma sp. (sponge Geodia corticostylifera, same location) ${ }^{307}$ led to the unusual polyketides, (Z)-2-ethylhex-2-enedioic acid 340 and (E)-4-oxo-2-propylideneoct7-enoic acid 341. ${ }^{308} \mathrm{~A}$ chloro-trinoreremophilane sesquiterpene 342 and three chlorinated eremophilane sesquiterpenes 343345 were isolated from Penicillium sp. (deep-sea sediment, Prydz Bay, Antarctica). Just $\mathbf{3 4 2}$ was cytotoxic to HTCLs (moderate). ${ }^{309}$<smiles>C=CCC(CC(=O)O)CC(=O)CCCC(=O)O[18O]</smiles><smiles>CC1C=C(Cl)C2=CC(=O)C(O)=CC2(C)C1C</smiles><smiles>CC1C(O)C=C(Cl)C2=CC(=O)C3(CC21)CC1(CO)OC13C</smiles><smiles>CC(C)=C1C[C@]2(C)C(=CC1=O)C(Cl)[C@H](O)CC2C</smiles>

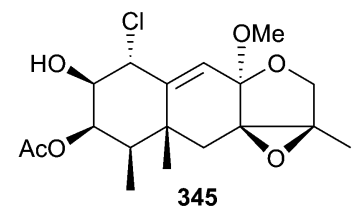

The isoaustamide alkaloid $\mathbf{3 4 6}$ was obtained from Penicillium sp. (unidentified sponge, Jeju Is., S. Korea). Also isolated for the first time as an NP was deoxydihydroisoaustamide, previously reported as an intermediate in the total synthesis of (+)-deoxyisoaustamide. ${ }^{310,311}$ Pestalotiopsis sp. (soft coral Sarcophyton sp., Yongxing Is., S. China Sea) was the source of the chlorinated benzophenone derivative $( \pm)$-pestalachloride D 347 (moderate antibacterial activity against several Gram-positive strains). Co-isolated was $( \pm)$-pestalachloride $\mathrm{C}$, known as a metabolite of terrestrial endophytic Pestalotiopsis adusta ${ }^{312}$ but now a first time MNP. ${ }^{313}$

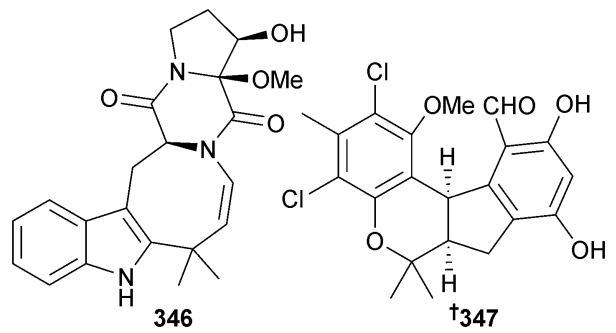

The eudesmane sesquiterpenes $\mathbf{3 4 8}$ and $\mathbf{3 4 9}$ were produced by Pestalotiopsis sp. (brown alga Sargassum horneri, Wenzhou, China) in response to abiotic stress elicitation by addition of $\mathrm{CuCl}_{2}$ to the growth media and both were both potent inhibitors of tyrosinase. ${ }^{314}$ Endophytic Phaeosphaeria spartinae (red alga Ceramium sp., North Sea, Büsum, Germany) was the source of spartopregnenolone 350. ${ }^{315}$

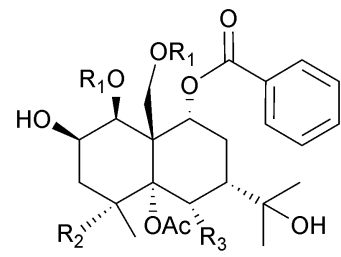

$348 \mathrm{R}_{1}=A c, \mathrm{R}_{2}=\mathrm{H}, \mathrm{R}_{3}=\mathrm{OAC}$ $349 R_{1}=R_{3}=H, R_{2}=O A C$<smiles>CC(=O)[C@H]1CC[C@H]2C3=C(CC[C@H]12)[C@@]1(C)CC[C@H](O)[C@H](O)[C@H]1CC3</smiles>

Polyporapyranones A-H 351-358 were isolated from two Polyporales species (seagrass Thalassia hemprichii, location unspecified, presumably Thailand). Polyporapyranones A 351 and D 354 exhibited moderate and weak inhibition of the Vero cell line respectively. ${ }^{316}$ Scopulariopsis sp. (gorgonian Carijoa sp., Weizhou, S. China Sea) was the source of fumiquinazoline L 359, an alkaloid with a heptacyclic<smiles>[R]c1cc(OC)c(-c2cc(=O)cco2)cc1[R]</smiles>

$351 \mathrm{R}_{1}=\mathrm{OMe}, \mathrm{R}_{2}=\mathrm{H}$ $352 \mathrm{R}_{1}=\mathrm{H}, \mathrm{R}_{2}=\mathrm{OMe}$ $353 \mathrm{R}_{1}=\mathrm{R}_{2}=\mathrm{OMe}$<smiles>CC(C)(C)c1cc(O)cc(-c2cc(=O)cco2)c1</smiles><smiles></smiles><smiles>O=c1ccoc(C2=C[C@H](O)[C@@H](O)[C@H](O)[C@H]2O)c1</smiles><smiles>O=c1ccoc(C2=C[C@H](O)[C@@H](O)[C@H](O)[C@H]2O)c1</smiles><smiles>O=c1ccoc(C2=C[C@H](O)[C@@H]3O[C@H]3[C@H]2O)c1</smiles>
skeleton. ${ }^{317}$ 


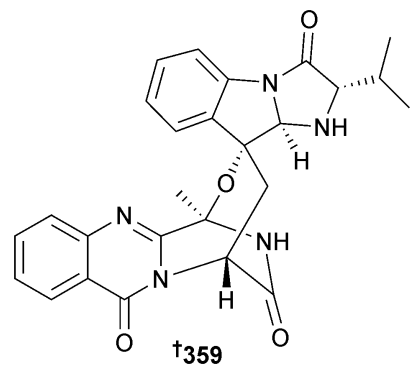

Stachybotrys chartarum (sponge Xestospongia testudinaris, Xisha Is., China) yielded new phenylspirodrimanes stachybotrin D-F 360-362, stachybocin E 363 and F 364 and stachyboside A 365 and B 366, of which stachybotrin D 360 inhibited replication of HIV-1 by targeting reverse transcriptase and blocked non-nucleoside reverse transcriptase inhibitors-resistant strains as well. The absolute configuration of a co-isolated known terrestrial sesquiterpenoid 367 (S. chortarum $^{318}$ ) was determined. ${ }^{319}$

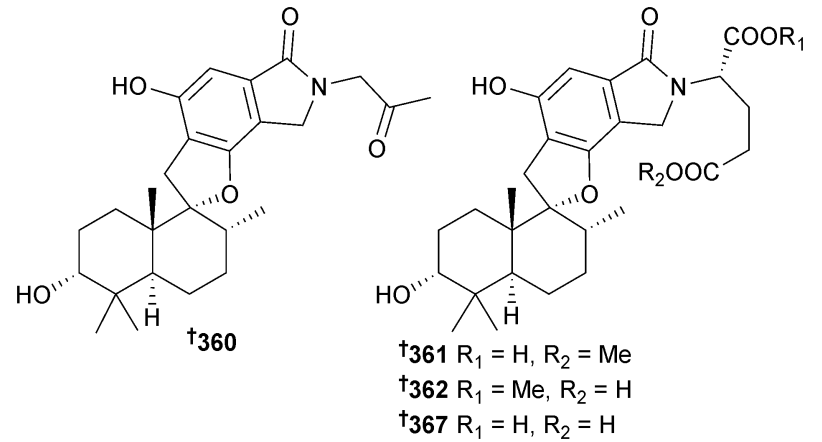<smiles>C[C@H]1CC[C@H]2C(C)(C)[C@@H](O)CC[C@@]2(C)[C@@]12Cc1c(O)cc3c(c1O2)CN(C)C3=O</smiles>

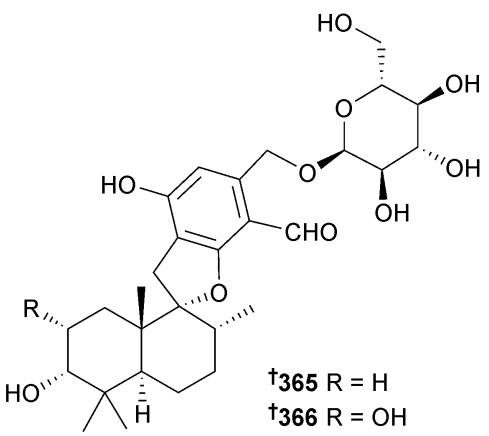

Several polyketides were obtained from Stachylidium sp. (sponge, Callyspongia sp. cf. C. flammea, Bear Is., Sydney, Australia) including cyclomarinone 368, maristachone A-E 369-373 and marilactone. ${ }^{320}$ Due to rotation values being close to zero, racemic mixtures were assumed for cyclomarinone 368, maristachone A 369 and the epimers 372 and 373. Marilactone ${ }^{320}$ is a known synthetic compound but now a first time NP. From a biosynthetic perspective, all of the isolated compounds are unusual due to the presence of an additional carbon atom over the basic polyketide skeleton. ${ }^{321}$

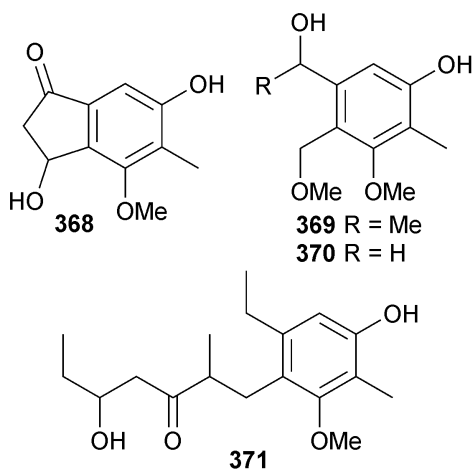<smiles>[R]C1(C)O[C@H](OC)c2c(C)c(OCC=C(C)CCC=C(C)C)c(OC)c(OC)c21</smiles>

Stagonosporopsis cucurbitacearum (unidentified sponge, Atami-shi, Shizuoka Prefecture, Japan) yielded the alkaloids didymellamides A-D 374-377. Didymellamide A 374 inhibited growth of several pathogenic fungi including azole-resistant $C$. albicans. ${ }^{322}$

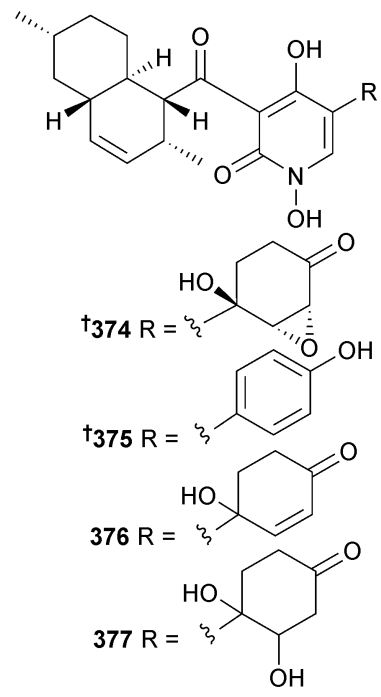

The peptaibols aspereline G 378 and H 379 were obtained from Trichoderma asperellum (sediment, Langqi Is., Fujian, China), ${ }^{323}$ while asperelines $\mathrm{G}^{-\mathrm{Z}_{13}}$ are thirty-two new short peptaibols detected from $T$. asperellum (sediment, Penguin Is., Antarctica) by ultrahigh pressure liquid chromatography in combination with electrospray-ionisation tandem mass 
<smiles>[R]C[C@H](NC(=O)C(C)(C)NC(=O)C(C)(C)NC(=O)[C@H](NC(=O)C(C)(C)NC(=O)[C@H](NC(=O)C(C)(C)NC(=O)C(C)(C)N=[Co])C(C)C)C(C)CC)C(=O)NC(C)(C)C(=O)N1CCC[C@H]1COC(C)=O</smiles>

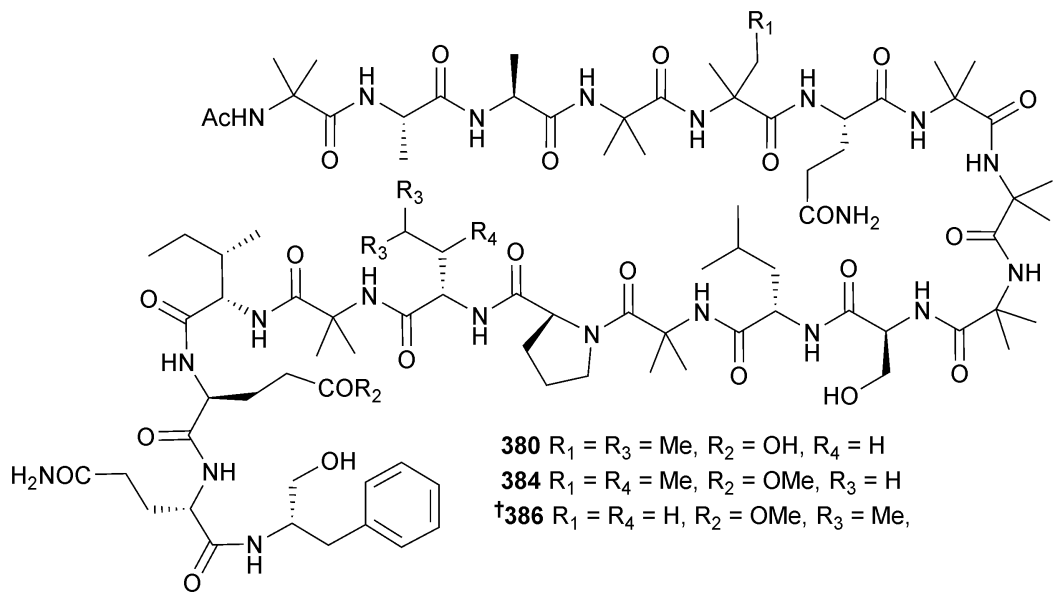

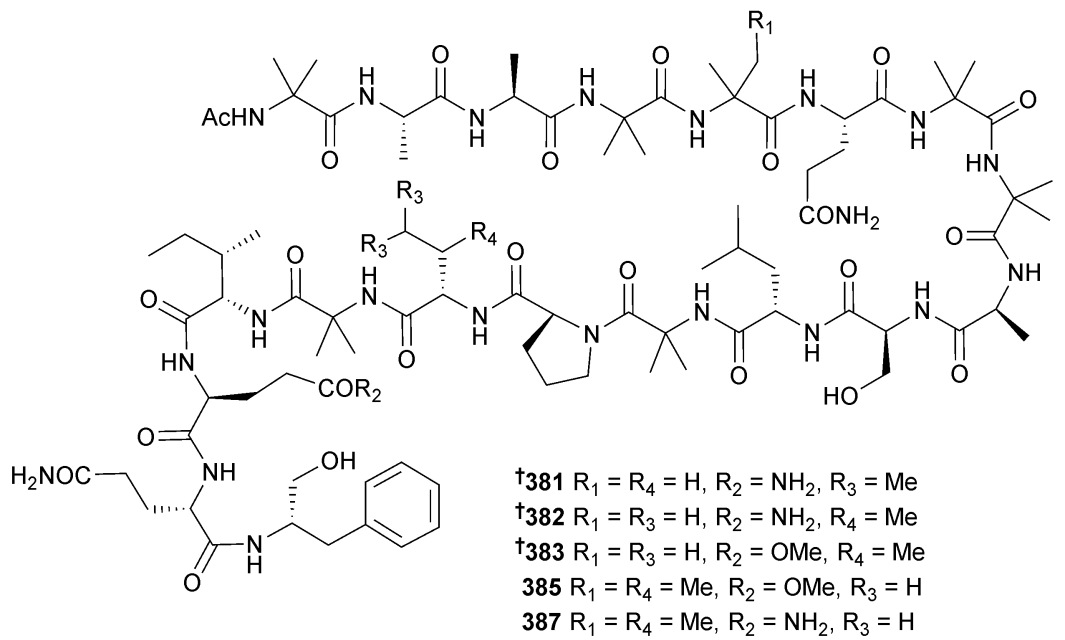

spectrometry (UHPLC-ESIMS/MS). ${ }^{324}$ Several strains of marinederived T. atroviride (University of Nantes culture collection) produced two series of 17-residue peptaibiotics with a common C-terminus ${ }^{325}$ and eight new peptaibols 380-387, trichorzianine 1938, 1909, 1895, 1896, 1924, 1910, 1924A and 1909A, linear 19residue hydrophobic peptides were obtained from $T$. atroviride (Axinellid sponge, Akhziv, Mediterranean coast, Israel). ${ }^{326}$

The diterpenoid lactone trichodermaerin $\mathbf{3 8 8}$ was isolated from endophytic $T$. erinaceum (sea star Acanthaster planci, Hainan Sanya National Coral Reef Reserve, China). ${ }^{327}$ A Xylariaceae sp. (gorgonian coral Melitodes squamata, S. China Sea) produced a number of polyketides including penicitrinol F 389, 7-carboxypenicitrinol C 390 and 391-393. Several known polyketides were also isolated and of these, dihydrocitrinin ${ }^{328}$ and phenol acid $\mathrm{A}^{328}$ strongly inhibited settlement of $B$. neritina larvae with dihydrocitrinin ${ }^{328}$ also an inhibitor of the enzymes SHP2 and IMPDH. Phenol acid $\mathrm{A}^{328}$ and dihydrocitrinone ${ }^{329}$ inhibited cathepsin $\mathrm{B}$ and $(3 R, 4 S)-(+)-4$-hydroxy-6-deoxyscytalone $^{330}$ inhibited the enzymes SHP2, PTP1B and IMPDH and is a first time MNP. ${ }^{331}$ There is considerable confusion surrounding this report: the name penicitrinol $\mathrm{F}$ has been given previously to a citrinin derivative obtained from a Penicllium sp. ${ }^{332}$ so 389 should be renamed. Also, for 7-carboxypenicitrinol C 390 there is a discrepancy between the configuration in the diagram and in the text. The text gives $(1 R)$ but the diagram gives $(1 S)$. If the diagram is correct, this is a known compound from both terrestrial ${ }^{333}$ and marine ${ }^{334,335}$ fungi. The configuration of cochliomycin $\mathrm{C}$, a resorcylic acid lactone obtained from 
the gorgonian-derived fungus Cochliobolus lunatus ${ }^{336}$ has been corrected to $394 .{ }^{337}$
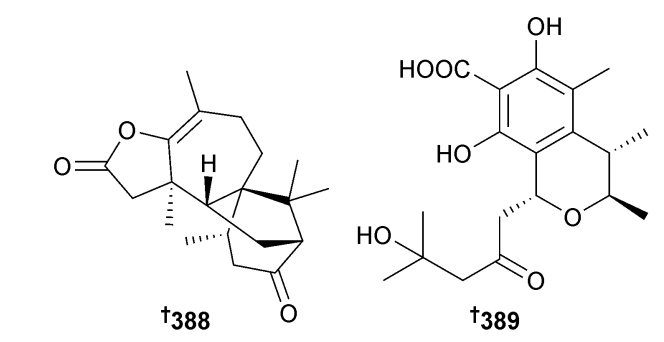<smiles>COC1=CC(=O)[C@H](C)[C@@H]1CO</smiles>

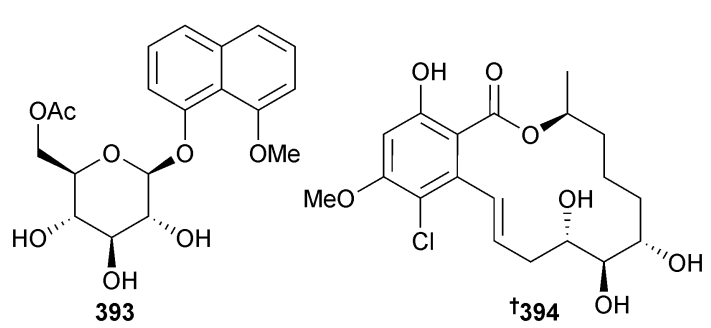

Addition of sodium bromide to a culture of Aspergillus ochraceus (red alga Chondria crassicualis, Yokji Is., Kyeongnam Province, S. Korea) resulted in medium-induced production of $(R)-(-)-5$-bromomellein as a modest radical scavenger (against 1,1-diphenyl-2-picrylhydrazyl (DPPH)). Both the racemate ${ }^{338}$ and antipode $^{339}$ have been previously synthesised but this is the first report of their isolation as NPs. ${ }^{340}$ The sesquiterpene helminthosporic acid has been reported previously as a semi-synthetic derivative of the fungal metabolite helminthosporol aldehyde ${ }^{341}$ but has been isolated for the first time as an NP from Drechslera sp. (green alga Ulva sp., Tönning, North Sea). ${ }^{342}$ Also as a first time MNP was the terrestrial fungal metabolite epiepoformin ${ }^{343}$ isolated from an endophytic Penicillium sp. (brown alga Fucus spiralis, Bridge End, Shetland Is., U.K.). ${ }^{344}$

\subsection{Fungi from mangroves}

Aspergillus effuses (rhizosphere soil, unidentified mangrove, Fujian Province, China) produced the prenylated indole diketopiperazine alkaloid dihydroneochinulin B 395 and the enantiomeric spiro-polyketide-diketopiperazine hybrids cryptoechinuline D 396 and 397. The latter compound has been isolated previously from terrestrial ${ }^{345}$ and marine ${ }^{346}$ fungi but in this study was resolved into enantiomers and absolute configurations assigned. ${ }^{347}$ The benzyl derivatives aspergentisyl A 398 and aspergentisyl B 399 and a naphthoquinone derivative aspergiodiquinone $\mathbf{4 0 0}$ were isolated from A. glaucus (mangrove sediment, unspecified species, Fujian Province, China). Aspergentisyls A 398 and B 399 were strong radical-scavengers (DPPH). ${ }^{348}$
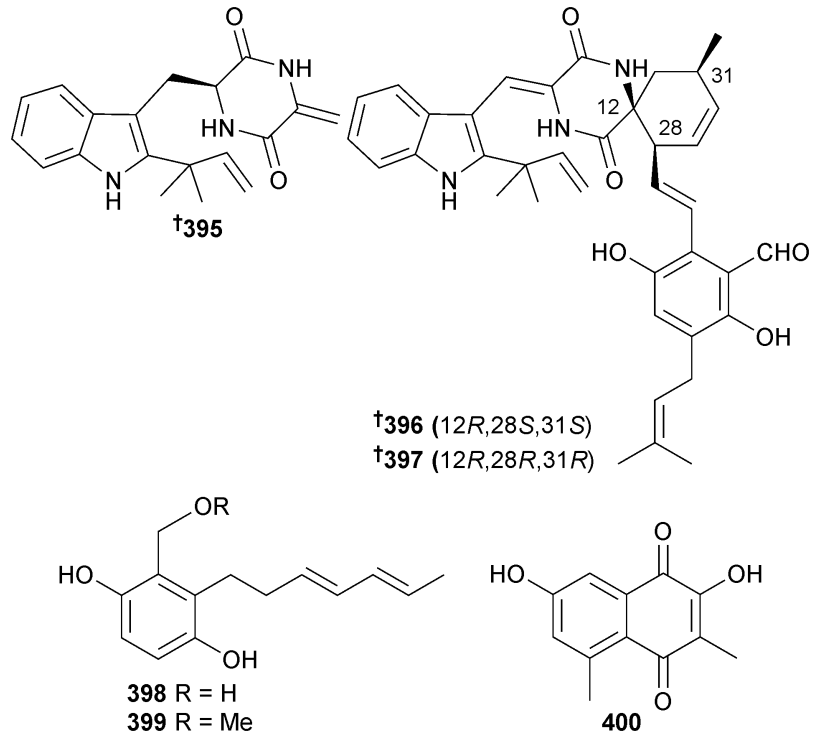<smiles>CC1=C(O)C(=O)c2cc(O)cc(C)c2C1=O</smiles>

Some 4-phenyl-3,4-dihydroquinolone derivatives were obtained from A. nidulans (mangrove leaves Rhizophora stylosa, source not given, presumably China), namely aniduquinolone A-C 401-403, 6-deoxyaflaquinolone E 404, isoaflaquinolone $\mathrm{E}$ 405 and 14-hydroxyaflaquinolone $\mathrm{F}$ 406. Of these, aniduquinolones B 402 and C 403 and the co-isolated aflaquinolone $\mathrm{A}^{349}$ were moderately toxic to brine shrimp. Aflaquinolone A, previously obtained from a terrestrial Aspergillus sp., was obtained for the first time as an MNP. ${ }^{350}$<smiles>C=C(C)C1CC[C@@](C)(/C=C/c2ccc3c(c2O)[C@@](O)(c2ccccc2)[C@@H](OC)C(=O)N3)O1</smiles><smiles>CO[C@H]1C(=O)Nc2ccc(/C=C/[C@@]3(C)CC[C@@H](C(C)(C)O)O3)c(O)c2[C@]1(O)c1ccccc1</smiles><smiles>CO[C@H]1C(=O)Nc2ccc(CC=C(C)C)c(O)c2[C@]1(O)c1ccccc1</smiles>

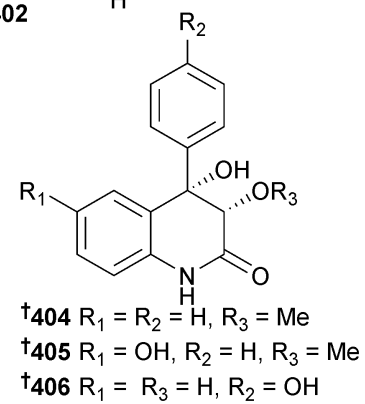

Aniquinazolines A-D 407-410 are quinazolinone alkaloids from the endophytic $A$. nidulans (mangrove leaves Rhizophora stylosa, unspecified location, presumably China) and were all strongly cytotoxic to brine shrimp. ${ }^{351}$ The nigerasterols A 411 and B 412 were obtained from endophytic $A$. niger (mangrove 

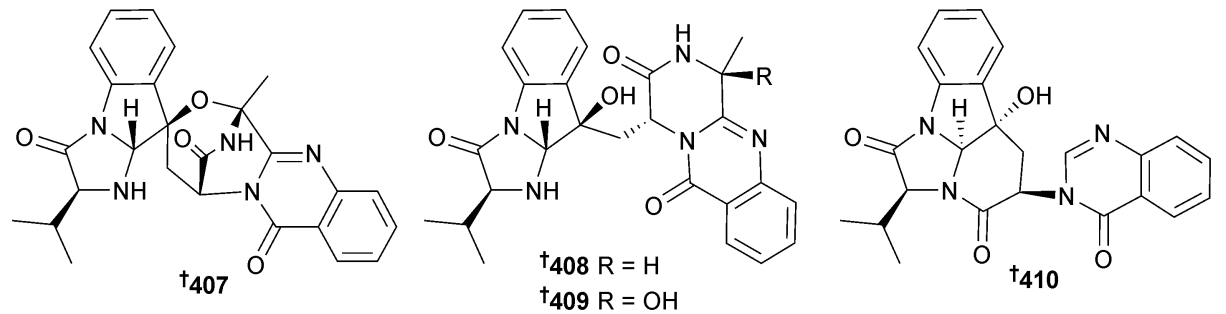

Avicennia marina, Hainan, China) as relatively potent inhibitors of the HTCLS HL60 and A549. ${ }^{352}$ The butenolide isoaspulvinone E $\mathbf{4 1 3}$ came from A. terreus (mangrove rhizospehere soil, Fujian Province, China) along with the known butenolides aspulvinone $\mathrm{E}^{353}$ and pulvic acid. ${ }^{354}$ All exhibited significant H1N1 virus inhibition but only isoaspulvinone E inhibited H1N1 viral neuraminidase. Pulvic acid was a first time MNP. ${ }^{355}$

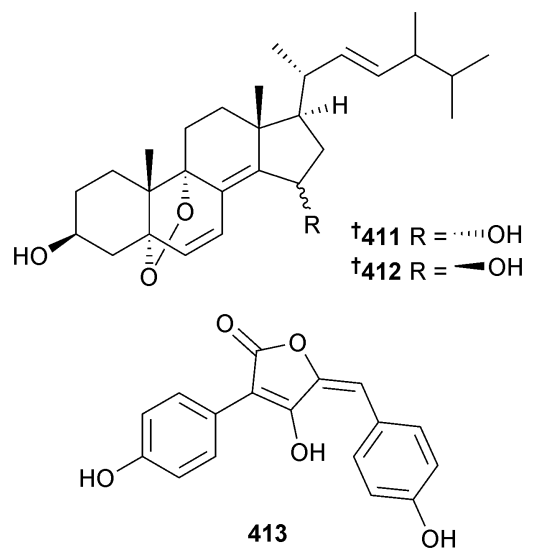

A. taichungensis (mangrove root soil Acrostichum aureum, no location given $)^{356}$ was the source of the prenylated indole alkaloids 6-epi-stephacidin A 414, $N$-hydroxy-6-epi-stephacidin A 415 and 6-epi-avrainillanide 416, and of these 415 and $\mathbf{4 1 6}$ were cytotoxic to two HTCLs. On exposure to light and air 415 converted to a complex mixture of analogues, including (+)-versicolamide $\mathrm{B}^{357}$ a mixture of two compounds (here named versicolamide C) and 416, which suggested that $\mathbf{4 1 6}$ may be an artefact. 6-Epi-stephacidin A $\mathbf{4 1 4}$ was stable under the same conditions. ${ }^{358}$

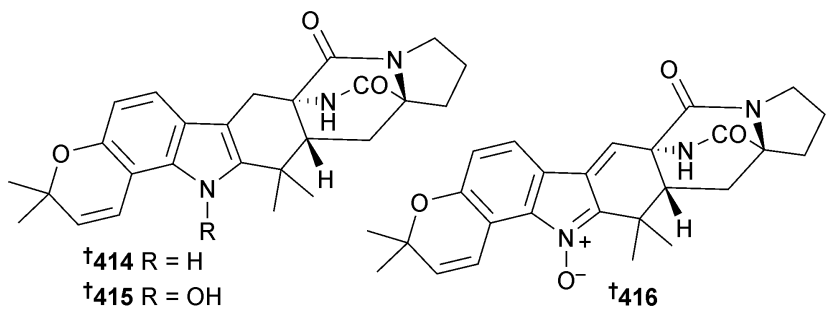

Botryosphaerin F $\mathbf{4 1 7}$ was obtained from endophytic $A$. terreus (mangrove branch Bruguiera gymnorhiza, Guangxi, China) and inhibited growth of HTCLs. ${ }^{359}$ Several known compounds were also isolated including LL-Z1271 $\beta,{ }^{360}$ which although reported as active against the HL60 cell line used here, had previously been reported as being inactive against a number of other HTCLs. ${ }^{361,362}$ Endophytic A. terreus (mangrove branch Bruguiera gymnorhiza, Guangxi province, China) was the source of a thiophene compound 418. The coisolated 6-ethyl-5-hydroxy-3,7-dimethoxynaphthoquinone, ${ }^{363}$ a known synthetic compound, was a first time NP. ${ }^{364}$ Asperterpenoid A 419, a sesterterpenoid with a new carbon skeleton, was isolated from endophytic Aspergillus sp. (mangrove species not specified, no location given) and displayed inhibitory activity against $M$. tuberculosis protein tyrosine phosphatase B (mPTPB). ${ }^{365}$ Asperterpenols A 420 and B 421 are sesterterpenoids with an unusual 5/8/6/6 tetracyclic ring skeleton. Both were acetylcholinesterase inhibitors and were obtained from endophytic Aspergillus sp. (mangrove, S. China Sea). ${ }^{366}$
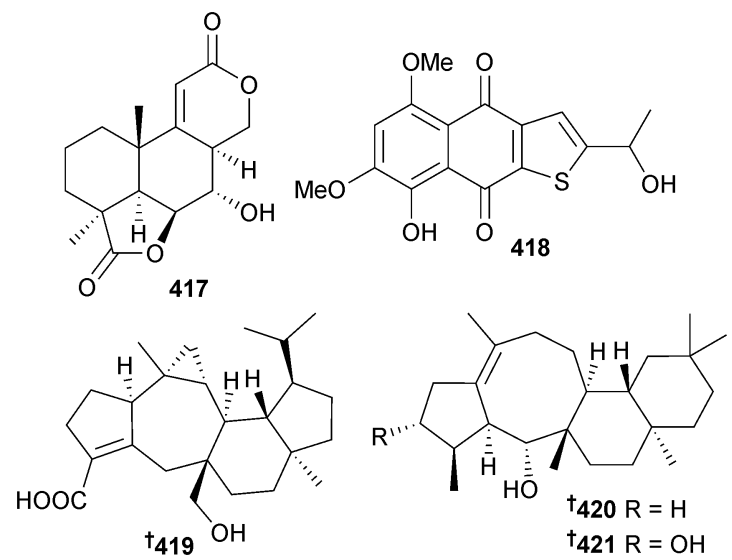

Cladosporium sp. (mangrove soil, Guangzhou, China) was the source of a number of indole alkaloids including five glyantrypine derivatives; 3-hydroxyglyantrypine 422, oxoglyantrypine 423, 424, cladoquinazoline 425 and epi-cladoquinazoline 426 and a pyrazinoquinazoline derivative norquinadoline A 427. Of these alkaloids, oxoglyantrypine 424 and norquinadoline A 427, together with the co-isolated known terrestrial Aspergillus alkaloid metabolites, deoxynortryptoquivaline,$^{367}$ deoxytryptoquivaline ${ }^{367}$ tryptoquivaline ${ }^{368}$ and quinadoline $\mathrm{B}^{369}$ had significant activities against H1N1. The latter four were also obtained for the first time as MNPs. Over time, a solution of oxoglyantrypine $\mathbf{4 2 3}$ partially converted into $\mathbf{4 2 4}$, leading to the proposal that $\mathbf{4 2 4}$ was an artefact. $^{370}$ 
<smiles>CC(C)(C)[R16]#N</smiles><smiles>CC(C)(C)[C@@H]1NC(=O)[C@@H](C[C@]2(O)C(=O)Nc3ccccc32)n2c1nc1ccccc1c2=O</smiles><smiles>CC(C)=C1NC(=O)[C@@H](C[C@]2(O)c3ccccc3N3C(=O)[C@H](C)N[C@H]32)n2c1nc1ccccc1c2=O</smiles><smiles>[R]c1c(O)cc2c(c1O)C(=O)C[C@@H](C[C@H](C)O)OC(=O)C[C@@H](C[13C@@H](C)[R]([R])([H])C)O2</smiles><smiles>C[C@H](O)C/C=C/C1=CC(=O)c2c(O)cc(O)cc2CC(=O)O1</smiles>

Further investigation of endophytic Corynespora cassiicola (mangrove leaf Laguncularia racemosa, Hainan Is., China), which originally yielded some decalactone derivatives, ${ }^{371}$ yielded some minor metabolites coryoctalactone A-E 428-432, of which coryoctalactones A 428 and B 429 were assumed to be C-9 epimers. $^{372}$

As part of a screening programme for new antimalarial compounds, four metabolites were obtained from several species of Chinese mangrove endophytic fungi from either Mai Po Nature Reserve, Hong Kong or Hainan Is., Taiwan. Despite lack of a tight correlation between location and source microorganism, this study described the isolation of a dimeric<smiles></smiles><smiles>CCC(C)CC(C)/C=C/C=C/C(=O)O</smiles>

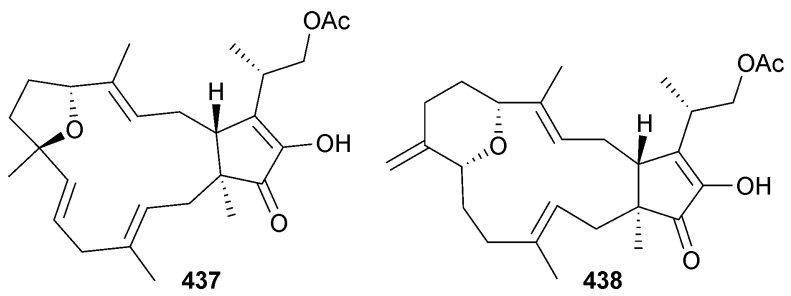<smiles>CCCCC(C)c1cc(O)c(C)c(=O)o1</smiles><smiles>CC(=CC(=O)O)c1ccc(CO)c(=O)o1</smiles><smiles>CC(=CC(=O)NCC(=O)O)c1ccc(C)c(=O)o1</smiles>

tetrahydroxanthone dicerandrol D 433 from a Diaporthe sp., diaporthochromes A 434 and B 435 from another Diaporthe sp. and the lipid $\mathbf{4 3 6}$ was obtained from Xylaria sp. Dicerandrol D 433 exhibited potent activity against $P$. falciparum with relatively low toxicity to A549 cells. ${ }^{373}$

Endophytic Fusarium proliferatum (mangrove Bruguiera sexangula, Hainan Is., China) produced the tricyclic 
sesterterpenes fusaprolifin A 437 and B 438 and the 2H-pyran-2-one derivatives prolipyrone A-C 439-441. Fusaprolifins $\mathrm{A}$ and $\mathrm{B}$ had modest activity against brine shrimp. ${ }^{374}$

Penicillium camemberti (mangrove soil Rhizophora apiculata, Wenchang, Hainan Province, China) produced the indole diterpenoids 442-447, as well as some known analogues. Of these, emindole $\mathrm{SB},{ }^{375}$ 21-isopentenylpaxilline, ${ }^{376}$ paspaline,$^{377,378}$ and paxilline ${ }^{379}$ displayed significant activity against H1N1 as did indole diterpenoids 442-444, 446 and 447. 21Isopentenylpaxilline $\mathrm{e}^{376}$ and dehydroxypaxilline ${ }^{380}$ were obtained for the first time as MNPs. ${ }^{381}$
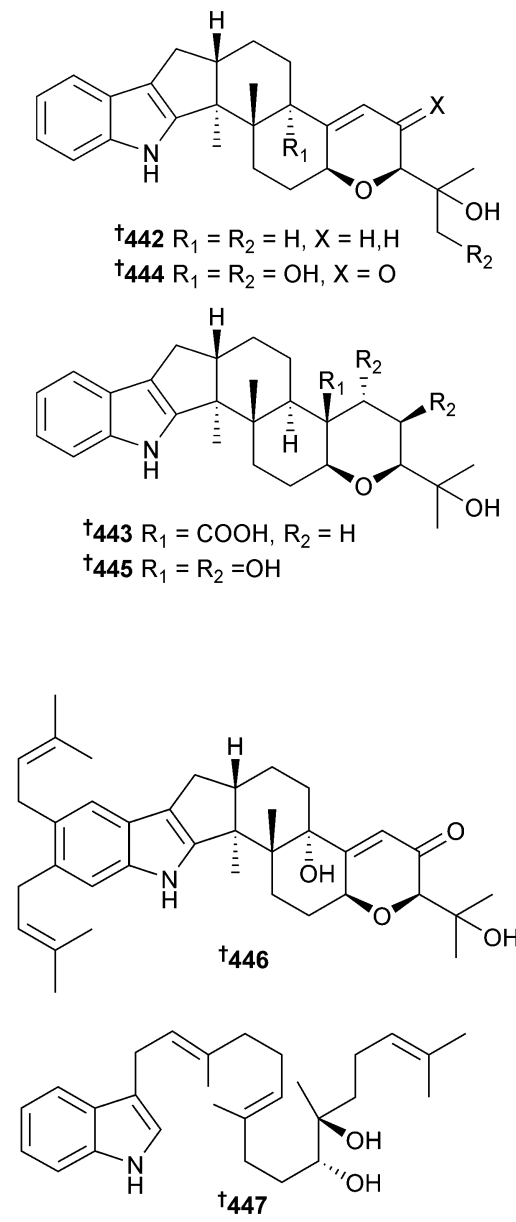

Penicillium sumatrense (mangrove rhizosphere Lumnitzera racemosa, WenChang, Hainan Is., China) yielded sumalarins A-C 448-450, sulfur-containing curvularin derivatives which were cytotoxic to several HTCLs. ${ }^{382}$ The planar structure of sumalarin C $\mathbf{4 5 0}$ had previously been reported as part of several compound libraries. ${ }^{383-385}$ The citrinin dimers penicitrinone E 451 and penicitrinol J 452 and the citrinin monomers penicitrinol $K \mathbf{4 5 3}$ and citrinolactone D $\mathbf{4 5 4}$ were isolated from Penicillium sp. (mangrove sediment, Fu Gong, Long Hai, Taiwan Strait, China). ${ }^{386}$
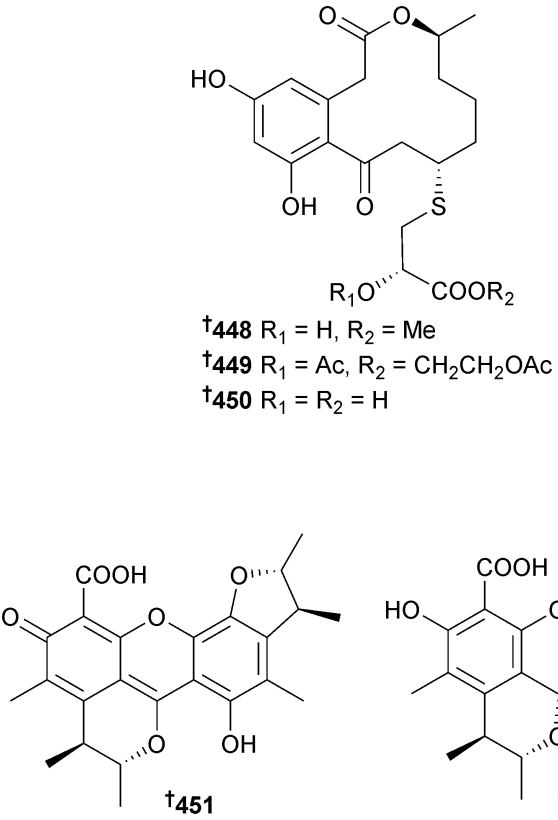<smiles>Cc1c(O)c(C(=O)O)c2c3c1[C@H](C)[C@H](C)O[C@H]3c1c(O)c(C)c3c(c1O2)O[C@H](C)[C@@H]3C</smiles><smiles></smiles>

Arisugacin I 455, an $\alpha$-pyrone meroterpene, was obtained from endophytic Penicillium sp. (mangrove leaves Kandelia candel, Shankou, Guangxi Province, China) as an inhibitor of acetylcholinesterase. ${ }^{387}$ The known fungal metabolite arisugacin $\mathrm{F}^{388}$ was also obtained for the first time from the marine environment. ${ }^{387}$ Endophytic Penicillium sp. (mangrove leaves Avicennia sp., Dong Sai, Hainan, China) yielded the isobenzofuranone $\mathbf{4 5 6}$ which was moderately cytotoxic to $\mathrm{KB}$ and $\mathrm{KB}_{\mathrm{V} 200}$ cells. ${ }^{389}$

Pestaliopens A 457 and B 458, hybrid sesquiterpene-cyclopaldic acid metabolites with an unusual carbon skeleton, were isolated from endophytic Pestalotiopsis sp. (mangrove leaves Rhizophora mucronata, Hainan Is. China). Pestaliopen A 457 exhibited modest inhibition of E. faecalis. ${ }^{390}$

$P$. virgatula (mangrove leaf Sonneratia caseolaris, Dong Zhai Gang mangrove garden, Hainan Is., China) yielded the $\alpha$-pyrone derivatives pestalotiopyrone I-L 459-462 as well as $\left(6 S, 1^{\prime} S, 2^{\prime} S\right)$ -

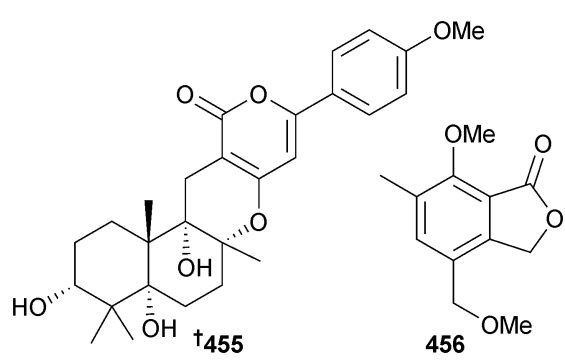


<smiles>COc1c(CO[C@]2(C)C[C@@H]3O[C@]4([C@@H]2C(=O)O)C(C)(C)[C@@H](Cl)CC[C@]34O)c(O)c(C=O)c2c1C(=O)O[C@H]2OC</smiles>

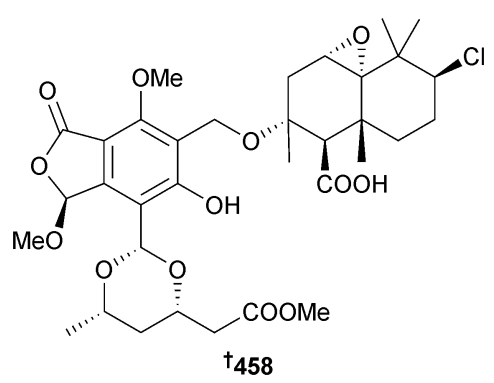<smiles>[R6]C[C@@H](O)[C@@H](O)COC(=O)/C=C(\C)c1cc(OC)cc(=O)o1</smiles><smiles>CCCC[C@](O)(CC(O)C(C)=O)c1cc(OC)cc(=O)o1</smiles>

hydroxypestalotin $463,{ }^{391}$ a diastereoisomer of a metabolite isolated from a plant associated Penicillium sp. ${ }^{392}$

The xanthones $O$-glycoside 464 isolated from endophytic Phomopsis sp. (mangrove stem Excoecaria agallocha, Dong Zai, Hainan, China) ${ }^{393}$ and 465 and 466 isolated from Phomopsis sp. (mangrove sediment, Shankou, Hainan, China) ${ }^{394,395}$ were moderate inhibitors of HEp-2 and HepG2 cells.<smiles>COc1c(O[C@@H]2O[C@H](CO[C@H]3OC[C@@H](O)[C@H](O)[C@H]3O)[C@@H](O)[C@H](O)[C@H]2O)cc(OC)c2c(=O)c3ccccc3oc12</smiles><smiles>COC(=O)c1cc(O)cc2oc3cc(C)c(O)cc3c(=O)c12</smiles>

Three new phomoxanthone compounds phomolactonexanthone A 467, B 468 and deacetyl-phomoxanthone C 469 were obtained from Phomopsis sp. (mangrove branch Acanthus ilicifolius, Hainan, S. China Sea) along with five phomoxanthones known as endophytic metabolites of terrestrial fungi, namely dicerandrol $\mathrm{A},{ }^{396}$ dicerandrol $\mathrm{B},{ }^{396}$ dicerandrol $\mathrm{C},{ }^{396}$ deacetylphomoxanthone $\mathrm{B}^{397}$ and penexanthone $\mathrm{A},{ }^{398}$ all isolated as first time MNPs. ${ }^{399}$<smiles>CC(=O)OC[C@]1([C@H]2OC(=O)C[C@@H]2C)CC(=O)c2c(O)ccc(-c3ccc4c(c3O)C(=O)C3=C(O)C[C@@H](C)[C@H](OC(C)=O)[C@@]3(CO)O4)c2O1</smiles><smiles>CC(=O)OC[C@]1([C@H]2OC(=O)C[C@@H]2C)CC(=O)c2c(ccc(-c3ccc4c(c3O)C(=O)C3=C(O)C[C@@H](C)[C@H](OC(C)=O)[C@@]3(CO)O4)c2O)O1</smiles><smiles>CC(=O)O[C@H]1[C@@H](C)CC(O)=C2C(=O)c3c(O)ccc(-c4ccc(O)c5c4O[C@]4(CO)OC(=O)C5=C(O)C[C@H](C)[C@@H]4O)c3O[C@]21C(C)=O</smiles>

469

Phomopsis sp. (mangrove plant Rhizhopora mucronata, Muara Angke, Jakarta, Indonesia) was the producer of the dimeric tetrahydroxanthone 12-O-deacetyl-phomoxanthone A 470 which exhibited moderate inhibition of several Gram-positive bacteria. ${ }^{400}$ A polysubstituted benzaldehyde derivative 471 was isolated from co-culture of two unidentified mangrove fungi (S. China Sea coast). ${ }^{401}$<smiles>CCOC(=O)c1cc(OCC)c(C)c(O)c1C=O</smiles>

Marinamide and the methyl ester, methyl-marinamide were originally isolated from a co-culture of two mangrove 
endophytic fungi from the S. China Sea Coast and assigned as pyrrolyl 1-isoquinolone alkaloids. ${ }^{402}$ Subsequently, the fungus Auxarthron reticulatum (sponge Ircinia variabilis) yielded the quinolinone methyl-penicinoline, shown to be identical to methyl-marinamide requiring structural revision. ${ }^{244}$ The revised structure of marinamide is identical to that of penicinoline, previously obtained from a mangrove endophytic fungus. ${ }^{403}$ This problem has already been addressed above in Section 3.3. Both marinamide/penicinoline ${ }^{403}$ and its methyl ester ${ }^{245}$ displayed potent cytotoxicity to several HTCLs.

\subsection{Cyanobacteria}

There has been a marked drop in the number of new metabolites reported from cyanobacteria, continuing the downward trend from 2012. The lipopeptide malyngamide 4472 was isolated from Moorea producens (Red Sea, Jeddah, Saudi Arabia) as a moderate inhibitor of several HTCLs. ${ }^{404}$

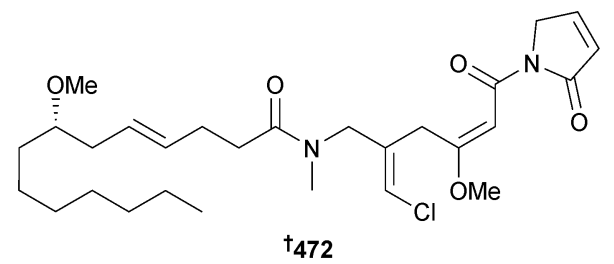

M. producens (La Parguera, Puerto Rico) was the source of the lipopeptides parguerene $\mathbf{4 7 3}$ and precarriebowmide $\mathbf{4 7 4}$. Studies of the stability of precarriebowmide 474 to atmospheric oxygen indicated that carriebowmide ${ }^{\mathbf{4 0 5}}$ and carriebowmide sulfone, ${ }^{406}$ previously isolated from Lyngbya polychroa and Lyngbya majuscula respectively, may in fact be isolation artefacts of precarriebowmide $\mathbf{4 7 4 . { } ^ { 4 0 7 }}$<smiles>CCC[C@H](NC(=O)[C@H](C)NC(=O)[C@H](CC(C)C)N(C)C(=O)[C@H](Cc1ccccc1)NC(=O)[C@H](CCS(C)(=O)=O)NC(=O)[C@H](Cc1ccccc1)N(C)C(=O)[C@@H](OC(=O)[C@H](C)C(C)C)C(C)C)C(=O)N[C@@H](C)CO</smiles>

Two new aprataoxin analogues, apratoxin H 475 and apratoxin A sulfoxide 476, were obtained from M. producens, (Nabq Mangroves, Gulf of Aqaba, Red Sea) and both exhibited cytotoxicity to NCI-H460 lung cancer cells, but apratoxin H 475 was much more potent than apratoxin A sulfoxide $476{ }^{408}$

M. bouillonii (New Britain, Papua New Guinea) was the source of bouillonamide 477 , a cyclic depsipeptide which contained two unique polyketide-derived moieties, a 2-methyl-6methylamino-hex-5-enoic acid residue and a unit of 3-methyl-5hydroxy-heptanoic acid. Bouillonamide $\mathbf{4 7 7}$ displayed moderate toxicity to neuron 2 a mouse neuroblastoma cells. ${ }^{409}$<smiles>CCC(C)[C@H](C(=O)N1CCCC[C@H]1C(=O)O[C@H](C[C@@H](C)CC(C)(F)F)C(C)(C)C)N(C)C(=O)[C@@H](C)N(C)C(=O)[C@H](Cc1ccc(OC)cc1)NC(=O)/C(C)=C/C1CSC([C@H](C)[C@@H](O)CC)=N1</smiles>

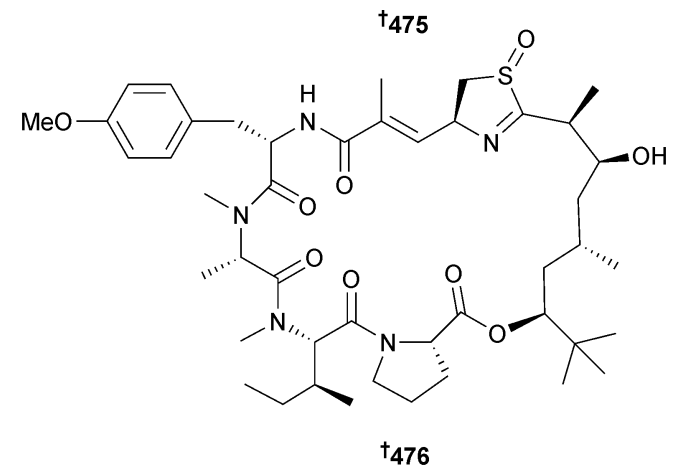<smiles>CCC(CC)CC(C)CC(=O)N(C)/C=C/CCC(C)C(=O)N[C@@H](C(=O)OC)C(=O)N(C)[C@@H](Cc1ccccc1)C(=O)N(C)[C@H](C(=O)N(C)[C@@H](Cc1ccccc1)C(C)C)C(C)O</smiles>

A cyanobacterium of similar morphology to Lyngbya sp. (Piti Bay, Guam) produced the lipids pitinoic acid A 478 and B 479. Pitinoic acid A 478 inhibited quorum sensing in Pseudomonas aeruginosa and pitinoic acid B 479 exhibited anti-inflammatory activity, inhibiting production of pro-inflammatory cytokine expression. Pitinoic acid B $\mathbf{4 7 9}$ has been synthesised. ${ }^{\mathbf{4 1 0}} \mathrm{A}$ species resembling the genus Symploca (Santa Cruz Is., Coiba National Park, Panama) yielded santacruzamate A 480, a potent and specific inhibitor of histone deacetylase 4 and cytotoxic to several HTCLs. Santacruzamate A 480 was synthesised from $\gamma$ aminobutyric acid. ${ }^{411}$<smiles>C=C(CCCCC)CCCCC(=O)O[C@H](C/C=C/Cl)C(=O)CCCC(=C)CCCCC</smiles>

\subsection{Dinoflagellates}

An Amphidinium sp. (sediment, Iriomote Is., Japan) was the producer of iriomoteolides-4a 481 and -5a 482, which displayed 
moderate cytotoxicity against human B lymphocyte DG-75 cells. $^{412}$<smiles>CC(C)=CC=CC(C)CC=CC(C)[C@H](CC=C[C@@H](O)[C@H](O)[C@H](O)C[C@@H](C)[C@H](O)C[C@@H](O)CCC(=O)O)OC(=O)CC(C)(C)C</smiles>

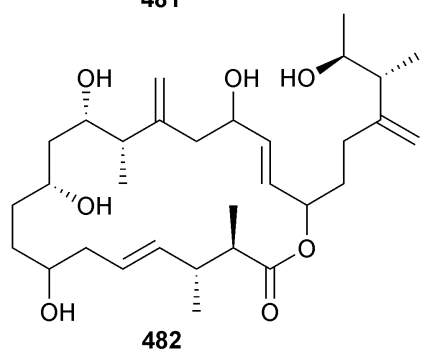

An epoxy polyether with twelve contiguous trans-fused ether rings, gambieroxide $\mathbf{4 8 3}$ was obtained from Gambierdiscus toxicus (Papeete, Tahiti, French Polynesia). ${ }^{\mathbf{4 1 3}}$ Gymnocin-A2 484 was isolated from Karenia (formerly Gymnodinium) mikimotoi (Kushimoto Bay, Wakayama, Japan) as a moderate cytotoxin to P388 cells, along with the known synthetic analogue, gymnocinA carboxylic acid ${ }^{\mathbf{4 1 4}}$ (first isolation from a natural source). ${ }^{\mathbf{4 1 5}}$

The epiphytic, benthic dinoflagellate Ostreopsis $c f$. ovata (Jeju Is., S. Korea) was the source of ostreol A 485, significantly cytotoxic to brine shrimp, ${ }^{\mathbf{4 1 6}}$ whilst the IK2 strain of O. ovata
(Ikei Is., Okinawa, Japan) produced ovatoxins-a, -d and -e, each tentatively assigned by negative fast-atom bombardment collision-induced tandem mass spectrometry (FAB CID MS/MS). ${ }^{417}$

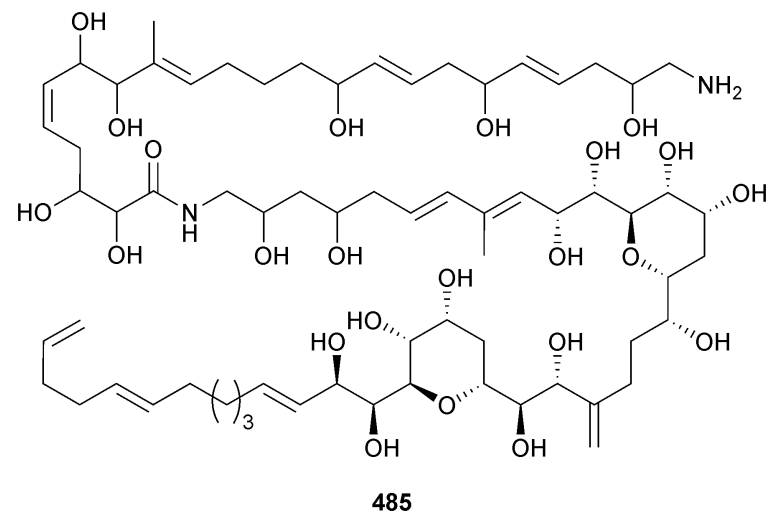

Pyrocystis lunula (University of Texas Culture Collection) yielded three polyunsaturated $\mathrm{C} 27$ hydrocarbons; $n$-heptacosa-3,6,9,12,15,18-hexaene (C27:6) 486, (approx. 0.7 ng per sheathed cell), $n$-heptacosa-3,6,9,12,15,18,21-heptaene (C27:7) 487 and $n$-heptacosa-3,6,9,12,15,18,21,24-octaene (C27:8) 488. ${ }^{418}$ The benthic dinoflagellate Vulcanodinium rugosum (Northland, New Zealand) yielded portimine 489, a polycyclic ether toxin containing a five-membered imine ring, which exhibited potent toxicity to P388 cells, in addition to activation of caspases, as an indication of apoptotic activity. ${ }^{\mathbf{4 1 9}}$

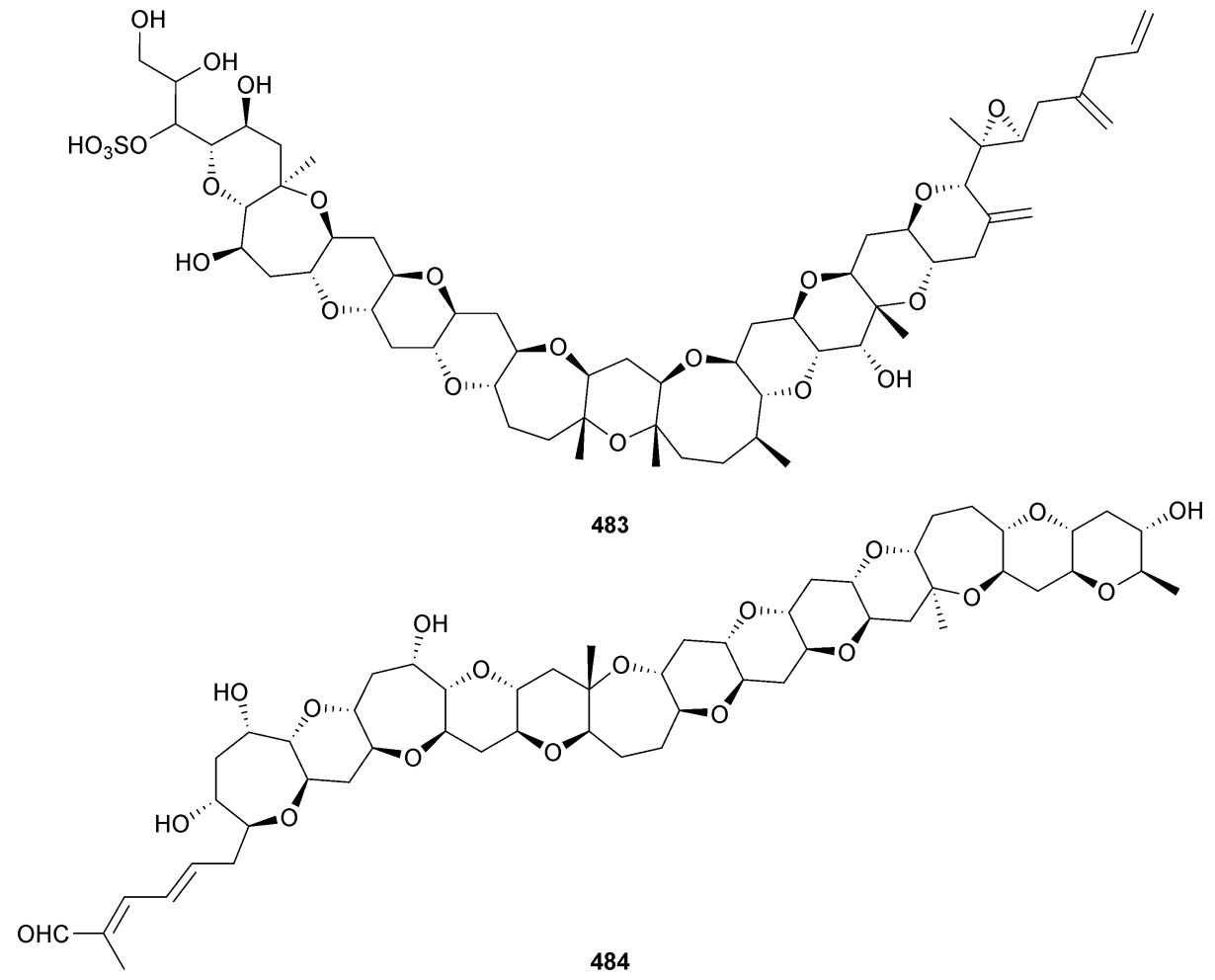




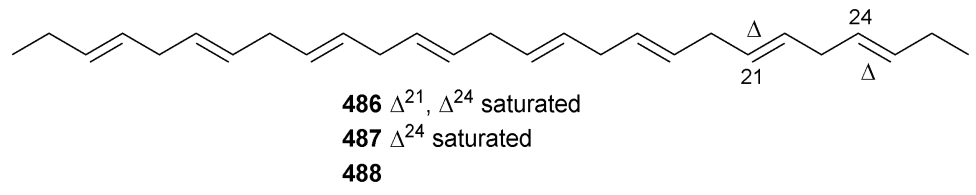

The structure of amphidinolide $\mathrm{N}$, the most potent cytotoxic macrolide isolated from Amphidinium sp. to date ${ }^{\mathbf{4 2 0}}$ has been revised to 490 (and the relative configuration has been assigned). ${ }^{421}$

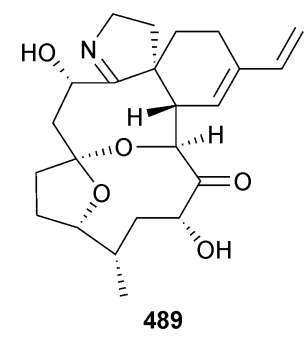<smiles></smiles>

\subsection{Microalgae}

The microalga Nannochloropsis granulata (Provasoli-Guillard National Centre for Culture of Marine Phytoplankton, West Boothbay Harbour, Maine) was the source of the digalactosyldiacylglycerols 491, 492 and the known 493 (ref. 422) and 494, ${ }^{422}$ whose configurations were determined. Also isolated were the monogalactosyl analogues 495, 422496 (ref. 423) (first time as an NP) and $497 . .^{423}$ All of the isolated metabolites exhibited strong NO inhibitory activity against LPS-induced NO production in RAW264.7 macrophage cells suggesting potential as anti-inflammatory agents. ${ }^{\mathbf{4 2 4}}$ The green microalga Tetraselmis sp. (National Institute of Technology and Evaluation Biological Resource Centre, Chiba, Japan) was a producer of the glycosylceramides GT1 498 and GT2 499. ${ }^{425}$

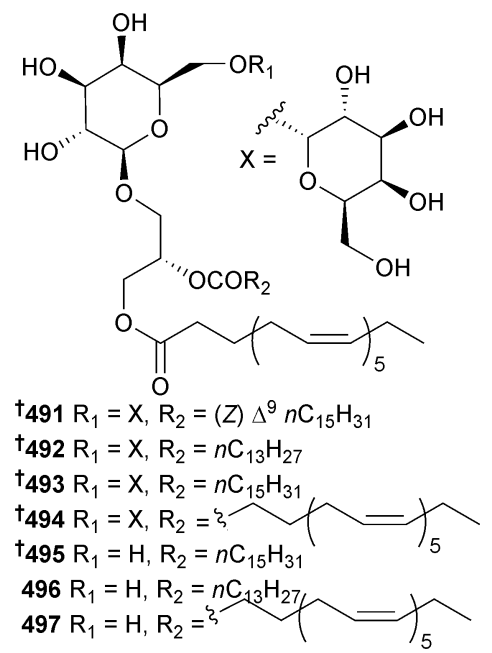

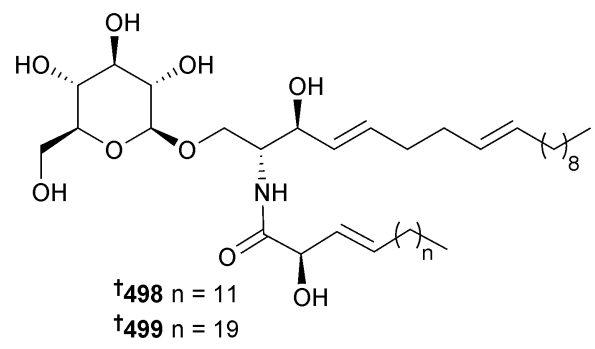

\subsection{Synthetic aspects}

Synthesis of acremolin, originally isolated from spongeassociated Acremonium strictum and assigned as containing a $1 H$-aziridine moiety ${ }^{\mathbf{4 2 6}}$ proved that the alternative structure independently proposed (an isomeric, substituted $\mathrm{N}^{2}, 3$ ethenoguanine $)^{\mathbf{4 2 7}}$ was indeed correct. ${ }^{\mathbf{4 2 8}}$ Total synthesis of ent-(-)-azonazine utilising a hypervalent iodine-mediated biomimetic oxidative cyclisation to construct the core, has resulted in revision of the absolute configuration of natural (+)-azonazine, originally obtained from Hawaiian Aspergillus insulicola ${ }^{\mathbf{4 2 9}}$ to $\mathbf{5 0 0 ,}{ }^{\mathbf{4 3 0}}$ while syntheses of versicolactones A and B, lactones originally isolated from coral-associated Aspergillus versicolor, ${ }^{\mathbf{4 3 1}}$ have resulted in revision of the absolute configurations of the NPs to $(4 Z, 6 R, 7 S)-501$ and $(4 E, 6 R, 7 S)-502$ respectively. ${ }^{432}$ It should be noted that the names versicolactones $A$ and $B$ have also been used to refer to unrelated sesquiterpene lactones isolated from the plant Aristolochia versicolor ${ }^{\mathbf{4 3 3 , 4 3 4}}$

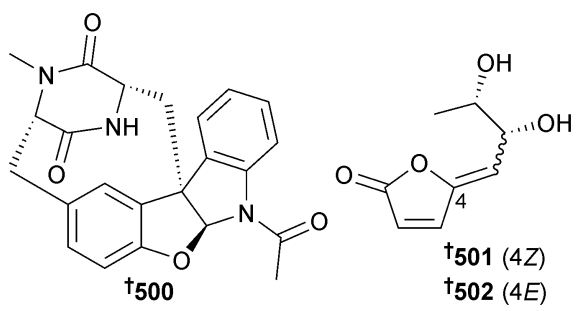

Citrinadins A and B are pentacyclic alkaloids, originally obtained from a red alga-associated strain of Penicillium citrinum. ${ }^{\mathbf{4 3 5 , 4 3 6}}$ An enantioselective total synthesis of (-)-citrinadin A has been achieved in twenty steps from commercially available materials which featured an asymmetric vinylogous Mannich addition of a dienolate to a chiral pyridinium salt to set the initial chiral centre. The synthesis led to revision of the core stereochemistry of the citrinadins and thus of citrinadin A to 503. ${ }^{437}$ An enantioselective total synthesis of (+)-citrinadin B featuring a stereoselective intermolecular nitrone cycloaddition reaction as a key step, similarly led to revision of the configuration of citrinadin $\mathrm{B}$ to $(+)-504 .{ }^{438}$ 
<smiles>CC(C)C1C(=O)O[C@@H](C[C@H]2C[C@@]3(O)[C@@H](C)N4C[C@@](N)(N(C)C)C[C@@]4(c4cccc(C(=O)C5OC5(C)C)c4NC2=O)C3(C)C)C1(C)C</smiles><smiles>C[C@H]1CCC[C@H]2C[C@]3(O)C(=O)N4CC(N)(N)C[C@]4(c4cccc(C(=O)C5OC5(C)C)c4NC12)C3(C)C</smiles>

Trichodermatide A, a polyketide isolated from the fungus Trichoderma reesei, ${ }^{439}$ has been synthesised from $\mathrm{L}$-tartaric acid utilising an intramolecular ketal formation reaction to construct the core of the molecule. ${ }^{440}$ The total syntheses of the putative structures of $( \pm)$-trichodermatides $\mathrm{B}$ and $\mathrm{C}$ featuring the oxa- $[3+3]$ annulation strategy have also been accomplished but mismatch of spectroscopic data between the synthetic and NP samples has indicated that the structural assignments of these metabolites may need revision. ${ }^{441}$ Syntheses of two diastereoisomers of penicillenol $\mathrm{C} 1$, originally obtained from an endophytic, mangrove-associated Penicillium species, ${ }^{\mathbf{4 2}}$ have led to reassignment of the absolute configuration as $\mathbf{5 0 5}$ $(5 S, 6 R, 9 S) .{ }^{443}$ The absolute configurations of the endophytic mangrove Pestalotiopsis sp. metabolites, pestalotiopsones D and $\mathrm{E}^{\mathbf{4 4 4}}$ were determined through total syntheses as 506 and $\mathbf{5 0 7}$ respectively. ${ }^{445}$
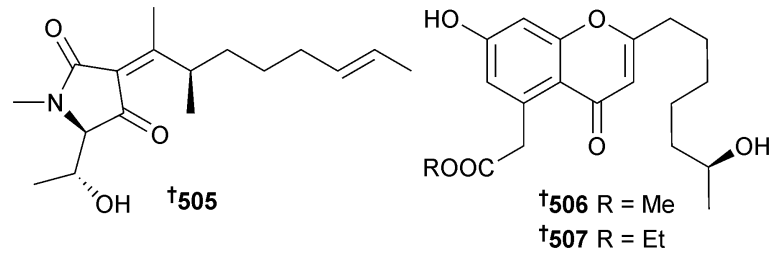

Synthesis of the reported structure of xylopyridine A, a DNAbinding agent originally obtained from a mangrove-associated Xylaria sp., ${ }^{\mathbf{4 4 6}}$ has indicated that the reported structure is incorrect and requires revision. ${ }^{\mathbf{4 4 7}}$ Total synthesis of laxaphycin

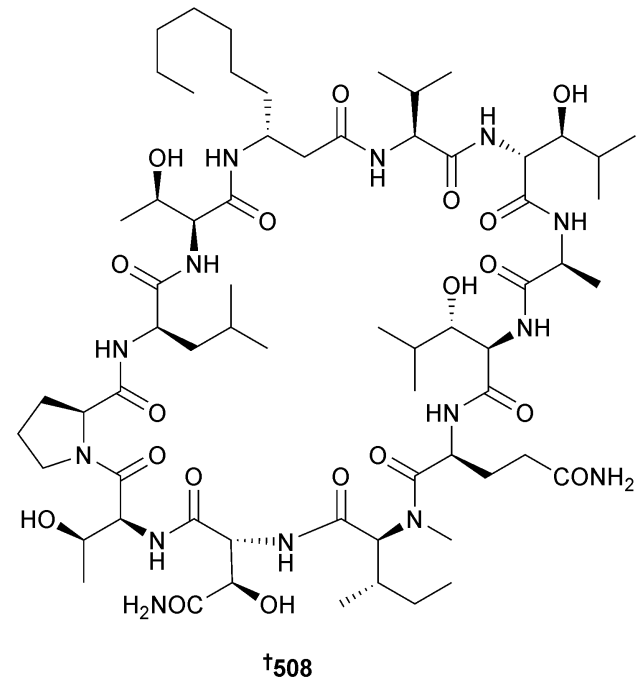

B, a metabolite of terrestrial Anabaena laxa ${ }^{448}$ and of marine $L$. majuscula, ${ }^{\mathbf{4 4 9}}$ was achieved through stepwise automated solidphase peptide synthesis, which led to revision of configuration to 508. The related $L$. majuscula metabolite lyngbyacyclamide $\mathrm{A}^{450}$ was also synthesised by a similar procedure. ${ }^{451}$

The dolastatin 14 analogue, malevamide E, was originally obtained from the cyanobacterium Symploca laete-viridis and the stereochemistry of the peptidic portion assigned. ${ }^{\mathbf{4 5 2}}$ Convergent synthesis of $(29 S, 37 S)$-malevamide E involving JuliaKocienski olefination, Urpi acetal aldol and Shiina macrolactonisation reactions has been achieved but a mismatch of the NMR data between the synthetic and natural samples indicated that the originally assigned configurations of some of the amino acids need revision. ${ }^{453}$ A stereoselective synthesis of the C-43-C-67 fragment of amphidinol 3, originally obtained from the dinoflagellate Amphidinium klebsii, ${ }^{454}$ revised the originally assigned configuration at C-51 from $(R)$ to $(S) .{ }^{455}$ Ieodomycins $\mathrm{A}$ and $\mathrm{B}$ are antimicrobial fatty acids originally obtained from a Bacillus sp. ${ }^{456}$ The first ${ }^{457}$ of several total syntheses of these published in $2013,{ }^{458-460}$ has been achieved in fifteen steps via the chiral pool approach from D-glucose. ${ }^{457}$ Syntheses of the glycolipopeptides ieodoglucomide A and B, originally obtained from Bacillus licheniformis, ${ }^{\mathbf{4 6 1}}$ have been accomplished via a method involving $\beta$-glycosylation and Grubbs olefin cross-metathesis as key steps. The syntheses highlighted that the optical rotation values were originally misreported as being of opposite sign to their actual values and the authors of the isolation paper had noted this also. ${ }^{\mathbf{4 6 2 , 4 6 3}}$ Syntheses of marinacarbolines A-D, antimalarial $\beta$-carboline alkaloids originally obtained from Marinactinospora thermotolerans $^{\mathbf{4 6 4}}$ were achieved in four steps from methyl 1-chloro- $\beta$ carboline-3-carboxylate ${ }^{\mathbf{4 6 5}}$ and the cyclic peptide urukthapelstatin A, originally isolated from the bacterium Mechercharimyces asporophorigenens ${ }^{\mathbf{4 6 6 , 4 6 7}}$ has been synthesised via a convergent strategy. ${ }^{468}$ Trioxacarcin A, a structurally complex glycosidic metabolite of terrestrial ${ }^{\mathbf{4 6 9}}$ and marine ${ }^{\mathbf{4 7 0}}$ Streptomyces species, has been synthesised via a method which utilised latestage stereoselective glycosylation reactions of aglycon substrates. ${ }^{471}$ Indoxamycins A, C, and F, cytotoxic tricyclic polypropionates originally obtained from a Streptomyces sp. ${ }^{472}$ and whose stereochemistry has also been revised as a result of a synthesis of indoxamycin $\mathrm{B},{ }^{473}$ have been synthesised via a divergent approach with an Ireland-Claisen rearrangement, a stereodivergent reductive 1,6-enyne cyclisation and a tandem 1,2-addition/oxa-Michael/methylenation reaction sequence as key steps. ${ }^{\mathbf{4 7}}$ Cytosporin D, an epoxyquinone metabolite of Eutypella scoparia ${ }^{\mathbf{4 7 5}}$ has been prepared from the Diels-Alder adduct of cyclopentadiene and 2-prenyl-p-benzoquinone, ${ }^{476}$ while helicascolide $\mathrm{B}$, a lactone originally obtained from the fungus Helicascus kanaloanus, ${ }^{477}$ has been synthesised in seven steps from commercially available tiglic aldehyde. ${ }^{478}$ Leptosin $\mathrm{D}$, originally obtained from a Leptosphaeria sp. associated with a brown alga $^{479}$ has been synthesised via a strategy which first prepared the known terrestrial ${ }^{480}$ and marine ${ }^{\mathbf{4 8 1}}$ fungal metabolite gliocladine $\mathrm{C}$, which was then manipulated to access various tryptophan-derived epidithiodioxopiperazine NPs. ${ }^{\mathbf{4 8 2}}$ Enantioselective total synthesis of $(-)$-penicipyrone, a polycyclic 
4-hydroxy-2-pyrone metabolite of a Penicillium species associated with a Thai sea fan Annella sp. ${ }^{483}$ was achieved in twelve steps by a biomimetic bimolecular cascade cyclisation featuring an intermolecular Michael addition/cyclo-(spiro-) ketalisation sequence $^{\mathbf{4 8 4}}$ and total syntheses of plectosphaeroic acids A-C (indoleamine 2,3-dioxygenase inhibitors from the fungus Plectosphaerella cucumerina ${ }^{\mathbf{4 8 5}}$ ) have been accomplished. ${ }^{\mathbf{4 8 6 , 4 8 7}}$ The quinoline alkaloid, 4,8-dimethyl-6- $O$ - $\left(2^{\prime}, 4^{\prime}\right.$-di- $O$-methyl- $\beta$-D-xylopyranosyl)hydroxyquinoline, originally obtained from a Caribbean collection of Lyngbya majuscula, ${ }^{\mathbf{4 8 8}}$ has been synthesised by a method which utilises unusual silyl group migrations ${ }^{489}$ and synthesis of nhatrangin A, an aplysiatoxin-related metabolite isolated from Vietnamese Lyngbya majuscula, ${ }^{\mathbf{4 9 0}}$ has been accomplished and confirmed the absolute configuration originally proposed. ${ }^{491}(+)$-Serinolamide A, a cannabinomimetic lipid metabolite of Panamanian Lyngbya majuscula ${ }^{\mathbf{9 2}}$ has been synthesised from L-serine in nine steps with $30 \%$ overall yield ${ }^{493}$ and total synthesis of viequeamide A, a cyclic depsipeptide metabolite of the Puerto Rican "button" cyanobacterium Rivularia sp. ${ }^{494}$ was achieved in ten linear steps based on three retrosynthetic fragments. ${ }^{495}$ Amphidinolide C, a macrocyclic lactone metabolite of the dinoflagellate Amphidinium sp. ${ }^{\mathbf{4 9 6}}$ has been synthesised through the use of a common intermediate to access both the C-1-C-8 and the C-18-C-25 sections. ${ }^{497}$

\subsection{Assorted bioactivities}

The sesterterpenes ophiobolin $\mathrm{K},{ }^{\mathbf{4 9 8 , 4 9 9}}$ 6-epi-ophiobolin $\mathrm{K}^{\mathbf{4 9 8 , 4 9 9}}$ and 6-epi-ophiobolin $\mathrm{G}^{\mathbf{4 9 9}} \mathrm{known}^{-}$metabolites of both terrestrial ${ }^{\mathbf{4 9 8}}$ and marine ${ }^{499}$ fungi were isolated from Emericella variecolor (sediment, Gokasyo Gulf, Mie Prefecture, Japan) as inhibitors of biofilm formation of Mycobacterium smegmatis and of M. bovis BCG at concentrations below those required for antimicrobial activity. ${ }^{\mathbf{5 0 0}}$ Toluquinol, a methylhydroquinone known as a metabolite of the soil fungus Nectria erubescens ${ }^{501}$ was isolated from a Penicillium sp. (Instituto Biomar, León, Spain) as an antiangiogenesis agent, inhibiting the growth of endothelial and tumour cells via apoptosis after a cell cycle block and caspase activation. ${ }^{502}$ Several known fungal metabolites were isolated as selective inhibitors of PTP1B, a potential target for the treatment of type 2 diabetes and obesity. ${ }^{503}$ Penicillium sp. (sediment, Wan Is., S. Korea) yielded fructigenine $\mathrm{A}^{\mathbf{5 0 4}}$ and cyclopenol, ${ }^{505}$ Eurotium sp. (sediment, Wan Is., Korea) yielded echinulin ${ }^{506}$ and flavoglaucin ${ }^{507}$ and a further Penicillium sp. (unidentified sponge, Jeju Is., S. Korea) was the source of viridicatol. ${ }^{505}$ Bis- $N$-norgliovictin, a known terrestrial ${ }^{508}$ and marine $e^{509,510}$ metabolite was isolated from a marine-derived endophytic fungus (no other details given), as an anti-inflammatory agent that inhibited LPS-induced TNF- $\alpha$ production in RAW264.7 cells. $^{511}$

\subsection{Biosynthesis}

The gene cluster responsible for the biosynthesis of the glycosylated diazofluorene polyketides lomaiviticins A-E, ${ }^{512,117}$ originally isolated from Salinispora pacifica (formerly Micromonospora lomaivitiensis), was identified in wild-type Salinispora tropica and several mutant strains through bioactivity-guided genome mining. ${ }^{513}$ An investigation of 163 strains of actinomycetes isolated from mangrove sediments via homologous screening of the biosynthetic genes and bioassay identified $16 \%$ of the strains as possessing the potential to produce halogenated NPs. ${ }^{514}$ The stephacidin and notoamide families of NPs occur in various Aspergillus species, both terrestrial ${ }^{515}$ and marine. ${ }^{516}$ In a further elaboration of the biosynthesis of these metabolites, notoamide $\mathrm{T}$ was identified as the likely precursor to stephacidin A and synthesised along with the C-6-epimer, 6-epi-notoamide T. Stephacidin A was chemically converted to notoamide $\mathrm{T}$ by reductive ring opening while notoamide $\mathrm{T}$ also underwent oxidative conversion to stephacidin A. $\left[{ }^{13} \mathrm{C}\right]_{2}$-Notoamide $\mathrm{T}$ was synthesised and fed to two Aspergillus strains resulting in significant incorporation into the advanced metabolite notoamide B. $^{517}$ Analysis of transcriptome data of a number of saxitoxin (STX)-producing dinoflagellates, especially Alexandrium tamarense strains, identified 265 putative homologues of 13 cyanobacterial STX synthesis genes, including all of the genes directly involved in toxin synthesis. Putative homologues of four proteins group closely in phylogenies with cyanobacteria but the phylogenies do not support transfer of these genes directly between toxic cyanobacteria and dinoflagellates, suggesting that the STX synthesis pathway was likely to have been assembled independently in cyanobacteria and dinoflagellates, but using some evolutionarily related proteins. ${ }^{518}$

\section{Green algae}

Interest in green alga chemistry continued at a low ebb in 2013. Further work on Caulerpa racemosa (Zhanjiang coastline, China), previously the source of caulerpin and two related caulerpin derivatives, ${ }^{519}$ led to the discovery of two prenylated para-xylenes caulerprenylol A 509 and B $\mathbf{5 1 0}$ that were each weakly antifungal. ${ }^{520}$
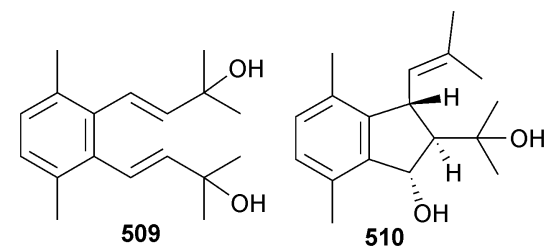

Interesting results were uncovered from the screening and careful bioassay-guided analysis of a collection of Floridian marine eukaryotic algae using an ARE-luciferase reporter gene assay that led to the detection and isolation of three monounsaturated fatty acids 511-513 from Ulva lactuca as activators of the ARE response. Each contained the identical $\Delta^{7}, 9$-keto motif. $^{521}$

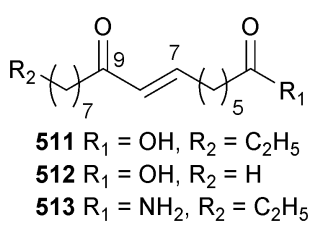

A stereoselective synthesis of the $\mathrm{C}-8^{\prime}-\mathrm{O}-\mathrm{C}-6^{\prime \prime}$ ether of the antimitotic agent nigricanoside $\mathrm{A}^{522}$ was successfully applied in model systems. ${ }^{523}$ Included in the green algal literature for 2013 
were reports on the cytotoxic effects of clerosterol from Codium fragile $^{\mathbf{5 2 4}}$ on HTCLs ${ }^{525}$ and the spasmolytic effects of caulerpine $^{526}$ on guinea pig ileum. ${ }^{527}$

\section{Brown algae}

The number of new compounds characterised in 2013 from the Ochrophyta was again relatively low and was dominated by terpenoid chemistry. Based on the in vitro cytotoxicity of a crude Dictyota dichotoma (Abu-Bakr, Red Sea, Egypt) extract an investigation was mounted and three new diterpenoids ( $Z$ )-pachydictyol B 514, (E)-pachydictyol B 515 and pachydictyol C 516 were characterised along with the known pachydictyol $\mathrm{A}^{\mathbf{5 2 8}}$ and several other well-known brown algal metabolites. ${ }^{529}$
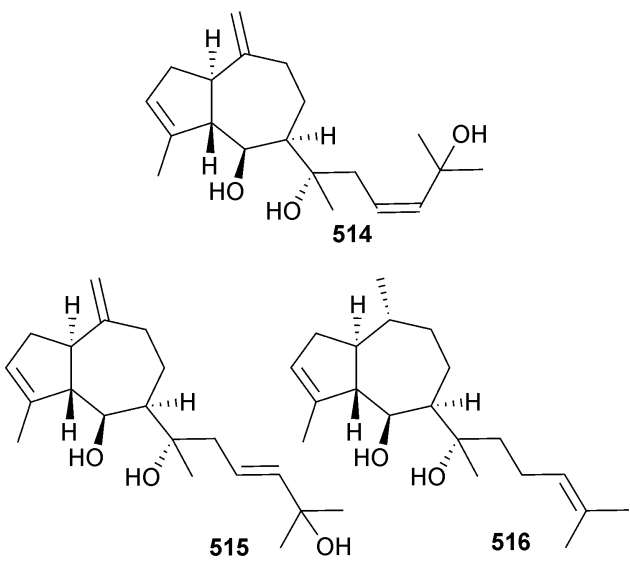

Re-investigation of Dilophus spiralis (Elafonissos Is., Greece) resulted in the isolation of three new dolastanes 517-519 and five previously reported perhydroazulenes. The relative configurations were established for all three dolastanes and the absolute configuration of $\mathbf{5 1 8}$ established by conversion to a compound of known absolute configuration. The absolute configurations of 517 and $\mathbf{5 1 9}$ were assumed on the basis of biogenetic considerations. ${ }^{530}$

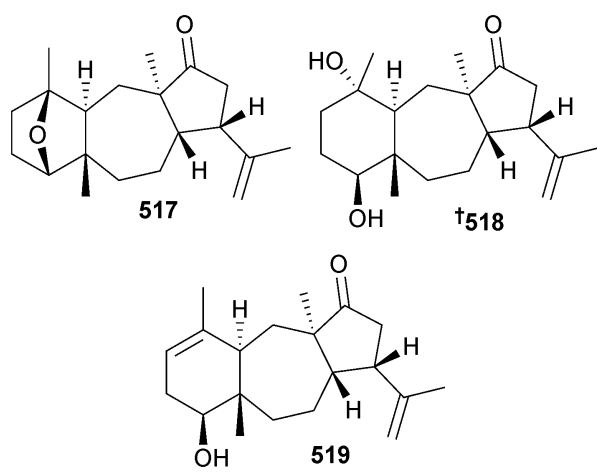

The cytotoxic meronorsesquiterpenoids cystoazorone A $\mathbf{5 2 0}$ and B 521 and meroditerpenoids cystoazorol A 522 and B 523 were isolated from Cystoseira abies-marina (Mosteiros, Sao Miguel Is., Azores) $)^{531}$ while a series of meroditerpenoids cystodione A-F 524-529, all with strong antioxidant properties in the ABTS assay, were isolated from Cystoseira usneoides (Gibraltar Strait). ${ }^{532}$<smiles>COc1cc(C)c(OC)c(C/C=C(\C)CC(=O)/C=C(\C)CCCC(C)=O)c1</smiles><smiles>[R]C(CC(O)C(C)(C)O)C(C)=CCCC(C)=CC(=O)CC(C)=CCc1cc(OC)cc(C)c1OC</smiles><smiles>COc1c(C)cc(O)cc1/C=C/C(C)(O)CC(=O)/C=C(\C)CCCC(C)C(=O)/C=C/C(C)(C)O</smiles><smiles>COc1c(C)cc(O)cc1/C=C/C(C)(O)CC(=O)/C=C(\C)CCCC(C)=O</smiles><smiles>COc1c(C)cc(O)cc1/C=C/C(C)(O)CC(=O)/C=C(\C)CCC[C@]1(C)O[C@@H](C(C)(C)O)CC1=O</smiles>

The mildly antiproliferative meroditerpenoid zonaquinone acetate $\mathbf{5 3 0}$ was obtained from a Jamaican Stypopodium zonale. ${ }^{533}$ Other known brown algal metabolites were co-isolated and these included flabellinone, ${ }^{534}$ not previously identified in $S$. zonale, stypoldione, ${ }^{535}$ and sargaol. ${ }^{536}$ The absolute configuration of $\mathbf{5 3 0}$ was determined by vibrational circular dichroism (VCD) calculations at several levels of theory. ${ }^{533}$

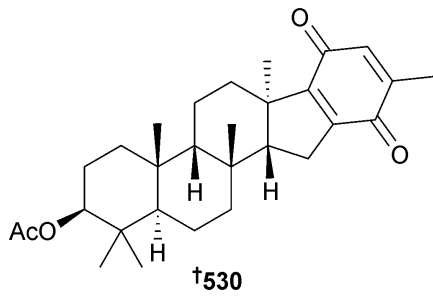

The synthesis of the core framework of the proposed structure of sargafuran ${ }^{537}$ was achieved but the ${ }^{1} \mathrm{H}$ and ${ }^{13} \mathrm{C}$ NMR 


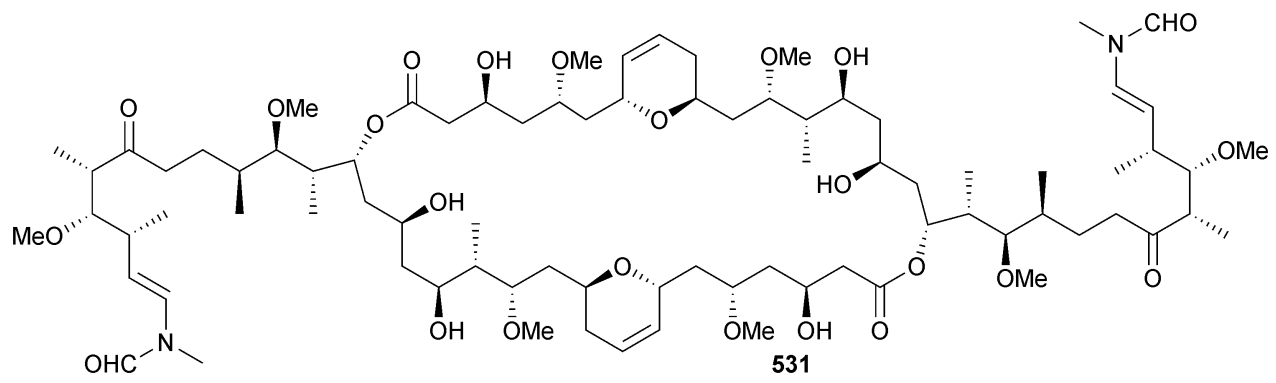

spectral data of the synthetic analogue did not match suggesting that the originally proposed structure of sargafuran is incorrect. ${ }^{538}$ The data matched better with the known sargachromenol. ${ }^{539}$ Another total synthesis of (-)-ecklonialactone $\mathrm{B}^{540}$ as well as the non-natural (+)-9,10-dihydro-ecklonialactone $\mathrm{B}$, was reported. ${ }^{541}$ In papers covering biological properties of brown algal metabolites, four papers were published on the eckol group of phlorotannins describing antiinflammatory properties, ${ }^{542,543}$ induction of apoptosis in carcinoma cells $\mathrm{s}^{544}$ and potential as SARS inhibitors. ${ }^{545}$ Two surveys were published on the antioxidant potential of brown algal extracts which included an excellent summary from species across the phylum as well as the properties of individual brown algal metabolites. ${ }^{546,547}$ The antiviral properties of sulfoquinovosyldiacylglycerols from Sargassum vulgare (Ilha de Itacuruçá, S.E. Brazil) were evaluated ${ }^{548}$ and the antiviral activity of Dictyota diterpenes assessed in docking studies against HIV-1 reverse transcriptases. ${ }^{549}$ A putative inhibitory mechanism for RANK-induced osteoclast formation by sargachromanol G from Sargassum siliquastrum ${ }^{550}$ has been proposed $^{551}$ and the antiplatelet and antithrombotic effects of sargahydroquinoic and sargaquinoic acids determined. ${ }^{552}$ In other reports of biological testing, the strong antimelanogenic properties of an extract from Dictyota coriacea (Jeju Is., S. Korea) were attributed to 1,9-dihydroxycrenulide ${ }^{553}$ and epiloliolide, ${ }^{554}$ known compounds. ${ }^{555}$ Seven known meroditerpenoids were isolated from Sargassum siliquastrum (Jeju Is., S. Korea) and evaluated for cytotoxicity against a range of HTCLs, ${ }^{556}$ while the cytotoxic sterol (24R)-hydroperoxy-24vinylcholesterol ${ }^{557}$ was reported for the first time from Nizamuddinia zanardinii (Oman Sea). ${ }^{558}$ In a comprehensive study the anticancer effects of fucoxanthin were examined from a mechanistic perspective. ${ }^{559}$ In another wide-ranging study, 20 green and brown algal extracts from the French coast were evaluated against Trypanosoma brucei rhodesiense (T. b. rhodesiense). ${ }^{560}$ The Bifurcaria bifurcata extract showed the strongest trypanocidal activity which was tracked to eleganolone. ${ }^{561}$ The potential of the HPLC/NMR technique for chemical profiling and dereplication was illustrated with the characterisation of nine known compounds from Cystophora torulosa (Pt. Lonsdale, Victoria, Australia). ${ }^{562}$

\section{Red algae}

The nine new compounds reported from red algae in 2013 is a marked reduction in the number reported from the previous year (47). The relative configurations of the 30 stereogenic centres in the macrodiolide luminaolide 531 (Hydrolithon reinbodii $)^{563}$ were assigned from NMR data, although the relationships of the two side chains to the macrolide ring are still to be established. ${ }^{564}$

The structures of laurefurenynes A 532 and B 533 (Laurencia $\mathrm{sp} .{ }^{565}$ were reassigned following syntheses of $\mathbf{5 3 2} 2^{566}$ and $\mathbf{5 3 3},{ }^{567}$ respectively, and density functional theory (DFT) calculations of NMR chemical shift data. ${ }^{567}$ There is still doubt about the configuration of the closely related elatenyne (L. elata). ${ }^{568}$ Computational $^{569}$ and synthetic ${ }^{570}$ efforts suggested a revised structure. However, recent more extensive NMR and chemical derivatisation studies proposed a further revision $\mathbf{5 3 4}$ but were unable to establish the absolute configuration. ${ }^{571}$

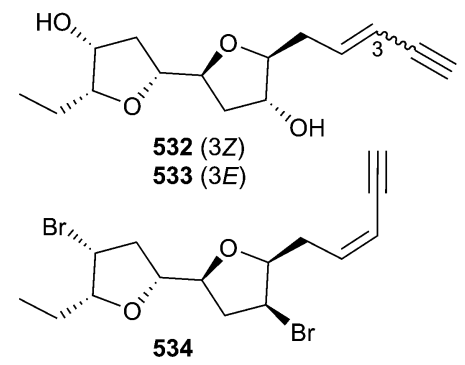

Various aspects of the configurations of armatols A-F (Chondria armata) ${ }^{572}$ have now been clarified through the total synthesis of armatol A $\mathbf{5 3 5}$ and hence by analogy to the structures for armatols B-F 536-540. ${ }^{573}$ This paper also reported the first total synthesis of dioxepandehydrothyrsiferol (Laurencia viridis $^{574}$ as the enantiomer.
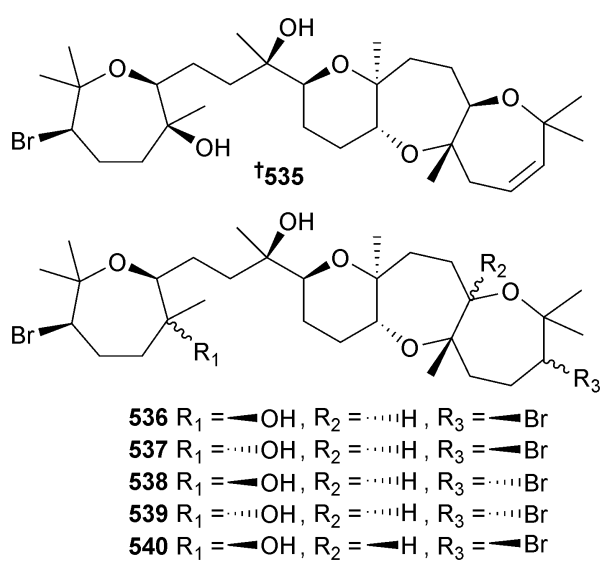
The chamigrane sesquiterpenes yicterpene A 541 and B 542 were isolated from L. composita (Pingtan Is., China). ${ }^{575} \mathrm{Of}$ the 7 compounds isolated from $L$. similis (Sepanggar Is., Kota Kinabalu, Sabah), ent-1(10)-aristolen-9 $\beta$-ol 543 was claimed as an enantiomer of a known compound..$^{576,577}$ Two bromophenols 544 and 545 with radical scavenging activity were obtained from Symphyocladia latiuscula (Qingdao, Shandong Province, China). ${ }^{578}$ This same collection of $S$. latiuscula also provided the weakly antifungal bromophenol sulfoxide $546 .{ }^{579}$

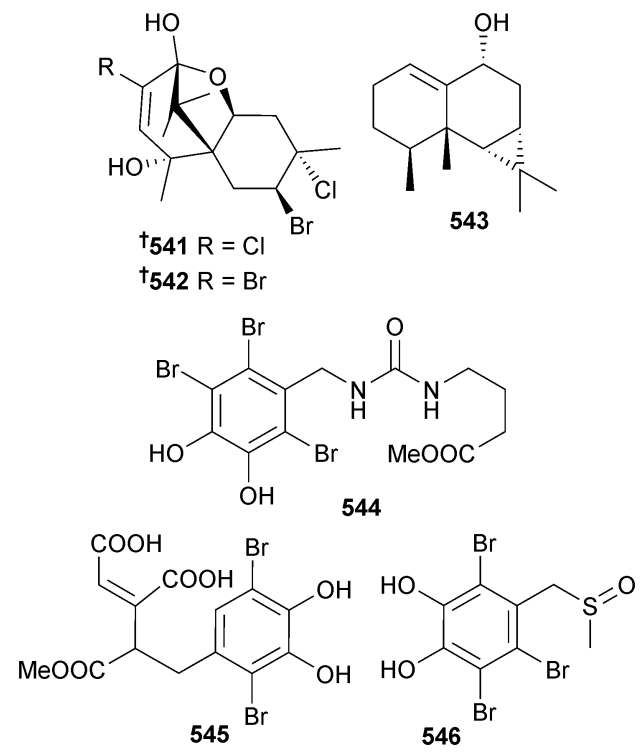

One new (547) and three known bromophenols isolated from Vertebrata lanosa (Oldervik, Ullsfjorden, Norway) had cellular antioxidant activities, the first time this activity has been reported for this class of compounds. ${ }^{580}$ The unprecedented polybrominated spiro-trisindole similisine A $\mathbf{5 4 8}$ and its enantiomer similisine B were obtained from Laurencia similis (S. China Sea)..581<smiles>Oc1cc(COCc2cc(O)c(Br)c(Cc3cc(O)c(O)c(Br)c3Br)c2Cc2cc(O)c(O)c(Br)c2Br)c(Cc2cc(O)c(O)c(Br)c2Br)c(O)c1O</smiles>

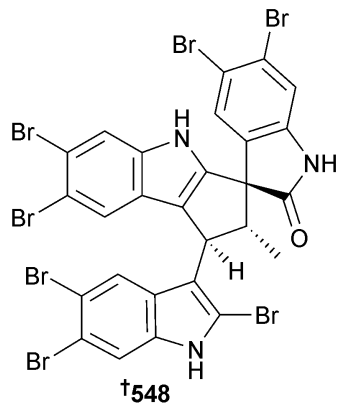

Synthesis of the two proposed diastereomers of prevezol C (L. obtusa $)^{582}$ showed that neither is the structure of the NP. ${ }^{583}$ Parguerenes (L. filiformis) ${ }^{584}$ were identified as inhibitors of Pglycoprotein (ABCB1) in multidrug resistant human cancer cells. ${ }^{585}$ Five known bromophenols from a variety of red algae had inhibitory activity against glucose 6-phosphate dehydrogenase, this being the first report of such inhibitors from red algae. ${ }^{56}$ Analysis of the metabolite compositions of seasonal collections of Graciliaria gracilis (Lesina Lagoon, S. Adriatic Sea, Italy) led to the proposition for using G. gracilis as a multi products source for biotechnological, nutraceutical and pharmaceutical applications. ${ }^{57}$ Bioactive metabolites isolated from Asparagopsis taxiformis were found to have little potential for therapy services to fish infected with Streptococcus iniae. ${ }^{588}$

\section{Sponges}

Even with only 243 new compounds reported in 2013, a significant decrease in relation to previous years $(19 \%$ and $33 \%$ down on 2011 and 2012, respectively), ${ }^{589,2}$ sponges remain the dominant phylum for the discovery of new marine-derived bioactives (see section 15 Conclusion). The modified sphingoid base halisphingosine B $\mathbf{5 4 9}$ was isolated from Haliclona tubifera (Santa Catarina, Brazil $)^{590}$ while taurinated fatty acid $\mathbf{5 5 0}$ was isolated from Axinella sp. (Hainan Is., S. China Sea). ${ }^{591}$<smiles>CCCC/C=C\CCCC(=O)NCCS(=O)(=O)O</smiles>

The asymmetric total synthesis of the "two-headed" sphingoid base rhizochalin C (Rhizochalina incrustata) $)^{592}$ has been completed. ${ }^{53}$ An Axinyssa djiferi found attached to mangrove tree roots (Djifer, Senegal) yielded axidjiferosides A-C 551-553, a mixture of which inhibited chloroquine-resistant $P$. falciparum..$^{59}$

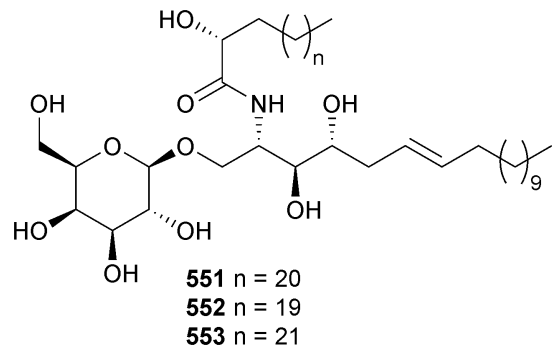

An acetylated nitrogenous glycolipid $\mathbf{5 5 4}$ was isolated from Plakinastrella clathrata (Gneerings Reef, Queensland, Australia), with the absolute configuration confirmed by synthesis of lipidchain analogues. The compound was claimed to be a moderate anti-inflammatory by inhibition of $\mathrm{PGE}_{2}$ but no data was provided..$^{595}$

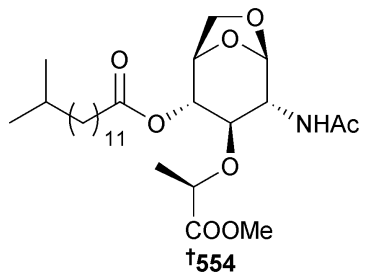


Mycalol 555 is a glycerol ether isolated from Mycale acerata (Terra Nova Bay, Antarctica). A combination of chiroptical and Mosher's methods were used to assign the absolute configuration of this specific inhibitor of human anaplastic thyroid carcinomas, the most aggressive and currently untreatable thyroid gland malignancies, but inactive against other solid tumours. ${ }^{596}$ The absolute configuration of topsentolide $\mathrm{C}_{2} \mathbf{5 5 6}$ (Topsentia sp.) ${ }^{597}$ was established by total synthesis of four possible diastereomers. ${ }^{598}$ The moderately antimicrobial fatty acid trimer manzamenone O $\mathbf{5 5 7}$ was isolated from Plakortis sp. (Manzamo, Okinawa). ${ }^{599}$

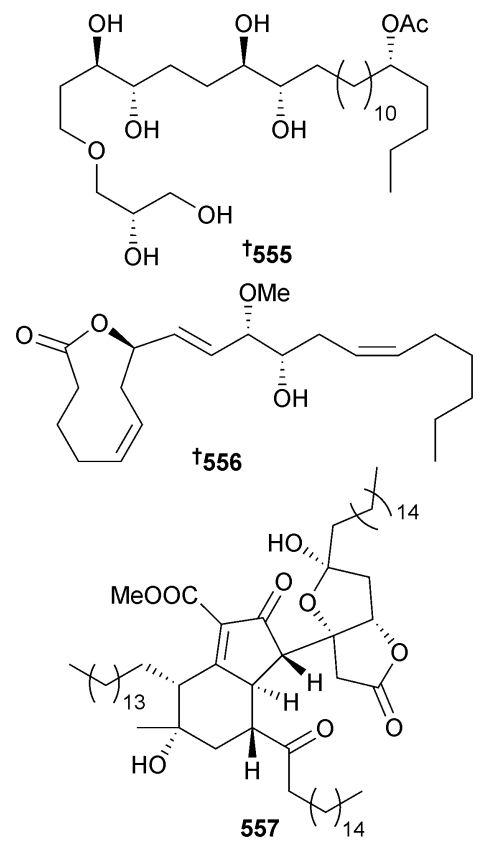

Sponges from the genus Petrosia continue to be a rich source of new polyacetylenes. The report of petrosiols A-E 558-562 from Petrosia strongylata (Ishigakijima Is., Okinawa) as inducers of nerve growth factor-like neuronal differentiation in PC12 cells was followed rapidly by reports of the total synthesis and absolute configuration of petrosiol D 560, ${ }^{\mathbf{6 0 0}, 601}$ and the discovery that $\mathbf{5 5 8}$ inhibits proliferation and migration of platelet derived growth factor-induced vascular smooth muscle cells and hence could be used as a lead for vascular disorders. ${ }^{602}$

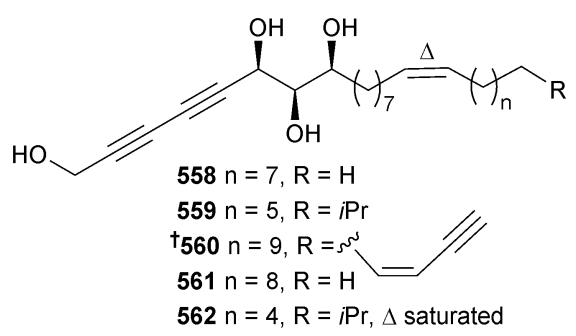

The absolute configuration of the isolated methyl group of miyakosyne A 563 (Petrosia sp. ${ }^{603}$ was established by chemical degradation and subsequent esterification with Ohrui's acid, ${ }^{604}$ thus correcting an earlier tentative assignment made from an analysis by X-ray crystallography of miyakosyne absorbed in a porous metal complex. ${ }^{7,605}$ A racemic mixture of C20 bisacetylenic alcohols 564 and 565 has been isolated from Callyspongia sp. (Iriomote Is., Okinawa), and separated by chiral HPLC. Total synthesis of both enantiomers and detailed biological evaluation showed 564 was more active than its enantiomer against HeLa and temperature sensitive rat lymphatic endothelial cells, thus defining the 1-yne-3-ol moiety as an essential pharmacophore. ${ }^{606}$ Petrosiacetylene E 566 (Petrosia sp. Dokdo Is., S. Korea) was a low $\mu \mathrm{M}$ inhibitor of multiple HTCLs. ${ }^{607}$<smiles>C#C[C@@H](O)/C=C/C(C)C(C)C(C)NC/C=C/[C@@H](O)C#C</smiles><smiles>C#C[C@@H](O)/C=C/C(C)C/C=C/[C@@H](O)C#C</smiles>

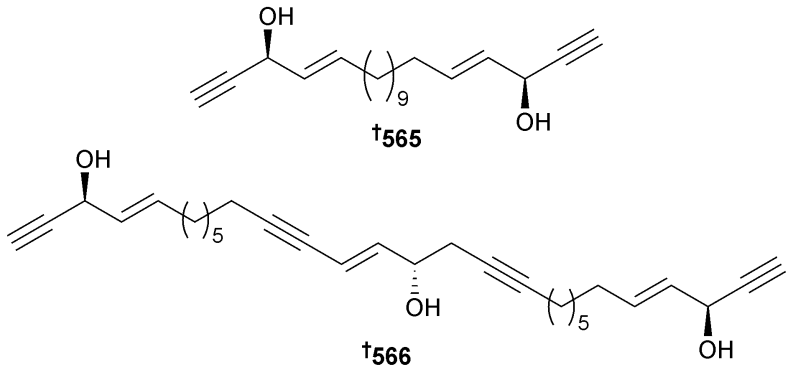

Petrosynic acids A-D 567-570 (Petrosia sp., Tutuila, American Samoa) all displayed similar activity versus various HTCLs and non-proliferative human fibroblasts and hence no therapeutic window is available. ${ }^{608}$
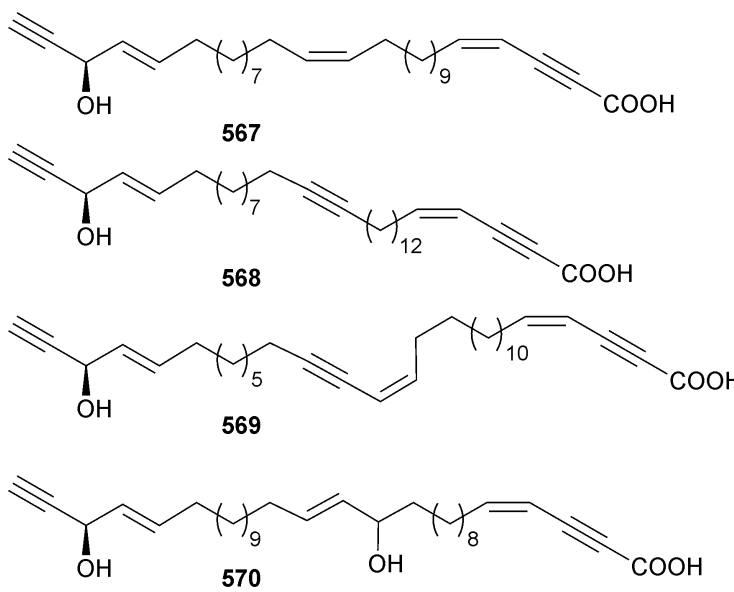

A New Caledonian Niphates sp. was the source of nepheliosyne B 571. ${ }^{609}$ Examination of Petrosia solida (Amami-Oshima, Japan) yielded petroacetylene $\mathbf{5 7 2}$ that inhibited starfish embryo blastulation. ${ }^{610}$ 


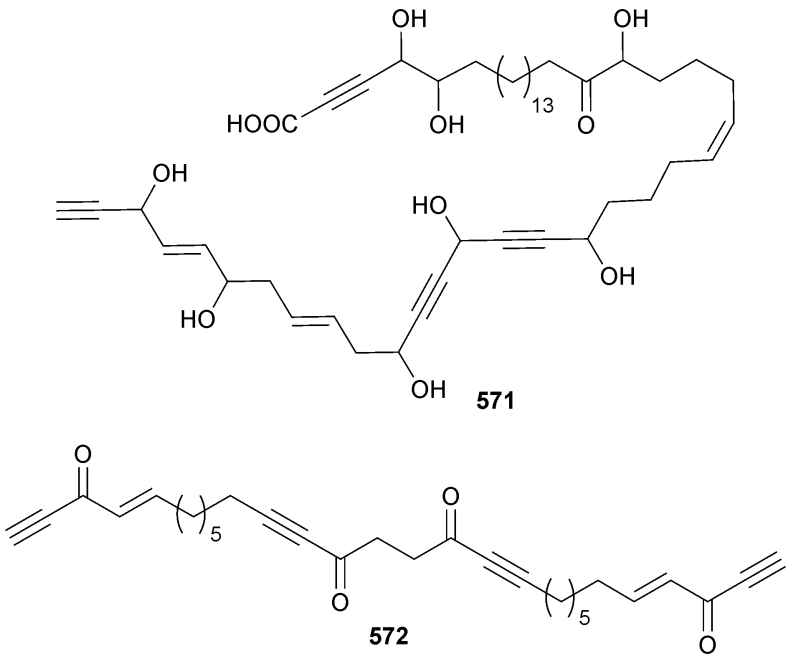

Bromoacetylene testafuran A $\mathbf{5 7 3}$ was isolated from Xestospongia testudinaria (Iwo Is., Kagoshima, Japan) along with four other polyacetylenes 574-577, all five of which induced apidogenesis (stimulation of the differentiation of preadipocytes to adipocytes), and hence may act as leads for treatment of cardiovascular disorders. ${ }^{611}$
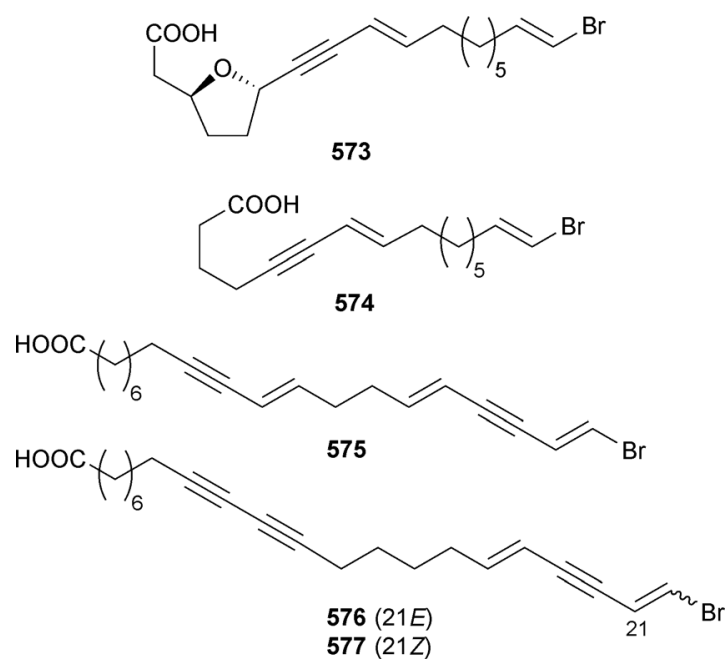

An inhibitor of starfish egg maturation, bromotheoynic acid 578, was reported from Theonella swinhoei (Tanegashima, Kagoshima, Japan), ${ }^{\mathbf{6 1 2}}$ while two further bromopolyacetylenes $\mathbf{5 7 9}$ and 580 were obtained from Haliclona sp. (Sharm Obhur, Jeddah, Saudi Arabia). ${ }^{613}$<smiles>C#C/C=C\CCC=C(Br)CCC#CCCC(=O)O</smiles><smiles>CC(C)=CC=CC#CCCCC=CC#CBr</smiles><smiles>COC(=O)C(C)(C)CC#C/C=C/C(C)(C)C#C/C=C/Br</smiles>

Phosphoiodyns A 581 and B 582 are iodinated and phosphate containing alkynes from Placospongia sp. (Tong-Young City, S. Korea). Phosphoiodyn B was inactive, but 581 was a potent inhibitor of human peroxisome proliferator-activated receptor delta (hPPAR $\delta$ ) with 200-fold selectivity over other PPARs, and therefore a potent regulator of lipid and glucose metabolism, and potentially a lead for treating type 2 diabetes or metabolic disorders. ${ }^{614,615}$

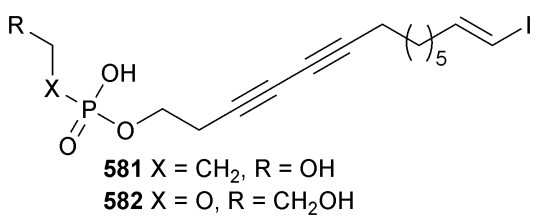

Four mono- or di-iodinated polyacetylene acids were isolated from Suberites mammilaris (583 and 584) and S. japonicus (585 and 586) (Gageo Is., S. Korea). Anti-inflammatory bioactivity profiling of the methyl esters indicated that pre-treatment with the $S$. mammilaris metabolites inhibited nitrite production in LPS-stimulated RAW 267.4 macrophages while the $S$. japonicus metabolites inhibited NO production in BV2 microglial cells, with each pair being inactive in the other assay. ${ }^{616}$

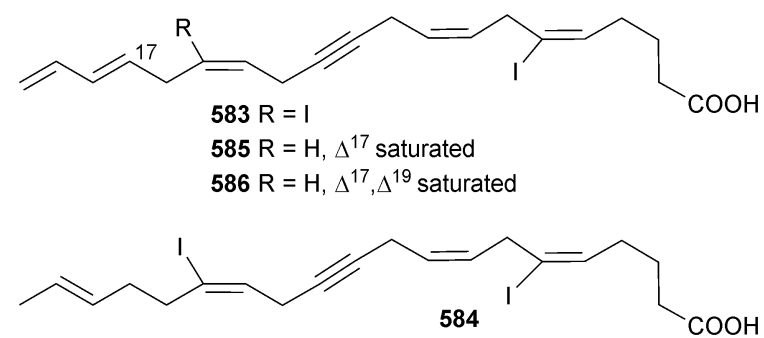

A mixed extract from Smenospongia aurea, S. cerebriformis and Verongula rigida (Key Largo, Florida) yielded a linear phenyl alkene 587 with activity against HL-60 cells. Molecular modelling docking studies suggested that $\mathbf{5 8 7}$ had a pharmacophore similar to that of eribulin and hence potential to interfere with microtubule dynamics. ${ }^{617}$ Dysideolides A 588 and B 589 are methyl-branched lactones from Dysidea cinerea (Lang Co Beach, Vietnam), ${ }^{618}$ while 12-manadoperoxide B 590, manadoperoxidic acid B 591 and monoester 592 were reported from Plakortis lita (Bunaken Is., Manado, Indonesia). Both 591 and the likely oxidative breakdown product 592 showed potent antitrypanocidal activity against $T . b$. rhodesiense. ${ }^{619}$
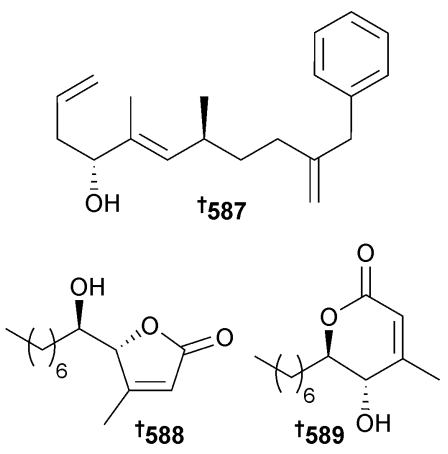


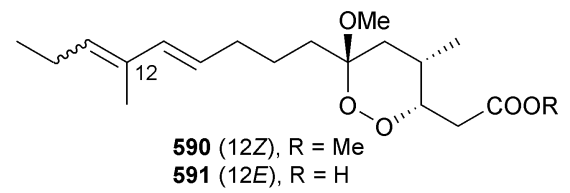<smiles>CC(=O)CC(C)[C@@H](O)CC(=O)O</smiles>

Six new methylated peroxidic acids 593-598 were isolated from Plakortis simplex (Keomun Is., West Sea, S. Korea). All showed low moderate cytotoxic activity against RAW264.7 cells. $^{620}$

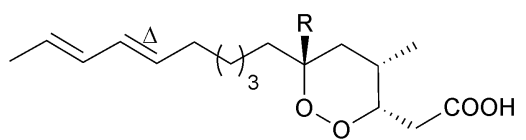

$\dagger_{593} \mathrm{R}=\mathrm{OMe}, \Delta$ saturated

$594 \mathrm{R}=\mathrm{OMe}$

$597 \mathrm{R}=\mathrm{Me}$
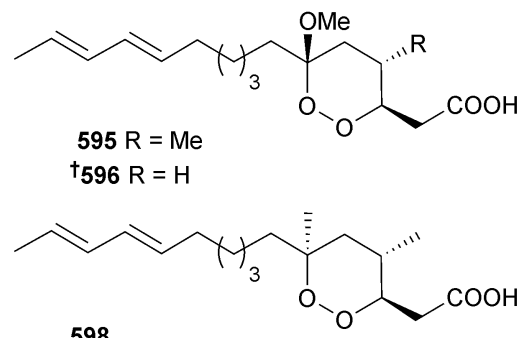

598

A chemical ecological study of Discodermia dissoluta held in Santa Marta, Colombia has shown that $<40 \mathrm{~kg}$ of sponge could be sufficient to sustainably produce $1 \mathrm{~g}$ of discodermolide $\mathrm{e}^{\mathbf{6 2 1}}$ over six months for clinical trials. ${ }^{62}$ A comprehensive study combining computation, chemical derivatisation and NMR studies was used to assign both the relative and absolute configurations of plakilactones G 599 and H 600 from a Fijian Plakinastrella mamillaris. ${ }^{623}$<smiles>CCCC1(CC(C[13CH3])[C@@H](O)[C@H](O)CC)C=C(CC)C(=O)O1</smiles>

Plakortoxides A 601 and B 602, simplextones C 603 and D 604 and plakorsin D 605 were all isolated from Plakortis simplex (Yongxing Is., S. China Sea) although only 603 showed activity. ${ }^{\mathbf{6 2 4}}$
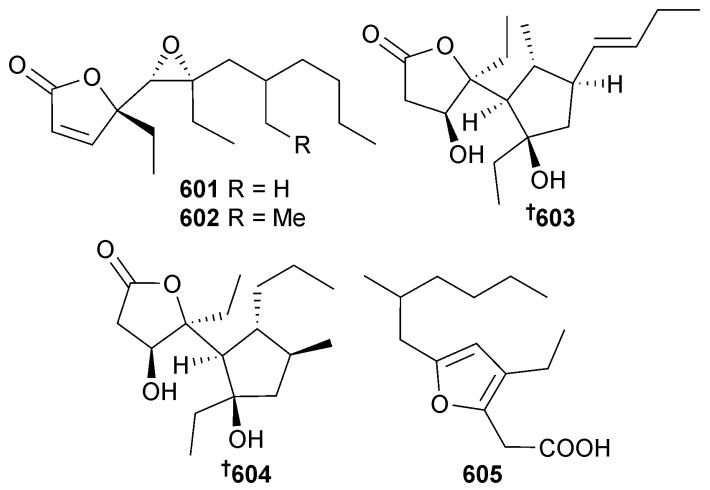

A two-sponge association between Plakortis communis and Agelas mauritiana (Mooloolaba, Queensland, Australia) yielded a new peroxy acid 606. ${ }^{625}$ Plakinastrella mamillaris (Fiji Is.) produced plakortides R-U 607-610. Congener 610 was a potent antimalarial agent against chloroquine-resistant $P$. falciparum. The remaining compounds were less active and none of the compounds were cytotoxic against Vero cells at much higher concentrations. ${ }^{626}$

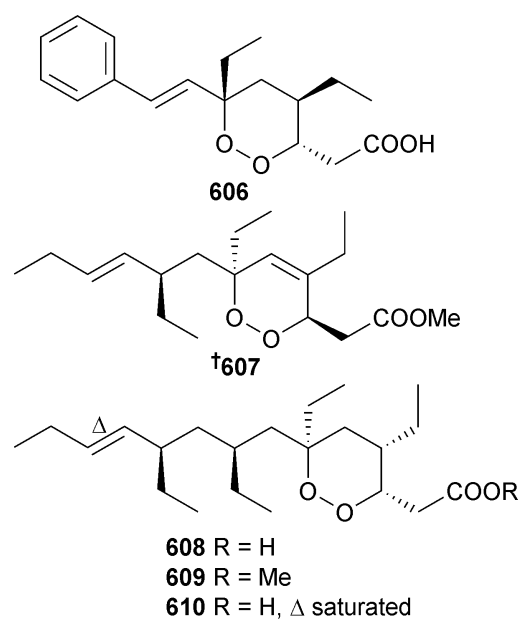

Gracilioether K 611 is a Pregnane X-Receptor (PXR) agonist with no activity against the Farnesoid X-Receptor isolated from Plakinastrella mamillaris (Fiji Is.). In silico docking studies suggested a similar binding motif to other gracilioether congeners. ${ }^{627}$ The sponge Hippospongia lachne (Xisha Is., S. China Sea) provided hippolachnin A 612, a compound with an unprecedented carbon skeleton, that was potently antifungal, but had no activity against three cancer cell lines. The absolute configuration of 612 was determined from comparison of calculated and experimental electronic circular dichroism (ECD) spectra. $^{628}$

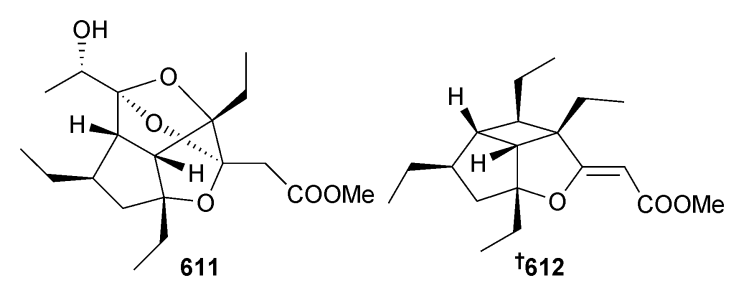

Manzamenones L-N 613-615 were isolated from Plakortis sp. (Manzamo, Okinawa). Manzamenones $\mathrm{M}$ and $\mathrm{N}$ showed some antimicrobial activity against $E$. coli, S. aureus and Cryptococcus neoformans (C. neoformans), while manzamenone L (isolated as a racemate) was inactive. ${ }^{629}$

Callylactam A 616 was isolated from Callyspongia sp. (Hainan Is., China) ${ }^{\mathbf{6 3 0}}$ while allos-hemicalyculin $\mathbf{6 1 7}$ was reported from Discodermia calyx (Shikine-Jima Is., Japan). Photo-oxidative cleavage of the oxazole moiety of calyculin A was suggested as a route to the formation of $617 .^{631}$ The lipopeptide ciliatamide D 618 was found from a dredged Stelletta sp. $(170 \mathrm{~m}$, Oshimashinsone seamount, Japan). ${ }^{632}$ This study also reaffirmed the absolute configuration of ciliatamide A (Aaptos ciliata) as that 


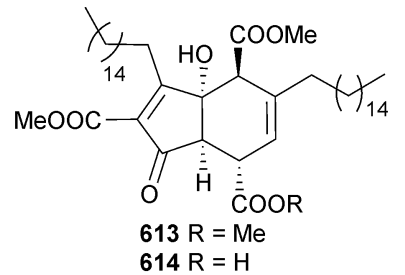<smiles>COC(=O)C1=C(CC(C)C)CC(C(C)=O)C2=C1C(=O)[C@H](C(C)C)[C@H]2CC(C)C</smiles>

assigned during the original isolation, ${ }^{633}$ and subsequently incorrectly reassigned by synthesis. ${ }^{634}$<smiles>O=C1NCCC=C1CC(=O)c1ccccc1</smiles><smiles>COC[C@@H](O)[C@@H](O)[C@H](O[18CH])C(=O)NCCC(C)C(=O)O</smiles><smiles>C=CCC(=O)N(C)[C@@H](CCS(C)=O)C(=O)N[C@H]1CCCCNC1=O</smiles>

The sponge Lithoplocamia lithistoides (Madagascar) produced PM050489 619 and PM060184 620, polyketide amides that differ only in the presence of a chlorine atom. Both are active at sub-nanomolar levels against several cancer cell lines. The gram-scale total syntheses of each compound were also reported. PM060184 620 has undergone a remarkably rapid development from the source sponge collection in 2005 through isolation, characterisation and synthesis in 2006, to the commencement of phase I clinical trials in $2011 .^{635}$

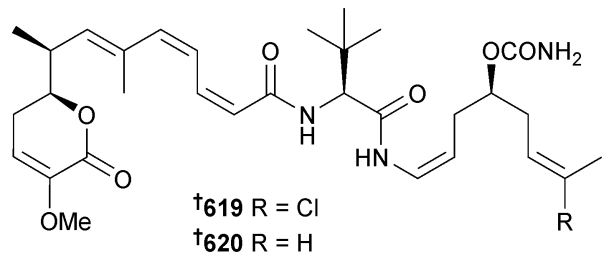

A detailed study of the terrestrial myxobacterial genera Sorangium and Jahnella has delineated the biosynthesis of the microsclerodermins, unusual peptides isolated from Microscleroderma and Theonella sponges, ${ }^{636,637}$ hence suggesting the likely microbial origin of these NPs. ${ }^{638}$ Gombamide A 621, a disulfide linked hexapeptide, was isolated from Clathria gombawuiensis (Gageo-Do, S. Korea). ${ }^{639}$ Stylissatin A 622, a cyclic heptapeptide from Stylissa massa (Loloata Is., Papua New Guinea), inhibited NO production in LPS-stimulated macrophages, ${ }^{\mathbf{6 4 0}}$ while euryjanicins E-G 623-625 are phenylalanineand proline-rich heptapeptides from Prosuberites laughlini (Puerto Rico). ${ }^{641}$
$\mathrm{HO}$<smiles>CC[C@@H](C)C(=O)N1CCC[C@@H]1C(=O)N1CCC[C@H]1C(=O)N[C@@H](Cc1ccccc1)C(=O)N[C@@H](CSSC[C@H](NC(=O)[C@H]1CCC(=O)N1)C(=O)N[C@@H]1CCCN1)C(=O)N/C=C/c1ccc(F)cc1</smiles>

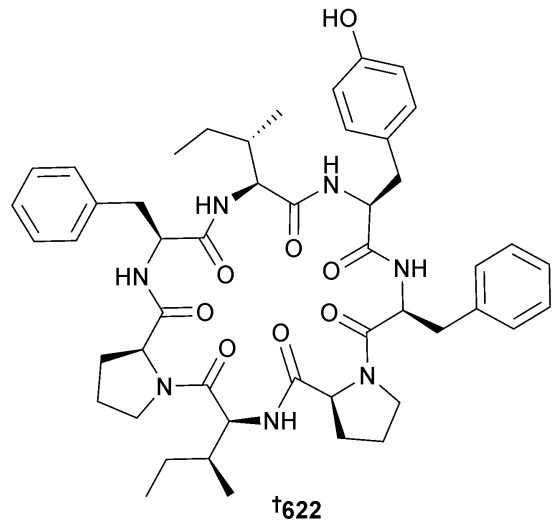

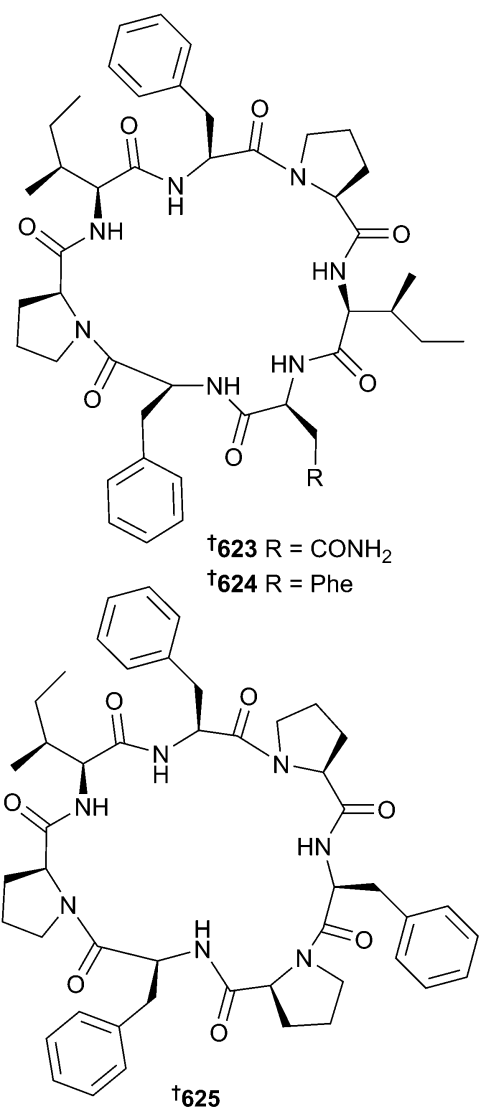

Although the structure of the NP is yet to be reported, the proline-rich octapeptide phakellistatin-19 626 has been synthesised. Interestingly, the bioactivity of the natural $\left(\mathrm{GI}_{50}=\right.$ 
440-515 nM vs. three cell lines) and synthetic (not active) versions differ significantly, a puzzling discrepancy that has been noted previously. ${ }^{642,643}$

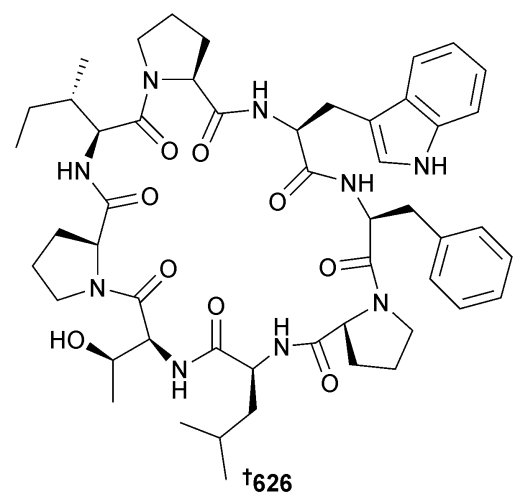

The antifungal activity of the theonellamides (Theonella sp. $)^{644}$ has been linked to their ability to bind to the $3 \beta-\mathrm{OH}$ of sterols in lipid bilayers. This was established using solid state ${ }^{2} \mathrm{H}-\mathrm{NMR}$ and surface plasmon resonance spectroscopies. ${ }^{\mathbf{6 4 5}}$ Sulfinyltheonellapeptolide 627 and theonellapeptolide If $\mathbf{6 2 8}$ were isolated from Theonella swinhoei (N. Sulawesi, Indonesia), both with similar activities against HepG2 hepatic carcinoma cells. $^{646}$

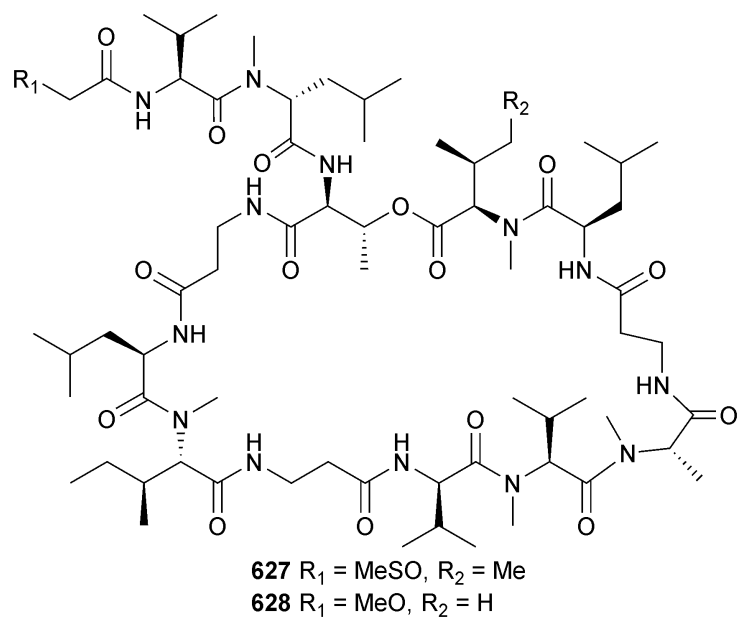

The total synthesis of yaku'amide A $\mathbf{6 2 9}$ (Ceratopsion sp. ${ }^{\mathbf{6 4 7}}$ established the configuration of the C-terminal methyl. Altering the configuration of the methyl had no significant effect on bioactivity. ${ }^{648}$ Asteropsin A 630 (Asteropus sp., Geoje Is., S. Korea) is a cysteine-knot peptide with an unusual $N$-terminal pyroglutamate residue that enhanced neuronal $\mathrm{Ca}^{2+}$ influx in murine cerebrocortical neuron cells and therefore may be useful for the treatment of topical pain or hypertension. ${ }^{\mathbf{6 4 9}}$

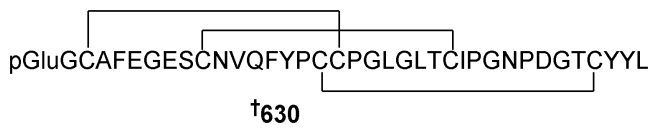

The total syntheses of 18-epi-latrunculol A (Negombata magnifica) ${ }^{\mathbf{6 5 0}}$ and haliclamide (Haliclona sp.) ${ }^{\mathbf{6 5 1}}$ have been achieved, with the latter study determining the absolute configuration 631 of the NP. ${ }^{652,653}$ Two separate collections of Pachastrissa nux (Koh Tao, Surat Thani Province, and Chumphon Is. National Park, Thailand) yielded the antimalarial trioxazole macrolide kabiramide L $632 .{ }^{654}$<smiles></smiles>

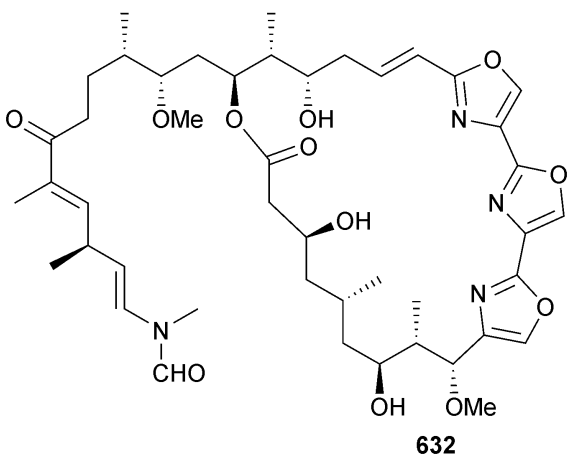

A comprehensive study using $J$-based conformational analysis, the universal NMR database and chemical derivatisations, established the absolute configurations of theonezolide $\mathrm{A}-\mathrm{C}$ 633-635, originally isolated from a Theonella sponge. ${ }^{655-657}$

Theonella swinhoei (Bunaken Marine Park, Manado, Indonesia) provided isoswinholide B 636 and swinholide K 637.

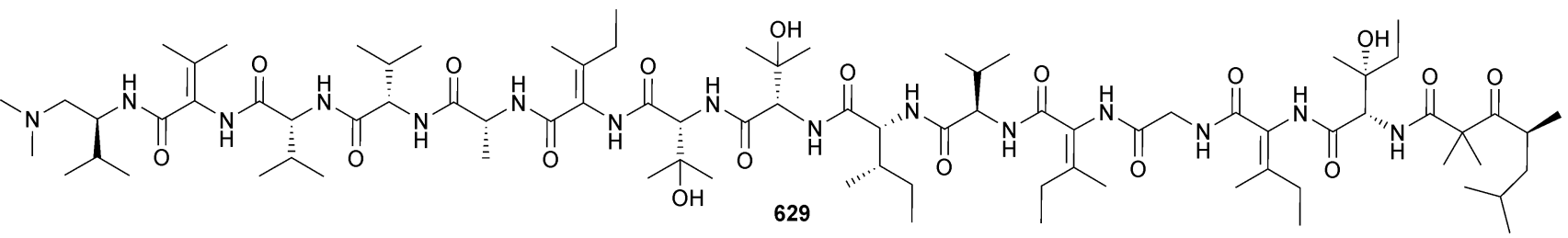




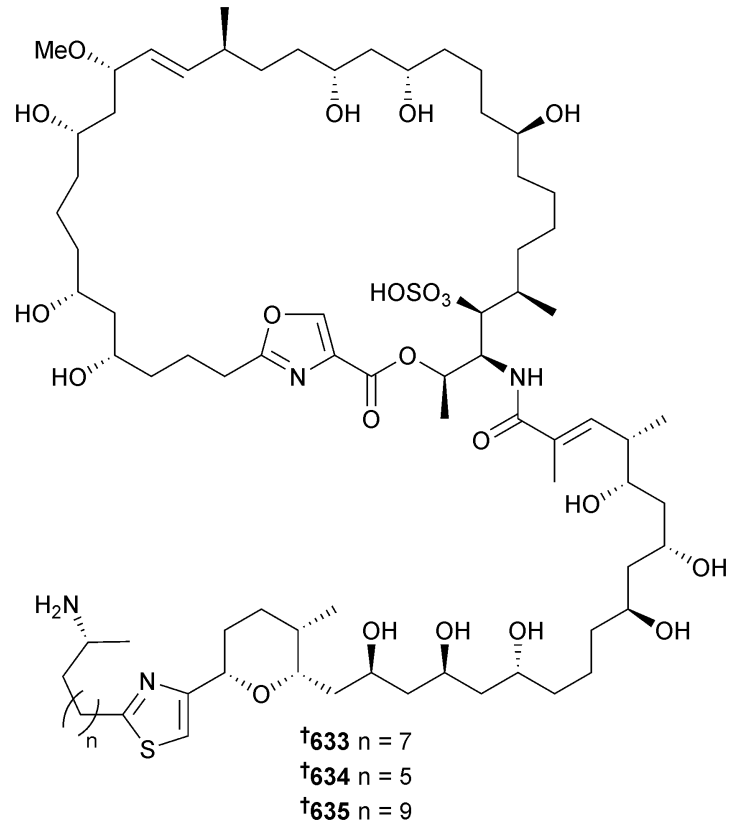

Interestingly 636 was completely inactive while 637 showed significant potency against HepG2 cells consistent with other swinholide congeners. ${ }^{658}$

The absolute configuration of (-)-dysibetaine CPa 638 (Dysidea herbacea $)^{659}$ was established by total synthesis, although the current study incorrectly mentions Lendenfeldia chondrodes as the original source. ${ }^{600}$

The synthesis of nakinadine $\mathrm{C}$ (Amphimedon sp.) ${ }^{\mathbf{6 6 1}}$ confirmed the absolute structure. ${ }^{662}$ Synthesis also confirmed the structures of batzellasides A and C (Batzella sp.). ${ }^{663,664}$ Manzamine A (Haliclona sp.) ${ }^{665}$ inhibited autophagy, and hence could prevent pancreatic cancer, by uncoupling vacuolar ATPases, ${ }^{666}$ as well as suppressing hyperlipidaemia and hence atherosclerosis in apoE-deficient mice. ${ }^{667}$ Zamamiphidin A 639 is a moderately antibacterial ( $S$. aureus) manzamine-type alkaloid isolated along with ircinic acid $2 \mathbf{6 4 0}$ from Amphimedon sp. (Zamami, Okinawa). ${ }^{668}$

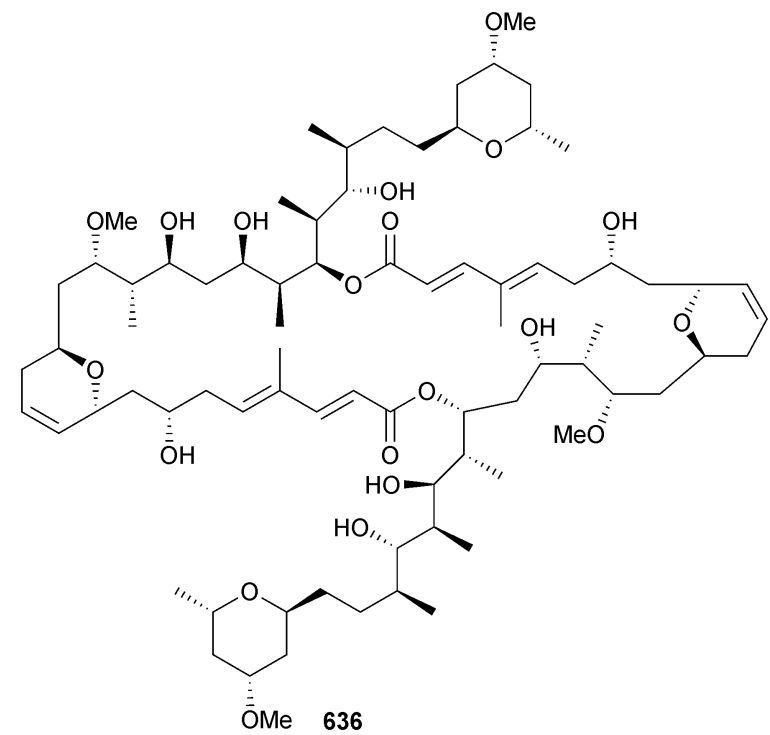

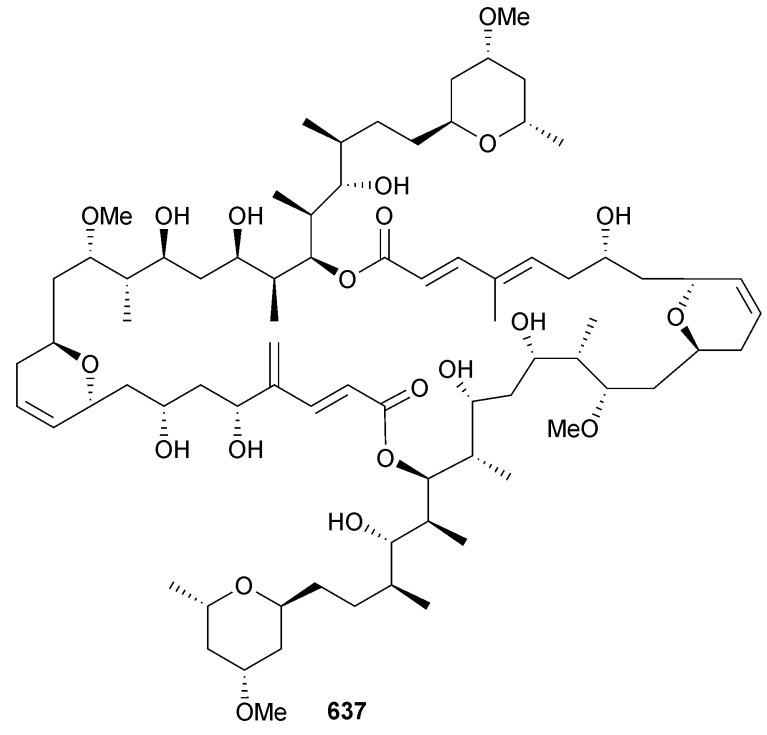<smiles></smiles>

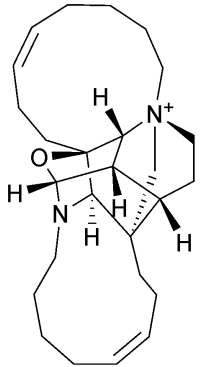

639

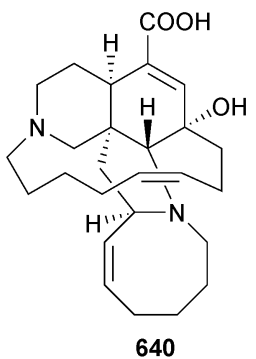

640
The synthesis of two unstable stereoisomers of 'upenamide (Echinochalina sp. ${ }^{669}$ has shown that the putative structure was incorrect, although the constitution of the NP could not be established and given the paucity of remaining compound, structural revision will be difficult. ${ }^{670}$ The sponge Haliclona sp. (d'Urville Is., New Zealand) yielded dehydrohaliclocyclins C 641 and $\mathrm{F} 642$ but lack of material prevented bioactivity profiling. ${ }^{671}$ Plakortis simplex (Keomun Is., West Sea, S. Korea) provided two regioisomeric alkylpyridinium carboxylates 643 and $644 .^{620}$ The pyridinium diamine callyimine A $\mathbf{6 4 5}$ was obtained from Callyspongia sp. (Hainan Is., China). ${ }^{\mathbf{6 3 0}}$

Synthesis confirmed the structures of amphimedosides A-C (Amphimedon sp.). ${ }^{672,673}$ Pyrinodemins G-I 646-648 are bis-3alkylpyridinium alkaloids from Amphimedon sp. (Okinawa), although the exact positioning of the alkyne functionalities is uncertain and hence the compounds are likely a mixture of related congeners. ${ }^{674}$ 


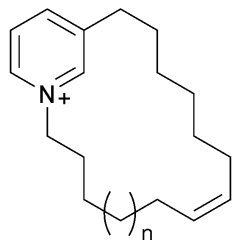

$641 \mathrm{n}=1$<smiles>C[n+]1ccc(CC(C)(C)C)c(C(=O)O[14C](=O)[O-])c1</smiles><smiles>CS(=O)(=O)c1c(-c2ccc(N)cc2)ccc2[n+]1CCC2</smiles>

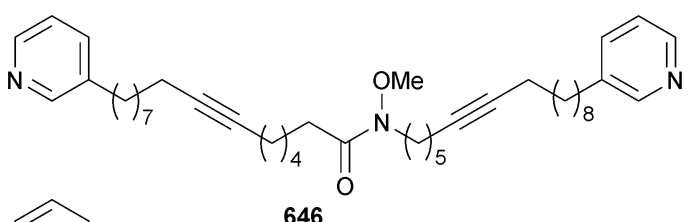

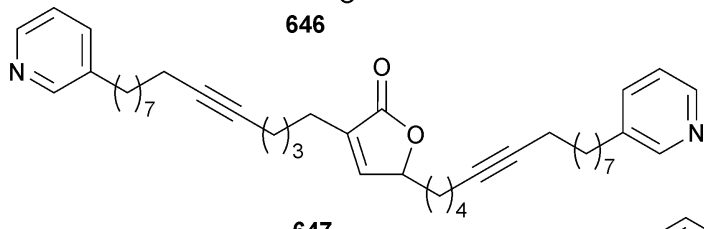

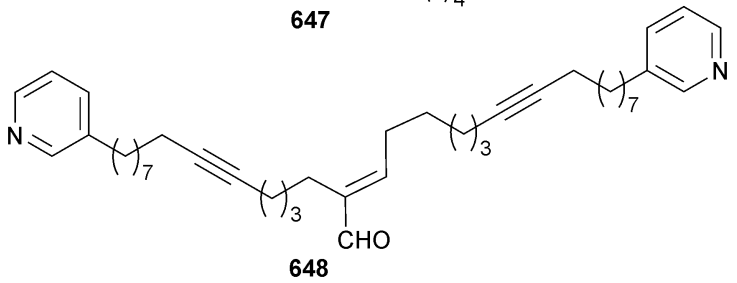

High-level DFT calculations helped confirm the unusually deshielded ${ }^{13} \mathrm{C}$ chemical shifts found in trikentramides A-D 649-652, isolated using an NMR-guided approach from Trikentrion flabelliforme (East Point Bommies, Northern Territory, Australia). ${ }^{675}$ The synthesis of igzamide (Plocamissa igzo) ${ }^{676}$ was achieved. ${ }^{677}$ Three 5-hydroxyindole compounds 653-655 were reported from Scalarispongia sp. (Dokdo, S. Korea). ${ }^{678}$

Hyrtioreticulin F 656 was obtained from Hyrtios reticulatus (N. Sulawesi, Indonesia) and is the likely product of a PictetSpengler reaction between tryptophan, alanine and glycine. ${ }^{679}$ The bis-indole $6^{\prime \prime}$-debromohamacanthin A (Spongosorites $\left.\mathrm{sp.}\right)^{680}$ inhibited angiogenesis by suppressing vascular endothelial growth factor VEGFR2-mediated PI3K/ALT/mTOR signalling in human umbilical vascular endothelial cells and mouse embryonic stem cells. ${ }^{681}$

Hyrtioerectines D-F 657-659 are indolo- $\beta$-carboline alkaloids from a Red Sea Hyrtios species, with all three showing antimicrobial and radical scavenging activity. ${ }^{682}$ Two brominated indolo-carbazoles 660 and $\mathbf{6 6 1}$ were isolated from a<smiles>[X]c1c([R2])c2c(C)cc3c(c2[nH]c1=O)C(C)CC3[R7]</smiles><smiles>CC(=O)C(=O)c1c[nH]c2ccc(O)cc12</smiles>

$649 \mathrm{R}_{1}=-\mathrm{Me}, \mathrm{R}_{2}=\mathrm{Et}, \mathrm{X}=\mathrm{O}$

$650 R_{1}=\cdots M M, R_{2}=E t, X=0$

$651 R_{1}=-M e, R_{2}=M e, X=0$

$652 R_{1}=-M e, R_{2}=M e, X=H, H$<smiles>CC(C)(C)Oc1ccc(O)cc1-c1cncnc1</smiles><smiles>CC(C)(C)S(=O)(=O)c1ccc(O)cc1-c1cncc(-c2c[nH]c3ccc(O)cc23)c1</smiles><smiles>C[C@@H]1NC(C(=O)O)Cc2c1[nH]c1ccc(O)c([C@H](C)NCC(=O)O)c21</smiles>

deep water Asteropus sp. (offshore from Bimini, Ocean Cay, Bahamas). While catechol 660 showed antimicrobial activity (C. albicans and MRSA), sulfonate 661 was completely inactive. ${ }^{683}$<smiles>[R20]Oc1ccc2[nH]c3cnc(-c4c[nH]c5cc(O)ccc45)c(C([R2])[R])c3c2c1</smiles>

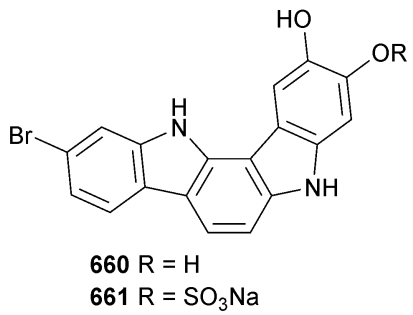

Hyrtimomines A-C 662-664 are 5-hydroxyindole alkaloids from Hyrtios sp. (Kerama Is., Okinawa), although only 662 showed activity against tumour cells. ${ }^{684}$ Hyrtimomines D 665 and E 666 from the same collection are bisindole dimers with some activity against $C$. albicans, C. neoformans, $S$. aureus and Trichophyton mentagrophytes. ${ }^{685}$ 
<smiles></smiles><smiles>CC(C)(C)[N+]1=C2Oc3ccc4[nH]cc(c4c32)C[C@@H](C(=O)O)Nc2ccc(O)cc21</smiles><smiles>CC(C)(C)Oc1ccc2[nH]cc3c2c1C(c1c[nH]c2ccc(O)cc12)=NCC3=O</smiles><smiles>[R]c1cc2c3cc(O)ccc3n3c(=O)c(-c4c[nH]c5ccc(O)cc45)c(-c4c(C)n(C)c[n+]4C)c(n1)c23</smiles>

The Australian sponge Plakortis lita (Tydeman Reef, Queensland) yielded thiaplakortones A-D 667-670 following HTS of a library of 202983 fractions from 18453 extracts. All were potent inhibitors of $P$. falciparum with 667 showing greater than 60-fold selectivity for Plasmodium over human embryonic kidney cells. ${ }^{686}$ The total syntheses of zyzzyanones A-D (Zyzzya fuliginosa $)^{\mathbf{6 8 7 , 6 8 8}}$ have been achieved. ${ }^{689}$ Atkamine A 671 is a new pyrroloiminoquinone isolated from a deep water Latrunculia sp. (Aleutian Is., Alaska). Olefin metathesis was used to identify the location of the side-chain alkene of this surprisingly inactive metabolite. ${ }^{690}$<smiles>NCCc1c[nH]c2c1C(=O)C1=C(NC=CS1(=O)=O)C2=O</smiles><smiles>CNC(Cc1c[nH]c2c1C(=O)C1=C(NC=CS1(=O)=O)C2=O)C(=O)O</smiles><smiles>CN[C@@H](Cc1c[nH]c2c1C(=O)C1=C(C2=O)S(=O)(=O)C=CN1)C(=O)O</smiles>

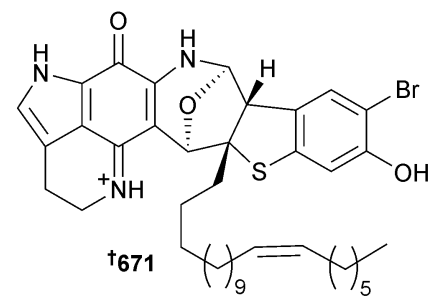

Of four new aaptamine-derivatives 672-675 (Aaptos suberitoides, Ambon, Indonesia) only 674 showed any activity against murine lymphoma. ${ }^{691}$ The total synthesis of 2-deoxy-2aminokealiiquinone (Leucetta chagosensis) ${ }^{692}$ confirmed the structure of the NP. ${ }^{693}$

Pulchranins A-C 676-678, isolated from two dredged Monachora pulchra samples (Kuril Is. Chain, Russia), were moderately active inhibitors of the transient receptor potential cationic channel subfamily $\mathrm{V}$ (capsaicin receptor), and hence are pain and thermal reception modulators. ${ }^{694,695}$ The same sponge that yielded pulchranins $\mathrm{B}$ and $\mathrm{C}$ also yielded<smiles></smiles><smiles>COC1=Cc2ccnc3c(N)cnc(c23)C1=O</smiles>

monanchomycalin C 679, a modest inhibitor of MDA-MB-231 breast cancer cells. ${ }^{696}$
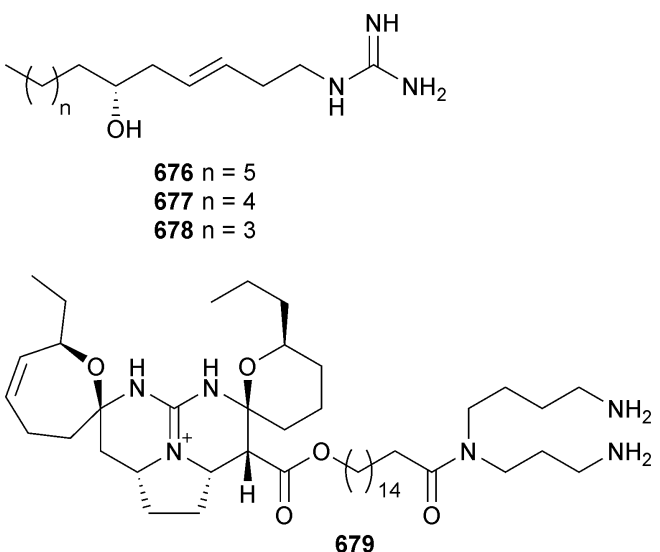

Spongiacidin C (Stylissa massa, Indonesia) ${ }^{697}$ is the first selective inhibitor of USP-7 over other ubiquitin-specific-processing proteases to be isolated from a natural source, and hence is a new lead as an oncological therapeutic. ${ }^{698}$ Nagelamides U-Z 680-685 are bromopyrrole alkaloids from Agelas sp. (Kerama Is., Okinawa) with a variety of biological activities, especially the inhibition of the growth of $C$. albicans. Congeners 683 and 684 were isolated as racemates. ${ }^{699,700}$

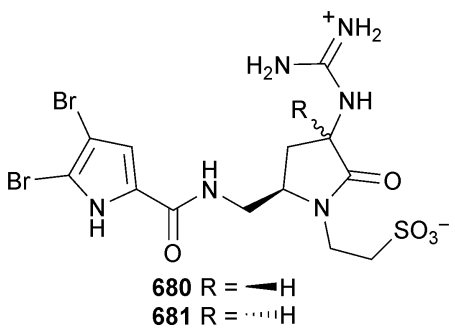<smiles>CC(C)(C)OC(=O)c1cc(Br)c(Br)[nH]1</smiles> 


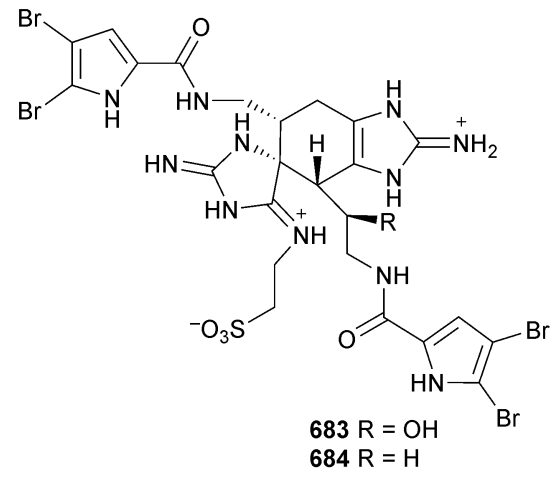<smiles>CCCCC(C)(C)C(=O)NC/C=C/c1[nH]c(=[NH2+])[nH]c1C(/C=C/c1c[nH]c(=[NH2+])[nH]1)NC(=O)c1cc(Br)c(Br)[nH]1</smiles>

Three new bromotyrosine compounds 686-688 were isolated from Aplysina sp. (Ladda Reef, S. China Sea) ${ }^{701}$ while the structures of ma'edamines A and B (Suberea sp. $)^{702}$ have been confirmed by synthesis. ${ }^{703}$

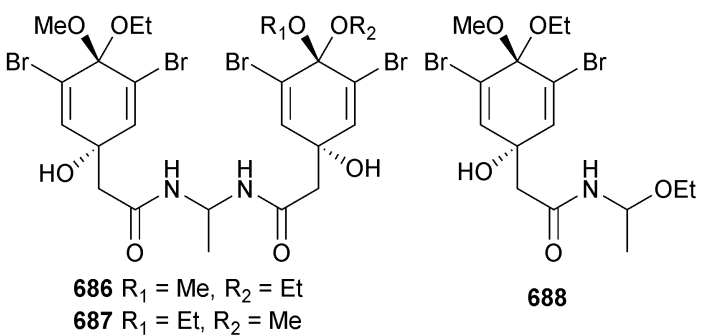

Pseudoceratina verrucosa (Hook Reef Lagoon, Queensland, Australia) yielded pseudoceralidinone A 689 and aplysamine 7 690, with the absolute configurations established by Mosher's method and by total synthesis, respectively. The latter compound inhibited the growth of PC3 prostate adenocarcinoma cells while the former was inactive. ${ }^{704}$<smiles>CNCCCOc1c(Br)cc([C@@H]2CNC(=O)O2)cc1Br</smiles><smiles>CNCCCOc1c(Br)cc([C@@H](O)CNC(=O)/C(Cc2ccc(OC)c(Br)c2)=N\O)cc1Br</smiles>

Eight new bromotyrosine derivatives of the psammaplysin 691-693, ceratinamide 694 and subereamide 695-698 classes were isolated from Suberea sp. (Chuuk, Federated States of Micronesia). Only psammaplysin X 691 and the 19-hydroxy derivative 692 showed activity against six HTCLs. ${ }^{705}$<smiles>[Y]CNCC([R])c1cc(Br)c(OCCCNC(=O)C2=NOC3(CC(Br)=C(OC)C(Br)=CO3)[C@H]2O)c(Br)c1</smiles><smiles>[R2]NCC([R])c1cc(Br)c(OCCCNC(=O)C#N)c(Br)c1</smiles>

Sesquibastadin 699 (Ianthella basta, Ambon, Indonesia) is a trimer of hemibastadin that inhibited a variety of protein kinases from a panel of 24 enzymes, but had no effect on the proliferation of murine lymphoma cells (L5178Y). ${ }^{706}$

The Verongid sponges Ianthella basta and Aplysina cavernicola were examined for the presence of brominated skeletal components within their organic and siliceous matrices. The conclusions drawn from this work were that the bastadin and aerothionin compounds found are likely of microbial origin and that the known secondary metabolites are not associated with the sponge skeletons. However, a considerable quantity of brominated mass was found within the skeleton and it is possible that this represents tightly bound sponge-derived 
<smiles>CC(C)(C)CC(=N/O)/C(=N\CCc1ccc(O)c(Br)c1)NCCc1ccc(O)c(Br)c1</smiles>

secondary metabolites with a defensive role. ${ }^{707}$ Reticulatins A 700 and B 701 are dimethylimidazolium cations isolated from Hyrtios reticulatus (N. Sulawesi, Indonesia). Surprisingly, they differ in absolute configuration of the side chain carbinol. ${ }^{679}$<smiles>CO[C@H](C(=O)[O-])c1c(S(C)(=O)=O)n(C)c[n+]1C</smiles>

Bis-uracil 702 was isolated from Agelas clathrodes (Yongxing Is., S. China Sea). ${ }^{708}$ A Fasciospongia sp. (Weizhou Is., Guangxi, China) gave the sesquiterpene alkaloid fasciospyrinadine $\mathbf{7 0 3},{ }^{\mathbf{7 0 9}}$ while Dysidea avara (Fethiye, Turkey) yielded the merosesquiterpenoid $N$-methylmelemeleone-A 704. ${ }^{\mathbf{7 1 0}}$<smiles>NCCC(n1ccc(=O)[nH]c1=O)n1ccc(=O)[nH]c1=O</smiles><smiles>CC(=CCCc1cccnc1)CCC1=C(C)CCCC1(C)C</smiles><smiles>CC1=CCC[C@H]2[C@]1(C)CC[C@H](C)[C@]2(C)CC1=CC(=O)C(N(C)CCS(=O)(=O)O)=CC1=O</smiles>

Samples of Dactylospongia elegans collected in both Malaysia and Palau contained the related 5,8-di-epi-ilimaquinone 705, 4,5-di-epi-dactylospongiaquinone 706, 8-epi-dactyloquinone 707, 10,17-O-cyano,4,5-di-epi-dactylospongiaquinone 708 and cyclospongiacatechol 709. All five compounds showed antiproliferative effects at high concentrations while 706 and 707 also activated Hypoxia Inducible Factor-1 (HIF-1), with the 1,4benzoquinone moiety demonstrated as essential for activity. ${ }^{711}$

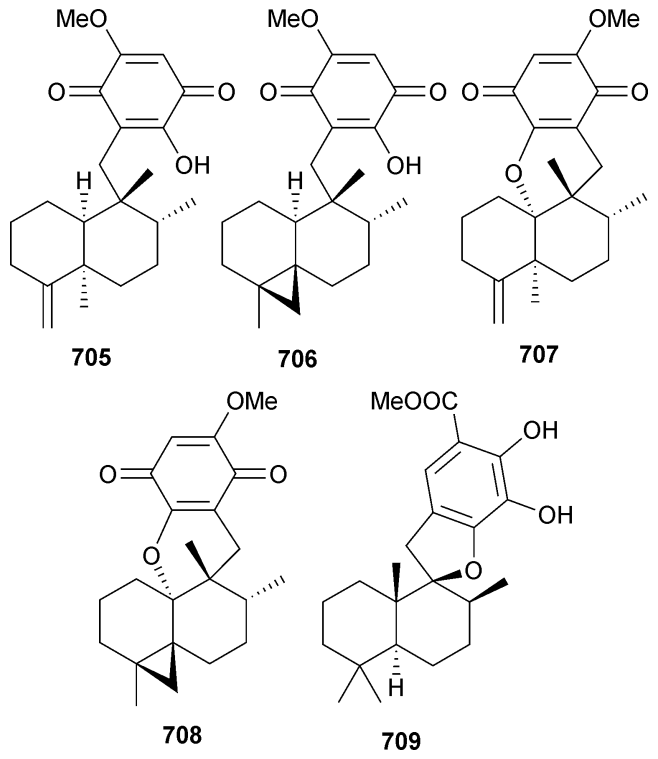

The asymmetric total synthesis of strongylin A (Strongylophora hartmani $)^{712}$ confirmed the absolute configuration, ${ }^{713}$ while synthesis of dysideavarone A (Dysidea avara) ${ }^{714}$ confirmed the structure and also provided material to demonstrate the compound's potent antimicrobial activity, especially against Grampositive bacteria, in particular various Staphylococci spp. ${ }^{715}$ The bisabolane sesquiterpenoids 3-oxobolene $\mathbf{7 1 0}$ and 1-oxocurcuphenol $\mathbf{7 1 1}$ were isolated from Myrmekioderma sp. (Phi-Phi Is., Thailand) and were potent inhibitors of HT-29 cancer cells. ${ }^{716}$<smiles>C=C(C)C(=O)CC[C@@H](C)c1ccc(C)cc1O</smiles>

Ianthellalactams A 712 and B $\mathbf{7 1 3}$ (Ianthella flabelliformis, Port Philip Heads, Victoria, Australia) did not inhibit Glycine-gated chloride channel receptors (GlyR) like other related glycinal lactams. ${ }^{717}$ Euryspongins A-C 714-716 (Euryspongia sp., Iriomote Is., Okinawa) have rare six- or eight-membered skeletons with either fused furan or $\gamma$-lactone rings. The presence of the C-4 hydroxyl group in all three compounds was thought to totally abrogate activity compared with other active analogues. ${ }^{718}$<smiles>CC(C)=CCC/C(C)=C/CCC1=CCN(CC(=O)O)C1=O</smiles><smiles>CC(C)=CCC/C(C)=C/CCC1=CC(=O)N(CC(=O)O)C1</smiles>

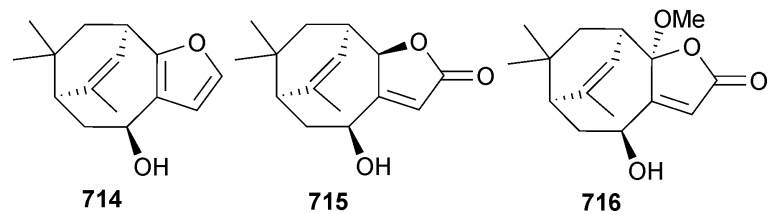


Phorbasin $\mathrm{H}$, originally isolated from Phorbas gukulensis ${ }^{719}$ but differing from another structure with the same name from Phorbas sp., ${ }^{720}$ inhibits the hypha-specific HWP1 and ALS3 mRNAs of C. albicans, preventing the yeast-to-hyphae transition and therefore inhibits virulence of the pathogen. ${ }^{721}$ Axistatins 13 717-719 are pyrimidine diterpenoids from Agelas axifera (Koror, Republic of Palau). All three were low $\mu \mathrm{M}$ inhibitors of various human and murine cancer cell lines, as well as being potent broad-spectrum antibiotics against several Gram-positive and negative bacteria. ${ }^{722}$<smiles>CNc1ncnc(N)c1N(CO)C/C=C1/CC[C@H]2[C@@H](CC[C@H]3C(C)=CCC[C@]23C)C1</smiles><smiles>CNc1ncnc(NC(C)C)c1N(C=O)CC=C(C)CCC=C(C)CC[C@]1(C)C(C)=CCC[C@H]1C</smiles>

Phenotypic screening using zebra fish as a genome-wide eukaryote assay identified kalihinol $\mathrm{F}$ (Acanthella sp. . $^{723}$ as a copper chelator, resulting in abnormal development as indicated by an undulating notochord, and both pigmentation and neural defects. This study exemplifies the use of zebra fish as a viable chemical genetic tool for assessing bioactives in a complex eukaryotic organism. ${ }^{724}$ The total syntheses of cyanthiwigins A, C (Epipolasis reiswigi) ${ }^{725}$ and $\mathrm{H}$ (Myrmekioderma $\operatorname{sty} x)^{726}$ have been achieved, confirming the absolute structures. ${ }^{727}$ Hamigera tarangaensis (Cape Karikari, North Is., New Zealand) provided hamigerans F-K 720-725, 10-epi-hamigeran $\mathrm{K}$ 726, 4-bromohamigeran $\mathrm{K}$ 727, hamigeran $\mathrm{L} 728$ and the methyl ester 729, hamigeran A ethyl ester 730 and an unrelated congener of epi-verrucosane 731. All but the latter compound inhibited the growth of HL-60 cells while chemical genetic screening using yeast as a model organism showed that the<smiles>CC(=O)OC1C(=O)[C@]2(C)CC[C@@H](C(C)(C)C)[C@]2(C)c2cc(C)c(Br)c(O)c2C1O</smiles><smiles>[Z12]C(C)[C@H]1CC[C@]2(C)CC(=O)C(=O)c3c(cc(C)c(Br)c3O)[C@]12C</smiles><smiles>[R20]C1CC[C@]2(C)[C@H](C(C)C)C(=O)[C@](C)(O)c3c(O)cc(C)cc3[C@]12C</smiles>

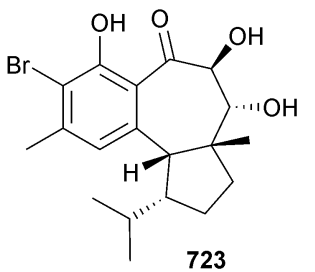

mode of action of the antifungal hamigeran G 721 was via influence of Golgi function and Golgi vesicle formation. ${ }^{728}$<smiles>CC(=O)OC1(C(C)=O)C(=O)[C@]2(C)CC[C@@H](C(C)C)[C@H]2c2cc(C)c(Br)c(O)c21</smiles>
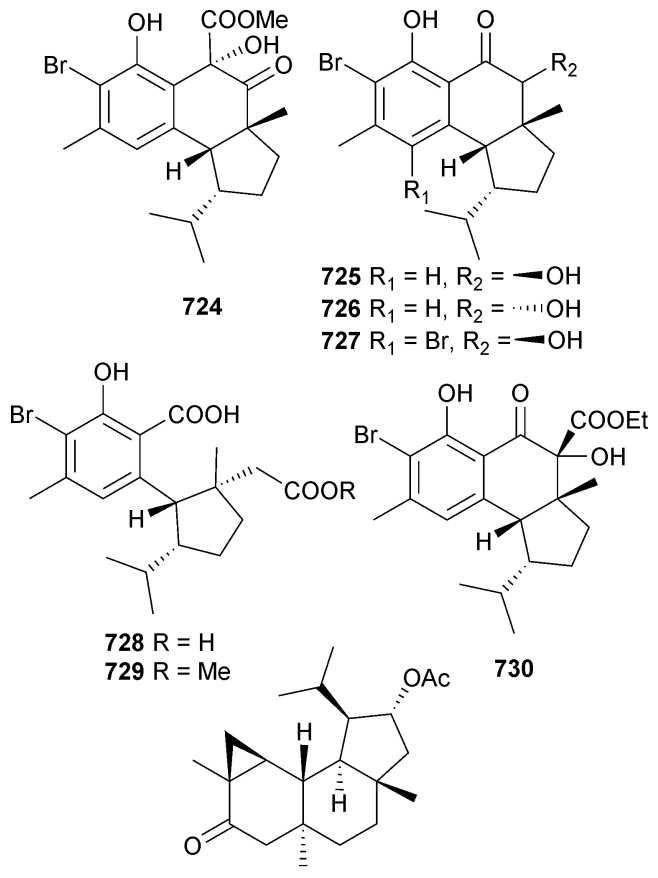

731

Two new isoneoamphilectane diterpenes 732 and 733 were isolated from Svenzea flava (previously described as Pseudoaxinella flava) (Great Inagua Is., Bahamas). The absolute configurations of these compounds were secured by comparison of experimental and calculated VCD data. Both compounds inhibited the growth of Mycobacterium, but had no effect on mammalian cell lines. ${ }^{729}$ Petronigrione 734 is a cembranoid dimer from Petrosia nigricans (Haivan, Danang, Vietnam) with moderate activity against HTCLs, ${ }^{730}$ while Phorbas gukhulensis (Gagu-Do Is., S. Korea) yielded the diterpene pseudo-dimers gukulenin C-F 735-738. All four were cytotoxic against K562 and A549 cancer cell lines but none showed any activity against various microbes. ${ }^{731}$
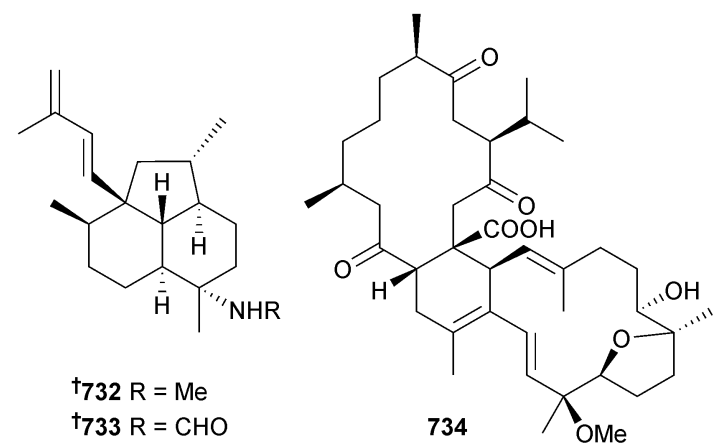

The norsesterterpene cyclic peroxides 13,14-epoxymuqublin A 739 and the 9,10-epoxy isomer 740 were isolated from Diacarnus erythraeanus (Elfanadir, Hurghada coast, Egypt). Both were low micromolar inhibitors of various HTCLs. ${ }^{732}$ 


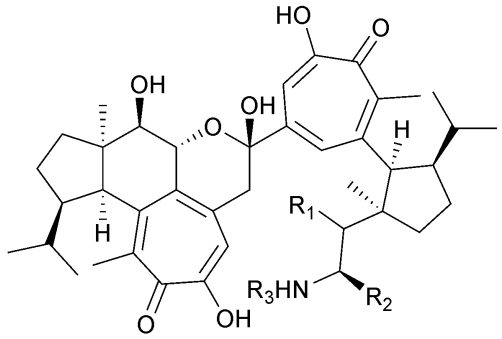

$735 \mathrm{R}_{1}=\cdots \cdots \mathrm{OH}, \mathrm{R}_{2}=\mathrm{OMe}, \mathrm{R}_{3}=\mathrm{Ac}$

$736 \mathrm{R}_{1}=\cdots \cdots \mathrm{OH}, \mathrm{R}_{2}=\mathrm{OH}, \mathrm{R}_{3}=\mathrm{Ac}$

$737 \mathrm{R}_{1}=\mathrm{O}, \mathrm{R}_{2}=\mathrm{H}, \mathrm{R}_{3}=\mathrm{CH}_{2} \mathrm{CH}_{2} \mathrm{SO}_{3} \mathrm{H}$<smiles></smiles>
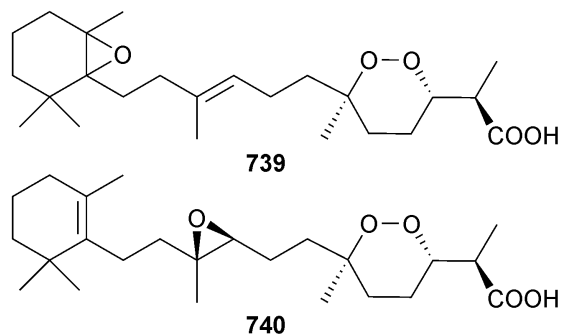

740

Collections of the Homoscleromorpha sponge Oscarella balibaloi at two sites near Marseilles (Mediterranean Sea) yielded the glucosidated sesterterpenes balibaloside 741, $6^{\prime \prime}-O$ acetylbalibaloside 742, $6^{\prime \prime \prime}$-O-acetylbalibaloside 743 and $6^{\prime \prime}, 6^{\prime \prime \prime}$ $O$-diacetylbalibaloside $\mathbf{7 4 4}$. These metabolites are the first glycosidated sesterterpenes reported and although tested in a wide variety of assays, proved to be inactive. ${ }^{733}$

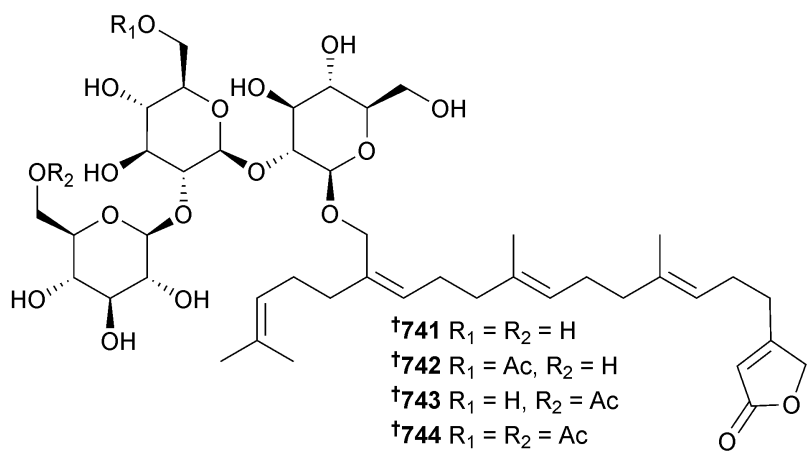

Hyrtios communis (Northern Reef region, Palau) yielded thorectidaeolide A 745, the 4-acetoxy congener 746, and thorectidaeolides B-E 747-750. Compounds 745-747 inhibited HIF-1 yet did not show any antiproliferative effects against the parent T47D or NDA-MB-231 breast cancer cell lines. ${ }^{734}$
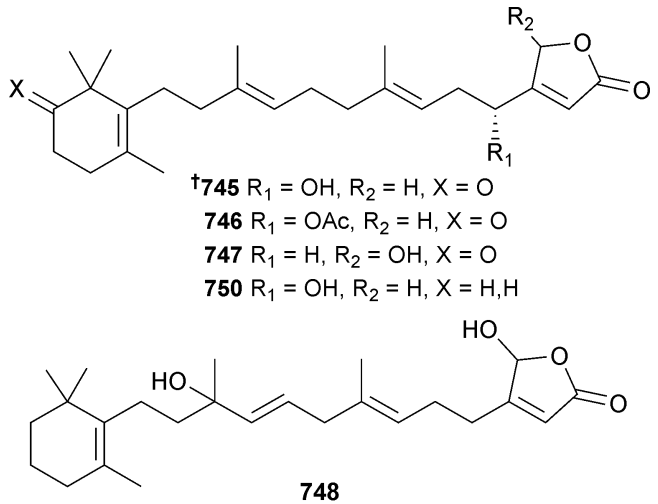<smiles>[Y9][C@H]1CCCC(C)(C)[C@@]1(O)CC/C(C)=C/CC/C(C)=C/CCC1=CC(=O)O[C@@H]1O</smiles>

A Canadian Phorbas sp. (Ansell Point, Howe Sound, British Columbia), provided four distinct sesterterpenes ansellone $B$ 751, phorbadione 752, secoepoxyansellone A 753 and alotaketal C 754. The latter compound showed similar levels of activation of cAMP signalling to the standard probe, forskolin. ${ }^{735}$

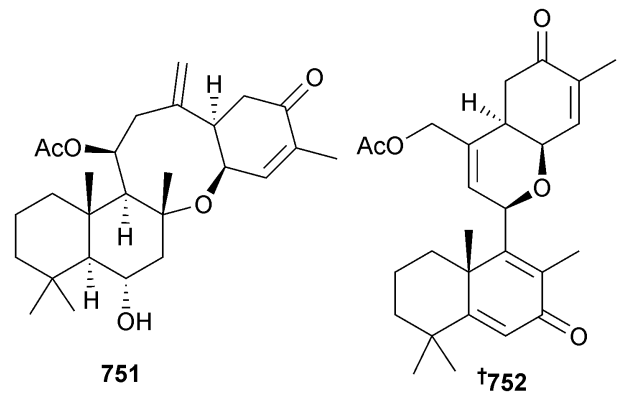

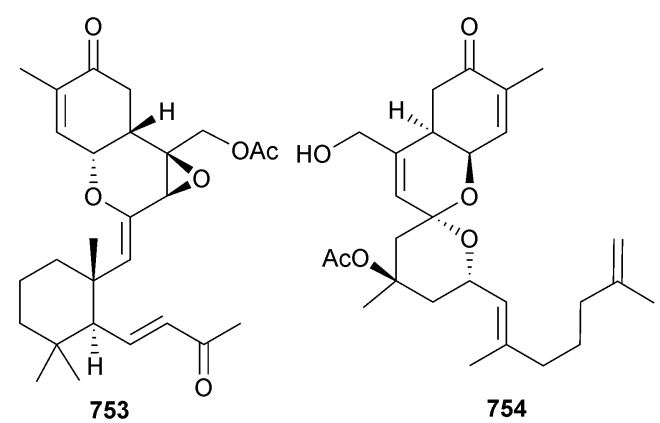

Five new sesterterpenes were reported from three different Psammocinia sp. (various locations in New South Wales and Victoria, Australia). Ircinianin lactam A 755, the sulfate derivative $\mathbf{7 5 6}$, oxoircinianin 757 , oxoircinianin lactam A 758 and ircinianin lactone A 759 were all assessed for GlyR modulating activity with 755 and 758 being selective and potent potentiators of $\alpha 3$-GlyR and $\alpha 1$-GlyR, respectively, having potential as leads for treatment of inflammatory pain, epilepsy and both breathing or movement disorders. ${ }^{736}$ 


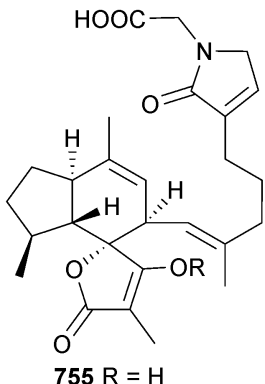

$756 \mathrm{R}=\mathrm{SO}_{3} \mathrm{H}$

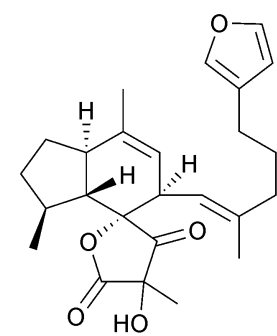

757

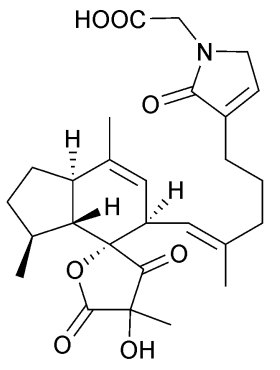

758

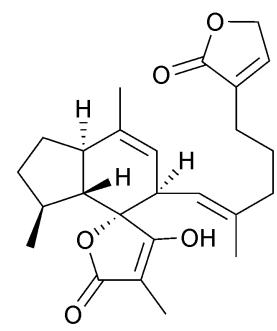

759
Phorbaketals D-K 760-767 and phorbin A 768 were reported from Monachora sp. (Gageo Is., Korea), with 764 and 765 weakly active against A498 cancer cells. The absolute configurations of all the new compounds were established by Mosher's method and comparison of CD-curves with known congeners. ${ }^{737}$

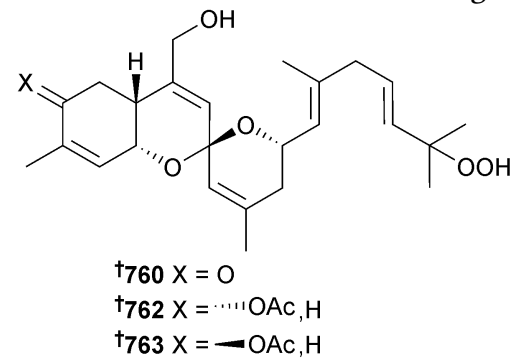<smiles>CC1=C[C@]2(C=C(CO)[C@H]3CC(=O)C(C)=C[C@@H]3O2)O[C@@H](/C=C(\C)CCC(=O)C(C)C)C1</smiles><smiles>[X]C1=C(C)C=C2O[C@@]3(C=C(C)C[C@@H](/C=C(\C)CCC=C(C)C)O3)C=C(C=O)[C@H]2C1</smiles>

$\dagger_{764} \mathrm{X}=\cdots \cdot \mathrm{OH}, \mathrm{H}$

${ }^{7} 765 \mathrm{x}=0$

${ }_{7766 \mathrm{X}}=\cdots \cdots \mathrm{OAC}, \mathrm{H}$

$t_{767} \mathrm{X}=-\mathrm{OAc}, \mathrm{H}$<smiles>C=C(C[C@H](O)/C=C(\C)CC/C=C(\C)CCC=C(C)C)[C@H]1CC(=O)C(C)=C[C@H]1O</smiles>

The scalarane sesterterpenoid hippospongide C $\mathbf{7 6 9}$ (Hippospongia sp., Tai-Tung, Taiwan) had moderate activity against four $\mathrm{HTCLs},{ }^{738}$ while 12-deacetoxy-23hydroxyscalardial 770, 12-deacetoxy-23-hydroxyhyrtiolide 771 and 12-O-acetyl-16-deacetoxy-23-acetoxyscalarafuran 772 from Psammocinia sp. (S. Korea) were inactive in all assays used. ${ }^{739}$

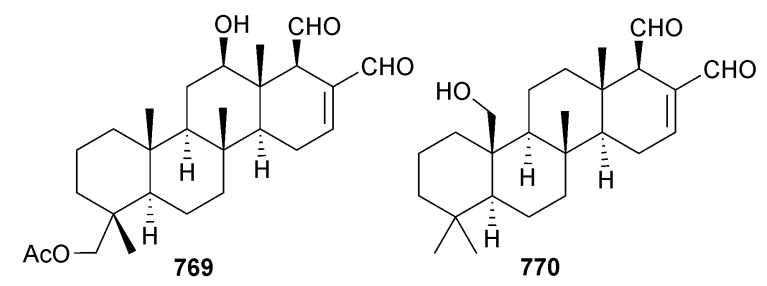

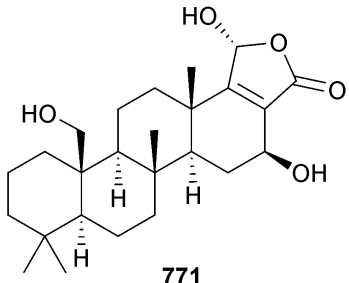<smiles>CC(=O)OC[C@]12CCCC(C)(C)[C@H]1CC[C@@H]1[C@@H]2C[C@H](OC(C)=O)[C@@]2(C)c3cocc3CC[C@H]12</smiles>

Four new scalaranes 773-776 were reported from Carteriospongia sp. (Nosy Be, Madagascar) with 773 and 774 being significantly more active than the other two congeners, indicating the importance of the aldehyde pharmacophore. ${ }^{740}$

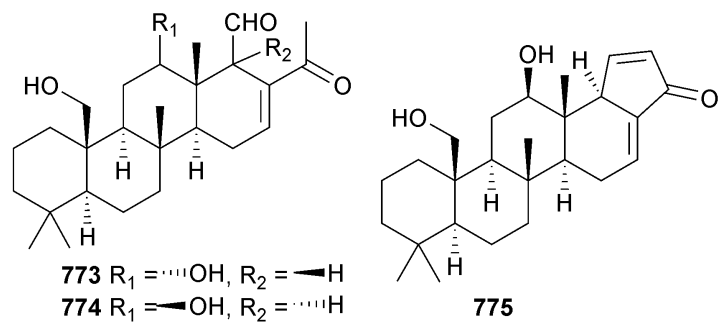<smiles>CC1(O)OC(=O)C2=C1CC[C@@H]1[C@@H]2CC[C@H]2C(C)(C)CCC[C@]21CO</smiles>

Cholic acid-3,7-diacetate 777 was isolated as an MNP for the first time from Siphonochalina fortis (Bahia Bustamante, Chubat, Argentina), ${ }^{741}$ while the $5 \alpha, 8 \alpha$-epidioxy sterol 3-acetylaxinysterol $\mathbf{7 7 8}$ was isolated from Axinyssa sp. (Pingtung, Taiwan). ${ }^{742}$ Haliclona crassiloba (Dongshan Is., Guangdong, China) yielded halicrasterols A-D 779782 with moderate activity against various microbial pathogens. ${ }^{73}$ 

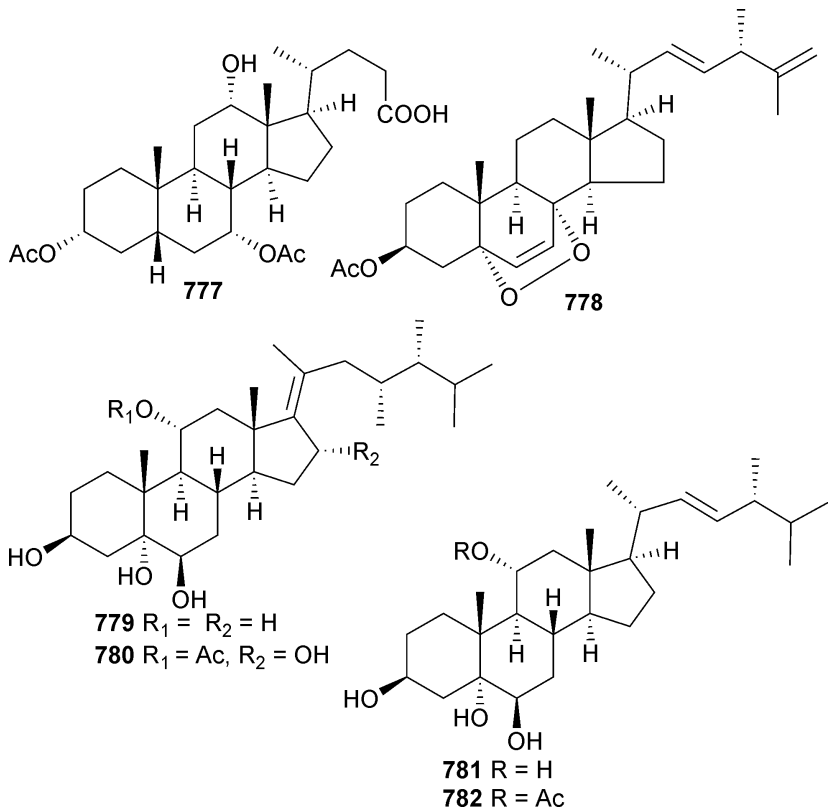

Cyclopropanated sterols aragusterol I 783, 21-O-octadecanoyl-xestokerol A 784 and 7 $\beta$-hydroxypetrosterol 785 were isolated from Xestospongia testudinaria (Truong Sa Archipelago, Khanh Hoa, Vietnam). Both $\mathbf{7 8 3}$ and $\mathbf{7 8 4}$ had antifouling potential (growth inhibition of Pseudoalteromonas and Polaribacter bacterial species) at similar levels of activity to the nowbanned antifoulant marine pollutant tributyltin oxide. ${ }^{74}$

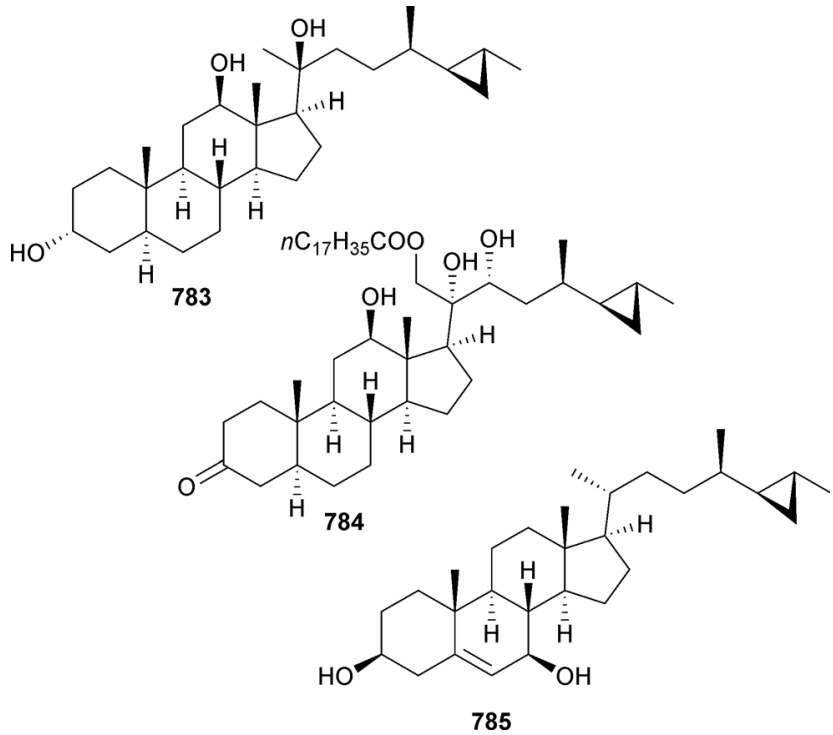

The structure of the unusual autophagy-modulating aminosterol clionamine B (Cliona celata $)^{745}$ was confirmed by synthesis, which also confirmed the assumed absolute configuration. ${ }^{746}$ A Corticium sp. (New Britain, Papua New Guinea) yielded the steroidal alkaloid plakinamine $\mathbf{M}$ 786, which displayed antitubercular activity. ${ }^{747}$ Stellettin $\mathrm{N} 787$ is an isomalabaricane triterpene acid from Stelletta sp. (Lingshui Bay, Hainan, China), which along with the other isolated congeners presented a chemotaxonomic link between three genera within the sponge order Astrophorida. ${ }^{748}$<smiles>COCC/C(=C\C[C@H](C)[C@H]1CC[C@H]2C3=CC[C@H]4C[C@H](N(C)C)[C@@H](O)C[C@]4(C)C3CC[C@]2(C)[C@H]1C)C(C)C</smiles><smiles>CC(=O)O[C@H]1CC[C@@]2(C)[C@@H]3CC(=O)/C(=C(C)\C=C\C=C(C)\C=C\C=C(\C)C(=O)O)[C@@]3(C)CC[C@H]2C1(C)C</smiles>

A dredged Penares sp. (Vietnam) provided six new lanosterol congeners 788-793. Only 793 showed any significant activity against HL-60 cells. A combination of CD and X-ray data allowed the assignment of absolute configuration for $\mathbf{7 8 9}$ and also permitted reassignment of the aglycone of eryloside U 794 from $7 \alpha, 8 \alpha$ to $7 \beta, 8 \beta .^{749,750}$

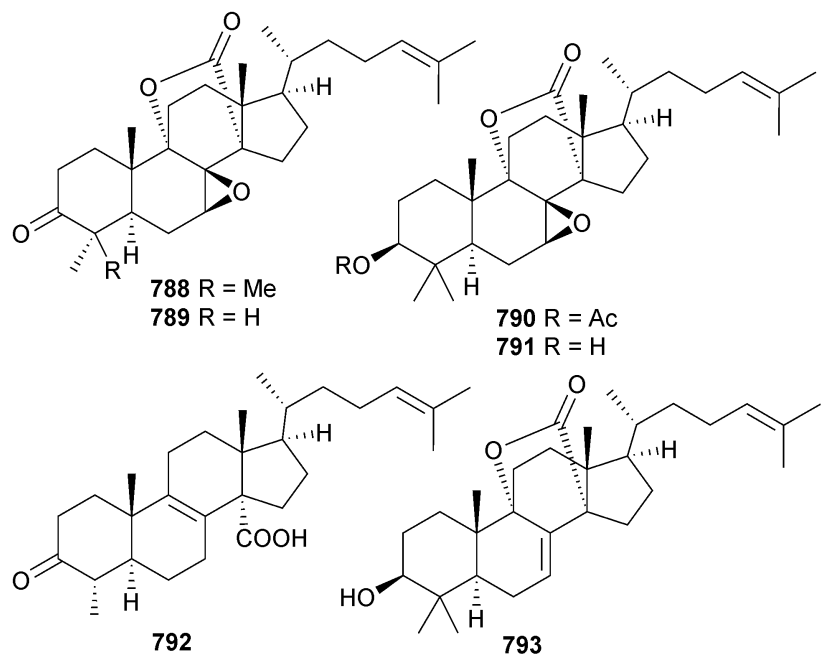

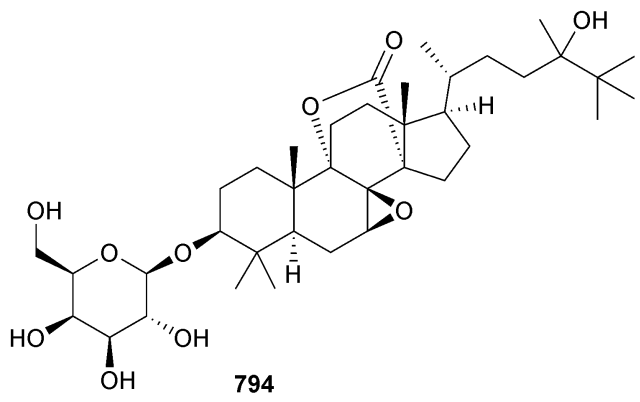

Finally, ulososide F 795, urabosides A 796 and B 797 are triterpene saponins from Ectyoplasia ferox (Caribbean Sea, Colombia), with 797 being the first reported compound with both C-4 methyls elevated to the carboxylic acid oxidation state. ${ }^{751}$ 


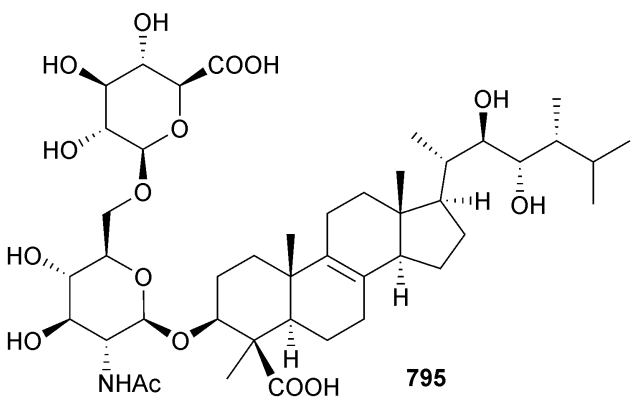

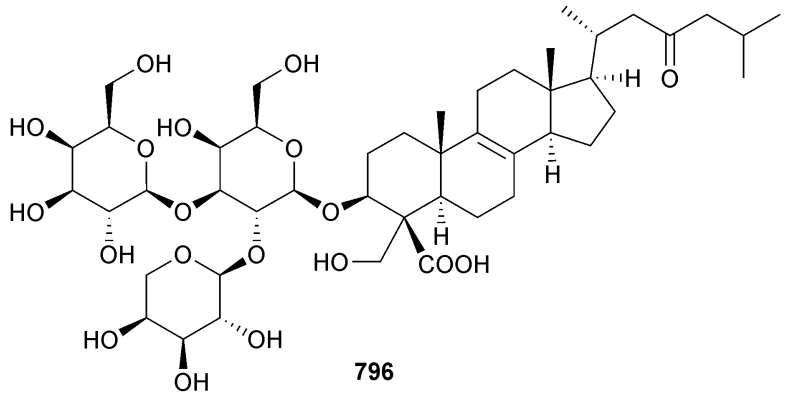<smiles>CC(C)CC(=O)C[C@H](C)[C@]1(C)CC[C@H]2C3=C(CC[C@]21C)[C@@]1(C)CC[C@H](O[C@@H]2O[C@H](C(=O)O)[C@@H](O)[C@H](O)[C@H]2O[C@H]2O[C@H](CO)[C@@H](O)[C@H](O)[C@H]2O)C(C)(C(=O)O)[C@]1(C)CC3</smiles>

\section{Cnidarians}

The number of new compounds reported from cnidarians in 2013 (281) has increased by 38\% over the average for each of the previous 10 years. In addition to an epidioxysterol (see later), three ceramides 798-800 were isolated from Sinularia candidula (Safaga, Egyptian Red Sea). ${ }^{752}$ Of the three ceramides, 798 was the most potent anti-H5N1 virus agent.<smiles>CC(C)=C1C(=O)N[C@H](CO)[C@@H](O)C1=CCC(C)(C)C</smiles>

798<smiles>CC(C)(C)CCC(=O)N[C@@H](CO)C(O)[C@H](O)C(C)(C)C</smiles><smiles>CC(C)(C)C[C@H](O)C(=O)N[C@H](CO)[C@@H](O)[C@H](O)C(C)(C)C(C)(C)C</smiles>

Pyrimidinedione $\mathbf{8 0 1}$ was reported from Verrucella umbraculum (Hainan Is., S. China Sea), ${ }^{753}$ while Mediterranean specimens of the scleractinian coral Astroides calycularis afforded the new aplysinopsin analogue 802. ${ }^{754}$ The highly strained cyclo-1,3-carbazole structure originally proposed for<smiles>CC(=O)c1cn(C)c2c(=O)n(C)c(=O)n(C)c12</smiles><smiles>CN=C1N(C)C(=O)C(=Cc2c[nH]c3cc(Br)ccc23)N1C</smiles><smiles>Cn1c(=O)c2cc3[nH]c4ccccc4c3cc2n(C)c1=O</smiles>

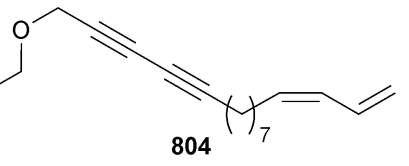

antipathine A (Antipathes dichotoma) ${ }^{755,756}$ has been corrected to the 2,3-carbazole $\mathbf{8 0 3}$ by total synthesis. ${ }^{757}$ Polyacetylenic montiporic acid D $\mathbf{8 0 4}$ (Montipora digitata, Sesoko Is., Okinawa, Japan) exhibited only mild antibacterial and antioxidant properties. ${ }^{758}$

New clovane-type sesquiterpenes rumphellclovane C-E 805$\mathbf{8 0 7}$ and four unnamed variants 808-811 were reported from the same collection of Rumphella antipathies (Southern Taiwan). ${ }^{759,760}$ The latter four compounds are reported as NPs for the first time. Clovane $\mathbf{8 0 8}$ inhibited superoxide generation and elastase release by stimulated human neutrophils.

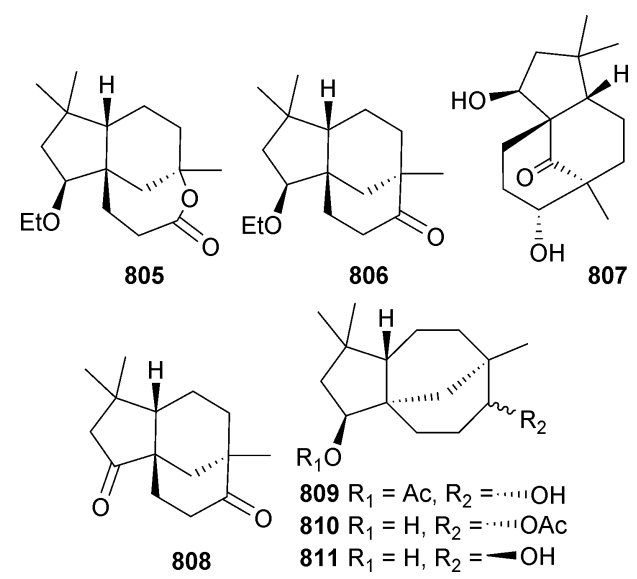

Sesquiterpenes capillosanane A-N 812-825 and seco-variants capillosanane O-R 826-829 were isolated from Sinularia capillosa (Sanya Bay, Hainan Province, China). ${ }^{761}$ Absolute configurations were established by combinations of chemical conversions, Mosher's method, CD analysis and biogenetic reasoning. Capillosanane A exhibited antifouling activity against $B$. amphitrite. 

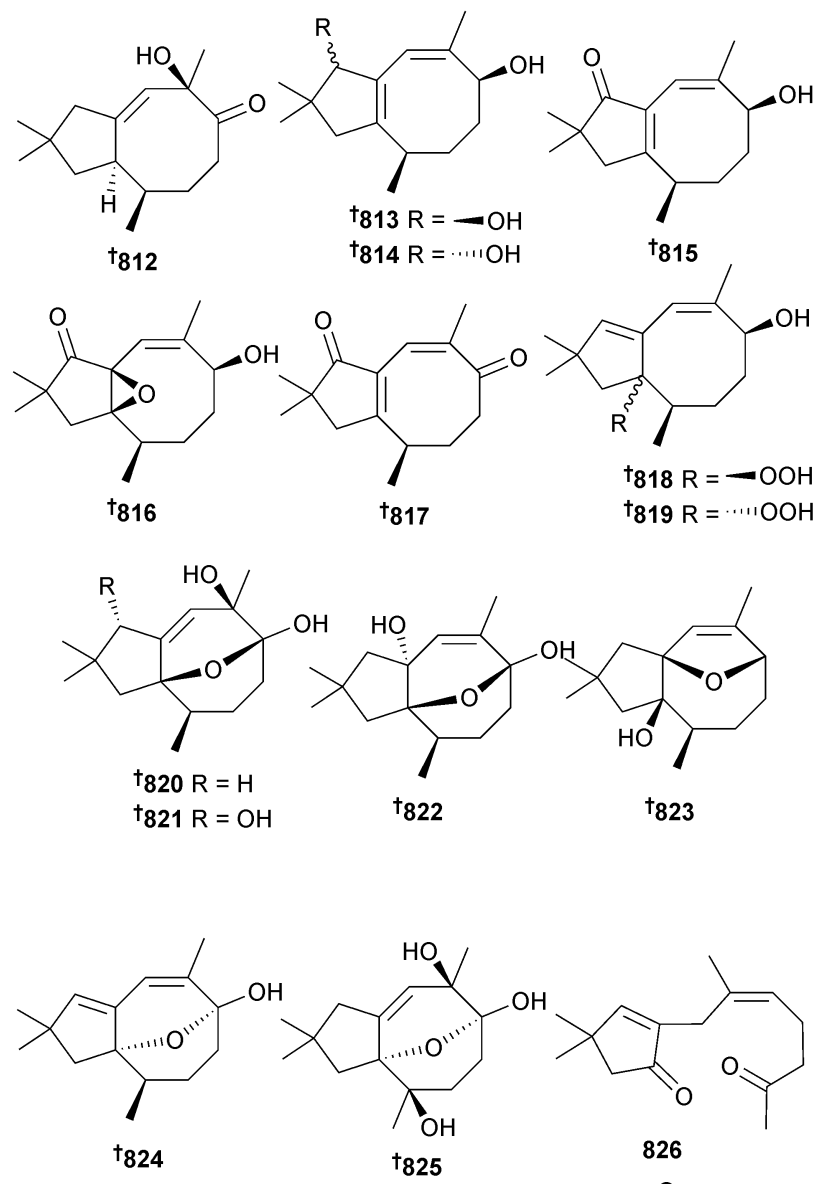

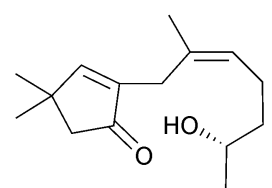

$\dagger_{827}$

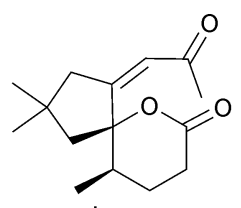

${ }^{+} 828$

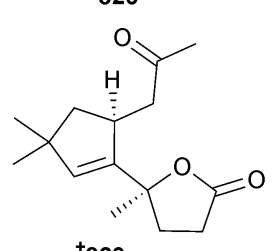

†829
Further examples of tricyclic sesquiterpenes were reported from Lemnalia philippinensis (philippinlins A 830 and B 831) collected at Lanyu, Taiwan ${ }^{762}$ and Paralemnalia thyrsoides (parathyrsoidins A-D 832-835) collected at Sansiantai, Taitong County also in Taiwan. ${ }^{763}$

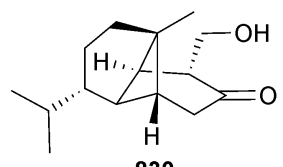

830

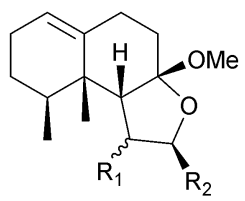

$832 \mathrm{R}_{1}=\cdots \cdots M e, \mathrm{R}_{2}=\mathrm{H}$

$833 \mathrm{R}_{1}=\cdots \cdot M \mathrm{Me}, \mathrm{R}_{2}=\mathrm{OMe}$

$834 R_{1}=-M e, R_{2}=$ OMe

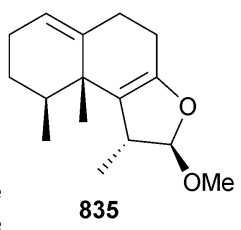

Spiro-butenolides sinularianins C 836 and D 837 and potential biosynthetically-related precursors sinularianins $\mathrm{E}$ 838 and F 839 were isolated as mild inhibitors of NF- $\kappa$ B activation from Sinularia sp. (Dongluo Is., Hainan Province, China). ${ }^{764}$<smiles>CO[C@]1(C)CC[C@H]2[C@@]3(C)O[C@H]3C[C@]3(C=C(C)C(=O)O3)[C@]21C</smiles><smiles>C=C/C(C)=C\CCC(C)(OC)C1C(=O)C=C(C)C1O</smiles>

Perezoperezone $\mathbf{8 4 0}$ and curcuperezone 841 (Pseudopterogorgia rigida, Caribbean Sea) are envisaged to arise, in the case of 840, from non-symmetrical dimerisation of known cometabolite perezone $\mathrm{e}^{765}$ and in the case of $\mathbf{8 4 1}$, through coupling of perezone and $\alpha$-curcumene. ${ }^{766}$ Flexibilisquinone $\mathbf{8 4 2}$ (cultured specimen of Sinularia flexibilis) ${ }^{767}$ was claimed to be the enantiomer of sarcophytonone (Sarcophyton crassocaule) ${ }^{768}$ based upon optical rotation data $\left(842[\alpha]_{\mathrm{D}}-19.6\right.$, sarcophytonone $\left.[\alpha]_{\mathrm{D}}+5.8\right)$.

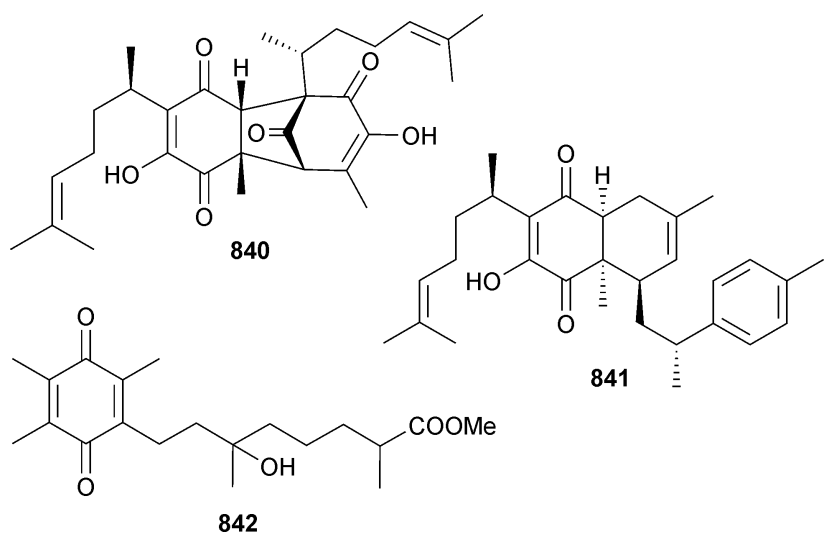

Of two new $\mathrm{C}_{19}$-norditerpenes 12-hydroxy-scabrolide A 843 and 13-epi-scabrolide C $\mathbf{8 4 4}$ (Sinularia maxima, Nha Trang Bay, Vietnam) the latter was identified as an inhibitor of the production of IL-6 and IL-12 by LPS-stimulated bone marrowderived dendritic cells. ${ }^{769}$ In addition to five sterols (see later), $\delta$ lactone $\mathbf{8 4 5}$ was isolated from Scleronephthya gracillimum (Green Is., Taiwan) as a modest inhibitor of expression of iNOS and COX-2 in stimulated macrophages. ${ }^{770}$ The weakly cytotoxic spatane diterpene leptoclalin A $\mathbf{8 4 6}$ was reported from cultured specimens of Sinularia leptoclados. ${ }^{771}$

As with most years, a diverse array of cembranoid diterpenes were reported from soft corals in 2013. Arbolides A 847 and B 848, epoxy-alcohols with the former also containing a hydroperoxide functional group, were obtained from Sinularia arborea (southern Taiwan). ${ }^{772}$ Similarly functionalised cembranes flexibilins A 849 and B 850 in addition to $\varepsilon$-lactone- 
$\mathrm{HO}$,

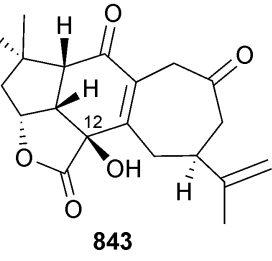<smiles>C=C(C)[C@H](CC(=O)C[C@H]1OC(=O)C2=C[C@H](CC(=O)C[C@H]2OC)C[C@](C)(C(C)(C)C)O1)C(C)=O</smiles><smiles>CC(=O)OC(C)(C)CCCC(C)CCCC(C)CC1CC(C)=CC(=O)O1</smiles>

845

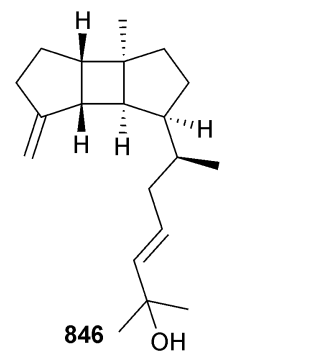

containing flexibilin C $\mathbf{8 5 1}$ were reported from S. flexibilis also collected from southern Taiwan. ${ }^{773}$

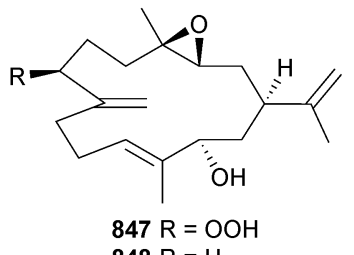
$848 \mathrm{R}=\mathrm{H}$<smiles>C=C(C(=O)O)[C@H](CC[C@@](C)(O)C(=O)CCC1=CCCC(C)(C)OC1)CC(=O)O</smiles><smiles>C=C1C(=O)O[C@@]2(C)CC[C@@H]1C[C@@H](O)[C@](C)(O)CC/C=C\CCC2=O</smiles>

The absolute configuration of co-metabolite (-)-sandensolide (Dendronephthya sp.) ${ }^{774}$ was confirmed by X-ray crystal analysis. Of the $\delta$-lactones 11-acetylsinuflexolide 852 and dihydro analogue 853 (S. flexibilis, Pingtung county, Taiwan), only the former exhibited cytotoxicity as anticipated for an exomethylene-conjugated lactone. ${ }^{775}$ Sinularia flexibilis (southern Taiwan) was also the source of flexibilin D 854 and of known
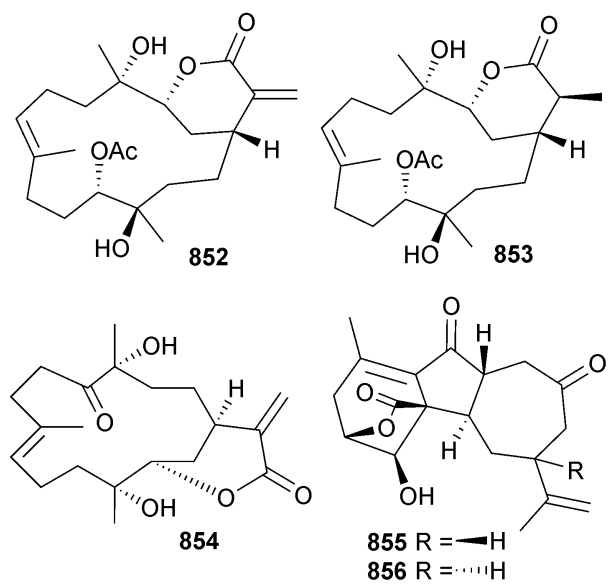

congener 5-dehydrosinulariolide ${ }^{776}$ the absolute configuration of which was determined by X-ray crystal analysis. ${ }^{77}$ The same publication and a second one $\mathrm{e}^{778}$ also described sinulanorcembranolide A 855 and the 1-epi-diastereomer $\mathbf{8 5 6}$ from the same collection of $S$. gaweli (Sansiantai, Taitung county, Taiwan).

While cembranoid cugibberosene A 857 (S. gibberosa, Pingtung, Taiwan $)^{779}$ was found to be devoid of cytotoxic or antibacterial properties, one of sinulariols $\mathrm{T}-\mathrm{Z}_{5}$ 858-869 (S. rigida, Sanya Bay, Hainan Is., S. China Sea), specifically 864, exhibited effects against the model fouling organisms $B$. amphitrite and $B$. neritina. $^{780}$
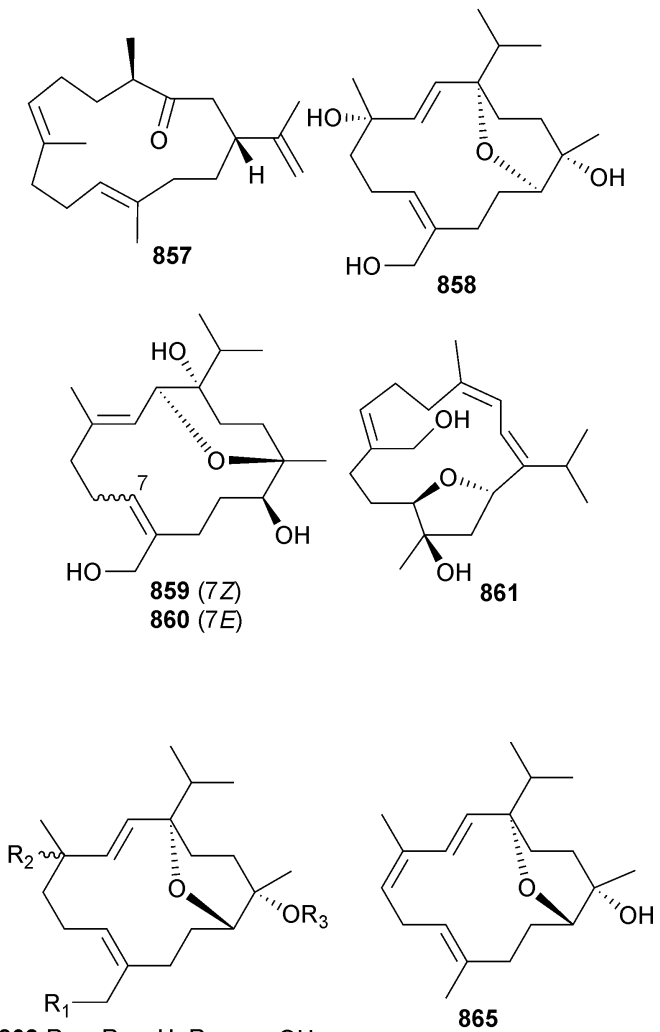

$862 \mathrm{R}_{1}=\mathrm{R}_{3}=\mathrm{H}, \mathrm{R}_{2}=\cdots \cdot \cdots \mathrm{OH}$
$863 \mathrm{R}_{1}=\mathrm{OH}, \mathrm{R}_{2}=\cdots \cdot \mathrm{OH}, \mathrm{R}_{3}=\mathrm{Et}$

$864 \mathrm{R}_{1}=\mathrm{R}_{3}=\mathrm{H}, \mathrm{R}_{2}=-\mathrm{OH}$
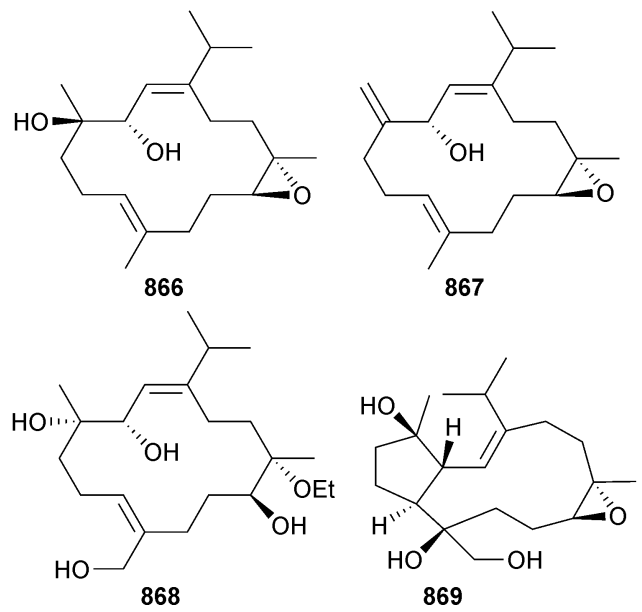

The casbane family of cembranoid diterpenes is characterised by the presence of a fused dimethyl-cyclopropyl ring. Of 
new examples sinularcasbanes A-F 870-875 (Sinularia sp., Ximao Is., Hainan, S. China Sea), 871 and $\mathbf{8 7 4}$ exhibited modest ability to inhibit NO production by stimulated macrophages. ${ }^{781}$
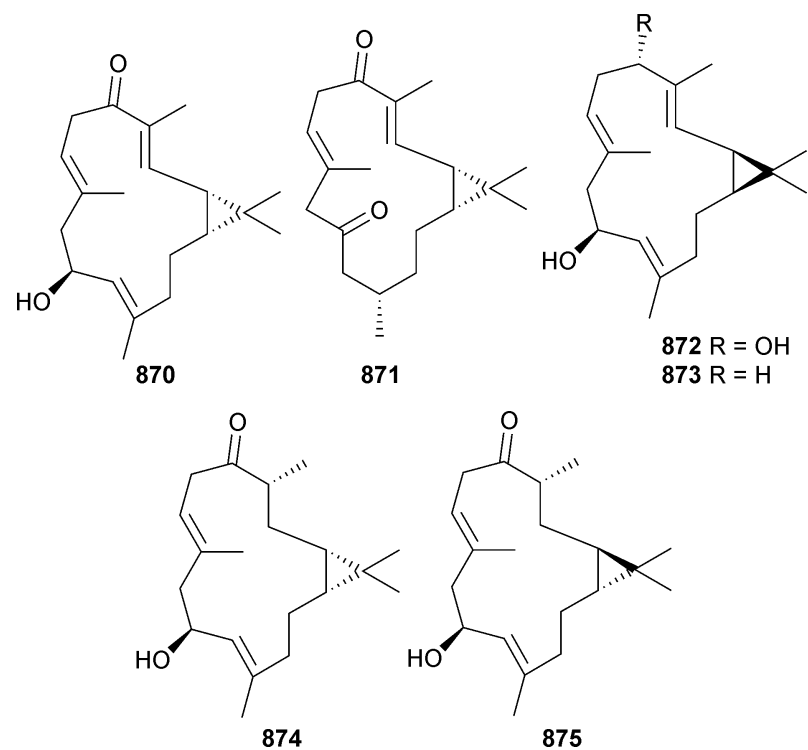

Two separate collections of Lobophytum sp. yielded epoxycembranes 876-880 (Ximao Is., Sanya Bay, Hainan, China) ${ }^{\mathbf{7 8 2}}$ and $\alpha$-methylene- $\gamma$-lactones 881-883 (Sanya Bay, Hainan, China). ${ }^{783}$ This is the first report $\mathbf{8 8 0}$ as an NP. Epoxycembrane 878 was a modest inhibitor of NO production by stimulated macrophages, while $\mathbf{8 8 1 - 8 8 3}$ were each found to be moderately cytotoxic towards a range of human and murine tumour cell lines.
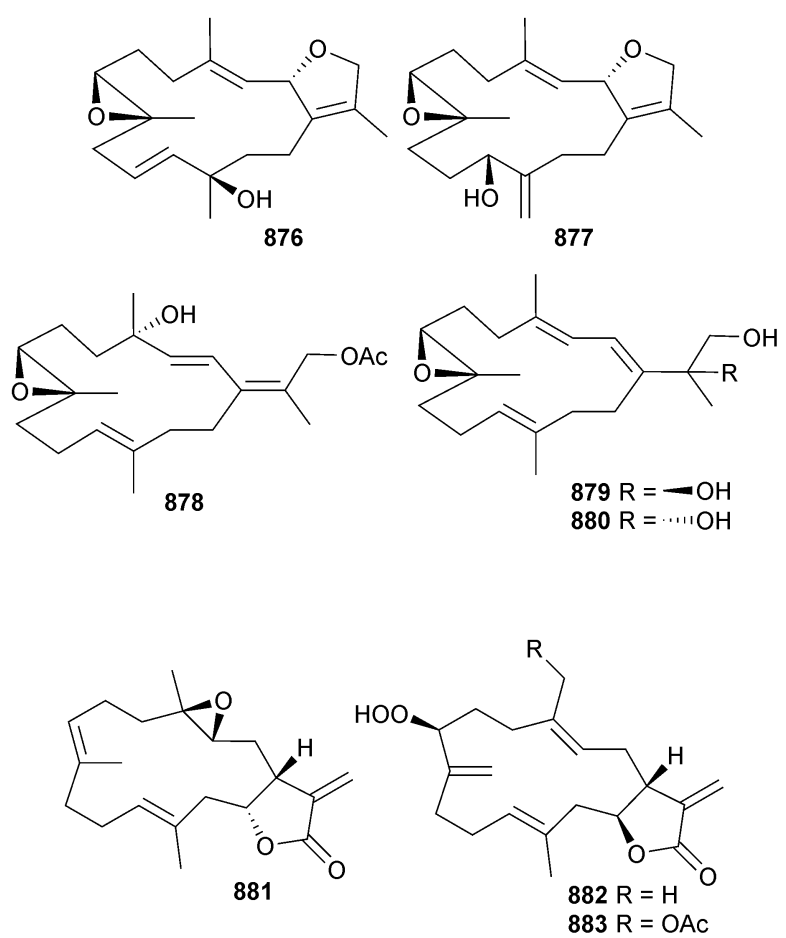

Hydroxycembrane sarcophytol W $\mathbf{8 8 4}$ was isolated from Sarcophyton sp. (Xuwen coral reef area, Guangdong Province,
China) - absolute configuration was assigned based upon that determined for a previously reported (Sinularia ovispiculata ${ }^{784}$ co-metabolite. ${ }^{785}$ Sarcophyton ehrenbergi (San-hsian-tai, Taitong county, Taiwan) was the source of diterpenes ehrenbergol C 885 and acetylehrenberoxide B $\mathbf{8 8 6}$ which both exhibited mild cytotoxicity (P388) but $\mathbf{8 8 6}$ was more potent as an anti-human cytomegalovirus agent. ${ }^{786}$
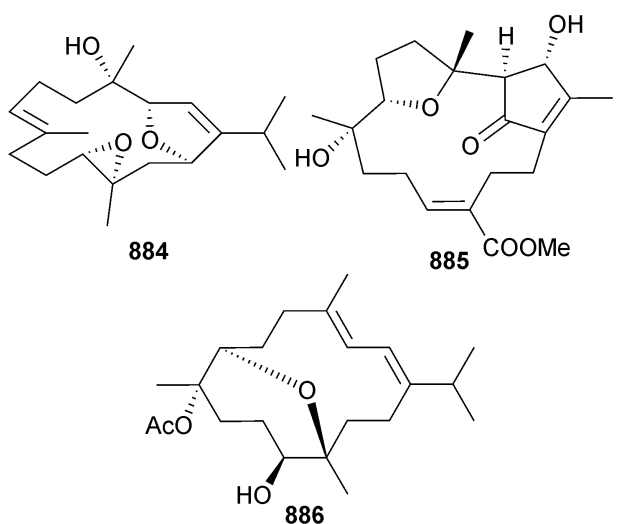

Of the sarcophyolides B-E 887-890 isolated from $S$. elegans (Xidao Is., Hainan, China), the structures and absolute configurations of $\mathbf{8 8 7}$ and $\mathbf{8 8 8}$ were established by X-ray crystal studies. ${ }^{787}$
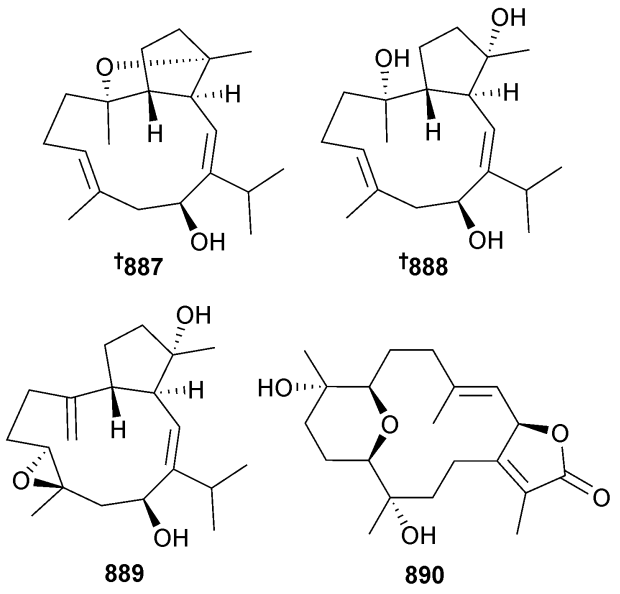

Sarcophyolide B exhibited modest cytotoxicity. Red Sea collections of $S$. glaucum afforded 891-893 with 893 being reported as an NP for the first time. ${ }^{788}$ While 891 and 892 were
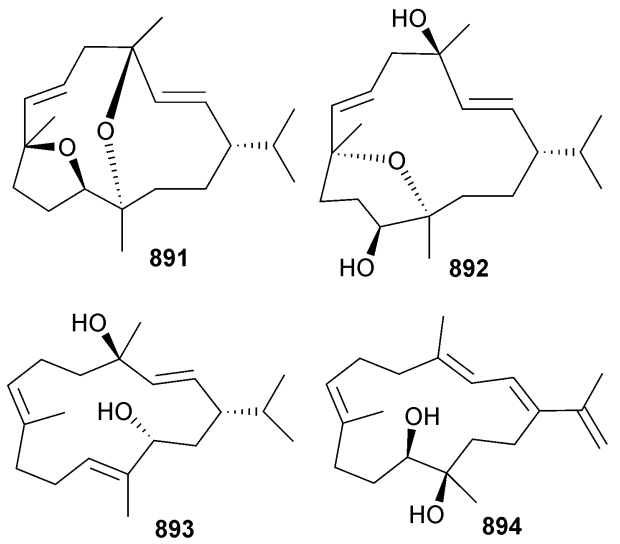
equally cytotoxic towards a melanoma and a mouse kidney cell line, $\mathbf{8 9 2}$ exhibited selectivity towards the tumour cell line. Due to the presence of the conjugated triene functionality in sarglaucol 894 (S. glaucum, Sanya Bay, Hainan, China), it can be considered a diene-precursor to biscembranoids typically isolated from soft corals of the genus Sarcophyton. ${ }^{789}$

The same collection of $S$. elegans that afforded sarcophyolides B-E (see earlier) also yielded new examples of an isobiscembranoid and biscembranoids, the sarcophytolides G-L 895-900. ${ }^{790}$ These structures represent minor modifications to previously reported biscembranoids, being a dihydroxylated analogue of lobophytone $\mathrm{F}^{791}$ a positional isomer of lobophytone $\mathrm{S}^{792}$ a methoxylated analogue of lobophytone $\mathrm{H}^{793}$ a dehydrated analogue of methyl tortuoate $\mathrm{A},{ }^{794}$ an oxidised analogue of lobophytone $\mathrm{U}^{795}$ and a 31-epimer also of lobophytone $\mathrm{U}$, respectively.
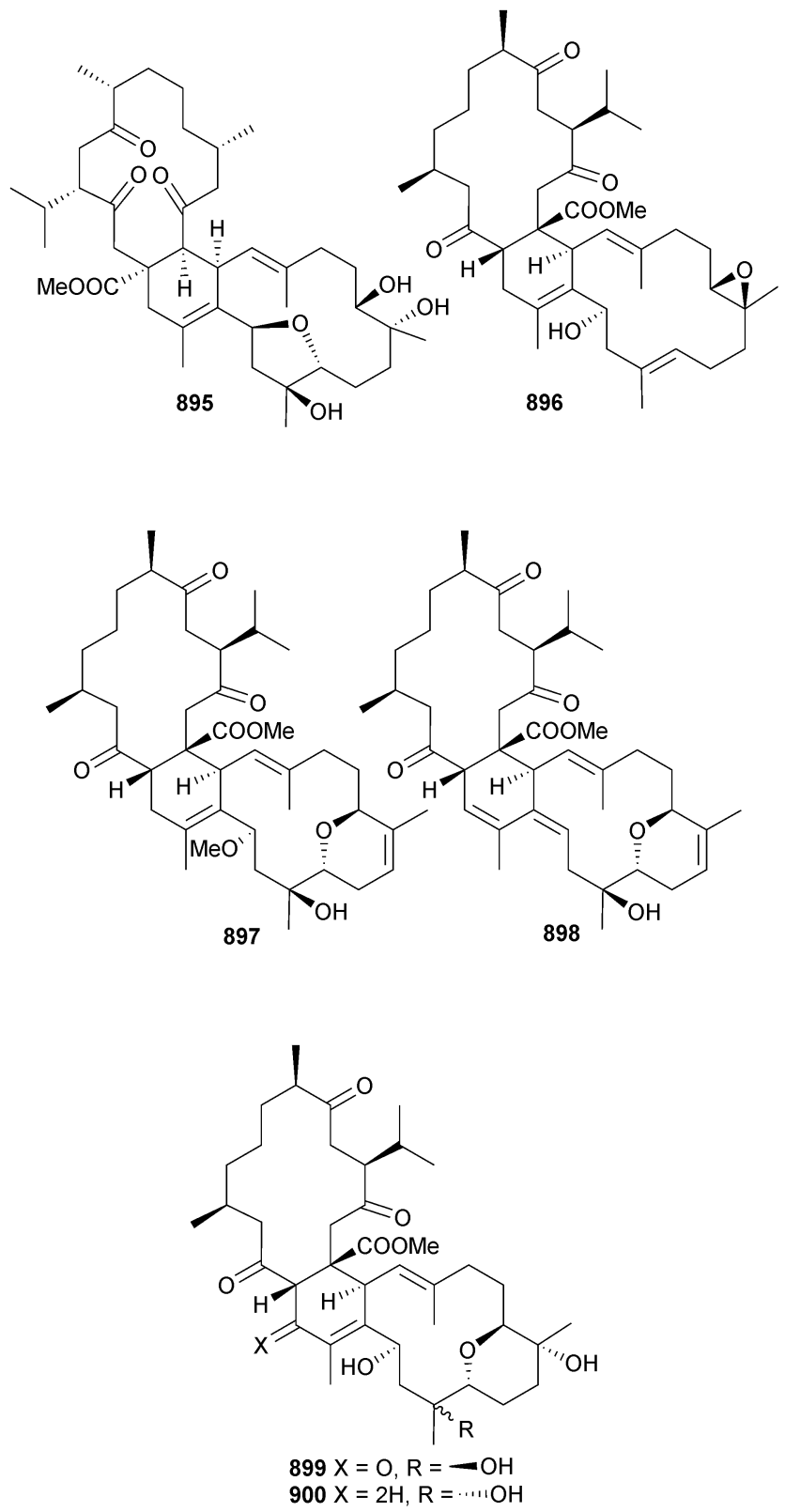

Further investigation of S. latum (Sanya, Hainan Province), that had previously afforded, amongst other metabolites, biscembranoids bislatumlides $\mathrm{A}$ and $\mathrm{B},{ }^{796}$ has now yielded four more congeners bislatumlides C-F 901-904. ${ }^{797}$ Detailed examination of the absolute configuration of 901 and 903 by time dependent DFT (TDDFT) calculations of ECD data necessitated reassignment of the C-21 configuration of bislatumlides A 905 and B 906.

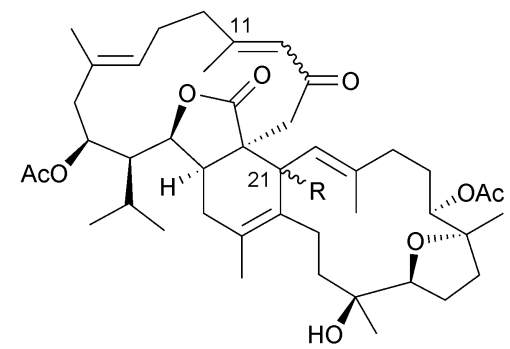

t901 (11E), R = ‥1H

† 902 (11Z), $\mathrm{R}=\cdots \cdot \cdots \mathrm{H}$

$\operatorname{tg} 03(11 E), \mathrm{R}=-\mathrm{H}$

t904 (11Z), $\mathrm{R}=-\mathrm{H}$

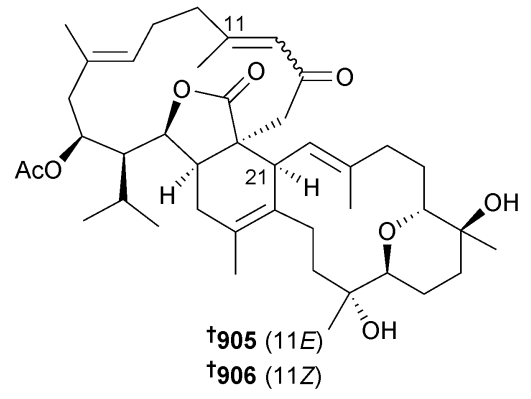

Re-isolation of methyl tortuoate $\mathrm{D}^{798}$ (Sarcophyton tortuosum, Yalong Bay, Hainan, China) has led to its structural revision to $\mathbf{9 0 7}$, with absolute configuration assigned by comparison of ECD data with that of co-metabolite ximaolide A. ${ }^{799}$ The study also concluded that the structure previously attributed to lobophytone K (Lobophytum pauciflorum ${ }^{\mathbf{8 0 0}}$ should also be corrected to 907.

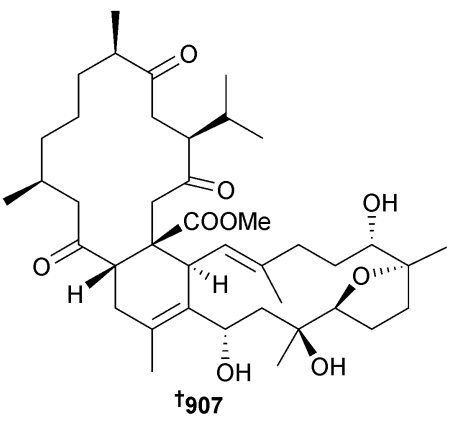

A Red Sea (Hurghada) collection of $S$. trocheliophorum provided trochelioids A 908 and B 909 and 16-oxosarcophytonin E 910, the latter reported for the first time as an NP. ${ }^{801}$ 


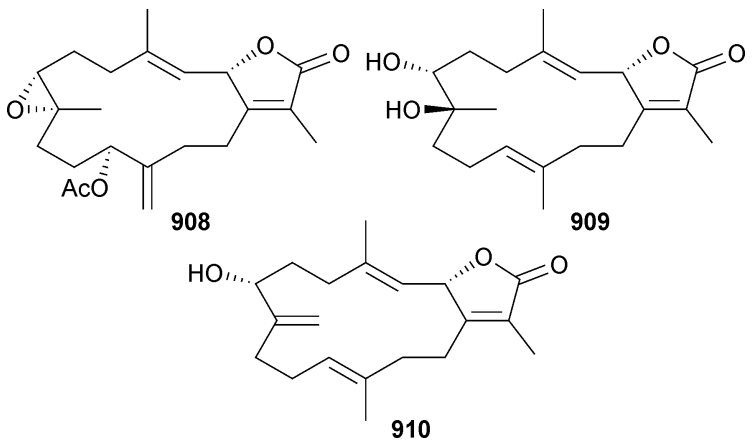

In three separate accounts, sixteen new cembranoids were reported from $S$. trocheliophorum (Yalong Bay, Hainan, China). Of methyl sarcotroates A 911 and B 912, and sarcophytonolides M-R 913-918, only hydroperoxide-containing 912 and sarcophytonolide N 914 were found to inhibit human PTP1B. ${ }^{\mathbf{8 0 2 , 8 0 3}}$
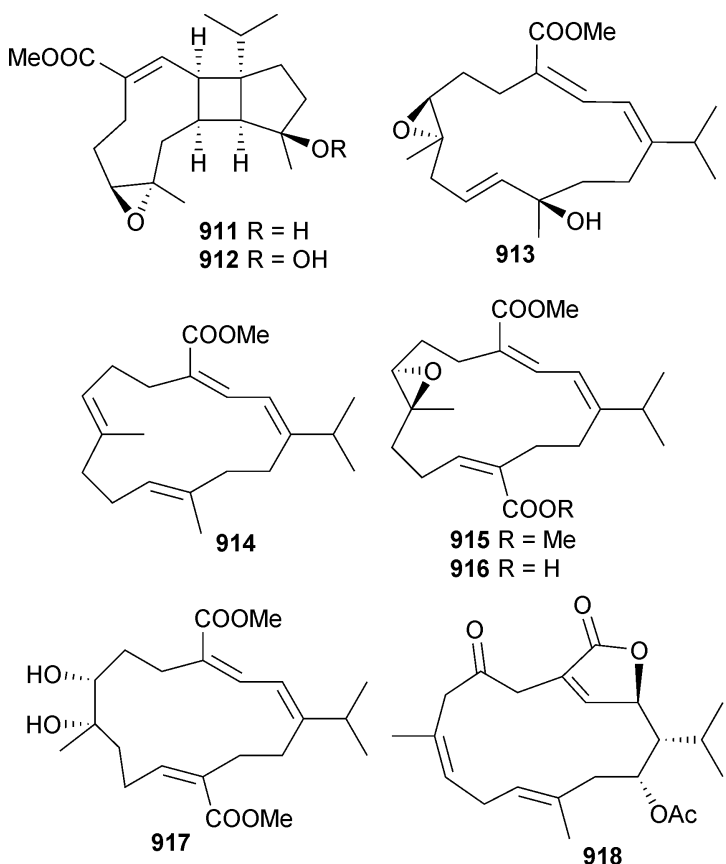

Also isolated were $\varepsilon$-lactone-containing cembranolides sartrolide A-G 919-925 and dimer bissartrolide 926. ${ }^{\mathbf{8 0 4}}$ The unusual $(1 E, 3 Z)$-diene configuration of 925 was supported by
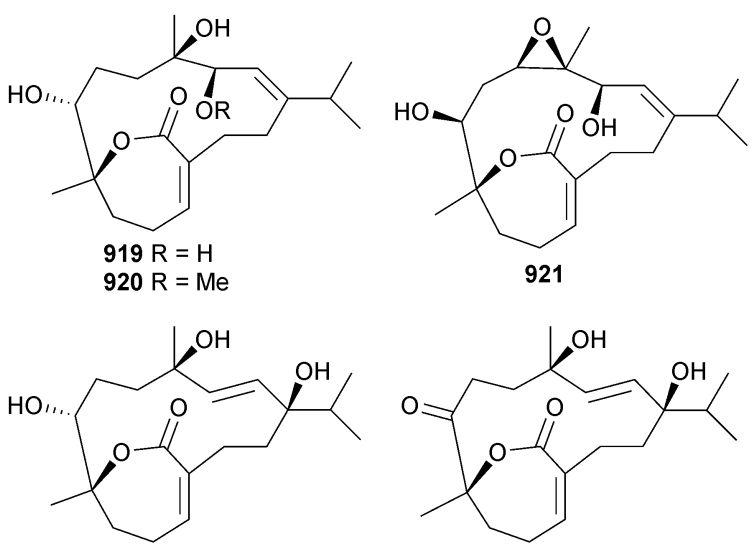

922
$\mathrm{X}$-ray crystal analysis of isomeric co-metabolites sarcrassin $\mathrm{D}^{\mathbf{8 0 5}}$ and emblide ${ }^{806}$ Bissartrolide represents a dimer of sartrolide A and a free carboxylic acid analogue of sarcophytonolide B. ${ }^{\mathbf{8 0 7}}$
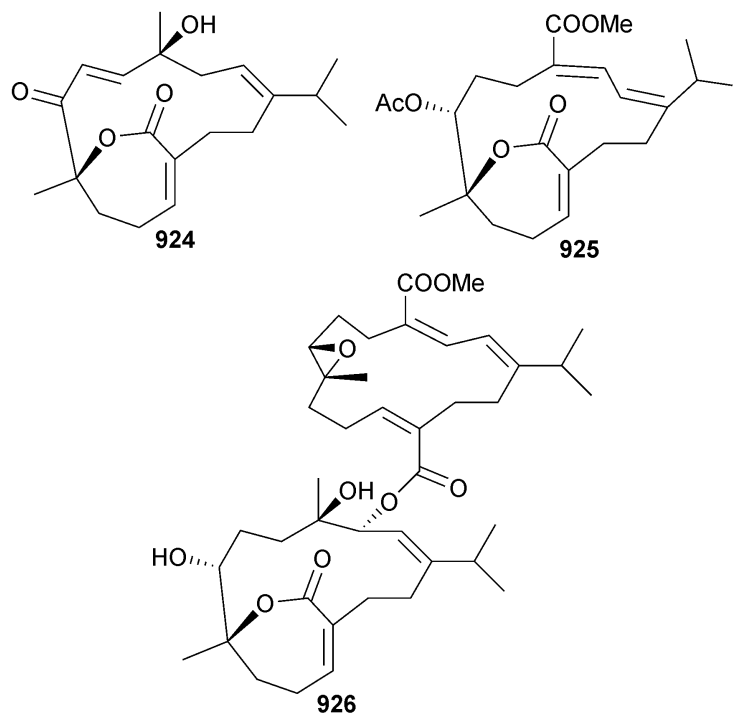

A total of 34 new briarane diterpenes were reported from two collections of Dichotella gemmacea: gemmacolides AA-AR 927944 (S. China Sea) ${ }^{808}$ and dichotellides F-U 945-960 (Meishan Is., Hainan, China). ${ }^{809}$ The absolute configurations of 927-944 were assigned by comparison of ECD data with those of dichotellide $\mathrm{T} \mathbf{9 4 1}$, the absolute configuration of which was established by X-ray crystal analysis. Modest to moderate levels of cytotoxicity were observed for the gemmacolides while the dichotellides were all poorly cytotoxic with some examples exhibiting strong antifouling activity.

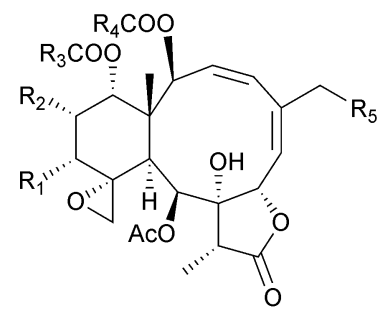

t927 $\mathrm{R}_{1}=\mathrm{R}_{2}=\mathrm{OAc}, \mathrm{R}_{3}=\mathrm{Me}, \mathrm{R}_{4}=\mathrm{CH}_{2} \mathrm{OH}, \mathrm{R}_{5}=\mathrm{OMe}$

t928 $\mathrm{R}_{1}=\mathrm{OCO} / \mathrm{Bu}, \mathrm{R}_{2}=\mathrm{OAC}, \mathrm{R}_{3}=\mathrm{Me}, \mathrm{R}_{4}=\mathrm{CH}_{2} \mathrm{OH}, \mathrm{R}_{5}=\mathrm{OMe}$

t929 $\mathrm{R}_{1}=$ OCOiBu, $\mathrm{R}_{2}=\mathrm{OAc}, \mathrm{R}_{3}=\mathrm{R}_{4}=\mathrm{Me}, \mathrm{R}_{5}=\mathrm{OMe}$

${ }^{9} 930 \mathrm{R}_{1}=\mathrm{OCO} i \mathrm{Bu}, \mathrm{R}_{2}=\mathrm{OAc}, \mathrm{R}_{3}=i \mathrm{Bu}, \mathrm{R}_{4}=\mathrm{Me}, \mathrm{R}_{5}=\mathrm{OMe}$

${ }^{1} 931 \mathrm{R}_{1}=\mathrm{R}_{2}=\mathrm{H}, \mathrm{R}_{3}=\mathrm{Me}, \mathrm{R}_{4}=\mathrm{CH}_{2} \mathrm{OCO} i \mathrm{Bu}, \mathrm{R}_{5}=\mathrm{OMe}$

t932 $R_{1}=R_{5}=$ OCOiBu, $R_{2}=$ OAc, $R_{3}=R_{4}=M e$

t933 $R_{1}=R_{2}=O A c, R_{3}=R_{4}=M e, R_{5}=$ OCOiBu

t934 $\mathrm{R}_{1}=\mathrm{R}_{5}=$ OCOiBu, $\mathrm{R}_{2}=\mathrm{OAC}, \mathrm{R}_{3}=\mathrm{Me}, \mathrm{R}_{4}=\mathrm{CH}_{2} \mathrm{OCO} i \mathrm{Bu}$

t935 $\mathrm{R}_{1}=\mathrm{OH}, \mathrm{R}_{2}=\mathrm{OAC}, \mathrm{R}_{3}=\mathrm{Me}, \mathrm{R}_{4}=\mathrm{CH}_{2} \mathrm{OCO} i \mathrm{Bu}, \mathrm{R}_{5}=\mathrm{OCO} i \mathrm{Bu}$

t936 $\mathrm{R}_{1}=$ OCOiBu, $\mathrm{R}_{2}=\mathrm{OAC}, \mathrm{R}_{3}=\mathrm{Me}, \mathrm{R}_{4}=\mathrm{CH}_{2} \mathrm{OCO} i \mathrm{Bu}, \mathrm{R}_{5}=\mathrm{Cl}$

t937 $\mathrm{R}_{1}=\mathrm{OAc}, \mathrm{R}_{2}=\mathrm{OCO} i \mathrm{Bu}, \mathrm{R}_{3}=\mathrm{Me}, \mathrm{R}_{4}=\mathrm{CH}_{2} \mathrm{OH}, \mathrm{R}_{5}=\mathrm{OMe}$

${ }^{9} 938 \mathrm{R}_{1}=\mathrm{OAc}, \mathrm{R}_{2}=\mathrm{OCO} i \mathrm{Bu}, \mathrm{R}_{3}=\mathrm{Me}, \mathrm{R}_{4}=\mathrm{CH}_{2} \mathrm{OCO} i \mathrm{Bu}, \mathrm{R}_{5}=\mathrm{OMe}$

t939 $\mathrm{R}_{1}=\mathrm{OAc}, \mathrm{R}_{2}=$ OCOiBu, $\mathrm{R}_{3}=\mathrm{Me}, \mathrm{R}_{4}=\mathrm{CH}_{2} \mathrm{OCO} i \mathrm{Bu}, \mathrm{R}_{5}=\mathrm{Cl}$

t940 $\mathrm{R}_{1}=\mathrm{OAC}, \mathrm{R}_{2}=$ OCOiBu, $\mathrm{R}_{3}=\mathrm{Me}, \mathrm{R}_{4}=\mathrm{CH}_{2} \mathrm{OH}, \mathrm{R}_{5}=\mathrm{Cl}$

t941 $\mathrm{R}_{1}=\mathrm{R}_{2}=\mathrm{R}_{5}=$ OCOiBu, $\mathrm{R}_{3}=\mathrm{Me}, \mathrm{R}_{4}=\mathrm{CH}_{2} \mathrm{OH}$

t942 $\mathrm{R}_{1}=\mathrm{R}_{2}=\mathrm{OAc}, \mathrm{R}_{3}=i \mathrm{Bu}, \mathrm{R}_{4}=\mathrm{CH}_{2} \mathrm{OH}, \mathrm{R}_{5}=\mathrm{Cl}$

t943 $R_{1}=R_{2}=O A c, R_{3}=i B u, R_{4}=M e, R_{5}=O H$

t944 $R_{1}=R_{2}=R_{5}=O A c, R_{3}=i B u, R_{4}=M e$ 


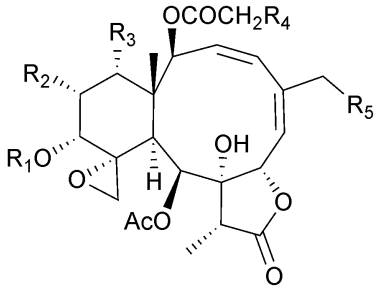

$945 R_{1}=A c, R_{2}=R_{3}=O A c, R_{4}=$ OCOiBu, $R_{5}=O M e$ $946 R_{1}=A c, R_{2}=R_{4}=$ OCOiBu, $R_{3}=$ OAc, $R_{5}=$ OMe $947 \mathrm{R}_{1}=\mathrm{CO} i \mathrm{Bu}, \mathrm{R}_{2}=\mathrm{R}_{3}=$ OAC, $\mathrm{R}_{4}=$ OCOiBu, $\mathrm{R}_{5}=\mathrm{Cl}$ $948 R_{1}=A c, R_{2}=R_{3}=O A c, R_{4}=R_{5}=$ OCOiBu

$949 R_{1}=A c, R_{2}=R_{3}=R_{5}=O A c, R_{4}=H$

$950 \mathrm{R}_{1}=\mathrm{Ac}, \mathrm{R}_{2}=\mathrm{R}_{5}=$ OCOiBu, $\mathrm{R}_{3}=\mathrm{OAc}, \mathrm{R}_{4}=\mathrm{H}$

$951 R_{1}=A c, R_{2}=O A c, R_{3}=R_{5}=O C O i B u, R_{4}=H$

$952 \mathrm{R}_{1}=$ COiBu, $\mathrm{R}_{2}=$ OCOiBu, $\mathrm{R}_{3}=\mathrm{OAc}, \mathrm{R}_{4}=\mathrm{H}, \mathrm{R}_{5}=\mathrm{OMe}$

$953 \mathrm{R}_{1}=\mathrm{Ac}, \mathrm{R}_{2}=\mathrm{R}_{4}=\mathrm{H}, \mathrm{R}_{3}=$ OCOiBu, $\mathrm{R}_{5}=\mathrm{OMe}$

$954 \mathrm{R}_{1}=\mathrm{CO} B \mathrm{Bu}, \mathrm{R}_{2}=\mathrm{R}_{4}=\mathrm{H}, \mathrm{R}_{3}=\mathrm{OAc}, \mathrm{R}_{5}=\mathrm{OMe}$

$955 R_{1}=A c, R_{2}=R_{4}=H, R_{3}=R_{5}=$ OCOiBu

$956 \mathrm{R}_{1}=\mathrm{R}_{4}=\mathrm{H}, \mathrm{R}_{2}=$ OCOiBu, $\mathrm{R}_{3}=\mathrm{OH}, \mathrm{R}_{5}=\mathrm{Cl}$

$957 \mathrm{R}_{1}=\mathrm{R}_{4}=\mathrm{H}, \mathrm{R}_{2}=\mathrm{R}_{5}=$ OCOiBu, $\mathrm{R}_{3}=\mathrm{OH}$

$958 \mathrm{R}_{1}=\mathrm{R}_{4}=\mathrm{H}, \mathrm{R}_{2}=\mathrm{OAc}, \mathrm{R}_{3}=\mathrm{OH}, \mathrm{R}_{5}=\mathrm{OCO} i \mathrm{Bu}$

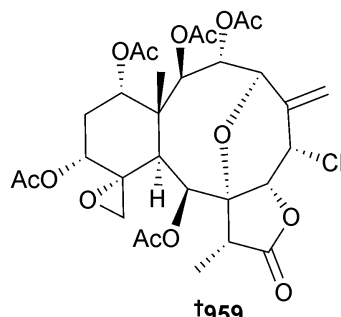

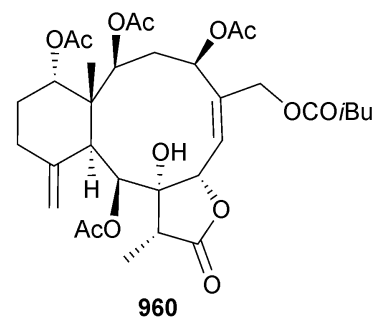

Junceella fragilis (Tai-Tong county, Taiwan) was the source of four more briaranes, frajunolide P-S 961-964. ${ }^{\mathbf{8 1 0}}$ Hirsutalins I-M 965-969 are eunicellin diterpenes isolated from Cladiella hirsuta (Sianglu Islet, Penghu Is., Taiwan). ${ }^{\mathbf{8 1 1}}$ Moderate inhibition of NO production by stimulated macrophages for 967 was shown.

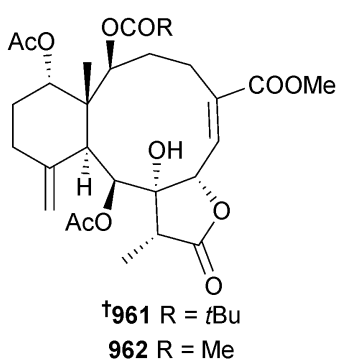

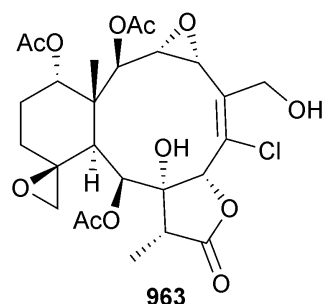

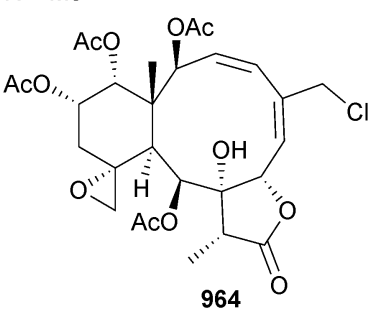

In addition to a number of related metabolites, C. krempfi (Weizhou Is., S. China Sea) yielded oxylitophynol 970, litophynol A acetate 971, litophynol C 972 and krempfenin 973. ${ }^{\mathbf{8 1 2}}$

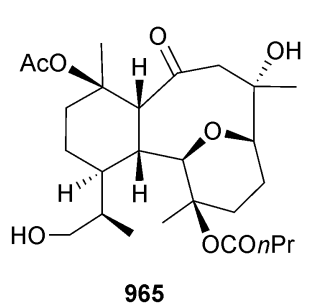

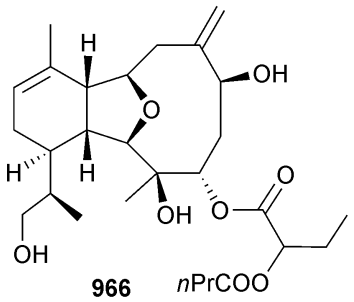

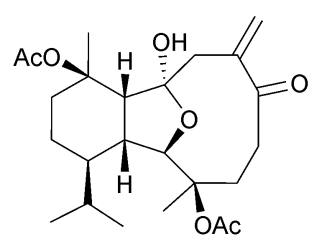

967<smiles></smiles>

968

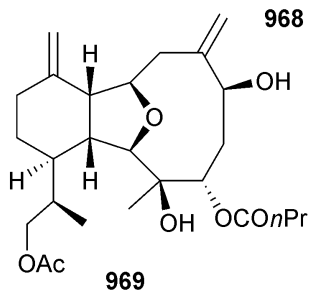

Reduction of 970 gave a product identical to known co-metabolite litophynol A, ${ }^{\mathbf{8 1 3}}$ subsequent acetylation of which afforded a product identical to $\mathbf{9 7 1}$.

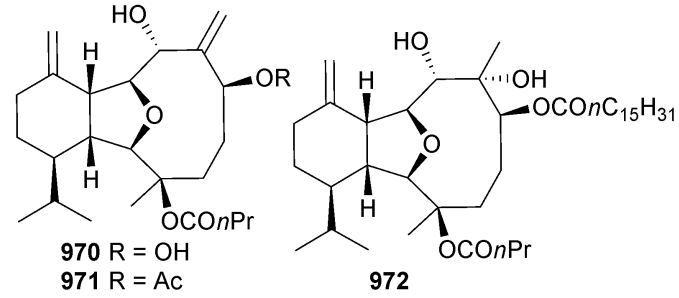

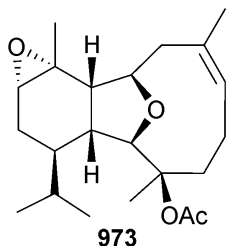

Also isolated from C. krempfi (Penghu Is., Taiwan) were krempfielins E-M 974-982. ${ }^{\mathbf{8 1 4}, 815}$ Although 974-977 were inactive in antitumour and anti-inflammatory assays, structurally related co-metabolites did exhibit activity.

Of four new eunicellins reported from Cladiella sp. (Penghu Is., Taiwan), cladieunicellins I 983, K 984, and L 985 and litophynin I diacetate $\mathbf{9 8 6}$, the latter has been previously reported ${ }^{\mathbf{8 1 6}}$ as a semi-synthetic derivative. ${ }^{\mathbf{8 1 7 , 8 1 8}}$ Cladieunicellins I and $\mathrm{L}$ exhibited moderate activity towards an HTCL.

An unusual member of the klymollins I-S 987-997 (Klyxum molle, Penghu Is., Taiwan) is the phenylacetate-bearing klymollin M 991. ${ }^{819}$ This same metabolite was the most potent of the set, exhibiting cytotoxicity and the ability to inhibit superoxide generation and elastase release from stimulated human neutrophils. 


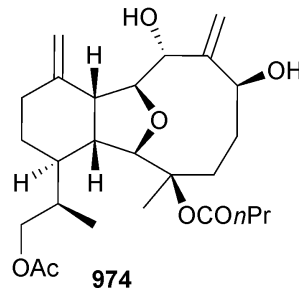

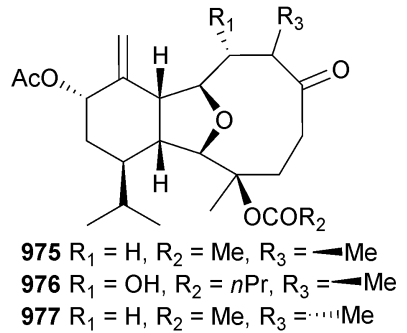

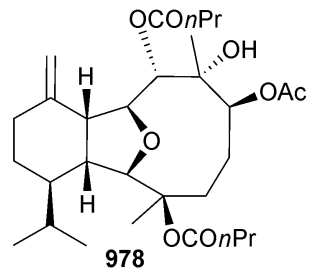

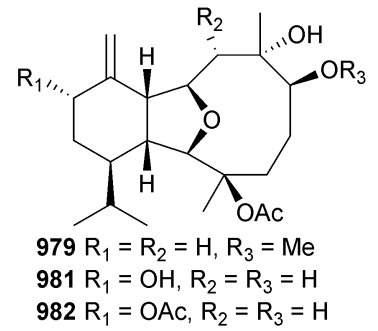

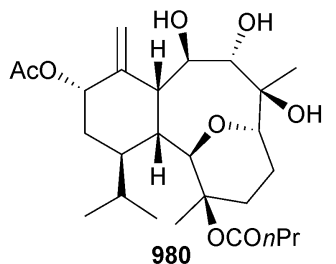

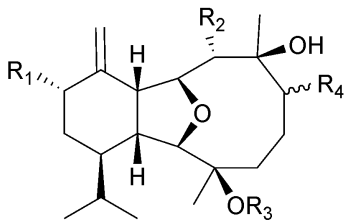

$983 \mathrm{R}_{1}=\mathrm{H}, \mathrm{R}_{2}=\mathrm{OAc}, \mathrm{R}_{3}=\mathrm{CO} n \mathrm{Pr}, \mathrm{R}_{4}=\cdots \cdot \mathrm{OH}$ $985 R_{1}=O A c, R_{2}=O H, R_{3}=A c, R_{4}=-O A c$ $986 \mathrm{R}_{1}=\mathrm{OAc}, \mathrm{R}_{2}=\mathrm{H}, \mathrm{R}_{3}=\mathrm{COnPr}, \mathrm{R}_{4}=-\mathrm{OAC}$

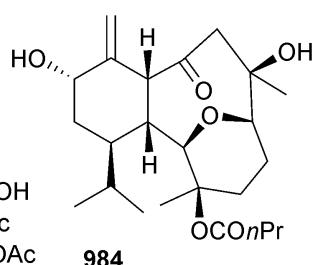

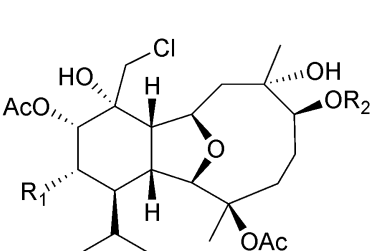

$987 R_{1}=O A C, R_{2}=A C$ $988 R_{1}=O A C, R_{2}=H$ $989 \mathrm{R}_{1}=\mathrm{H}, \mathrm{R}_{2}=A C$ $990 R_{1}=R_{2}=H$

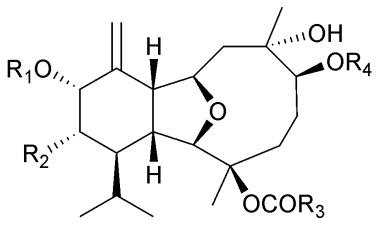

$991 \mathrm{R}_{1}=\mathrm{R}_{2}=\mathrm{H}, \mathrm{R}_{3}=n \mathrm{Pr}, \mathrm{R}_{4}=\mathrm{COCH}_{2} \mathrm{Ph}$ $992 \mathrm{R}_{1}=\mathrm{H}, \mathrm{R}_{2}=\mathrm{OAc}, \mathrm{R}_{3}=n \mathrm{Pr}, \mathrm{R}_{4}=\mathrm{Ac}$ $993 \mathrm{R}_{1}=\mathrm{Ac}, \mathrm{R}_{2}=\mathrm{OH}, \mathrm{R}_{3}=n \mathrm{Pr}, \mathrm{R}_{4}=\mathrm{Ac}$ $994 \mathrm{R}_{1}=\mathrm{R}_{4}=\mathrm{H}, \mathrm{R}_{2}=\mathrm{OAc}, \mathrm{R}_{3}=n \mathrm{Pr}$ $995 R_{1}=R_{2}=H, R_{3}=M e, R_{4}=A c$ $996 R_{1}=R_{2}=R_{4}=H, R_{3}=M e$

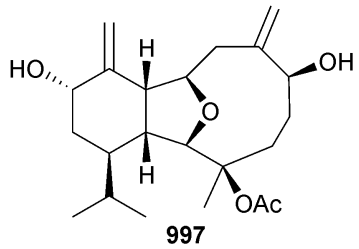

$998 \mathrm{R}=\mathrm{AC}$ $999 \mathrm{R}=\mathrm{Me}$

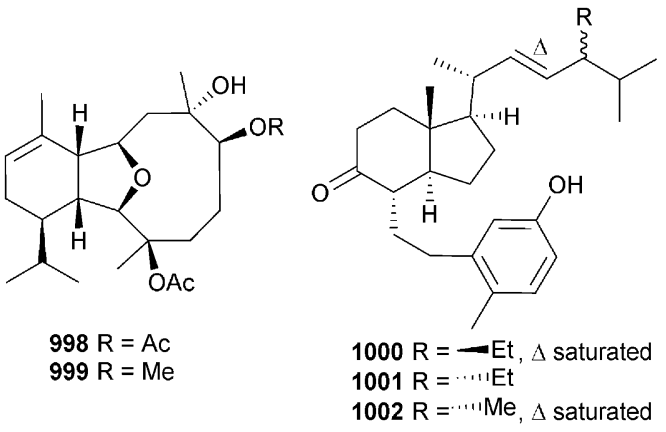

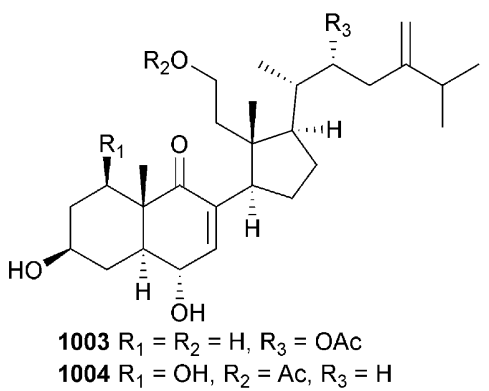

$1004 \mathrm{R}_{1}=\mathrm{OH}, \mathrm{R}_{2}=A c, \mathrm{R}_{3}=\mathrm{H}$

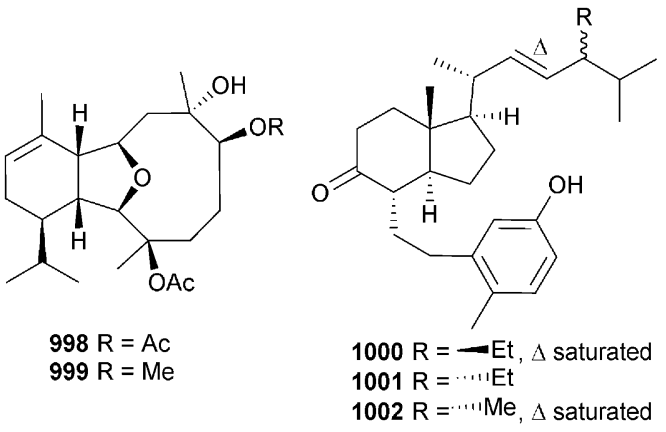

In addition to two eunicellin diterpenes sibogin A 998 and B 999, investigation of the NPs from Muricella sibogae (Weizhou Is., China) also afforded three new seco-sterols sibogol A-C 1000-1002. ${ }^{820}$ A further two seco-sterols 1003 and 1004 were reported from Sinularia nanolobata (Xiao-Liuqiu Is., Pingtung county, Taiwan) ${ }^{\mathbf{2 2 1}}$ and eleven, subergorgol A-J 1005-1014 and 1015, from Subergorgia suberosa (Meishan coast, S. China Sea). ${ }^{\mathbf{8 2 2}}$ The latter unnamed seco-sterol is reported as an NP for the first time. Subergorgols C 1007 and D 1008, and F 1010 and G 1011 were isolated as their respective epimeric pairs but with unassigned configuration. The latter two were considered artefacts of isolation. While 1013 was found to be the most cytotoxic (moderate), 1015 was devoid of activity.

As well as a modestly bioactive $\delta$-lactone noted earlier, an extract of Scleronephthya gracillimum (Green Is., Taiwan) also afforded pregnanes sclerosteroid J-N 1016-1020. ${ }^{70}$ Sclerosteroids $\mathrm{K}$ and $\mathrm{M}$ were more active than the other metabolites at inhibiting expression of iNOS and COX-2 in stimulated macrophages. Pregnane 1021 (Carijoa sp., Weizou Is., S. China Sea) exhibited potent antimicrobial properties. ${ }^{823}$

In addition to a number of known congeners, three new mildly cytotoxic polyhydroxylated steroids 1022-1024 were isolated from Sarcophyton sp. (Weizhou Is., S. China Sea). ${ }^{\mathbf{8 2 4}}$ The possible artefactual origin of methylether 1022 was noted.

A collection of Anthogorgia caerulea from the same general location afforded caerulsteroid A 1025. ${ }^{\mathbf{8 2 5}}$ Three studies of Red Sea (Hurghada) cnidarians afforded steroids - hurgadacin 1026 was isolated from Sinularia polydactyla, ${ }^{\mathbf{8 2 6}}$ gorgostane 1027 (= 11-acetyl-sarcoaldosterol $\mathrm{A}^{\mathbf{8 2 7}}$ ) from Heteroxenia ghardaqensis ${ }^{\mathbf{8 2 8}}$ and zahramycins A 1028 and B $\mathbf{1 0 2 9}$ from Sarcophyton 


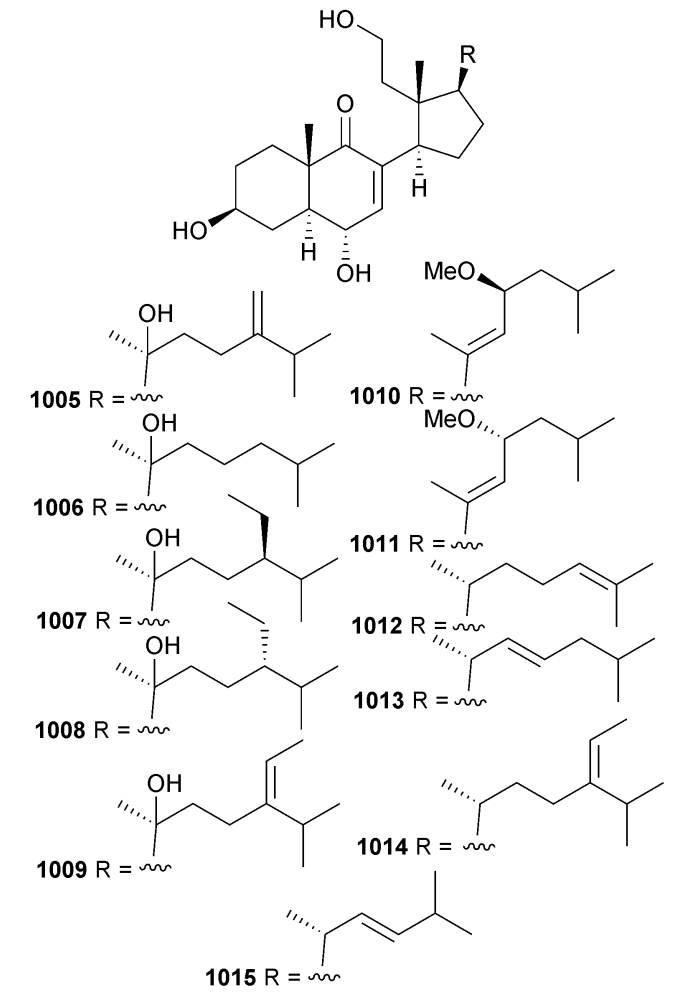<smiles>C=C[C@H]1CC[C@H]2[C@@H]3CCC4=CC(=O)CC[C@]4(COC(C)=CC4CCCCC4)[C@H]3CC[C@@]21C</smiles><smiles>C=C[C@H]1CC[C@H]2[C@@H]3CC[C@H]4C[C@@H](OC(C)=O)C[C@H](O)[C@]4(C)C3CC[C@@]21C</smiles>

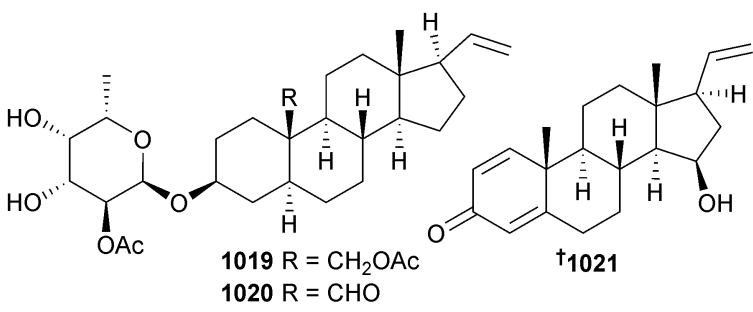

trocheliophorum. ${ }^{\mathbf{8 2}}$ Zahramycin B exhibited modest antibacterial activity.

Fourteen new sterols 1030-1043, plus one 1044 reported as an NP for the first time, were isolated as mildly cytotoxic constituents of Menella kanisa (coast of Beihai, Guangxi province, China). ${ }^{830}$

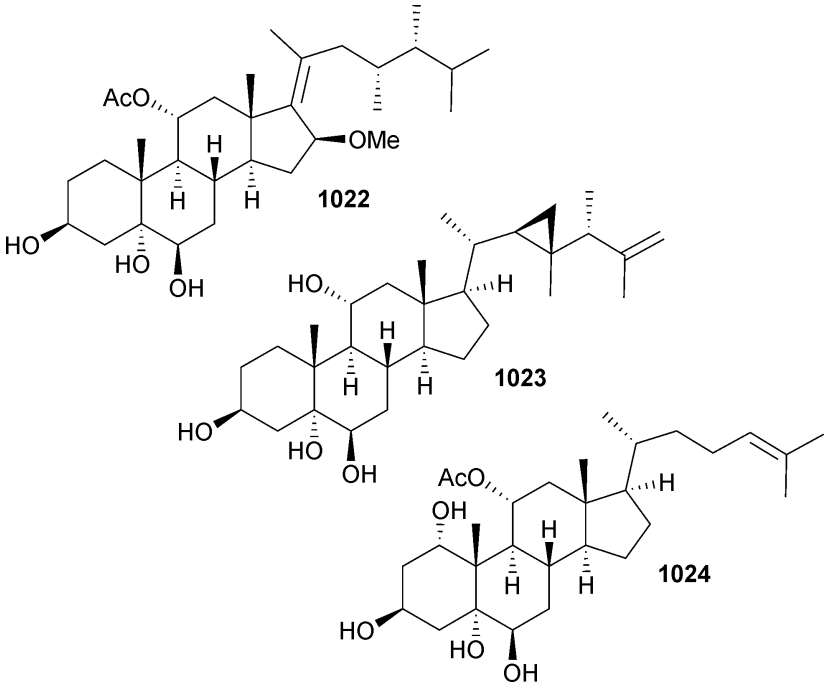

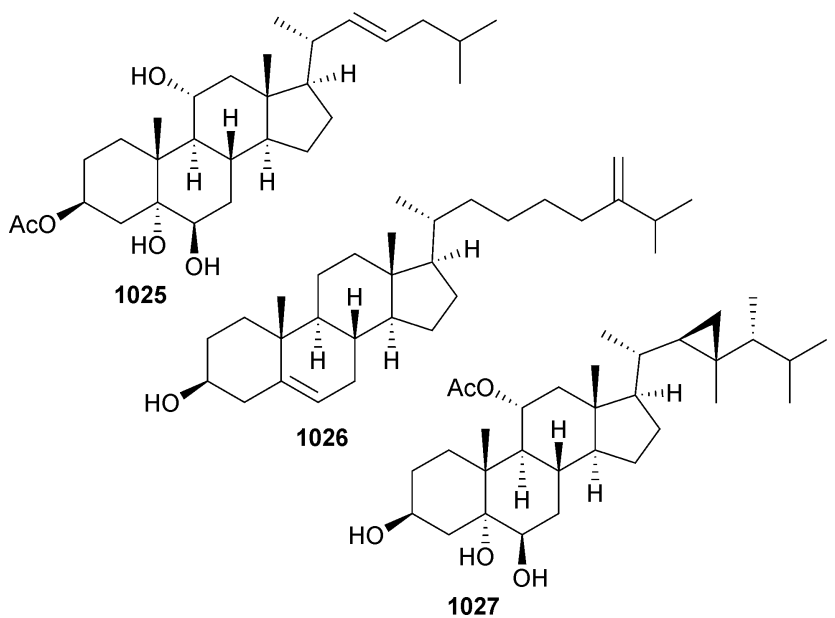<smiles>CC(C)[C@H](CO)CC[C@H](C)[C@]1(C)CC[C@H]2C3=C[C@H](O)[C@H]4C[C@@H](O)CC[C@]4(C)[C@H]3C(=O)C[C@]21C</smiles>

In addition to a number of co-metabolites, muriflasteroids A-C 1045-1047 were identified as weak to moderate cytotoxins (Muriceopsis flavida, Beihai, Guangxi province, China). ${ }^{\mathbf{8 3 1}}$ Sterols containing 24(28)-unsaturation were reported from Sinularia depressa (1048 and 1049, Lingshui Bay, Hainan, S. China Sea $)^{\mathbf{8 3 2}}$ 


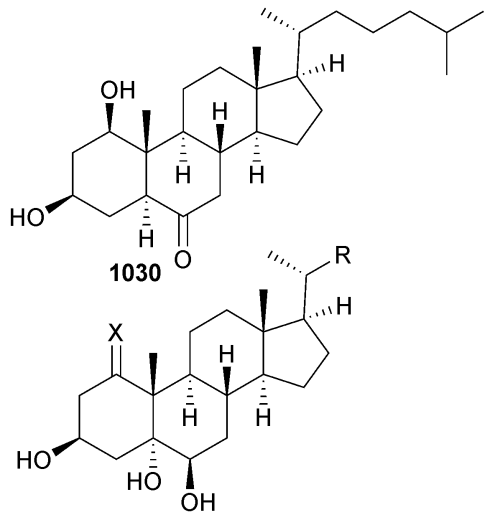<smiles>CO[R]=CCC=CC(C)(C)O</smiles><smiles>CC(C)=CCCC=[R]O</smiles><smiles></smiles><smiles>[R][R]#[R4]O[R]</smiles>

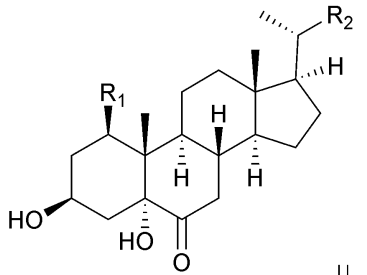

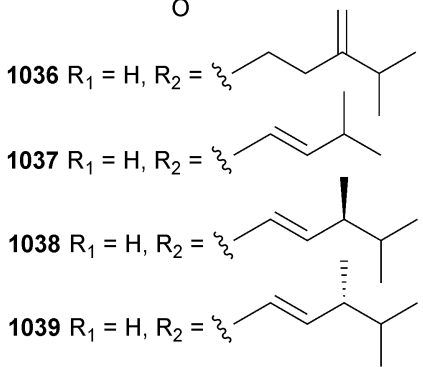

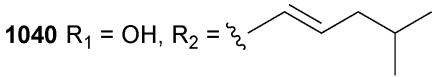<smiles>[R20]C/C=C\CC(C)C</smiles>

and Nephthea chabrolii (nebrosteroids Q-S, 1050-1052, SanHsian-Tai coast, Taitong county, Taiwan). ${ }^{\mathbf{8 3 3}}$ The latter three sterols exhibited mild cytotoxicity.

While sterols 1053-1059 (Sarcophyton sp., Weizhou Is., S. China Sea) ${ }^{\mathbf{8 3 4}}$ exhibited variable levels of antimicrobial activity, dissesterol 1060 (Sinularia dissecta, Hai Van-Son Cha, Hue,<smiles>[R9]C=CC=CC(C)C</smiles>

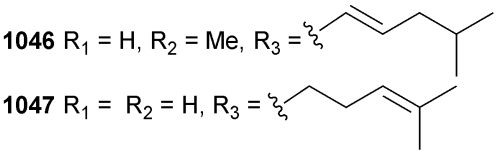

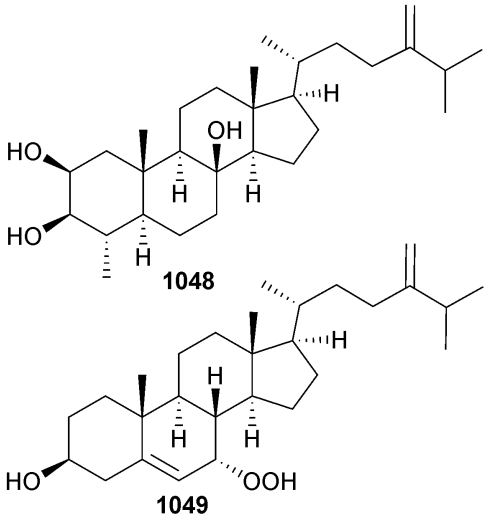

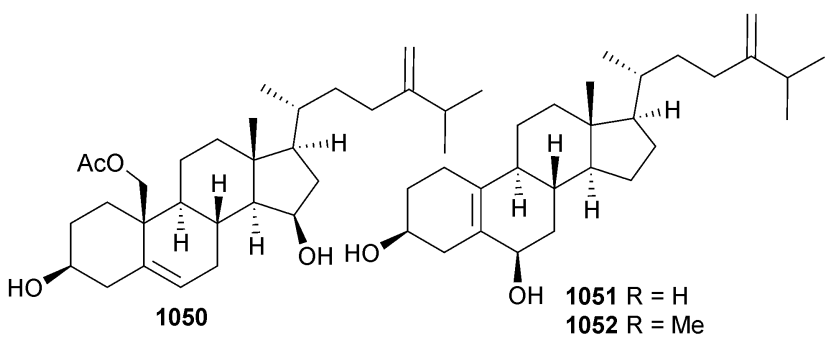

Vietnam) was a strong inhibitor of IL-12 p40 cytokine production by stimulated bone marrow-derived dendritic cells. ${ }^{835}$ One new 18-acetoxy sterol 1061 was isolated from a South China Sea (Xuwen coral reef area) collection of Sarcophyton $\mathrm{sp}^{\mathbf{8 3 6}}$

Two $5 \alpha, 8 \alpha$-epidioxysterols were reported: mildly cytotoxic 1062 from Sinularia gaweli (Sansiantai, Taitung county, Taiwan) ${ }^{837}$ and antiviral (H5N1) 1063 from S. candidula (Safaga, Egyptian Red Sea). ${ }^{752}$

A range of ring-A cross-conjugated steroids, including lactone side-chained withanolides, were reported from cnidarians. All five cholestadienones 1064-1068 (Nepthea sp., Naozhou Is., S. China Sea $)^{\mathbf{8 3 8}}$ exhibited cytotoxicity towards a panel of HTCLs, while of three carboxylic acid-containing examples, paraminabic acid A-C 1069-1071 (Paraminabea acronocephala, Pingtung county, Taiwan), $\mathbf{1 0 7 1}$ exhibited the most potent cytotoxicity. ${ }^{839}$ 


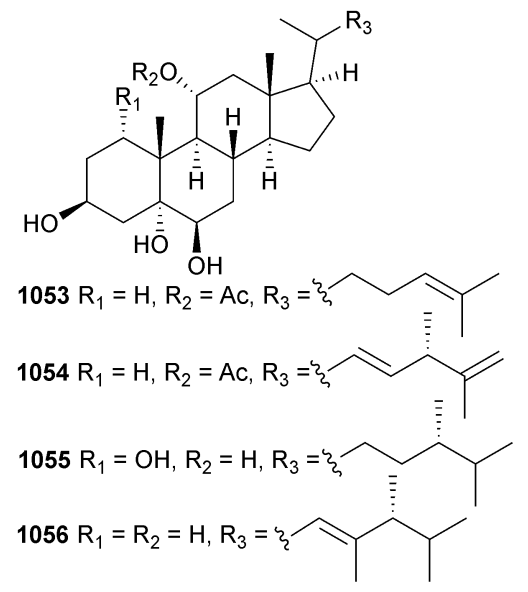

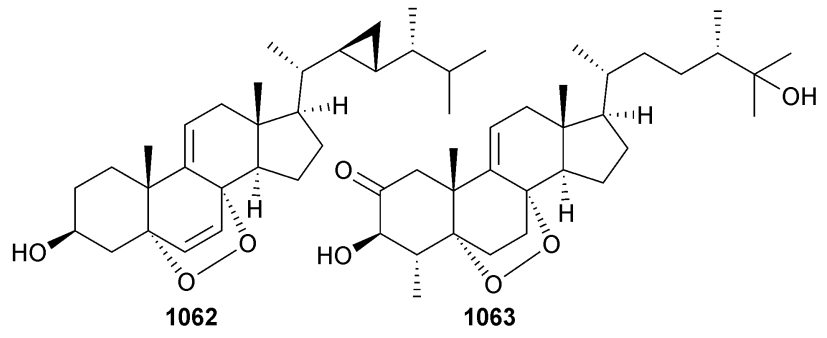

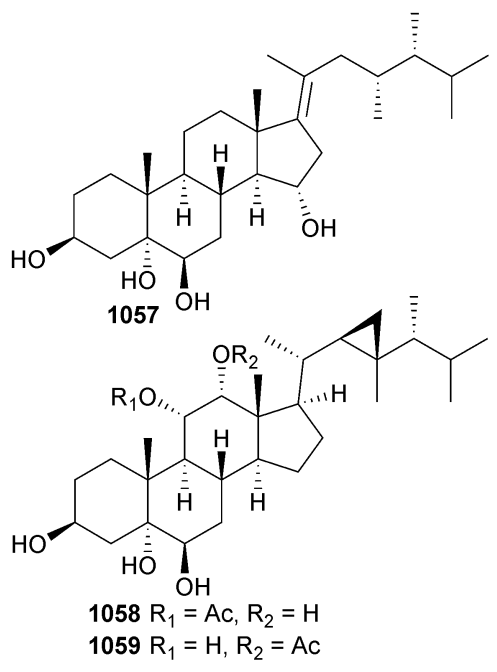
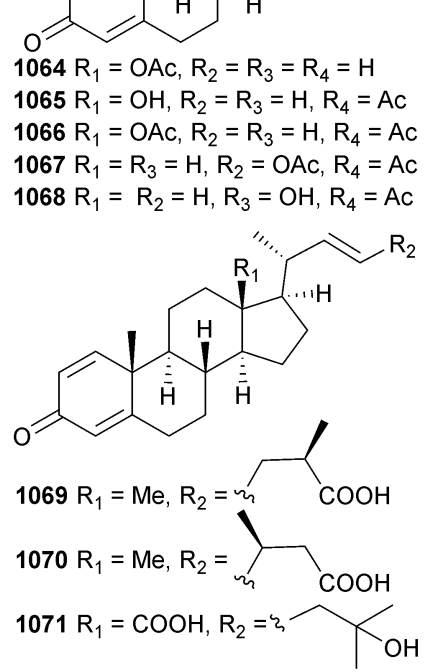

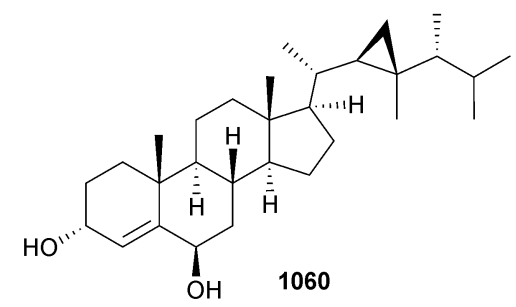

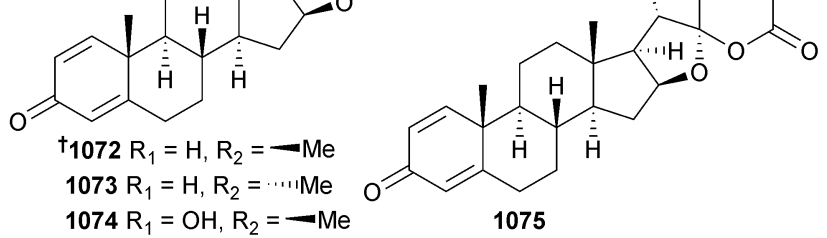

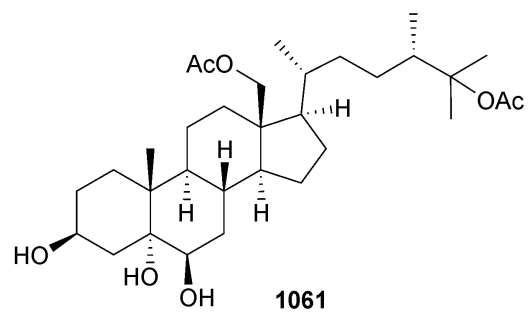

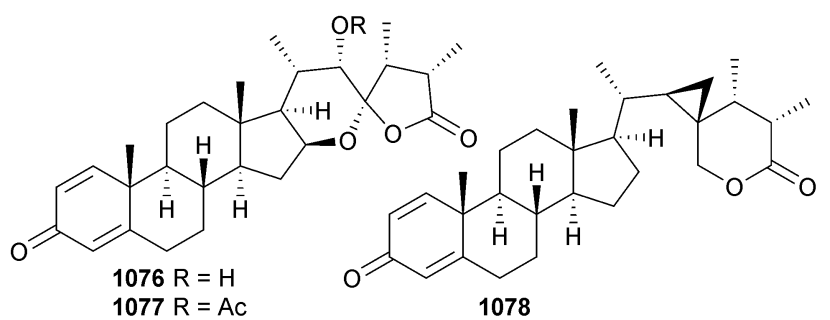


Sinubrasolides A-G 1072-1078 are withanolide-type steroids isolated from cultured specimens of Sinularia brassica (Taiwan) - the structure of $\mathbf{1 0 7 5}$ is notable for containing an unusual spiroketal moiety. ${ }^{\mathbf{8 4 0}}$ Mild cytotoxicity was observed for 1072, 1073 and 1076.

Acetylation of hemiacetal-containing nephthoacetal 1079 (Nephthea sp., Naozhou Is., S. China Sea) yielded two acetates. ${ }^{841}$ The NP inhibited the settlement of $B$. neritina larvae, an activity not observed for the acetate derivatives, while all three compounds were mildly cytotoxic to HeLa cells.

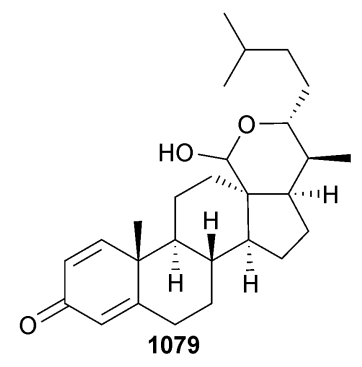

Finally, new steroidal glycosides junceelloside E-G 10801082 were reported from Dichotella gemmacea (Beihai, China).$^{\mathbf{8 4 2}}$ Detailed analysis of the nature of the arabinopyranose subunits (thiocarbamoyl-thiazolidine derivative) identified junceelloside $\mathrm{E}$ to contain the $\beta$-L anomer while junceellosides $\mathrm{F}$ and $\mathrm{G}$ contained the more standard $\beta$-D anomer. The arabinopyranose unit present in co-metabolite junceelloside C (Junceella juncea) ${ }^{\mathbf{8 4 3}}$ was corrected from $\beta$-D to $\beta$-L (1083). unsuccessful - a new model pathway was proposed, acting via a $(3+2)$ transannular cyclisation reaction. ${ }^{848}$ In a related study, the 5,5,6- and 5,5,7-tricyclic ring systems found in the cnidarian metabolites plumarellide and rameswaralide were constructed from linear furanbutenolide precursors under acidic conditions, suggesting a potential biosynthetic mechanism involving two-step carbocation cyclisation sequences. ${ }^{849}$ Further investigation of the previously reported anti-inflammatory activity of the sesquiterpene lemnalol (Lemnalia sp. $)^{\mathbf{8 5 0}}$ has revealed that intramuscular injection leads to attenuation of inflammation in a monosodium urate model of human gouty arthritis, and that the NP also suppressed neutrophil infiltration and expression of related proinflammatory cytokines. ${ }^{851}$ While the mechanisms of cytotoxicity of the cembranoid 5-episinuleptolide acetate ${ }^{\mathbf{8 5 2}}$ appear to include inhibition of levels of Hsp90 and induction of apoptosis, ${ }^{853}$ 11-episinulariolide acetate ${ }^{\mathbf{8 5 4}}$ targets EGFmediated cytoplasmic calcium levels and inhibits COX-2 and IL-8 expression. ${ }^{855}$ Of a range of exo-methylene lactonecontaining cembranoids tested for immunomodulatory effects, lobocrassin B (Lobophytum crassum) ${ }^{\mathbf{8 5 6}}$ was the most effective at blocking TNF- $\alpha$ production and attenuating LPSstimulated dendritic cell maturation and endocytosis. ${ }^{857} \mathrm{~A}$ hydroxypropyl- $\beta$-cyclodextrin formulation of pseudopterosin A (Pseudopterogorgia elisabethae $)^{\mathbf{8 5 8}}$ was more effective at inducing HUVEC cell proliferation than a DMSO solution of the NP - the change in formulation allowed observation of the decoupling of proliferative and cytotoxic effects. ${ }^{859}$ The previously reported ability of hippuristanol (Isis hippuris) ${ }^{\mathbf{8 6 0}}$ to inhibit RNA helicase and eukaryotic initiation factor $4 \mathrm{~A}$, has

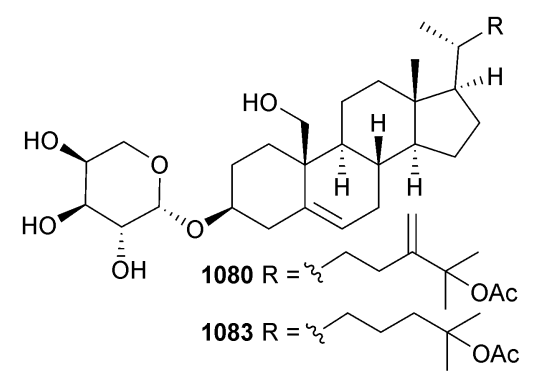

The structure of (-)-sinularianin B (Sinularia sp. $)^{\mathbf{8 4 4}}$ has been confirmed and absolute configuration established via synthesis which made use of sulfone-mediated tandem intramolecular-intermolecular alkylation. ${ }^{\mathbf{8 4 5}}$ Comparison of NMR and chiroptical data for two diastereomers of (+)-sarcophytonolide C (Sarcophyton $\mathrm{sp}$. ${ }^{\mathbf{8 0 7}}$ synthesised via a route including macrolactonisation and transannular RCM steps has confirmed the structure and established the absolute configuration of the NP. ${ }^{846}$ A general strategy for the synthesis of cladiellin diterpenoid NPs has been exemplified with the synthesis of ten examples. ${ }^{\mathbf{8 4 7}}$ Efforts to mimic the putative carbon-centred radical reactions proposed for the biosynthesis of selected norcembranoids in Sinularia sp. were prompted further investigation of the biological properties of the spiroacetal-containing steroid, identifying it as an inhibitor of primary effusion lymphoma cells, inducing $G_{1}$ phase arrest, caspase activation and apoptosis. ${ }^{\mathbf{8 6 1}}$ Activity was also observed in an in vivo model. Further investigation of antiinflammatory (15R)-prostaglandins from Plexaura homomalla $^{\mathbf{8 6 2}}$ has identified the metabolites (15R)-PGE 2 and $(15 R)-O A c-P_{2}$ as topically active inhibitors of oedema formation, leucocyte degranulation and elastase enzyme activity. ${ }^{863}$ As noted in the previous review in this series, simplexin Q (Klyxum simplex) ${ }^{\mathbf{8 6 4}}$ is a duplicate of klysimplexin $\mathrm{C}^{\mathbf{8 6 5}}$ and simplexin $\mathrm{S}^{\mathbf{8 6 4}}$ is identical to cladieunicellin G (Cladiella sp.). ${ }^{\mathbf{8 6 6 , 8 6 7}}$ 


\section{Bryozoans}

Only one new metabolite was reported from bryozoans in the last year, continuing the trend of minimal NP research efforts on this phylum. A new alkaloid, 7-bromo-1-ethyl- $\beta$-carboline 1084 was isolated from Pterocella vesiculosa (Aldermen Islands, New Zealand). ${ }^{\mathbf{8 6 8}}$

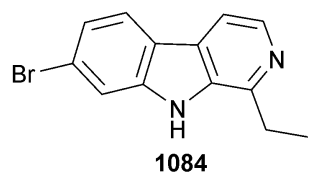

Wilsoniamines A and B, tribrominated alkaloids originally obtained from an Australian collection of Amathia wilsoni, ${ }^{\mathbf{8 6 9}}$ have been synthesised in two steps featuring a condensation reaction between (2,4,6-tribromo-3-methoxyphenyl)acetaldehyde and $(S)$ - $N$-methylpyrrolidine-2-carboxamide as a key step. ${ }^{870}$ Convolutamydine A, a dibrominated oxindole originally obtained from Amathia convoluta, ${ }^{\mathbf{8 7 1}}$ (along with two synthetic analogues) has/have been shown to possess antinociceptive effects comparable to those of morphine. ${ }^{872}$

\section{Molluscs}

The number of new metabolites reported from molluscs (15) is just over half the yearly average number reported over the past decade. The previously noted ability of molluscs to acylate dinoflagellate-produced toxin okadaic acid has been confirmed with acylating activity located in the digestive gland of various molluscs. ${ }^{873} \mathrm{~A}$ range of unusual $\Delta^{8}$ unsaturated 4-methyl and 4,4-dimethyl sterols was identified in extracts of the gonads of the Japanese limpet Cellana grata and C. toreuma ${ }^{874}$ Matrix solid-phase dispersion combined with GC-MS was demonstrated as a useful technique to detect the presence of brominated diphenyl ethers and newer halogenated flame retardants in mussel, cockle and clam extracts. ${ }^{875}$ New onchidione

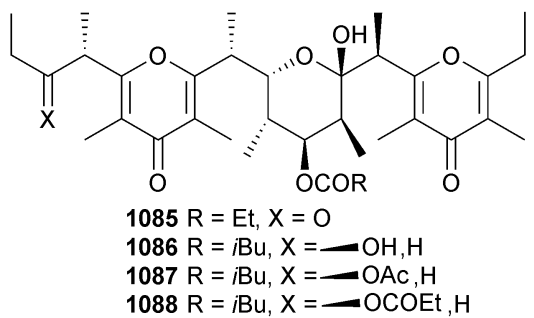

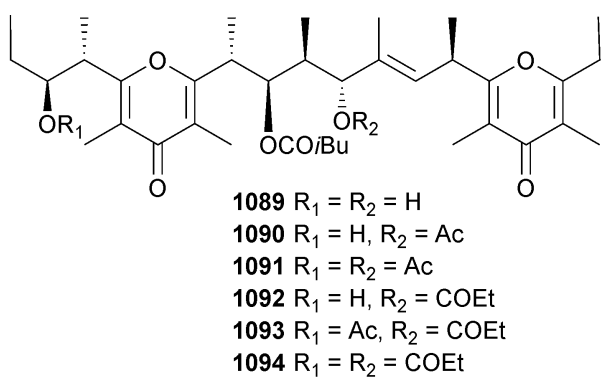

analogues 1085-1088 and ilikonapyrone esters 1089-1094 were reported from different Onchidium sp. molluscs. ${ }^{876}$ Acylation of 1086 gave 1087 and 1088, while reduction of co-metabolite onchidione afforded two diastereomers, one of which was identical to onchidionol 1086. The configurational relationships between 1089-1094 were identified by methanolysis of each, affording a product identical to co-metabolite ilikonapyrone. ${ }^{877}$ Mild cytotoxicity was observed for some of the compounds.

Two formamide-containing pupukeanane sesquiterpenoid congeners 1095 and 1096, the latter previously known as a synthetic derivative, were reported from the tubercle nudibranch Phyllidia coelestis (Koh-Ha Islet, Krabi province, Thailand). ${ }^{878}$ Moderate to strong cytotoxicity towards tumour cell lines was observed.

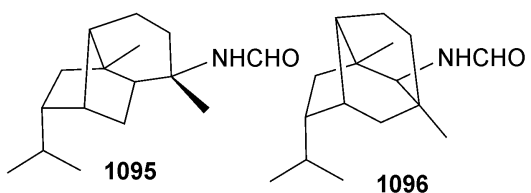

The absolute configuration of the mildly cytotoxic cyclic dodecapeptide cycloforskamide 1097 (Pleurobranchus forskalii, Ishigaki Is., Okinawa) was established by combinations of ozonolysis and acid hydrolysis. ${ }^{879}$ In addition to this peptide, the ergot alkaloid ergosinine ${ }^{880}$ was also isolated, an unusual finding as ergot alkaloids are usually only isolated from terrestrial higher plants and fungi. ${ }^{\mathbf{8 1}}$

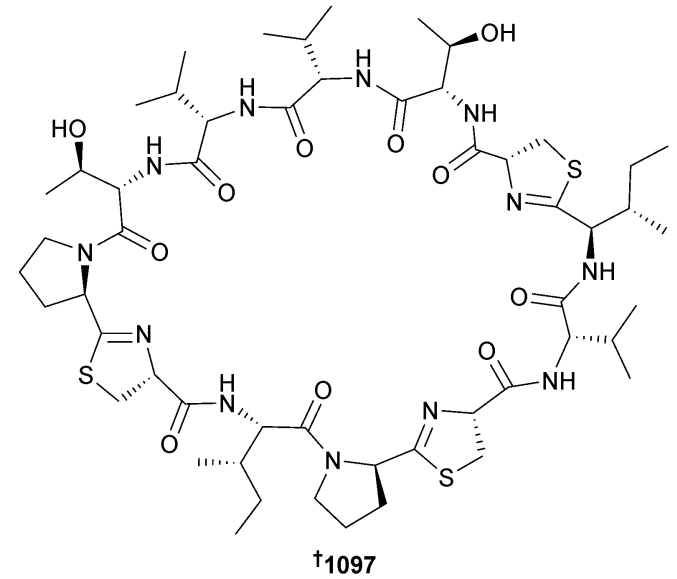

A potentially artefactual hydroperoxide, phototridachiapyrone J 1098 was isolated from the sacoglossan mollusc Elysia patagonica (San Jorge Gulf, Patagonia, Argentina). ${ }^{\mathbf{8 2} 2}$ The search for new leads for the treatment of leishmaniasis has identified the known $5 \alpha, 8 \alpha$-epidioxycholest-6-en-3 $\beta$-ol (Dolabrifera dolabrifera) as mildly active against the amastigote form with nearly sixty-fold selectivity versus Vero cells. ${ }^{883}$ The structure of furan 1099 (Hypselodoris jacksoni, S. E. Queensland) was confirmed and absolute configuration established by a thorough study using combinations of synthesis, chiral HPLC and MPA derivatisation. $^{\mathbf{8 8 4}}$ 


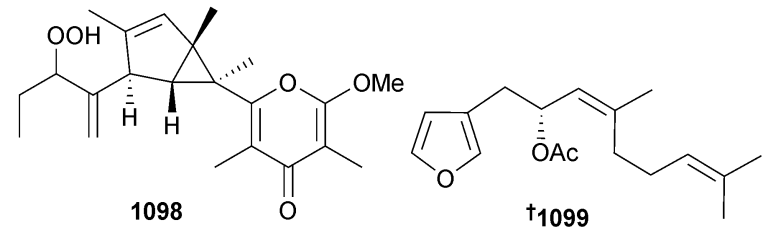

A new enantioselective route to oxazinin alkaloids (Mytilus galloprovincialis) $)^{885,886}$ has helped confirm the absolute configuration of amongst others, oxazinin-1 and $-2 .{ }^{887}$ Synthesis of a library of analogues of cytotoxic depsipeptide kulokekahilide-2 (Philinopsis speciosa) ${ }^{\mathbf{8 8 8}, \mathbf{8 8 9}}$ has revealed requirements of conformation, ring formation and ring size for biological potency. ${ }^{890}$ Aplysiatoxin (Stylocheilus long$\left.i_{\text {cauda }}\right)^{891}$ is a potent PKC binding tumour promoter synthesis and evaluation of simplified debromo analogues suggest that activation of PKC $\delta$ might play a role in the observed antiproliferative activity. ${ }^{892}$ Following the synthesis of sanguinamide B (Hexabranchus sanguineus), ${ }^{893}$ the same group has reported that the use of biotinylated analogues of two cytotoxic D-Phe analogues in combination with pull-down assays have identified cellular targets that include eukaryotic ribosomal subunits. ${ }^{894}$ Close investigation of the mechanisms of cell death induced by the compounds indicates that the exact mechanism depends on the position of the D-Phe group. The results of a dose-escalating phase I study of kahalalide $\mathrm{F}$ (originally mollusc Elysia rufescens and green alga Bryopsis pennata) ${ }^{895}$ have been reported, ${ }^{896}$ while evaluation of a kahalalide $\mathrm{F}$ analogue, elisidepsin, against a panel of tumour cell lines suggests that cell lines that exhibit high E-cadherin, ErbB3 and Muc1 gene expression can be regarded as being sensitive to the clinical candidate. ${ }^{897}$ Drug resistance was associated with the presence of KRAS activating mutations. Using constrained NOESY NMR data, a conformational search has helped assign the configuration (3S) in the 9-methyl-3decanol subunit of kahalalide Y (Elysia rufescens): ${ }^{898}$ unfortunately the study made use of the enantiomer of the NP and so the configuration should in fact be $(3 R) .{ }^{899,900}$ Investigation of the mechanism of cytotoxic action of aplyronine A (Aplysia kurodai $^{901}$ using photoaffinity biotinylated derivatives has identified aplyronine A to synergistically bind to tubulin in association with actin in a $1: 1: 1$ ratio, leading to inhibition of tubulin polymerisation, and ultimately prevention of spindle formation and mitosis. ${ }^{902}$ Similar experiments using aplyronine $\mathrm{C}^{\mathbf{9 0 2}}$ (lacks the trimethylserine sidechain of aplyronine $\mathrm{A} ;{ }^{903}$ three orders of magnitude less cytotoxic) showed it to bind to actin, as previously reported, but it did not bind to tubulin in this present study. Model compounds of the $\mathrm{N}$-methylformamide sidechain of aplyronine A exhibit cytotoxicity towards tumour cell lines which is strongly correlated with their ability to induce the disruption of actin filaments. ${ }^{904}$

\section{Tunicates (ascidians)}

The 35 new tunicate-derived NPs presented in this review is average for the number reported per annum over the last decade. The sulfonated serinol lipids siladenoserinol A-L 11001111 (Didemnidae, North Sulawesi, Indonesia) inhibited the interaction of tumour suppressor p53 with $\mathrm{Hdm} 2$, potentially leading to reactivation of p53 and induction of apoptosis in cancer cells. ${ }^{905}$ The absolute configuration of $\mathbf{1 1 0 0}$ was established by a combination of degradation, modified Mosher's analysis and comparison with similar fragments of defined configuration.

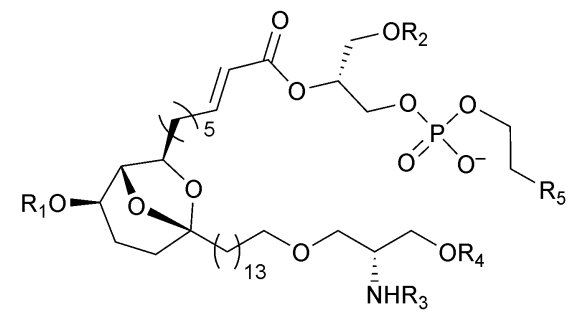

$\dagger_{1100 R_{1}}=R_{2}=A c, R_{3}=S_{3} H, R_{4}=H, R_{5}=N^{+} M e_{3}$ $1101 \mathrm{R}_{1}=\mathrm{R}_{2}=\mathrm{Ac}, \mathrm{R}_{3}=\mathrm{SO}_{3} \mathrm{H}, \mathrm{R}_{4}=\mathrm{H}, \mathrm{R}_{5}=\mathrm{N}^{+} \mathrm{H}_{3}$ $1102 \mathrm{R}_{1}=\mathrm{R}_{3}=\mathrm{H}, \mathrm{R}_{2}=\mathrm{Ac}, \mathrm{R}_{4}=\mathrm{SO}_{3} \mathrm{H}, \mathrm{R}_{5}=\mathrm{N}^{+} \mathrm{H}_{3}$ $1103 \mathrm{R}_{1}=A c, \mathrm{R}_{2}=\mathrm{R}_{4}=\mathrm{H}, \mathrm{R}_{3}=\mathrm{SO}_{3} \mathrm{H}, \mathrm{R}_{5}=\mathrm{N}^{+} \mathrm{Me}_{3}$ $1104 \mathrm{R}_{1}=\mathrm{R}_{3}=\mathrm{H}, \mathrm{R}_{2}=\mathrm{Ac}, \mathrm{R}_{4}=\mathrm{SO}_{3} \mathrm{H}, \mathrm{R}_{5}=\mathrm{N}^{+} \mathrm{Me}_{3}$ $1105 R_{1}=R_{4}=H, R_{2}=A c, R_{3}=S_{3} H, R_{5}=N^{+} M_{3}$ $1106 \mathrm{R}_{1}=\mathrm{R}_{2}=\mathrm{Ac}, \mathrm{R}_{3}=\mathrm{H}, \mathrm{R}_{4}=\mathrm{SO}_{3} \mathrm{H}, \mathrm{R}_{5}=\mathrm{N}^{+} \mathrm{Me}_{3}$

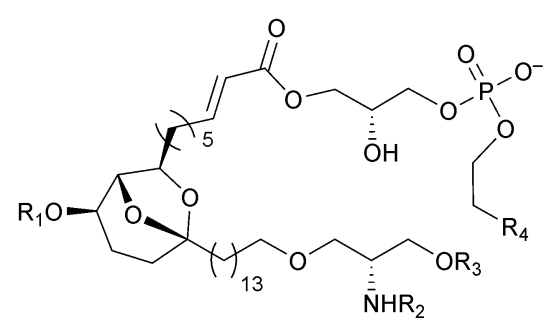

$1107 \mathrm{R}_{1}=\mathrm{Ac}, \mathrm{R}_{2}=\mathrm{SO}_{3} \mathrm{H}, \mathrm{R}_{3}=\mathrm{H}, \mathrm{R}_{4}=\mathrm{N}^{+} \mathrm{Me}_{3}$ $1108 R_{1}=A c, R_{2}=H, R_{3}=S_{3} H, R_{4}=N^{+} M_{3}$ $1109 \mathrm{R}_{1}=\mathrm{R}_{2}=\mathrm{H}, \mathrm{R}_{3}=\mathrm{SO}_{3} \mathrm{H}, \mathrm{R}_{4}=\mathrm{N}^{+} \mathrm{H}_{3}$ $1110 \mathrm{R}_{1}=\mathrm{R}_{3}=\mathrm{H}, \mathrm{R}_{2}=\mathrm{SO}_{3} \mathrm{H}, \mathrm{R}_{4}=\mathrm{N}^{+} \mathrm{Me}_{3}$ $1111 R_{1}=R_{2}=H, R_{3}=S_{3} H, R_{4}=N^{+} M_{3}$

Two new examples of the rare 1,2,4-thiadiazole ring system, polycarpathiamine A $\mathbf{1 1 1 2}$ and B 1113, were isolated from Polycarpa aurata (Ambon, Indonesia). While $\mathbf{1 1 1 2}$ exhibited submicromolar cytotoxicity (L5178Y), 1113 was inactive. ${ }^{906}$ The regiochemistry of the 1,2,4-thiadiazole ring was established by analysis of ${ }^{1} \mathrm{H}^{-15} \mathrm{~N}$ HMBC data and by synthesis of a model compound.<smiles>[R9]c1ccc(C(=O)c2nc(N)ns2)cc1[R16]([H])=N</smiles>

A diverse range of pteridine (duramidines A-D 1114-1117), thymidine (leptoclinidines A 1118 and B 1119), choline (durabetaines A 1120 and B 1121) and imidazole (leptoclinidamines D-F 1122-1124) analogues was isolated from Leptoclinides durus (Swains Reef, Great Barrier Reef). ${ }^{907}$ 
<smiles>[Y16]c1cc(O)ccc1/C=C(\OC)C(=O)OC[C@H]1O[C@@H](n2cc(C)c(=O)[nH]c2=O)C[C@@H]1OC(=O)c1c[nH]c2cc(Br)c(O)cc12</smiles><smiles>COC(=O)C(Cc1c(S(C)(=O)=O)n(C)c[n+]1C)NC(=O)c1c[nH]c2cc(Br)ccc12</smiles><smiles>[R]c1cc(C(=O)NCCc2c(SC)n(C)c[n+]2C)cc(Br)c1O</smiles>

Four methylsulfinyladenosine derivatives, momusine A-D 1125-1128, isolated as pairs of interconverting isomers, were reported from extracts of Herdmania momus (Jeju Is., S. Korea)..$^{908}$<smiles>[R][R5](=O)C[C@H]1O[C@@H](n2cnc3c(N)ncnc32)[C@H](O)[C@@H]1OC(=O)c1c[nH]c2cc(Br)c(O)cc12</smiles>

The structures of the modestly cytotoxic dioxothiazinomeroterpenes conthiaquinone A 1129 and B 1130 (Aplidium conicum, Porto Cesareo, Lecce, Italy) were established by interpretation of NMR data in combination with DP4 calculated chemical shifts. ${ }^{909}$ The absolute configuration of 1129 was proposed from TDDFT calculated ECD data.

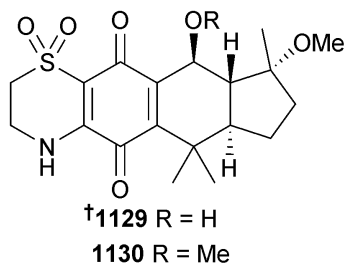

Four new examples of pyridoacridine alkaloids, shermilamine F 1131, dehydrokuanoniamine F 1132 arnoamine C 1133 and D 1134 (Cystodytes violatinctus, Solomon Is.) exhibited modest cytotoxicity towards a panel of HTCLs. ${ }^{910}$ A variant biosynthetic pathway to address the formation of arnoamines $\mathrm{C}$ and D was proposed. New analogues of the structurally related<smiles></smiles>

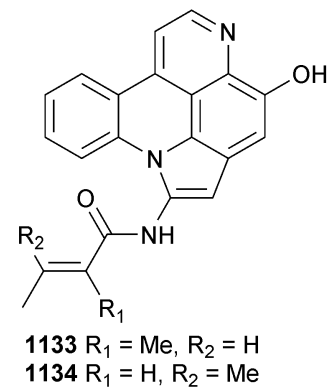


styelsamines ${ }^{911}$ were prepared and assessed for DNA binding ability and cytotoxicity. ${ }^{912}$

A sperm activation and attractant 1135 was isolated from egg seawater of Ascidia sydneiensis; structure elucidation by NMR and MS was performed on $2.6 \mu \mathrm{g}(4 \mathrm{nmol})$ of material. ${ }^{913}$ The proposed planar and stereo structure of 1135 was supported by the synthesis of model compounds. The structure of this sperm attractant is very similar to that previously reported from Ciona intestinalis and C. savignyi. ${ }^{\mathbf{1 1 4}}$

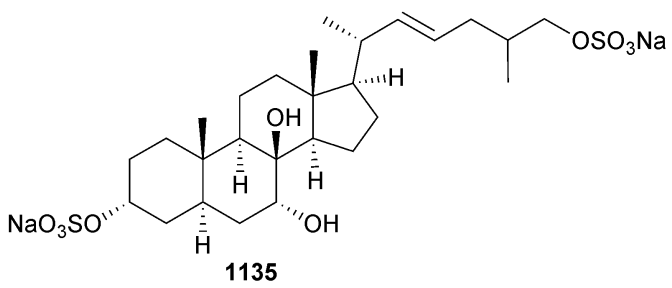

Synthesis and cytotoxic evaluation of aminol lipids clavaminol $\mathrm{G}^{\mathbf{9 1 5}}$ (Clavelina phlegrea) ${ }^{\mathbf{9 1 6}}$ and crucigasterins A, B and $\mathrm{D}^{\mathbf{9 1 7}, 918}$ (Pseudodistoma crucigaster) ${ }^{\mathbf{9 1 9}}$ have been reported; mild activity was observed. First syntheses of kottamide $\mathrm{E}^{\mathbf{9 2 0}}$ (Pycnoclavella kottae), ${ }^{921}$ lukianol B ${ }^{922}$ (unidentified tunicate) ${ }^{923}$ and eudistomin $\mathrm{Y}_{7}{ }^{\text {924-926 }}$ (Eudistoma $\mathrm{sp}$.) (2)7 $^{927}$ have been published. Syntheses of an isomer of didemnaketal $\mathrm{A}^{928}$ and the proposed structure of didemnaketal $\mathrm{B}^{\mathbf{9 2 9}}$ (Didemnum sp.) (130 $^{\mathbf{9}}$ provide further evidence that the NPs require revision of configurational assignments. Synthesis and structure-activity relationship studies on orthidine $\mathrm{F}^{\mathbf{9 3 1}}$ (antimalarial), ${ }^{932}$ ascidiathiazone $^{933}$ (antimalarial), ${ }^{934}$ meridianin $\mathrm{G}^{935}$ (antimalarial), ${ }^{936}$ perspicamide $\mathrm{A}^{\mathbf{9 3 7}}$ (antileishmanial), ${ }^{938}$ rigidin $^{939}$ (antitumour), ${ }^{\mathbf{9 4 0}}$ and ningalin $\mathrm{B}^{\mathbf{9 4 1}}$ (P-glycoprotein modulator $)^{942}$ have been reported. Further investigation of recently reported ascidian metabolites of the cadiolide and synoilide families of furanones (Synoicum sp.) ${ }^{\mathbf{9 4 3}}$ has identified cadiolides $\mathrm{E}, \mathrm{H}$ and $\mathrm{I}$ as being potent inhibitors of $C$. albicans isocitrate lyase, an enzyme associated with microorganism virulence. ${ }^{944}$ Semi-synthetic $N$-acyl derivatives of ecteinascidin

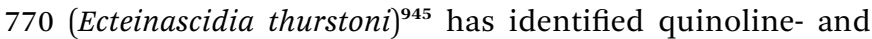
fluorocinnamoyl-containing examples that exhibit 50-70 fold increased cytotoxicity towards the HCT-116 cell line versus the parent NP. ${ }^{946}$ Minor corrections to manuscripts describing the mandelalides (Lissoclinum sp.) ${ }^{\mathbf{9 4 7}}$ and herdmanine $\mathrm{K}$ (Herdmania momus) $)^{\mathbf{9 4 8}}$ have been noted.

\section{Echinoderms}

The 33 new metabolites reported from echinoderms in this review is lower than the average number reported per annum over the last decade. A commercially available specimen of the starfish Asterias rollestoni (Xiamen food market, China) afforded the tetraosides 1136 and 1137 (ref. 949) while Astropecten polyacanthus (Cat Ba, Haiphong, Vietnam) contained the inactive or mildly cytotoxic sterols astropectenol A-D 1138-1141. ${ }^{950}$ The latter set of compounds was also reported to inhibit the expression of pro-inflammatory cytokines in bone marrowderived dendritic cells. ${ }^{951}$

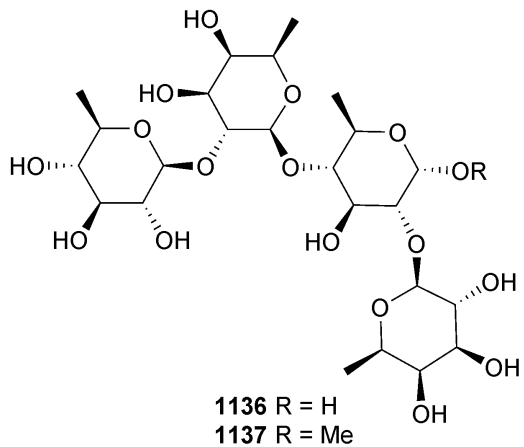

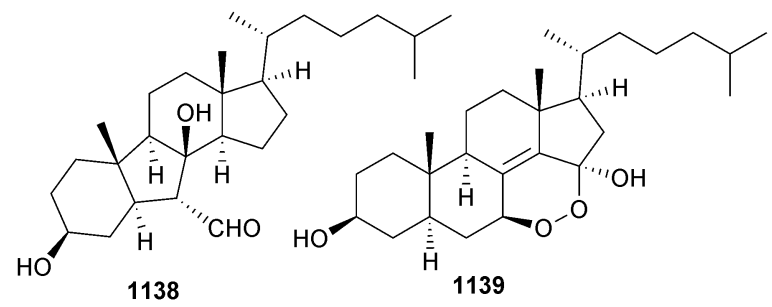

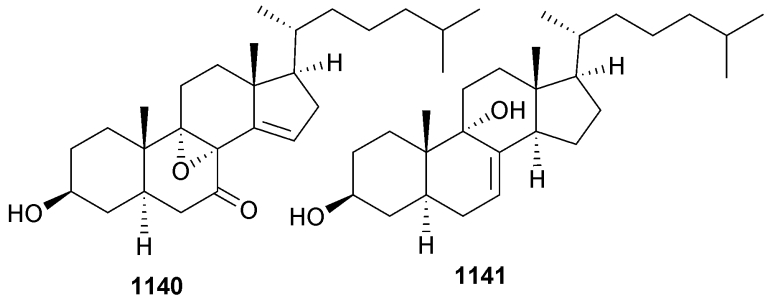

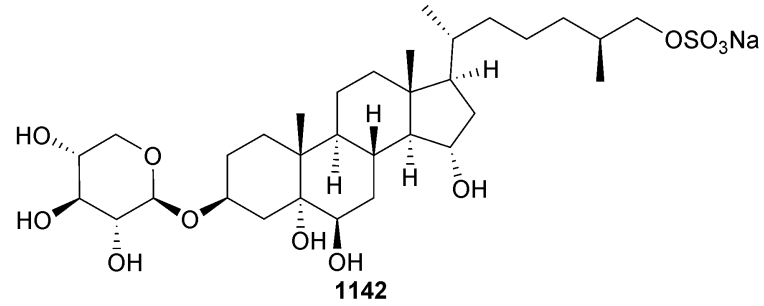

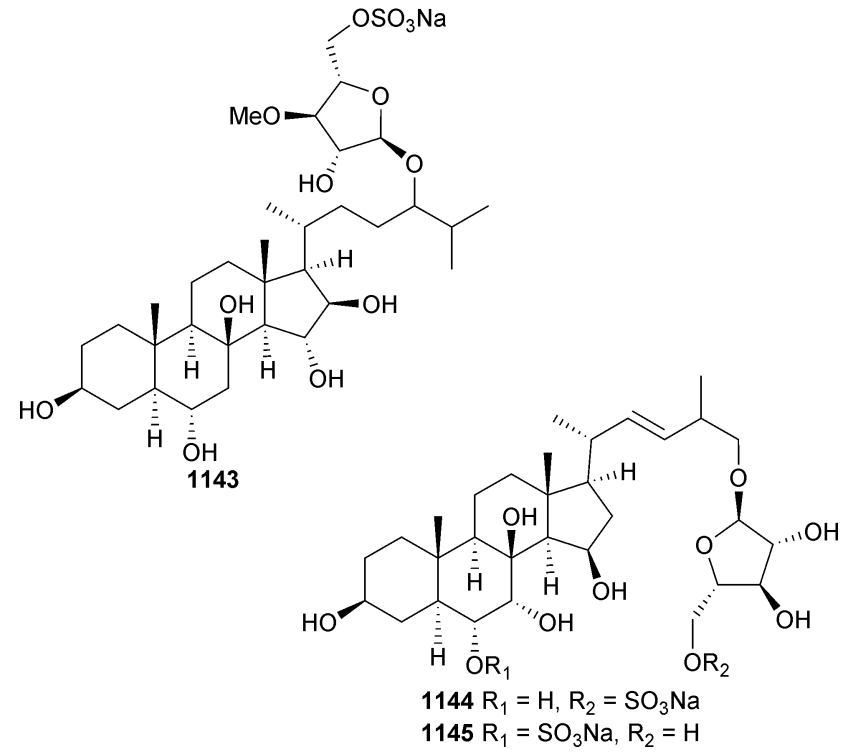


Aphelasteroside E 1142, which contains the rare sulfation at C-26, was isolated from Aphelasterias japonica (Poset Bay, Sea of Japan) $)^{\mathbf{9 5 2}}$ and the C-24-arabinosides pectinioside H-J 1143-1145 were identified in extracts of Asterina pectinifera (Dalian coast, Yellow Sea, China). ${ }^{953}$

Tetraosides typicoside $\mathrm{A}_{1} \mathbf{1 1 4 6}$ (the $24 E$ isomer of previously reported intercedenside A (Mensamaria intercedens) ${ }^{954}$ ), $\mathrm{A}_{2}, \mathrm{~B}_{1}$, $\mathrm{C}_{1}$ and $\mathrm{C}_{2}$ 1147-1150 are minor metabolites isolated from the sea cucumber Actinocucumis typica (Vizhinjam coast, Arabian Sea, India). ${ }^{955}$ Antifungal, haemolytic and cytotoxic evaluations of the five NPs identified widespread activity, with typicoside $\mathrm{C}_{1}$ being markedly less active in all assays. The presence of disulfated tetraoside turquetoside A 1151, which contains the rare 3-O-methyl-D-quinovose sugar unit, in both Staurocucumis turqueti and $S$. liouvillei suggests the sugar is a taxonomic character of this particular genus of Antarctic sea cucumber. ${ }^{956}$
Of the disulfated pentaosides cucumarioside $I_{1}, I_{3}$ and $I_{4}$ 1152-1154 (Eupentacta fraudatrix, Peter the Great Gulf, Sea of Japan), only 1152 exhibited biological activity including cytotoxicity (weak) and haemolytic activity (strong). ${ }^{957}$ Pentaosides cladoloside $\mathrm{B}_{1} 1155$ and $\mathrm{B}_{2} 1156$ and hexaosides cladoloside $\mathrm{C}$, $\mathrm{C}_{1}, \mathrm{C}_{2}$ and D 1157-1160 (Cladolabes schmeltzii, Nha Trang Gulf, S. China Sea) all exhibited similar levels of strong cytotoxicity and haemolytic activity. ${ }^{958}$

Extracts of the starfish Astropecten monacanthus (Cat Ba, Haiphong, Vietnam) afforded the hexaosides astrosterioside A-C 1161-1163 and pentaoside astrosterioside D 1164. ${ }^{959}$ While 1161 and 1163 exhibited mild inhibition of IL-6 production by stimulated bone marrow-derived dendritic cells, diketo-containing 1164 exhibited potent inhibition of production of IL-6, IL-12 p40 and TNF- $\alpha$.

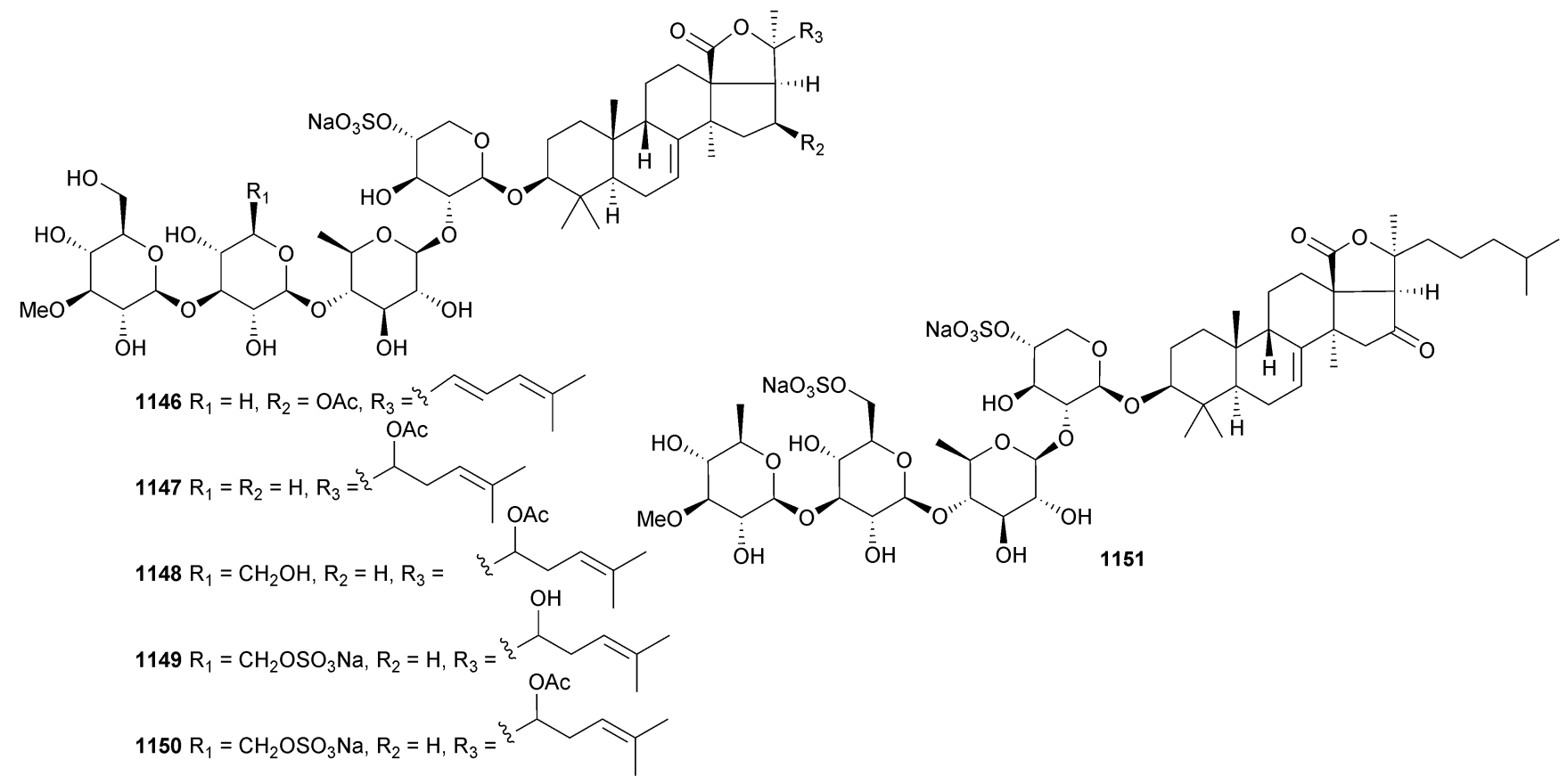

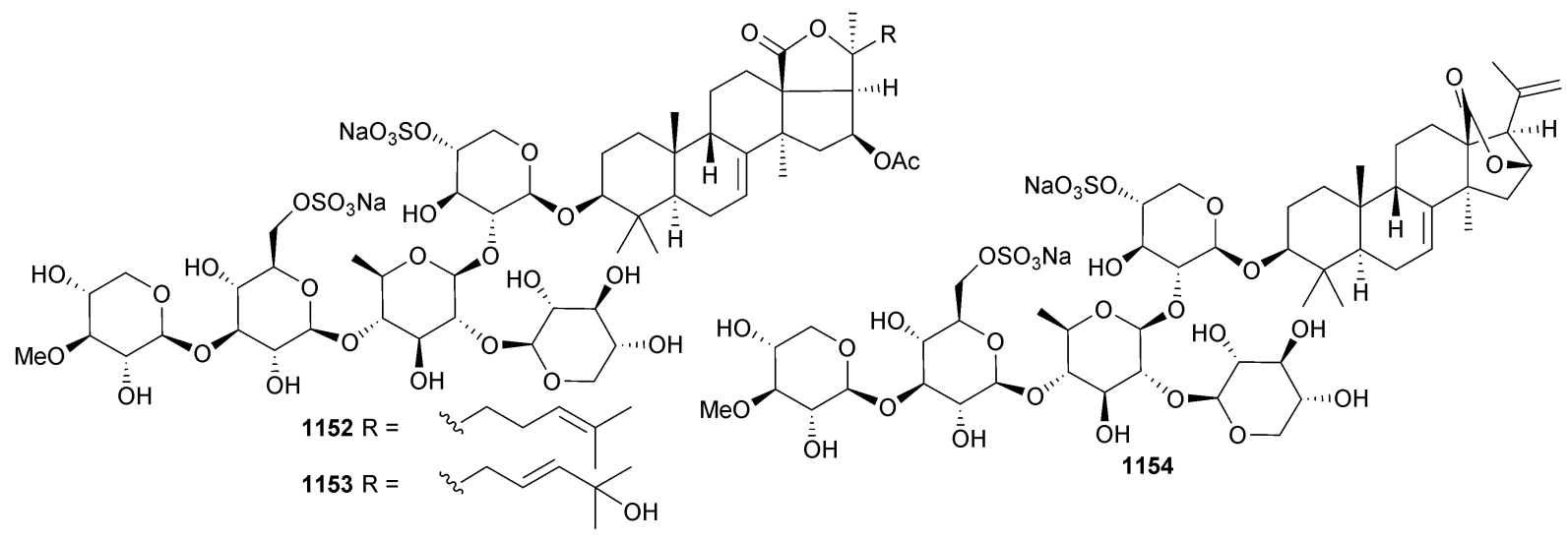




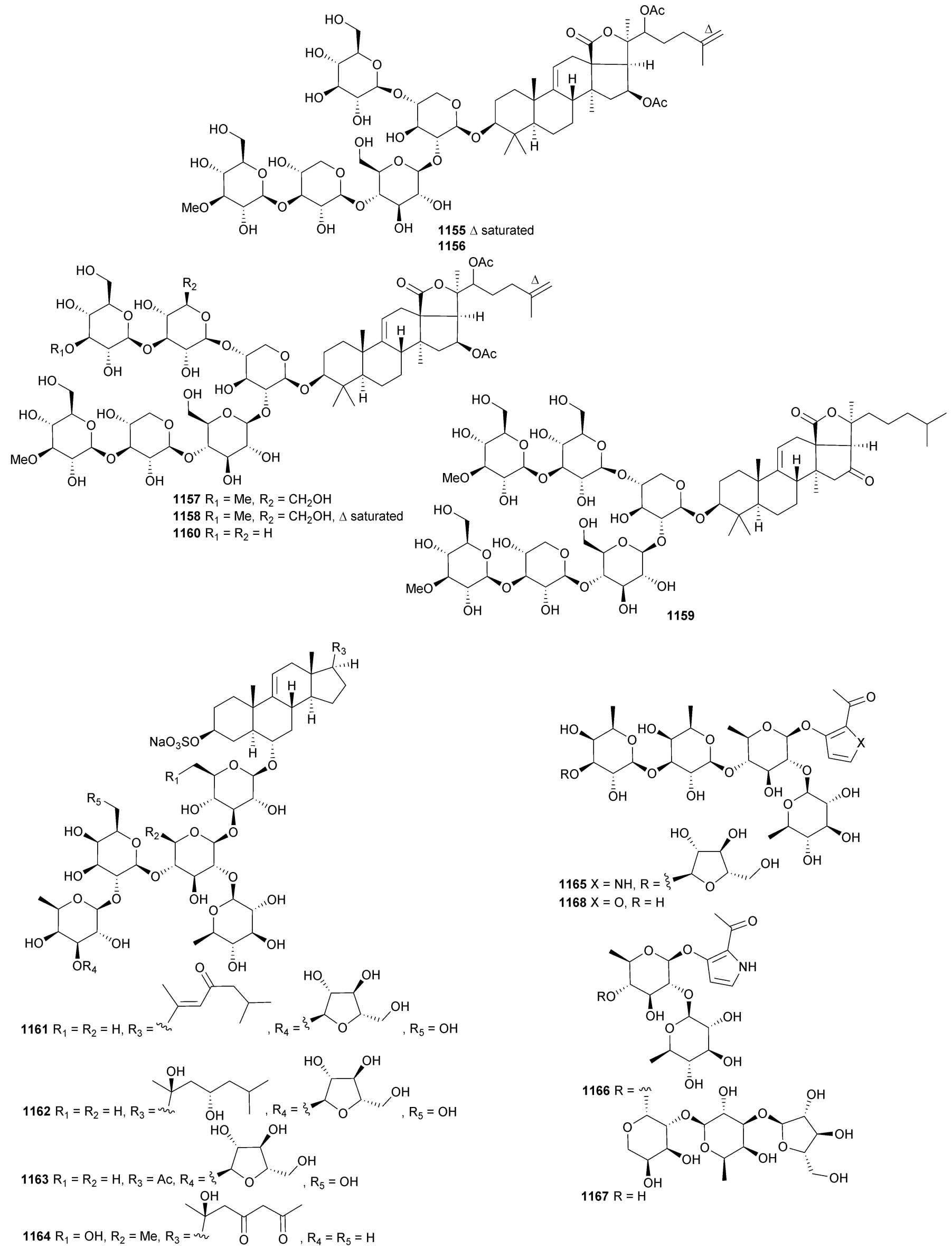


The pyrrole and furan oligoglycosides astebatherioside A-D 1165-1168 were reported from the starfish Asterina batheri (Catba, Haiphong, Vietnam). ${ }^{960}$ While 1165 was either inactive or weakly active, 1166-1168 demonstrated inhibition of IL-12 p40 production, and to a lesser extent of IL-6 production, in LPS-stimulated bone marrow-derived dendritic cells.

The synthesis of goniopectenoside B (starfish Goniopecten demonstrans $)^{961}$ has been reported. ${ }^{962}$ Purified polar steroids previously reported from the starfish Patiria pectinifera and Distolasterias nipon are potent enhancers of neurite outgrowth and acted as neuroprotectors against damage caused by oxygen-glucose deprivation. ${ }^{\mathbf{9 6 3}}$ Crude preparations of cerebrosides from the sea cucumber Acaudina molpadioides and the starfish Asterias amurensis were found to protect PC12 cells from oxidative damage due to exposure to $\mathrm{H}_{2} \mathrm{O}_{2}$ or tert-butyl hydroperoxide. ${ }^{964}$ In both cases the neuroprotection appeared to be conferred by upregulation of superoxide dismutase activity and modulation of components of the mitochondrial apoptotic pathway. High-energy CID tandem mass analysis has been used to determine the structures of ceramides and cerebrosides isolated from Distolasterias nipon. ${ }^{\mathbf{9 6 5}}$ Stable isotope biosynthesis feeding experiments have determined that dietary cholesterol and cholesterol 3-sulfate are elaborated into polyhydroxylated sterols in the starfish Patiria $(=$ Asterina $)$ pectinifera.$^{966}$

\section{Mangroves}

Aerial parts of the mangrove plant Kandelia obovata (Ximen Is., Zhejiang Province, China) afforded two new furofuran lignans kandelisesquilignan A 1169 and B 1170.967 Similar levels of antioxidant activity (DPPH assay) were observed for 1169 and 1170 versus ascorbic acid.

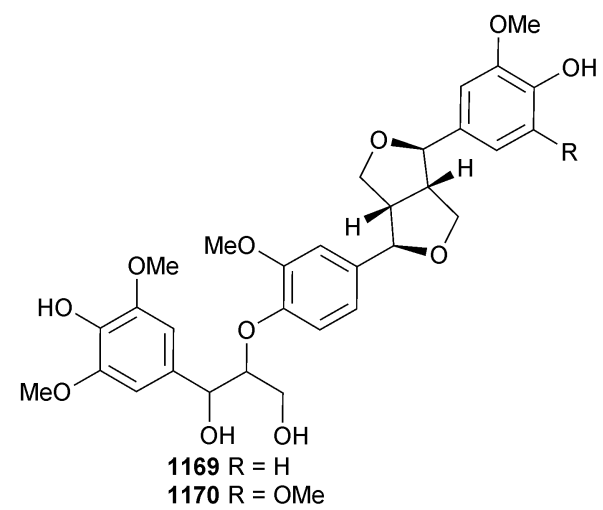

Ethanolic extracts of the bark of Ceriops decandra (Godavari estuary, Andhra Pradesh, India) afforded diterpenes decandrin A-K 1171-1181, the structures of which encompass abietane and podocarpane skeletons, ${ }^{968}$ while the wood of Excoecaria agallocha (Corangi forest, Godavari estuary) afforded ent-isopimarane diterpenoids agallochaexcoerin D-F 1182-1184. ${ }^{969}$

Two triterpenes tiliacol A 1185 and B 1186 were isolated from the semi-mangrove plant Hibiscus tiliaceus (Hainan Is., China). ${ }^{970}$

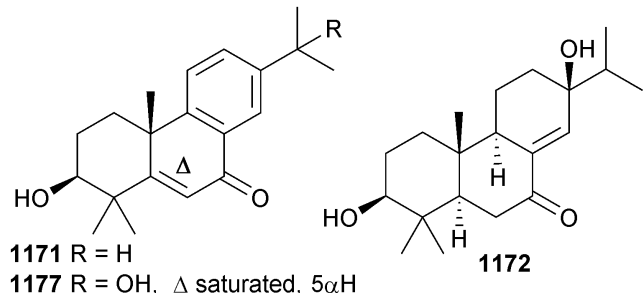<smiles>CC(C)c1ccc2c(c1)C(=O)C=C1[C@@](C)(CO)CCC[C@]12C</smiles><smiles>CC(C)C1=CC2=CC(=O)[C@H]3[C@](C)(CO)CCC[C@]3(C)[C@H]2CC1</smiles><smiles>CC(C)C1=CC[C@H]2C(=C1)C(=O)C[C@H]1C(C)(C)[C@@H](O)CC[C@@]21C</smiles>

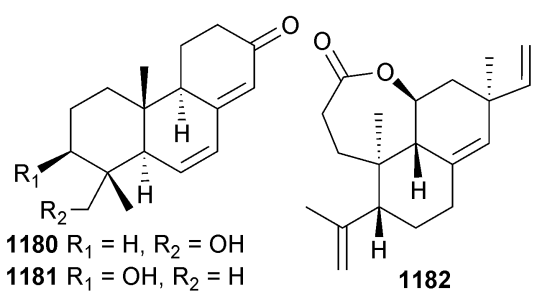

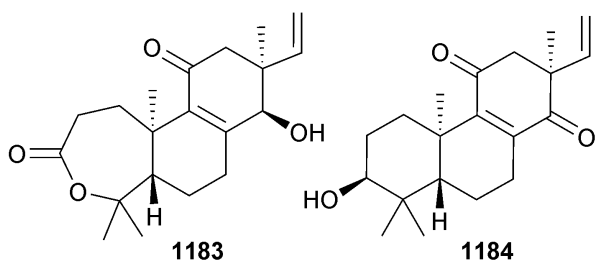

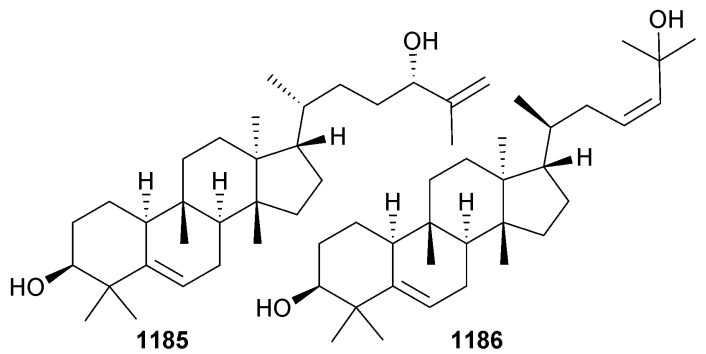

A diverse range of liminoids were reported from extracts of Xylocarpus granatum: granatumins H-K 1187-1190 (seeds, Krishna estuary, Andhra Pradesh), ${ }^{971}$ xylomexicanins C 1191 
and D 1192 (seeds, Hainan Province, China), ${ }^{972}$ and xylogranins A 1193 and B 1194 (leaves, Sundarbans Mangrove Forest, Bangladesh). ${ }^{973}$ Xylomexicanin C 1191 exhibited modest cytotoxicity towards a breast tumour cell line, while xylogranin B 1194 and co-metabolite swietephragmin were potent inhibitors of the Wnt signalling pathway and exhibited sub-micromolar cytotoxicity towards two human colorectal tumour cell lines.
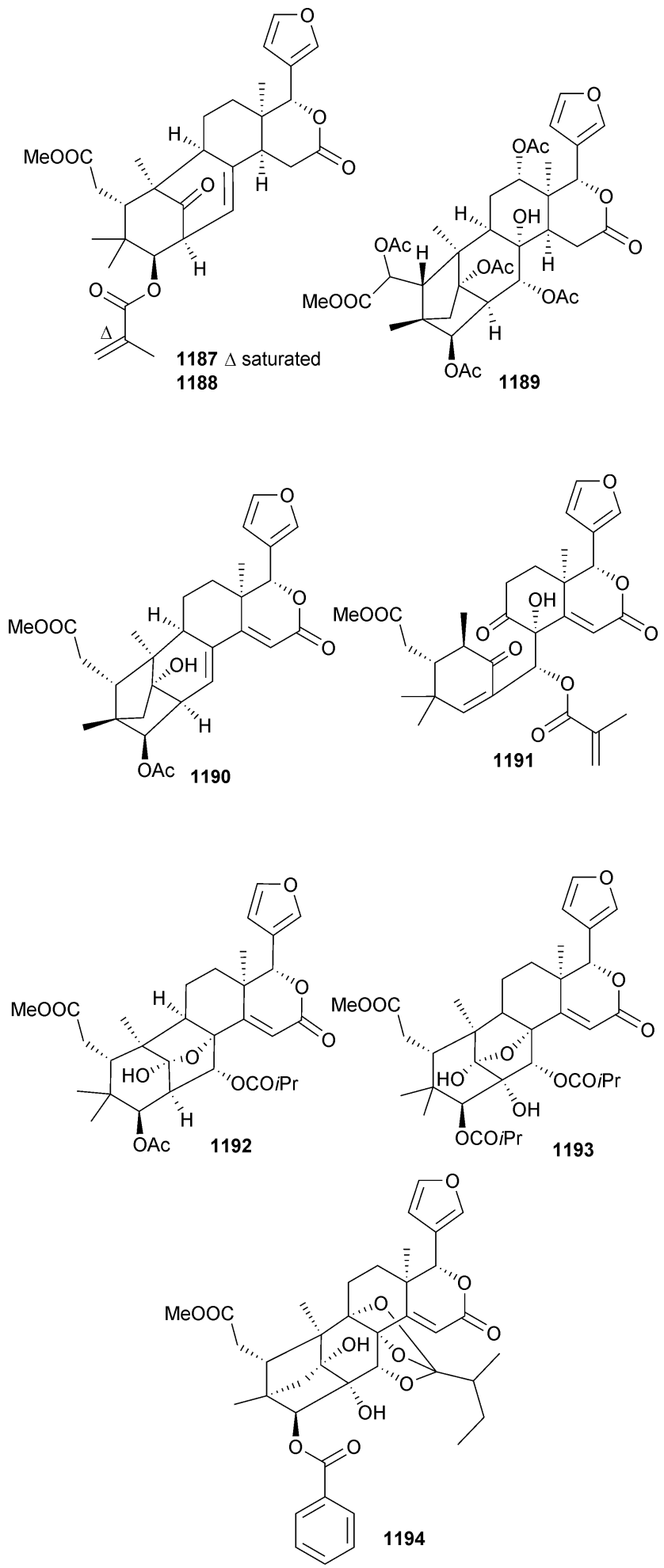

Extracts of the seeds of $X$. moluccensis (Trang province, Thailand) afforded thaixylomolins A-F 1195-1200. ${ }^{974,975}$ The structure of 1195 was secured by X-ray diffraction analysis and TDDFT calculations were used to establish the absolute configurations of 1196 and 1197, while 1198 was assigned by comparison of ECD data. The 4-hydro-dithiosulfonate, bruguiesulfurol (Bruguiera gymnorhiza) ${ }^{976}$ was detected as a modest inhibitor of PTP1B, prompting its synthesis and preparation of a library of analogues, some of which exhibited more potent activity. ${ }^{977}$

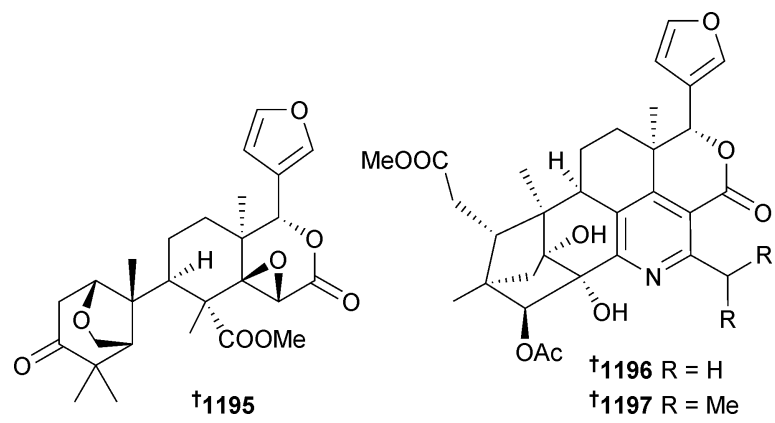

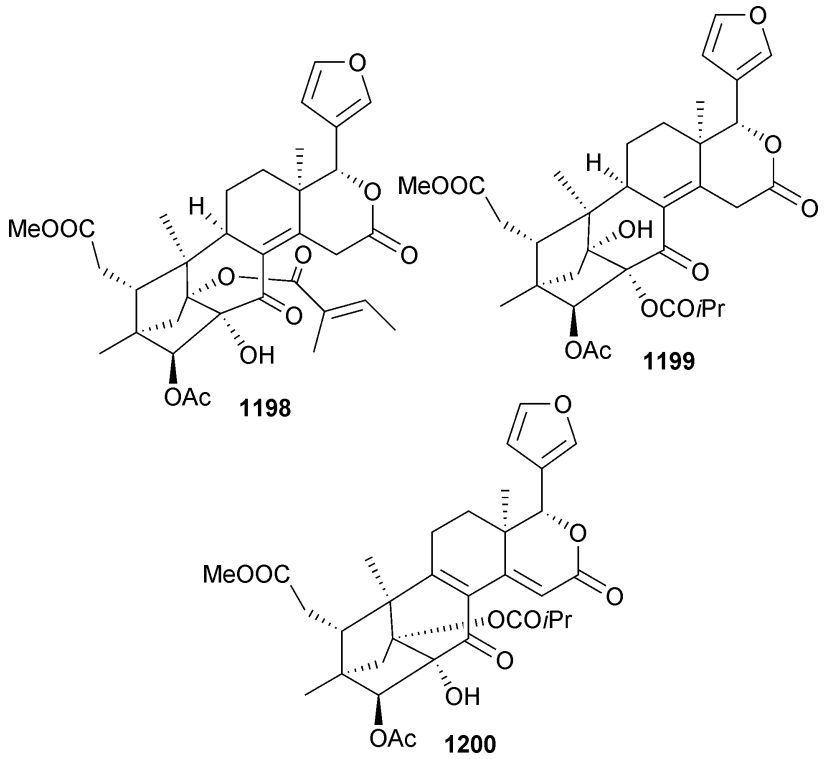

\section{Miscellaneous}

Investigation of water conditioned with sea lamprey (Petromyzon marinus) larvae afforded the hexahydrophenanthrene sulfate petromyzonin 1201.978 Absolute configuration was assigned by ECD analysis. Petromyzonin elicited potent $\left(10^{-11} \mathrm{M}\right)$ response in electro-olfactogram recordings using olfactory epithelia of adult male sea lamprey, indicating a likely ecological role as an odorant.<smiles>C[C@H]1CCC2=C(CCc3ccccc32)C1=O</smiles> 
The detection of 5,11-dideoxytetrodotoxin, ${ }^{979}$ isolated as an NP for the first time, in the pufferfish Takifugu poecilonotus and the flatworm Planocerid sp. 1 (Guam) prompted speculation on the putative biosynthetic pathways for the biosynthesis and metabolism of tetrodotoxins. ${ }^{\mathbf{9 8 0}}$ A new method involving sonication, SPE and LC-MS/MS has been reported to allow simultaneous quantification of Pacific ciguatoxins-1, -2 and -3 in the whole blood of fish. ${ }^{981}$

\section{Conclusion}

Fifty years ago in 1963 just four papers were published on MNPs with only one paper containing new compounds. At that time MNPs was becoming established as a field of interest. In this Conclusion the phylum-preferences of the MNP community across the subsequent 50 years period are examined. These preferences are presented (Fig. 1) as the annual number of publications reporting the isolation of new compounds for each phylum that has been sampled over this period. The most aggressively selected phylum has been the Porifera, but the popularity of this target has diminished somewhat since the mid 1990s coinciding with the very rapid rise in popularity of the Ascomycota, Actinobacteria and the Cyanobacteria. The Cnidaria have steadily increased in popularity across the years and while the phyla Rhodophyta, Ochrophyta, Echinodermata and Mollusca were as popular as the Porifera in the early years, interest waned in later years. The popularity of these phyla in earlier years may have been a reflection of the relative ease of collection by snorkeling and shore-wading as in the 1960s and 1970s SCUBA diving was more of a specialist technique. The numeric totals for the 50 years of collection are given in Table 1 along with the percentage contribution of each phylum to the marine literature. For the 50 years period from 19639220 papers have reported the isolation of 24662 new compounds. These 9220 papers constitute $37 \%$ of the total papers in MarinLit. ${ }^{77}$ The other 17284 papers are associated with topics such as reviews, syntheses, stereochemistry, corrections of structure or stereochemistry, bioactivities, and ecological surveys. Other data shown in Table 1 include the numbers of compounds reported/phylum over the 50 years period as well as the \% contributions each phylum has made to the number of papers reporting new compounds or the number of compounds. These relative proportions are comparable as the number of isolated compounds reported/paper is 2-3 across most of the phyla. Also included are the recognised totals of species/phylum from the World Register of Marine Species (WORMS), ${ }^{\mathbf{9} 2}$ allowing comparison of the numbers of samples of each phylum collected with the actual number of recognised species. This comparison should be used carefully as multiple collections of the same species have been made, or the sample may have only been identified to the genus level. However the comparison does offer insights into the coverage of each phylum. This point is emphasised by considering the various contributions the most studied genus for each phylum has made. For example, for

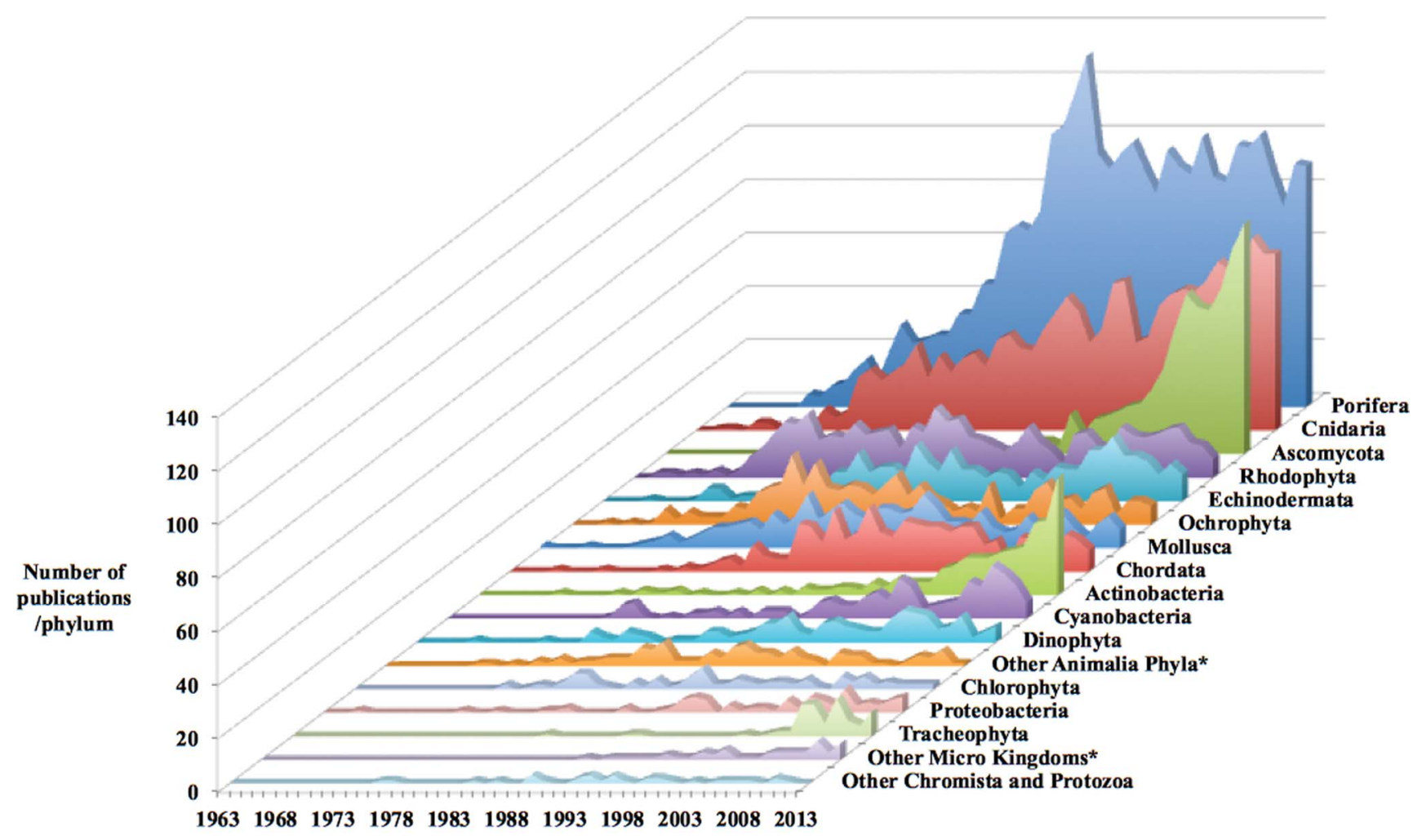

Year

Fig. 1 The phylum-preferences of the marine natural product research community across a 50-year period from 1963. 


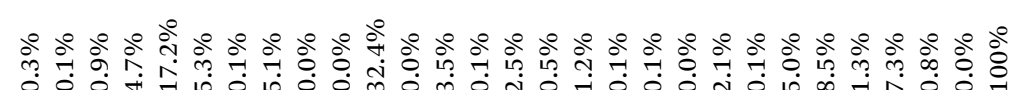


the Rhodophyta the most studied genus has been Laurencia. Even though Laurencia is only one of 84 genera studied, this one genus contributed 369 out of the total 672 papers from the Rhodophyta describing new MNPs and was the source of 824 of the 1668 new compounds from this phylum. The important consideration is that even though multiple collections of the same genus/species may have been made, the same genus or species at different locations is giving rise to a different suite of metabolites. Apart from Porifera and Cyanobacteria, the coverage of most phyla is very limited, although the credibility of the numbers of species recognised by WORMS ${ }^{982}$ for the Ascomycota and Actinobacteria is probably suspect as much of the micro-world has yet to be fully recognised. Over the past 50 years MNP chemists have studied samples collected from 1300 genera across 28 phyla. These 28 phyla represent an estimated (WORMS) 210892 marine species out of an estimated total of 224070 for all marine phyla. ${ }^{982}$ In other words MNP chemists have collected widely, but perhaps thinly across the Kingdoms. The Kingdom Virus (119 representatives) has not been sampled at all by MNP chemists and so has been excluded from consideration. As chemists we have published 9220 papers over the past 50 years describing new compounds from these 28 phyla. But, in fact, the 9220 papers describe compounds elicited from just 2657 named species with another 2485 occurrences across 484 genera that are only described as sp. So, the number of distinct species studied is a long way short of 9220. This nicely emphasises the point that there is still an enormous MNP resource waiting to be explored; probably in excess of 200000 species still to be evaluated.

\section{Acknowledgements}

We thank Dr Anthea Lees for assistance with the collection of data for this review.

\section{References}

1 J. W. Blunt, B. R. Copp, R. A. Keyzers, M. H. G. Munro and M. R. Prinsep, Nat. Prod. Rep., 2014, 31, 160-258.

2 J. W. Blunt, B. R. Copp, R. A. Keyzers, M. H. G. Munro and M. R. Prinsep, Nat. Prod. Rep., 2013, 30, 237-323.

3 R. A. Hill, Annu. Rep. Prog. Chem., Sect. B: Org. Chem., 2013, 109, 146-166.

4 A. M. S. Mayer, A. D. Rodríguez, O. Taglialatela-Scafati and N. Fusetani, Mar. Drugs, 2013, 11, 2510-2573.

5 G. M. Cragg and D. J. Newman, Biochim. Biophys. Acta, 2013, 1830, 3670-3695.

6 J. Khazir, B. A. Mir, S. A. Mir and D. Cowan, J. Asian Nat. Prod. Res., 2013, 15, 764-788.

7 S. Vinothkumar and P. S. Parameswaran, Biotechnol. Adv., 2013, 31, 1826-1845.

8 P. M. Murray, S. Moane, C. Collins, T. Beletskaya, O. P. Thomas, A. W. F. Duarte, F. S. Nobre, I. O. Owoyemi, F. C. Pagnocca, L. D. Sette, E. McHugh, E. Causse, P. Pérez-López, G. Feijoo, M. T. Moreira, J. Rubiolo, M. Leirós, L. M. Botana, S. Pinteus, C. Alves, A. Horta, R. Pedrosa, C. Jeffryes, S. N. Agathos, C. Allewaert,
A. Verween, W. Vyverman, I. Laptev, S. Sineoky, A. Bisio, R. Manconi, F. Ledda, M. Marchi, R. Pronzato and D. J. Walsh, New Biotechnol., 2013, 30, 839-850.

9 Y.-X. Li, S. W. A. Himaya and S.-K. Kim, Molecules, 2013, 18, 7886-7909.

10 C. Gao, X. Yi, R. Huang, F. Yan, B. He and B. Chen, Chem. Biodiversity, 2013, 10, 1435-1447.

11 M. Menna, C. Imperatore, F. D'Aniello and A. Aiello, Mar. Drugs, 2013, 11, 1602-1643.

12 M. Pelay-Gimeno, J. Tulla-Puche and F. Albericio, Mar. Drugs, 2013, 11, 1693-1717.

13 N. E. Golantsov, A. A. Festa, A. V. Karchava and M. A. Yurovskaya, Chem. Heterocycl. Compd., 2013, 49, 203-225.

14 A. Lorente, J. Lamariano-Merketegi, F. Albericio and M. Álvarez, Chem. Rev., 2013, 113, 4567-4610.

15 Y. Li, L. Liang, W. Xiao, J. Liang and Y. Guo, Chin. J. Org. Chem., 2013, 33, 1157-1166.

16 L.-F. Liang and Y.-W. Guo, Chem. Biodiversity, 2013, 10, 2161-2195.

17 F. Desriac, C. Jégou, E. Balnois, B. Brillet, P. Le Chevalier and Y. Fleury, Mar. Drugs, 2013, 11, 3632-3660.

18 V. L. Trainer, L. Moore, B. D. Bill, N. G. Adams, N. Harrington, J. Borchert, D. A. M. da Silva and B.-T. L. Eberhart, Mar. Drugs, 2013, 11, 1815-1835.

19 V. Gouveia, A. M. L. Seca, M. C. Barreto and D. C. G. A. Pinto, Mini-Rev. Med. Chem., 2013, 13, 11501159.

20 B.-G. Wang, J. B. Gloer, N.-Y. Ji and J.-C. Zhao, Chem. Rev., 2013, 113, 3632-3685.

21 J. A. R. Salvador, J. F. S. Carvalho, M. A. C. Neves, S. M. Silvestre, A. J. Leitão, M. M. C. Silva and M. L. Sá e Melo, Nat. Prod. Rep., 2013, 30, 324-374.

22 L. Wang, B. Yang, X.-P. Lin, X.-F. Zhou and Y. Liu, Nat. Prod. Rep., 2013, 30, 455-473.

23 L. M. Blair and J. Sperry, J. Nat. Prod., 2013, 76, 794-812.

24 Z. Jin, Nat. Prod. Rep., 2013, 30, 869-915.

25 A. Wang, Z. Zhao, X. Zheng and H. Cao, Chin. J. Org. Chem., 2013, 33, 483-491.

26 K. D. Cusick and G. S. Sayler, Mar. Drugs, 2013, 11, 9911018.

27 A. ElMarrouni, A. Kolleth, R. Lebeuf, J. Gebauer, S. Prevost, M. Heras, S. Arseniyadis and J. Cossy, Nat. Prod. Commun., 2013, 8, 965-972.

28 Z. Qin, S. Huang, Y. Yu and H. Deng, Mar. Drugs, 2013, 11, 3970-3997.

29 V. Valdiglesias, M. V. Prego-Faraldo, E. Pásaro, J. Méndez and B. Laffon, Mar. Drugs, 2013, 11, 4328-4349.

30 D. L. J. Clive and P. Cheng, Tetrahedron, 2013, 69, 50675078.

31 H. Abida, S. Ruchaud, L. Rios, A. Humeau, I. Probert, C. De Vargas, S. Bach and C. Bowler, Mar. Drugs, 4594, 11, 45944611.

32 R. Subramani and W. Aalbersberg, Appl. Microbiol. Biotechnol., 2013, 97, 9291-9321.

33 J. Vicente, A. Stewart, B. Song, R. T. Hill and J. L. Wright, Mar. Biotechnol., 2013, 15, 413-424. 
34 J.-R. Wang, W.-F. He and Y.-W. Guo, J. Asian Nat. Prod. Res., 2013, 15, 185-197.

35 P. Manivasagan, J. Venkatesan, K. Sivakumar and S.-K. Kim, Microbiol. Res., 2013, 168, 311-332.

36 Y. K. Ng, A. K. Hewavitharana, R. Webb, P. N. Shaw and J. A. Fuerst, Appl. Microbiol. Biotechnol., 2013, 97, 30973108.

37 L. T. Tan, Drug Discovery Today, 2013, 18, 863-871.

38 C. Zhao, T. Zhu and W. Zhu, Chin. J. Org. Chem., 2013, 33, 1195-1234.

39 Z.-Q. Xiong, J.-F. Wang, Y.-Y. Hao and Y. Wang, Mar. Drugs, 2013, 11, 700-717.

40 W. H. Gerwick and A. M. Fenner, Microb. Ecol., 2013, 65, 800-806.

41 K. Benkendorff, Mar. Drugs, 2013, 11, 1370-1398.

42 K. Osako and V. L. Teixeira, Nat. Prod. Commun., 2013, 8, 533-538.

43 Y. M. Lee, M. J. Kim, H. Li, P. Zhang, B. Bao, K. J. Lee and J. H. Jung, Mar. Biotechnol., 2013, 15, 499-519.

44 M. A. M. Mondol, H. J. Shin and M. T. Islam, Mar. Drugs, 2013, 11, 2846-2872.

45 W.-C. Wei, P.-J. Sung, C.-Y. Duh, B.-W. Chen, J.-H. Sheu and N.-S. Yang, Mar. Drugs, 2013, 11, 4083-4126.

46 J.-A. Kim and S.-K. Kim, Curr. Protein Pept. Sci., 2013, 14, 177-182.

47 A. J. Jones, T. Grkovic, M. L. Sykes and V. M. Avery, Mar. Drugs, 2013, 11, 4058-4082.

48 R. Pangestuti and S.-K. Kim, Food Sci. Biotechnol., 2013, 22, 1175-1186.

49 S. Indumathy and C. R. Dass, J. Pharm. Pharmacol., 2013, 65, 1280-1301.

50 K. Petit and J. F. Biard, Anti-Cancer Agents Med. Chem., 2013, 13, 603-631.

51 W. R. Sawadogo, M. Schumacher, M. H. Teiten, C. Cerella, M. Dicato and M. Diederich, Molecules, 2013, 18, 36413673.

52 B. Pejin, K. K. Jovanovic, M. Mojovic and A. G. Savic, Curr. Top. Med. Chem., 2013, 13, 2745-2766.

53 S. B. Bharate, S. D. Sawant, P. P. Singh and R. A. Vishwakarma, Chem. Rev., 2013, 113, 6761-6815.

54 M.-G. Zhong, Y.-F. Xiang, X.-X. Qiu, Z. Liu, K. Kitazato and Y.-F. Wang, RSC Adv., 2013, 3, 313-328.

55 X. Zhou, J. Liu, B. Yang, X. Lin, X.-W. Yang and Y. Liu, Curr. Med. Chem., 2013, 20, 953-973.

56 Y.-Q. Wang and Z.-H. Miao, Mar. Drugs, 2013, 11, 903-933.

57 P. A. Harnedy and R. J. FitzGerald, Curr. Protein Pept. Sci., 2013, 14, 162-172.

58 R. Nasri and M. Nasri, Curr. Protein Pept. Sci., 2013, 14, 199204.

59 V. L. T. Hoang and S.-K. Kim, Curr. Protein Pept. Sci., 2013, 14, 205-211.

60 T. Solov'eva, V. Davydova, I. Krasikova and I. Yermak, Mar. Drugs, 2013, 11, 2216-2229.

61 J.-T. Liu, X.-L. Lu, X.-Y. Liu, Y. Gao, B. Hu, B.-H. Jiao and H. Zheng, Mini-Rev. Med. Chem., 2013, 13, 617-626.

62 J. S. Roy, K. L. Poulson-Ellestad, R. D. Sieg, R. X. Poulin and J. Kubanek, Nat. Prod. Rep., 2013, 30, 1364-1379.
63 A. Holland and S. Kinnear, Mar. Drugs, 2013, 11, 2239-2258. 64 J. C. Morris, Nat. Prod. Rep., 2013, 30, 783-805.

65 M. Gordaliza and P. G. Baraldi, Curr. Med. Chem., 2013, 20, 2798-2811.

66 T. Nishikawa and M. Isobe, Chem. Rec., 2013, 13, 286-302.

67 I. Paterson, P. Maltas and E. A. Anderson, Pure Appl. Chem., 2013, 85, 1133-1147.

68 W. P. Unsworth and R. J. K. Taylor, Org. Biomol. Chem., 2013, 11, 7250-7261.

69 S. U. Kadam, B. K. Tiwari and C. P. O'Donnell, J. Agric. Food Chem., 2013, 61, 4667-4675.

70 D. Forner, F. Berrué, H. Correa, K. Duncan and R. G. Kerr, Anal. Chim. Acta, 2013, 805, 70-79.

71 Y. Inokuma, S. Yoshioka, J. Ariyoshi, T. Arai, Y. Hitora, K. Takada, S. Matsunaga, K. Rissanen and M. Fujita, Nature, 2013, 495, 461-466.

72 Y. Inokuma, S. Yoshioka, J. Ariyoshi, T. Arai, Y. Hitora, K. Takada, S. Matsunaga, K. Rissanen and M. Fujita, Nature, 2013, 501, 262.

73 Y. Zhang, S. Xiao, L. Sun, Z. Ge, F. Fang, W. Zhang, Y. Wang and Y. Cheng, Anal. Chim. Acta, 2013, 777, 49-56.

74 J. Y. Yang, L. M. Sanchez, C. M. Rath, X. Liu, P. D. Boudreau, N. Bruns, E. Glukhov, A. Wodtke, R. de Felicio, A. Fenner, W. R. Wong, R. G. Linington, L. Zhang, H. M. Debonsi, W. H. Gerwick and P. C. Dorrestein, J. Nat. Prod., 2013, 76, 1686-1699.

75 V. Gupta, R. S. Thakur, C. R. K. Reddy and B. Jha, RSC Adv., 2013, 3, 7037-7047.

76 M. C. Leal, M. H. G. Munro, J. W. Blunt, J. Puga, B. Jesus, R. Calado, R. Rosa and C. Madeira, Nat. Prod. Rep., 2013, 30, 1380-1390.

77 M. C. Leal, R. Calado, C. Sheridan, A. Alimonti and R. Osinga, Trends Biotechnol., 2013, 31, 555-561.

78 http://pubs.rsc.org/marinlit.

79 T. P. Wyche, M. Standiford, Y. Hou, D. Braun, D. A. Johnson, J. A. Johnson and T. S. Bugni, Mar. Drugs, 2013, 11, 5089-5099.

80 Y. Hu, M. B. Potts, D. Colosimo, M. L. Herrera-Herrera, A. G. Legako, M. Yousufuddin, M. A. White and J. B. MacMillan, J. Am. Chem. Soc., 2013, 135, 13387-13392.

81 H. J. Shin, F. S. Tareq, J. H. Kim, M. A. Lee, H.-S. Lee, Y.-J. Lee and J.-S. Lee, Heterocycles, 2013, 87, 307-318.

82 R. W. Phelan, M. Barret, P. D. Cotter, P. M. O'Connor, R. Chen, J. P. Morrissey, A. D. W. Dobson, F. O'Gara and T. M. Barbosa, Mar. Drugs, 2013, 11, 1878-1898.

83 M. A. M. Mondol, F. S. Tareq, J. H. Kim, M. A. Lee, H.-S. Lee, Y.-J. Lee, J. S. Lee and H. J. Shin, J. Nat. Prod., 2011, 74, 2582-2587.

84 M. A. M. Mondol, F. S. Tareq, J. H. Kim, M. A. Lee, H.-S. Lee, J. S. Lee, Y.-J. Lee and H. J. Shin, J. Antibiot., 2013, 66, 89-95.

85 T. A. Mansoor, J. Hong, C.-O. Lee, S.-J. Bae, K. S. Im and J. H. Jung, J. Nat. Prod., 2005, 68, 331-336.

86 X. Yang, Y. Shimizu, J. R. Steiner and J. Clardy, Tetrahedron Lett., 1993, 34, 761-764.

87 S. Felder, S. Kehraus, E. Neu, G. Bierbaum, T. F. Schäberle and G. M. König, ChemBioChem, 2013, 14, 1363-1371. 
88 S. Felder, S. Dreisigacker, S. Kehraus, E. Neu, G. Bierbaum, P. R. Wright, D. Menche, T. F. Schäberle and G. M. König, Chem.-Eur. J., 2013, 19, 9319-9324.

89 N. F. Montalvo, N. M. Mohamed, J. J. Enticknap and R. T. Hill, Antonie van Leeuwenhoek, 2005, 87, 29-36.

90 J. Martín, T. d. S. Sousa, G. Crespo, S. Palomo, I. González, J. R. Tormo, M. de la Cruz, M. Anderson, R. T. Hill, F. Vicente, O. Genilloud and F. Reyes, Mar. Drugs, 2013, 11, 387-398.

91 C. Hernandez, M. Librada, F. Romero Millan, A. Fernandez Medarde, R. I. Fernandez Chimeno and J. C. Hidalgo Villar, PCT Int. Appl., WO 2012062906 A1 20120518, 2012.

92 G. B. Mahajan, S. D. George, P. V. Ranadive, P. D. S. Mishra, S. S. Eyyammadichiyil, R. M. Panshikar, S. N. Sawant, S. Krishna, M. Sivakumar, K. Pari, B. M. Thomas, Z. E. Patel, R. Vishwakarma, C. G. Naik, L. D'Souza and P. Devi, PCT Int. Appl., WO 2007119201, A2 20071025, 2007.

93 S. Palomo, I. Gonzalez, M. de la Cruz, J. Martín, J. R. Tormo, M. Anderson, R. T. Hill, F. Vicente, F. Reyes and O. Genilloud, Mar. Drugs, 2013, 11, 1071-1086.

94 X. Just-Baringo, P. Bruno, L. K. Ottesen, L. M. Cañedo, F. Albericio and M. Álvarez, Angew. Chem., Int. Ed., 2013, 52, 7818-7821.

95 S. Carlson, L. Marler, S.-J. Nam, B. D. Santarsiero, J. M. Pezzuto and B. T. Murphy, Mar. Drugs, 2013, 11, 1152-1161.

96 F. Peng, C. Wang, Y. Xie, H. Jiang, L. Chen, P. Uribe, A. T. Bull, M. Goodfellow, H. Jiang and Y. Lian, Nat. Prod. Res., 2013, 27, 1366-1371.

97 D. W. Udwary, L. Zeigler, R. N. Asolkar, V. Singan, A. Lapidus, W. Fenical, P. R. Jensen and B. S. Moore, Proc. Natl. Acad. Sci. U. S. A., 2007, 104, 10376-10381.

98 E. J. Skellam, A. K. Stewart, W. K. Strangman and J. L. C. Wright, J. Antibiot., 2013, 66, 431-441.

99 K. W. Blake and P. G. Sammes, J. Chem. Soc. C, 1970, 980984.

100 Y. Macherla, poster, $3^{\text {rd }}$ Europ. Conf. Marine Nat. Prod., Elmau Castle, Germany, 2002.

101 J. Bryans, P. Charlton, I. Chicarelli-Robinson, M. Collins, R. Faint, C. Latham, I. Shaw and S. Trew, J. Antibiot., 1996, 49, 1014-1021.

102 Q. Zhang, S. Li, Y. Chen, X. Tian, H. Zhang, G. Zhang, Y. Zhu, S. Zhang, W. Zhang and C. Zhang, J. Antibiot., 2013, 66, 31-36.

103 I. Schneemann, B. Ohlendorf, H. Zinecker, K. Nagel, J. Wiese and J. F. Imhoff, J. Nat. Prod., 2010, 73, 1444-1447.

104 Z. Lin, J. P. Torres, M. A. Ammon, L. Marett, R. W. Teichert, C. A. Reilly, J. C. Kwan, R. W. Hughen, M. Flores, M. D. Tianero, O. Peraud, J. E. Cox, A. R. Light, A. J. L. Villaraza, M. G. Haygood, G. P. Concepcion, B. M. Olivera and E. W. Schmidt, Chem. Biol., 2013, 20, 73-81.

105 M. C. Kim, O.-W. Kwon, J.-S. Park, S. Y. Kim and H. C. Kwon, Chem. Pharm. Bull., 2013, 61, 511-515.

106 P. Fu, P. Liu, Q. Gong, Y. Wang, P. Wang and W. Zhu, RSC Adv., 2013, 3, 20726-20731.
107 R. Raju, A. M. Piggott, X.-C. Huang and R. J. Capon, Org. Lett., 2011, 13, 2770-2773.

108 R. Raju, A. M. Piggott, M. Conte, Z. Tnimov, K. Alexandrov and R. J. Capon, Chem.-Eur. J., 2010, 16, 3194-3200.

109 R. Raju, A. M. Piggott, M. Quezada and R. J. Capon, Tetrahedron, 2013, 69, 692-698.

110 Z. Wang, P. Fu, P. Liu, P. Wang, J. Hou, W. Li and W. Zhu, Chem. Biodiversity, 2013, 10, 281-287.

111 Z.-C. Wu, S. Li, S.-J. Nam, Z. Liu and C. Zhang, J. Nat. Prod., 2013, 76, 694-701.

112 N. I. Kalinovskaya, L. A. Romanenko, A. I. Kalinovsky, P. S. Dmitrenok and S. A. Dyshlovoy, Nat. Prod. Commun., 2013, 8, 381-384.

113 L. Kjaerulff, A. Nielsen, M. Mansson, L. Gram, T. O. Larsen, H. Ingmer and C. H. Gotfredsen, Mar. Drugs, 2013, 11, 5051-5062.

114 H. K. Zane and A. Butler, J. Nat. Prod., 2013, 76, 648-654. 115 D.-C. Oh, P. G. Williams, C. A. Kauffman, P. R. Jensen and W. Fenical, Org. Lett., 2006, 8, 1021-1024.

116 A. L. Lane, S.-J. Nam, T. Fukuda, K. Yamanaka, C. A. Kauffman, P. R. Jensen, W. Fenical and B. S. Moore, J. Am. Chem. Soc., 2013, 135, 4171-4174.

117 C. M. Woo, N. E. Beizer, J. E. Janso and S. B. Herzon, J. Am. Chem. Soc., 2012, 134, 15285-15288.

118 C. M. Woo, S. L. Gholap and S. B. Herzon, J. Nat. Prod., 2013, 76, 1238-1241.

119 X.-W. Yang, G.-Y. Zhang, J.-X. Ying, B. Yang, X.-F. Zhou, A. Steinmetz, Y.-H. Liu and N. Wang, Mar. Drugs, 2013, 11, 33-39.

120 A. I. M. Khedr, I. Kouno, T. Tanaka and K. Yamada, Heterocycles, 2013, 87, 1029-1037.

121 X.-Y. Lian and Z. Zhang, Nat. Prod. Res., 2013, 27, 21612167.

122 A. Yang, L. Si, Z. Shi, L. Tian, D. Liu, D. Zhou, P. Proksch and W. Lin, Org. Lett., 2013, 15, 5366-5369.

123 Y. Song, H. Huang, Y. Chen, J. Ding, Y. Zhang, A. Sun, W. Zhang and J. Ju, J. Nat. Prod., 2013, 76, 2263-2268.

124 N. Liu, F. Shang, L. Xi and Y. Huang, Mar. Drugs, 2013, 11, 1524-1533.

125 A. D. Batcho and W. Leimgruber, U.S. Pat., US 3524849 A 19700818, 1970.

126 M. R. Pena and J. K. Stille, J. Am. Chem. Soc., 1989, 111, 5417-5424.

127 R. H. Jiao, H. Xu, J. T. Cui, H. M. Ge and R. X. Tan, J. Appl. Microbiol., 2013, 114, 1046-1053.

128 I. Djinni, A. Defant, M. Kecha and I. Mancini, Mar. Drugs, 2013, 11, 124-135.

129 S. T. Khan, H. Komaki, K. Motohashi, I. Kozone, A. Mukai, M. Takagi and K. Shin-ya, Environ. Microbiol., 2011, 13, 391403.

130 M. Izumikawa, T. Kawahara, J.-H. Hwang, M. Takagi and K. Shin-Ya, Biosci., Biotechnol., Biochem., 2013, 77, 663-665.

131 S. Imai, A. Shimazu, K. Furihata, K. Furihata, Y. Hayakawa and H. Seto, J. Antibiot., 1990, 43, 1606-1607.

132 P. B. Gomes, M. Nett, H.-M. Dahse and C. Hertweck, J. Nat. Prod., 2010, 73, 1461-1464. 
133 A. Zeeck, S. Breiding-Mack, S. Grabley, H. Voelskow and G. Seibert, Eur. Pat. Appl., EP 260486 A1 19880323, 1998.

134 J. Ren, D. Liu, L. Tian, Y. Wei, P. Proksch, J. Zeng and W. Lin, Bioorg. Med. Chem. Lett., 2013, 23, 301-304.

135 Z.-Y. You, Y.-H. Wang, Z.-G. Zhang, M.-J. Xu, S.-J. Xie, T.-S. Han, L. Feng, X.-G. Li and J. Xu, Mar. Drugs, 2013, 11, 4035-4049.

136 P. Fu, F. Kong, Y. Wang, Y. Wang, P. Liu, G. Zuo and W. Zhu, Chin. J. Chem., 2013, 31, 100-104.

137 X. Alvarez-Mico, P. R. Jensen, W. Fenical and C. C. Hughes, Org. Lett., 2013, 15, 988-991.

138 S. M. Mantovani and B. S. Moore, J. Am. Chem. Soc., 2013, 135, 18032-18035.

139 H. Kanzaki, S. Yanagisawa and T. Nitoda, J. Antibiot., 2000, 53, 1257-1264.

140 R. Brown, C. Kelley and S. E. Wiberley, J. Org. Chem., 1965, 30, 277-280.

141 P. Wang, L. Xi, P. Liu, Y. Wang, W. Wang, Y. Huang and W. Zhu, Mar. Drugs, 2013, 11, 1035-1049.

142 C. Chen, J. Wang, H. Guo, W. Hou, N. Yang, B. Ren, M. Liu, H. Dai, X. Liu, F. Song and L. Zhang, Appl. Microbiol. Biotechnol., 2013, 97, 3885-3892.

143 T. A. Knappe, U. Linne, S. Zirah, S. Rebuffat, X. Xie and M. A. Marahiel, J. Am. Chem. Soc., 2008, 130, 11446-11454.

144 S. Um, Y.-J. Kim, H. Kwon, H. wen, S.-H. Kim, H. C. Kwon, S. Park, J. Shin and D.-C. Oh, J. Nat. Prod., 2013, 76, 873879.

145 K. Shiomi, H. Iinuma, M. Hamada, H. Naganawa, M. Manabe, C. Matsuki, T. Takeuchi and H. Umezawa, J. Antibiot., 1986, 39, 487-493.

146 K. Shiomi, H. Nakamura, H. Iinuma, H. Naganawa, T. Takeuchi, H. Umezawa and Y. Iitaka, J. Antibiot., 1987, 40, 1213-1219.

147 Y.-B. Cheng, P. R. Jensen and W. Fenical, Eur. J. Org. Chem., 2013, 18, 3751-3757.

148 Z. Wu, S. Li, J. Li, Y. Chen, K. Saurav, Q. Zhang, H. Zhang, W. Zhang, W. Zhang, S. Zhang and C. Zhang, Mar. Drugs, 2013, 11, 2113-2125.

149 Y. Igarashi, T. Iida, K. Miyanochi and Y. Sudo, Jpn. Kokai Tokkyo Koho, JP 2011010586 A 20110120, 2011.

150 K. H. Jang, S.-J. Nam, J. B. Locke, C. A. Kauffman, D. S. Beatty, L. A. Paul and W. Fenical, Angew. Chem., Int. Ed., 2013, 52, 7822-7824.

151 K. Takada, A. Ninomiya, M. Naruse, Y. Sun, M. Miyazaki, Y. Nogi, S. Okada and S. Matsunaga, J. Org. Chem., 2013, 78, 6746-6750.

152 A. Pesic, H. I. Baumann, K. Kleinschmidt, P. Ensle, J. Wiese, R. D. Süssmuth and J. F. Imhoff, Mar. Drugs, 2013, 11, 48344857.

153 Y. Zhang, X. Zhou, H. Huang, X. Tian, Y. Song, S. Zhang and J. Ju, J. Antibiot., 2013, 66, 327-331.

154 D. E. Williams, D. S. Dalisay, F. Li, J. Amphlett, W. Maneerat, M. A. G. Chavez, Y. A. Wang, T. Matainaho, W. Yu, P. J. Brown, C. H. Arrowsmith, M. Vedadi and R. J. Andersen, Org. Lett., 2013, 15, 414-417.

155 S.-J. Nam, C. A. Kauffman, P. R. Jensen and W. Fenical, Tetrahedron, 2011, 67, 6707-6712.
156 S.-J. Nam, C. A. Kauffman, L. A. Paul, P. R. Jensen and W. Fenical, Org. Lett., 2013, 15, 5400-5403.

157 M. S. Abdelfattah, Nat. Prod. Res., 2013, 27, 2126-2131.

158 E. Z. Ilan, M. R. Torres, J. Prudhomme, K. Le Roch, P. R. Jensen and W. Fenical, J. Nat. Prod., 2013, 76, 18151818.

159 C. Wu, Y. Tan, M. Gan, Y. Wang, Y. Guan, X. Hu, H. Zhou, X. Shang, X. You, Z. Yang and C. Xiao, J. Nat. Prod., 2013, 76, 2153-2157.

160 S. Um, T. J. Choi, H. Kim, B. Y. Kim, S.-H. Kim, S. K. Lee, K.-B. Oh, J. Shin and D.-C. Oh, J. Org. Chem., 2013, 78, 12321-12329.

161 M. Bae, H. Kim, Y. Shin, B. Y. Kim, S. K. Lee, K.-B. Oh, J. Shin and D.-C. Oh, Mar. Drugs, 2013, 11, 2882-2893.

162 H.-Q. Pan, S.-Y. Zhang, N. Wang, Z.-L. Li, H.-M. Hua, J.-C. Hu and S.-J. Wang, Mar. Drugs, 2013, 11, 3891-3901.

163 Y. Igarashi, T. Zhou, S. Sato, T. Matsumoto, L. Yu and N. Oku, Org. Lett., 2013, 15, 5678-5681.

164 X.-W. Yang, K. Peng, Z. Liu, G.-Y. Zhang, J. Li, N. Wang, A. Steinmetz and Y. Liu, J. Nat. Prod., 2013, 76, 2360-2363.

165 X. Xu, L. Yin, S. Wang, H. Liu, J. Gao and S. Zhao, Rec. Nat. Prod., 2013, 7, 292-295.

166 D.-C. Oh, W. K. Strangman, C. A. Kauffman, P. R. Jensen and W. Fenical, Org. Lett., 2007, 9, 1525-1528.

167 Y. Xu, R. D. Kersten, S.-J. Nam, L. Lu, A. M. Al-Suwailem, H. Zheng, W. Fenical, P. C. Dorrestein, B. S. Moore and P.-Y. Qian, J. Am. Chem. Soc., 2012, 134, 8625-8632.

168 I. Kaneko, H. Minekura, Y. Takeuchi, K. Kodama, T. Nakamura, H. Haruyama and Y. Sakaida, Japanese Patent, JP 06298796 A 1994.

169 A. C. Ross, Y. Xu, L. Lu, R. D. Kersten, Z. Shao, A. M. AlSuwailem, P. C. Dorrestein, P.-Y. Qian and B. S. Moore, J. Am. Chem. Soc., 2013, 135, 1155-1162.

170 S. Um, Y. Pyee, E.-H. Kim, S. K. Lee, J. Shin and D.-C. Oh, Mar. Drugs, 2013, 11, 611-622.

171 X. Li, S. Vanner, W. Wang, Y. Li, V. A. Gallardo and N. A. Magarvey, J. Antibiot., 2013, 66, 443-446.

172 J. Riedlinger, A. Reicke, H. Zaehner, B. Krismer, A. T. Bull, L. A. Maldonado, A. C. Ward, M. Goodfellow, B. Bister, D. Bischoff, R. D. Süssmuth and H.-P. Fiedler, J. Antibiot., 2004, 57, 271-279.

173 S. Keller, G. Nicholson, C. Drahl, E. Sorensen, H.-P. Fiedler and R. D. Süssmuth, J. Antibiot., 2007, 60, 391-394.

174 Q. Wang, F. Song, X. Xiao, P. Huang, L. Li, A. Monte, W. M. Abdel-Mageed, J. Wang, H. Guo, W. He, F. Xie, H. Dai, M. Liu, C. Chen, H. Xu, M. Liu, A. M. Piggott, X. Liu, R. J. Capon and L. Zhang, Angew. Chem., Int. Ed., 2013, 52, 1231-1234.

175 R. Raju, A. M. Piggott, M. M. Conte and R. J. Capon, Org. Biomol. Chem., 2010, 8, 4682-4689.

176 R. Sugiyama, S. Nishimura and H. Kakeya, Tetrahedron Lett., 2013, 54, 1531-1533.

177 K. Motohashi, M. Takagi and K. Shin-ya, J. Nat. Prod., 2010, 73, 226-228.

178 T. Hosoya, T. Hirokawa, M. Takagi and K. Shin-ya, J. Nat. Prod., 2012, 75, 285-289. 
179 K. Motohashi, M. Takagi and K. Shin-ya, J. Nat. Prod., 2013, 76, 1230.

180 T. Hosoya, T. Hirokawa, M. Takagi and K. Shin-ya, J. Nat. Prod., 2013, 76, 1231.

181 T. Kameyama, A. Takahashi, S. Kurasawa, M. Ishizuka, Y. Okami, T. Takeuchi and H. Umezawa, J. Antibiot., 1987, 40, 1664-1670.

182 A. Takahashi, H. Nakamura, T. Kameyama, S. Kurasawa, H. Naganawa, Y. Okami, T. Takeuchi, H. Umezawa and Y. Iitaka, J. Antibiot., 1987, 40, 1671-1676.

183 G. Winkelmann, B. Busch, A. Hartmann, G. Kirchhof, R. Sussmuth and G. Jung, BioMetals, 1999, 12, 255-264.

184 M. J. Fujita, K. Nakano and R. Sakai, Molecules, 2013, 18, 3917-3926.

185 Y. Hu, K. Wang and J. B. MacMillan, Org. Lett., 2013, 15, 390-393.

186 R. D. Shingare, R. Velayudham, J. R. Gawade and D. S. Reddy, Org. Lett., 2013, 15, 4556-4559.

187 G. Deltour, F. Binon, F. Henaux and R. Charlier, Arch. Int. Pharmacodyn. Ther., 1961, 131, 84-106.

188 H. Koshima, K. Ding, Y. Chisaka, T. Matsuura, I. Miyahara and K. Hirotsu, J. Am. Chem. Soc., 1997, 119, 10317-10324.

189 C. Gang, M.-X. Shen, W. Xin, X.-M. Fan, H.-M. Ma, H.-H. Wu and Y.-H. Pei, Chem. Nat. Compd., 2013, 49, 291-293.

190 K. Hong, G. Yuan, H. Lin, Q. Xie, C. Wang, X. Huang and Y. Tang, Faming Zhuanli Shenqing, CN 101792474 A 20100804, 2010.

191 G. Yuan, K. Hong, H. Lin, Z. She and J. Li, Mar. Drugs, 2013, 11, 817-829.

192 W.-J. Ding, S.-Q. Zhang, J.-H. Wang, Y.-X. Lin, Q.-X. Liang, W.-J. Zhao and C.-Y. Li, J. Asian Nat. Prod. Res., 2013, 15, 209-214.

193 G. Assante, S. Dallavalle, L. Malpezzi, G. Nasini, S. Burruano and L. Torta, Tetrahedron, 2005, 61, 7686-7692.

194 Suciati, J. A. Fraser, L. K. Lambert, G. K. Pierens, P. V. Bernhardt and M. J. Garson, J. Nat. Prod., 2013, 76, 1432-1440.

195 D. Li, Q. Gu, G. Zhang and T. Zhu, Faming Zhuanli Shenqing, CN 102001921 A 20110406, 2011.

196 G. Zhang, G. Wu, T. Zhu, T. Kurtán, A. Mándi, J. Jiao, J. Li, X. Qi, Q. Gu and D. Li, J. Nat. Prod., 2013, 76, 1946-1957.

197 L.-R. Xie, D.-Y. Li, Z.-L. Li, H.-M. Hua, P.-L. Wang and X. Wu, Nat. Prod. Res., 2013, 27, 847-850.

198 L. Chen, W.-W. Zhang, Q.-H. Zheng, Q.-Y. Liu, P. Zhong, X. Hu, Z.-X. Fang and Q.-Q. Zhang, Heterocycles, 2013, 87, 861-868.

199 O. I. Zhuravleva, S. S. Afiyatullov, E. A. Yurchenko, V. A. Denisenko, N. N. Kirichuk and P. S. Dmitrenok, Nat. Prod. Commun., 2013, 8, 1071-1074.

200 W. Jiang, P. Ye, C.-T. A. Chen, K. Wang, P. Liu, S. He, X. Wu, L. Gan, Y. Ye and B. Wu, Mar. Drugs, 2013, 11, 4761-4772.

201 G.-X. Zhou, E. M. K. Wijeratne, D. Bigelow, L. S. Pierson III, H. D. VanEtten and A. A. L. Gunatilaka, J. Nat. Prod., 2004, 67, 328-332.

202 W. Keller-Schierlein and E. Kupfer, Helv. Chim. Acta, 1979, 62, 1501-1524.
203 Z. Lin, T. Zhu, H. Wei, G. Zhang, H. Wang and Q. Gu, Eur. J. Org. Chem., 2009, 3045-3051.

204 T. Tomikawa, K. Shin-Ya, H. Seto, N. Okusa, T. Kajiura and Y. Hayakawa, J. Antibiot., 2002, 55, 666-668.

205 C.-J. Zheng, C.-L. Shao, L.-Y. Wu, M. Chen, K.-L. Wang, D.-L. Zhao, X.-P. Sun, G.-Y. Chen and C.-Y. Wang, Mar. Drugs, 2013, 11, 2054-2068.

206 X. Liu, F. Song, L. Ma, C. Chen, X. Xiao, B. Ren, X. Liu, H. Dai, A. M. Piggott, Y. Av-Gay, L. Zhang and R. J. Capon, Tetrahedron Lett., 2013, 54, 6081-6083.

207 G.-Y. Li, B.-G. Li, T. Yang, J.-H. Yin, H.-Y. Qi, G.-Y. Liu and G.-L. Zhang, J. Nat. Prod., 2005, 68, 1243-1246.

208 K. Arai, T. Yoshimura, Y. Itatani and Y. Yamamoto, Chem. Pharm. Bull., 1983, 31, 925-933.

209 M. H. Haroon, S. R. Premaratne, M. I. Choudhry and H. R. W. Dharmaratne, Nat. Prod. Res., 2013, 27, 1060-1066.

210 F. He, J. Bao, X.-Y. Zhang, Z.-C. Tu, Y.-M. Shi and S.-H. Qi, J. Nat. Prod., 2013, 76, 1182-1186.

211 S. Sureram, C. Kesornpun, C. Mahidol, S. Ruchirawat and P. Kittakoop, RSC Adv., 2013, 3, 1781-1788.

212 S. Nozoe, M. Morisaki, K. Fukushima and S. Okuda, Tetrahedron Lett., 1968, 42, 4457-4458.

213 H.-B. Liu, R. Edrada-Ebel, R. Ebel, Y. Wang, B. Schulz, S. Draeger, W. E. G. Mueller, V. Wray, W.-H. Lin and P. Proksch, Helv. Chim. Acta, 2011, 94, 623-631.

214 X.-H. Liu, F.-P. Miao, M.-F. Qiao, R. H. Cichewicz and N.-Y. Ji, RSC Adv., 2013, 3, 588-595.

215 K. Yamada, M. Doi, T. Yamada, K. Minoura and A. Numata, Tennen Yuki Kagobutsu Toronkai Koen Yoshishu, 2000, 42, 397-402.

216 K. Nakanishi, M. Doi, Y. Usami, T. Amagata, K. Minoura, R. Tanaka, A. Numata and T. Yamada, Tetrahedron, 2013, 69, 4617-4623.

217 N.-Y. Ji, X.-H. Liu, F.-P. Miao and M.-F. Qiao, Org. Lett., 2013, 15, 2327-2329.

218 L.-N. Zhou, H.-Q. Gao, S.-X. Cai, T.-J. Zhu, Q.-Q. Gu and D.-H. Li, Helv. Chim. Acta, 2011, 94, 1065-1070.

219 H. Gao, L. Zhou, S. Cai, G. Zhang, T. Zhu, Q. Gu and D. Li, J. Antibiot., 2013, 66, 539-542.

220 M. N. Oliveira, L. S. Santos, G. M. S. P. Guilhon, A. S. Santos, I. C. S. Ferreira, M. L. Lopes-Junior, M. S. P. Arruda, A. M. R. Marinho, M. N. da Silva, E. Rodrigues-Filho and M. C. F. Oliveira, J. Braz. Chem. Soc., 2011, 22, 993-996.

221 H.-F. Sun, X.-M. Li, L.-H. Meng, C.-M. Cui, S.-S. Gao, C.-S. Li and B.-G. Wang, Helv. Chim. Acta, 2013, 96, 458-462.

222 R.-R. Sun, F.-P. Miao, J. Zhang, G. Wang, X.-L. Yin and N.-Y. Ji, Magn. Reson. Chem., 2013, 51, 65-68.

223 J. Peng, X.-Y. Zhang, Z.-C. Tu, X.-Y. Xu and S.-H. Qi, J. Nat. Prod., 2013, 76, 983-987.

224 S. Tsukamoto, H. Hirota, M. Imachi, M. Fujimuro, H. Onuki, T. Ohta and H. Yokosawa, Bioorg. Med. Chem. Lett., 2005, 15, 191-194.

225 T. Kuwana, M. Miyazaki, H. Kato and S. Tsukamoto, Chem. Pharm. Bull., 2013, 61, 105-107.

226 J. Bao, X.-Y. Zhang, X.-Y. Xu, F. He, X.-H. Nong and S.-H. Qi, Tetrahedron, 2013, 69, 2113-2117. 
227 Y. Zhou, A. Debbab, A. Mándi, V. Wray, B. Schulz, W. E. G. Müller, M. Kassack, W. Lin, T. Kurtán, P. Proksch and A. H. Aly, Eur. J. Org. Chem., 2013, 5, 894906.

228 J. Wang, Z. Lu, P. Liu, Y. Wang, J. Li, K. Hong and W. Zhu, Planta Med., 2012, 78, 1861-1866.

229 K. A. Miller, S. Tsukamoto and R. M. Williams, Nat. Chem., 2009, 1, 63-68.

230 H. Kato, T. Yoshida, T. Tokue, Y. Nojiri, H. Hirota, T. Ohta, R. M. Williams and S. Tsukamoto, Angew. Chem., Int. Ed., 2007, 46, 2254-2256.

231 S. Li, J. M. Finefield, J. D. Sunderhaus, T. J. McAfoos, R. M. Williams and D. H. Sherman, J. Am. Chem. Soc., 2012, 134, 788-791.

232 M. Chen, C.-L. Shao, X.-M. Fu, R.-F. Xu, J.-J. Zheng, D.-L. Zhao, Z.-G. She and C.-Y. Wang, J. Nat. Prod., 2013, 76, 547-553.

233 S. Tsukamoto, H. Kato, M. Samizo, Y. Nojiri, H. Onuki, H. Hirota and T. Ohta, J. Nat. Prod., 2008, 71, 2064-2067.

234 S. Tsukamoto, H. Umaoka, K. Yoshikawa, T. Ikeda and H. Hirota, J. Nat. Prod., 2010, 73, 1438-1440.

235 J. M. Finefield and R. M. Williams, J. Org. Chem., 2010, 75, 2785-2789.

236 J. M. Finefield and R. M. Williams, J. Org. Chem., 2013, 78, 8214.

237 S. Tsukamoto, H. Kato, M. Samizo, Y. Nojiri, H. Ohnuki, H. Hirota and T. Ohta, J. Nat. Prod., 2013, 76, 1233.

238 S. Tsukamoto, H. Umaoka, K. Yoshikawa, T. Ikeda and H. Hirota, J. Nat. Prod., 2013, 76, 1232.

239 J. Bao, X.-Y. Xu, X.-Y. Zhang and S.-H. Qi, Nat. Prod. Commun., 2013, 8, 1127-1128.

240 G. N. Belofsky, P. R. Jensen, M. K. Renner and W. Fenical, Tetrahedron, 1998, 54, 1715-1724.

241 G. Assante, L. Carmada, R. Locci, L. Merlini, G. Nasini and E. Papadopoulos, J. Agric. Food Chem., 1981, 29, 785-787.

242 X. Xu, F. He, X. Zhang, J. Bao and S. Qi, Food Chem. Toxicol., 2013, 53, 46-51.

243 X.-Y. Xu, X.-Y. Zhang, F. He, J. Peng, X.-H. Nong and S.-H. Qi, Nat. Prod. Commun., 2013, 8, 1069-1070.

244 M. F. Elsebai, V. Rempel, G. Schnakenburg, S. Kehraus, C. E. Müller and G. M. König, ACS Med. Chem. Lett., 2011, 2, 866-869.

245 F. Zhu, G. Y. Chen, J. Wu and J. Pan, Nat. Prod. Res., 2013, 27, 1960-1964.

246 L.-Y. Zang, W. Wei, T. Wang, Y. Guo, R.-X. Tan and H.-M. Ge, Nat. Prod. Bioprospect., 2012, 2, 117-120.

247 E. Yoshida, H. Fujimoto, M. Baba and M. Yamazaki, Tennen Yuki Kagobutsu Toronkai Koen Yoshishu, 1993, 35, 290-297.

248 X.-L. Sun, H. Takayanagi, K. Matsuzaki, H. Tanaka, K. Furuhata and S. Omura, J. Antibiot., 1996, 49, 689-692.

249 N. Jansen, B. Ohlendorf, A. Erhard, T. Bruhn, G. Bringmann and J. F. Imhoff, Mar. Drugs, 2013, 11, 800-816.

250 G. Schlingmann, L. Milne and G. T. Carter, Tetrahedron, 2002, 58, 6825-6835.

251 J. Silber, B. Ohlendorf, A. Labes, A. Erhard and J. F. Imhoff, Mar. Drugs, 2013, 11, 3309-3323.
252 H. Matsumoto, K. Yoshikawa, S. Arihara and T. Miyataka, Jpn. Kokai Tokkyo Koho, JP 2005213144 A 20050811, 2005.

253 Y. Zhao, S.-Q. Li, H.-J. Li and W.-J. Lan, Chem. Nat. Compd., 2013, 49, 653-656.

254 Y.-M. Ying, W.-G. Shan, L.-W. Zhang, Y. Chen and Z.-J. Zhan, Helv. Chim. Acta, 2013, 96, 2092-2097.

255 H.-J. Li, Y.-L. Xie, Z.-L. Xie, Y. Chen, C.-K. Lam and W.-J. Lan, Mar. Drugs, 2012, 10, 627-638.

256 H. Takazawa and S. Kashino, Chem. Pharm. Bull., 1991, 39, 555-557.

257 E. Amouzou, W. A. Ayer and L. M. Browne, J. Nat. Prod., 1989, 52, 1042-1054.

258 F. Bohlmann, E. Inhoffen and P. Herbst, Chem. Ber., 1957, 90, 1661-1667.

259 H.-J. Li, T. Chen, Y.-L. Xie, W.-D. Chen, X.-F. Zhu and W.-J. Lan, Mar. Drugs, 2013, 11, 551-558.

260 J. Jeon, E. Julianti, H. Oh, W. Park, D.-C. Oh, K.-B. Oh and J. Shin, Tetrahedron Lett., 2013, 54, 3111-3115.

261 P. Sun, D.-X. Xu, A. Mándi, T. Kurtán, T.-J. Li, B. Schulz and W. Zhang, J. Org. Chem., 2013, 78, 7030-7047.

262 L. Sun, D. Li, M. Tao, Y. Chen, Q. Zhang, F. Dan and W. Zhang, Nat. Prod. Res., 2013, 27, 1298-1304.

263 T. Amagata, M. Tanaka, T. Yamada, K. Minoura and A. Numata, J. Nat. Prod., 2008, 71, 340-345.

264 T. Amagata, M. Tanaka, T. Yamada, Y.-P. Chen, K. Minoura and A. Numata, Tetrahedron Lett., 2013, 54, 5960-5962.

265 J. Sanz, A. C. Soria and M. C. Garcia-Vallejo, J. Chromatogr. A, 2004, 1024, 139-146.

266 K. Mori, Agric. Biol. Chem., 1976, 40, 1617-1619.

267 H. Zhu, X. Hua, T. Gong, J. Pang, Q. Hou and P. Zhu, Phytochem. Lett., 2013, 6, 392-396.

268 A. N. Yurchenko, O. F. Smetanina, Y. V. Khudyakova, N. N. Kirichuk, E. L. Chaikina, M. M. Anisimov and S. S. Afiyatullov, Chem. Nat. Compd., 2013, 49, 857-860.

269 S. B. Singh, D. L. Zink, G. F. Bills, A. Teran, K. C. Silverman, R. B. Lingham, P. Felock and D. J. Hazuda, Bioorg. Med. Chem. Lett., 2003, 13, 713-717.

270 K. Koyama, K. Kinoshita, N. Hamada, S. Natori and Y. Iitaka, Tennen Yuki Kagobutsu Toronkai Koen Yoshishu, 1987, 29, 713-720.

271 X. Kong, X. Ma, Y. Xie, S. Cai, T. Zhu, Q. Gu and D. Li, Arch. Pharmacal Res., 2013, 36, 739-744.

272 A. Eamvijarn, N. M. Gomes, T. Dethoup, J. Buaruang, L. Manoch, A. Silva, M. Pedro, I. Marini, V. Roussis and A. Kijjoa, Tetrahedron, 2013, 49, 8583-8591.

273 N. Xu, Y. Cao, L. Wang, G. Chen and Y.-H. Pei, J. Asian Nat. Prod. Res., 2013, 15, 731-736.

274 F.-T. Sun, G. Chen, J. Bai, W. Li and Y.-H. Pei, J. Asian Nat. Prod. Res., 2012, 14, 1109-1115.

275 Z. Mosadeghzad, Z. Zuriati, A. Asmat, U. Gires, R. Wickneswari, P. Pittayakhajonwut and G. H. N. Farahani, Chem. Nat. Compd., 2013, 49, 621-625.

276 C.-Y. An, X.-M. Li, C.-S. Li, S.-S. Gao, Z. Shang and B.-G. Wang, Helv. Chim. Acta, 2013, 96, 682-687.

277 P. Wang, D. Li, L. Xie, X. Wu, H. Hua and Z. Li, Nat. Prod. Commun., 2013, 8, 1397-1398. 
278 S. Shen, W. Li and J. Wang, Nat. Prod. Res., 2013, 27, 22862291.

279 Y.-L. Sun, J. Bao, K.-S. Liu, X.-Y. Zhang, F. He, Y.-F. Wang, X.-H. Nong and S.-H. Qi, Planta Med., 2013, 79, 1474-1479.

280 T. Sassa, H. Kachi and M. Nukina, J. Antibiot., 1985, 38, 439441.

281 M. Imran, L. Mitu, S. Latif, Z. Mahmood, I. Naimat, S. S. Zaman and S. Fatima, J. Serb. Chem. Soc., 2010, 75, 1075-1084.

282 C.-S. Li, X.-M. Li, S.-S. Gao, Y.-H. Lu and B.-G. Wang, Mar. Drugs, 2013, 11, 3068-3076.

283 F. Sóti, M. Incze, M. Kajtár-Peredy, E. Baitz-Gács, L. Imre and L. Farkas, Chem. Ber., 1977, 110, 979-984.

284 N. Tan, Y. Tao, J. Pan, S. Wang, F. Xu, Z. She, Y. Lin and E. B. G. Jones, Chem. Nat. Compd., 2008, 44, 296-300.

285 K. Drauz, A. Kleemann, J. Martens, P. Scherberich and F. Effenberger, J. Org. Chem., 1986, 51, 3494-3498.

286 S. Jin, P. Wessig and J. Liebscher, Eur. J. Org. Chem., 2000, 1993-1999.

287 Y. Kimura, T. Yoshinari, H. Koshino, S. Fujioka, K. Okada and A. Shimada, Biosci., Biotechnol., Biochem., 2007, 71, 1896-1901.

288 M.-H. Wang, X.-M. Li, C.-S. Li, N.-Y. Ji and B.-G. Wang, Mar. Drugs, 2013, 11, 2230-2238.

289 M. Vansteelandt, E. Blanchet, M. Egorov, F. Petit, L. Toupet, A. Bondon, F. Monteau, B. Le Bizec, O. P. Thomas, Y. F. Pouchus, R. Le Bot and O. Grovel, J. Nat. Prod., 2013, 76, 297-301.

290 H. Gao, L. Zhou, D. Li, Q. Gu and T.-J. Zhu, Helv. Chim. Acta, 2013, 96, 514-519.

291 E. Julianti, J.-H. Lee, L. Liao, W. Park, S. Park, D.-C. Oh, K.-B. Oh and J. Shin, Org. Lett., 2013, 15, 1286-1289.

292 A. Numata, C. Takahashi, T. Matsushita, T. Miyamoto, K. Kawai, Y. Usami, E. Matsumura, M. Inoue, H. Ohishi and T. Shingu, Tetrahedron Lett., 1992, 33, 1621-1624.

293 C.-B. Cui, H. Kakeya and H. Osada, Tennen Yuki Kagobutsu Toronkai Koen Yoshishu, 1996, 38, 49-54.

294 C. Takahashi, T. Matsushita, M. Doi, K. Minoura, T. Shingu, Y. Kumeda and A. Numata, J. Chem. Soc., Perkin Trans. 1, 1995, 2345-2353.

295 P. M. Scott, J. Polonsky and M. A. Merrien, J. Agric. Food Chem., 1979, 27, 201-202.

296 K. Nozawa and S. Nakajima, J. Nat. Prod., 1979, 42, 374-377. 297 S. Ohmomo, T. Sato, T. Utagawa and M. Abe, Agric. Biol. Chem., 1975, 3, 1333-1334.

298 K. F. Nielsen, M. W. Sumarah, J. C. Frisvad and J. D. Miller, J. Agric. Food Chem., 2006, 54, 3756-3763.

299 F. He, Z. Han, J. Peng, P.-Y. Qian and S.-H. Qi, Nat. Prod. Commun., 2013, 8, 329-332.

300 R. J. Capon, M. Stewart, R. Ratnayake, E. Lacey and J. H. Gill, J. Nat. Prod., 2007, 70, 1746-1752.

301 D.-S. Lee, J.-H. Jang, W. Ko, K.-S. Kim, J. H. Sohn, M.-S. Kang, J. S. Ahn, Y.-C. Kim and H. Oh, Mar. Drugs, 2013, 11, 1409-1426.

302 H. Ren, L. Tian, Q. Gu and W. Zhu, Arch. Pharmacal Res., 2006, 29, 59-63.
303 V. H. Powell and M. D. Sutherland, Aust. J. Chem., 1967, 20, 541-553.

304 T. Jiang, L. Tian, A. Guo, H. Fu, Y. Pei and W. Lin, Yaoxue Xuebao, 2002, 37, 271-274.

305 J. Bao, Y.-L. Sun, X.-Y. Zhang, Z. Han, H.-C. Gao, F. He, P.-Y. Qian and S.-H. Qi, J. Antibiot., 2013, 66, 219-223.

306 J. Qi, C.-L. Shao, Z.-Y. Li, L.-S. Gan, X.-M. Fu, w.-T. Bian, H.-Y. Zhao and C.-Y. Wang, J. Nat. Prod., 2013, 76, 571-579.

307 M. H. Kossuga, A. G. Ferreira, L. D. Sette and R. G. S. Berlinck, Rev. Bras. Farmacogn., 2012, 22, 257-267. 308 M. H. Kossuga, A. G. Ferreira, L. D. Sette and R. G. S. Berlinck, Nat. Prod. Commun., 2013, 8, 721-724.

309 G. Wu, A. Lin, Q. Gu, T. Zhu and D. Li, Mar. Drugs, 2013, 11, 1399-1408.

310 P. S. Baran and E. J. Corey, J. Am. Chem. Soc., 2002, 124, 7904-7905.

311 T. H. Quang, D.-S. Lee, J. H. Sohn, Y.-C. Kim and H. Oh, Bull. Korean Chem. Soc., 2013, 34, 3109-3112.

312 E. Li, L. Jiang, L. Guo, H. Zhang and Y. Che, Bioorg. Med. Chem., 2008, 16, 7894-7899.

313 M.-Y. Wei, D. Li, C.-L. Shao, D.-S. Deng and C.-Y. Wang, Mar. Drugs, 2013, 11, 1050-1060.

314 B. Wu, X. Wu, M. Sun and M. Li, Mar. Drugs, 2013, 11, 27132721.

315 M. F. Elsebai, S. Kehraus and G. M. König, Steroids, 2013, 78, 880-883.

316 V. Rukachaisirikul, S. Kannai, S. Klaiklay, S. Phongpaichit and J. Sakayaroj, Tetrahedron, 2013, 69, 6981-6986.

317 C.-L. Shao, R.-F. Xu, M.-Y. Wei, Z.-G. She and C.-Y. Wang, J. Nat. Prod., 2013, 76, 779-782.

318 M. J. Vazquez, A. Vega, A. Rivera-Sagredo, M. D. JimenezAlfaro, E. Diez and J. A. Hueso-Rodriguez, Tetrahedron, 2004, 60, 2379-2385.

319 X. Ma, L. Li, T. Zhu, M. Ba, G. Li, Q. Gu, Y. Guo and D. Li, J. Nat. Prod., 2013, 76, 2298-2306.

320 M. Muto, H. Kohri, H. Ishitani and K. Higaki, Nagoya Kogyo Daigaku Gakuho, 1970, 22, 159-164.

321 C. Almeida, E. Eguereva, S. Kehraus and G. M. König, J. Nat. Prod., 2013, 76, 322-326.

322 A. Haga, H. Tamoto, M. Ishino, E. Kimura, T. Sugita, K. Kinoshita, K. Takahashi, M. Shiro and K. Koyama, J. Nat. Prod., 2013, 76, 750-754.

323 L. Chen, P. Zhong, J.-R. Pan, K.-J. Zhou, K. Huang, Z.-X. Fang and Q.-Q. Zhang, Heterocycles, 2013, 87, 645-655.

324 J. Ren, Y. Yang, D. Liu, W. Chen, P. Proksch, B. Shao and W. Lin, J. Chromatogr. A, 2013, 1309, 90-95.

325 A. Carroux, A.-I. van Bohemen, C. Roullier, T. R. du Pont, M. Vansteelandt, A. Bondon, A. Zalouk-Vergnoux, Y. F. Pouchus and N. Ruiz, Chem. Biodiversity, 2013, 10, 772-786.

326 I. Panizel, O. Yarden, M. Ilan and S. Carmeli, Mar. Drugs, 2013, 11, 4937-4960.

327 Z.-L. Xie, H.-J. Li, L.-Y. Wang, W.-L. Liang, W. Liu and W.-J. Lan, Nat. Prod. Commun., 2013, 8, 67-68.

328 B. R. Clark, R. J. Capon, E. Lacey, S. Tennant and J. H. Gill, Org. Biomol. Chem., 2006, 4, 1520-1528. 
329 M. M. Chien, P. L. Schiff Jr, D. J. Slatkin and J. E. Knapp, Lloydia, 1977, 40, 301-302.

330 S. Iwasaki, H. Muro, S. Nozoe, S. Okuda and Z. Sato, Tetrahedron Lett., 1972, 13-16.

331 X.-H. Nong, Z.-H. Zheng, X.-Y. Zhang, X.-H. Lu and S.-H. Qi, Mar. Drugs, 2013, 11, 1718-1727.

332 L. Chen, W. Liu, K. Huang, X. Hu, Z.-X. Fang, J.-L. Wu and Q.-Q. Zhang, Heterocycles, 2011, 83, 1853-1858.

333 L. Xu, J. Xue, H. Xu, X. Liu, W. Ma and X. Wei, Heterocycles, 2006, 68, 1955-1959.

334 L. Chen, K. Huang, P. Zhong, X. Hu, Z.-X. Fang, J. Wu and Q.-Q. Zhang, Heterocycles, 2012, 85, 413-419.

335 N. Khamthong, V. Rukachaisirikul, S. Phongpaichit, S. Preedanon and J. Sakayaroj, Tetrahedron, 2012, 68, 8245-8250.

336 C.-L. Shao, H.-X. Wu, C.-Y. Wang, Q.-A. Liu, Y. Xu, M.-Y. Wei, P.-Y. Qian, Y.-C. Gu, C.-J. Zheng, Z.-G. She and Y.-C. Lin, J. Nat. Prod., 2011, 74, 629-633.

337 C.-L. Shao, H.-X. Wu, C.-Y. Wang, Q.-A. Liu, Y. Xu, M.-Y. Wei, P.-Y. Qian, Y.-C. Gu, C.-J. Zheng, Z.-G. She and Y.-C. Lin, J. Nat. Prod., 2013, 76, 302.

338 A. McClay, H. van Den Berg, P. Johnston, W. Watters, K. McGarell, D. Waugh, P. Armstrong, Z. Delbederi, C. Higgins and T. Mills, PCT Int. Appl., WO 2006046071 A1 20060504, 2006.

339 C. D. Donner and M. Gill, J. Chem. Soc., Perkin Trans. 1, 2002, 938-948.

340 K. Yun, Z. Feng, H. D. Choi, J. S. Kang and B. W. Son, Chem. Nat. Compd., 2013, 49, 24-26.

341 S. Tamura and A. Sakurai, Agric. Biol. Chem., 1964, 28, 331336.

342 A. Abdel-Lateff, T. Okino, W. M. Alarif and S. S. Al-Lihaibi, J. Saudi Chem. Soc., 2013, 17, 161-165.

343 H. Nagasawa, A. Suzuki and S. Tamura, Agric. Biol. Chem., 1978, 42, 1303-1304.

344 A. J. Flewelling, J. A. Johnson and C. A. Gray, Nat. Prod. Commun., 2013, 8, 373-374.

345 G. Gatti, R. Cardillo, C. Fuganti and D. Ghiringhelli, J. Chem. Soc., Chem. Commun., 1976, 435-436.

346 D.-L. Li, X.-M. Li, T.-G. Li, H.-Y. Dang and B.-G. Wang, Helv. Chim. Acta, 2008, 91, 1888-1893.

347 H. Gao, T. Zhu, D. Li, Q. Gu and W. Liu, Arch. Pharmacal Res., 2013, 36, 952-956.

348 S.-W. Sun, C.-Z. Ji, Q.-Q. Gu, D.-H. Li and T.-J. Zhu, J. Asian Nat. Prod. Res., 2013, 15, 956-961.

349 S. A. Neff, S. U. Lee, Y. Asami, J. S. Ahn, H. Oh, J. Baltrusaitis, J. B. Gloer and D. T. Wicklow, J. Nat. Prod., 2012, 75, 464-472.

350 C.-Y. An, X.-M. Li, H. Luo, C.-S. Li, M.-H. Wang, G.-M. Xu and B.-G. Wang, J. Nat. Prod., 2013, 76, 1896-1901.

351 C.-Y. An, X.-M. Li, C.-S. Li, M.-H. Wang, G.-M. Xu and B.-G. Wang, Mar. Drugs, 2013, 11, 2682-2694.

352 D. Liu, X.-M. Li, C.-S. Li and B.-G. Wang, Helv. Chim. Acta, 2013, 96, 1055-1061.

353 N. Ojima, S. Takenaka and S. Seto, Phytochemistry, 1973, 12, 2527-2529.
354 P. Karrer, K. A. Gehrckens and W. Heuss, Helv. Chim. Acta, 1926, 9, 446-457.

355 H. Gao, W. Guo, Q. Wang, L. Zhang, M. Zhu, T. Zhu, Q. Gu, W. Wang and D. Li, Bioorg. Med. Chem. Lett., 2013, 23, 1776-1778.

356 S. Cai, S. Sun, H. Zhou, X. Kong, T. Zhu, D. Li and Q. Gu, J. Nat. Prod., 2011, 74, 1106-1110.

357 T. J. Greshock, A. W. Grubbs, P. Jiao, D. T. Wicklow, J. B. Gloer and R. M. Williams, Angew. Chem., Int. Ed., 2008, 47, 3573-3577.

358 S. Cai, Y. Luan, X. Kong, T. Zhu, Q. Gu and D. Li, Org. Lett., 2013, 15, 2168-2171.

359 C. Deng, C. Huang, Q. Wu, J. Pang and Y. Lin, Nat. Prod. Res., 2013, 27, 1882-1887.

360 G. A. Ellestad, R. H. Evans Jr and M. P. Kunstmann, Tetrahedron Lett., 1971, 497-500.

361 H.-F. Sun, X.-M. Li, L. Meng, C.-M. Cui, S.-S. Gao, C.-S. Li, C.-G. Huang and B.-G. Wang, J. Nat. Prod., 2012, 75, 148152.

362 H. M. T. Bandara Herath, W. H. M. W. Herath, P. Carvalho, S. I. Khan, B. L. Tekwani, S. O. Duke, M. Tomaso-Peterson and N. P. D. Nanayakkara, J. Nat. Prod., 2009, 72, 20912097.

363 B. Caron and P. Brassard, Tetrahedron, 1991, 47, 4287-4298. 364 C.-M. Deng, S.-X. Liu, C.-H. Huang, J.-Y. Pang and Y.-C. Lin, Mar. Drugs, 2013, 11, 2616-2624.

365 X. Huang, H. Huang, H. Li, X. Sun, H. Huang, Y. Lu, Y. Lin, Y. Long and Z. She, Org. Lett., 2013, 15, 721-723.

366 Z. Xiao, H. Huang, C. Shao, X. Xia, L. Ma, X. Huang, Y. Lu, Y. Lin, Y. Long and Z. She, Org. Lett., 2013, 15, 2522-2525.

367 G. Buechi, K. C. Luk, B. Kobbe and J. M. Townsend, J. Org. Chem., 1977, 42, 244-246.

368 J. Clardy, J. P. Springer, G. Buechi, K. Matsuo and R. Wightman, J. Am. Chem. Soc., 1975, 97, 663-665.

369 N. Koyama, Y. Inoue, M. Sekine, Y. Hayakawa, H. Homma, S. Oinmura and H. Tomoda, Org. Lett., 2008, 10, 5273-5276.

370 J. Peng, T. Lin, W. Wang, Z. Xin, T. Zhu, Q. Gu and D. Li, J. Nat. Prod., 2013, 76, 1133-1140.

$371 \mathrm{~W}$. Ebrahim, A. H. Aly, A. Mandi, F. Totzke, M. H. G. Kubbutat, V. Wray, W.-H. Lin, H. Dai, P. Proksch, T. Kurtán and A. Debbab, Eur. J. Org. Chem., 2012, 3476-3484.

372 W. Ebrahim, A. H. Aly, V. Wray, P. Proksch and A. Debbab, Tetrahedron Lett., 2013, 54, 6611-6614.

373 L. Calcul, C. Waterman, W. S. Ma, M. D. Lebar, C. Harter, T. Mutka, L. Morton, P. Maignan, A. van Olphen, D. E. Kyle, L. Vrijmoed, K.-L. Pang, C. Pearce and B. J. Baker, Mar. Drugs, 2013, 11, 5036-5050.

374 D. Liu, X.-M. Li, C.-S. Li and B.-G. Wang, Helv. Chim. Acta, 2013, 96, 437-444.

375 Z. Huang, C. Shao, Y. Chen, Z. She, Y. Lin and S. Zhou, Chem. Nat. Compd., 2007, 43, 655-658.

376 G. N. Belofsky, J. B. Gloer, D. T. Wicklow and P. F. Dowd, Tetrahedron, 1995, 51, 3959-3968.

377 T. Fehr and W. Acklin, Helv. Chim. Acta, 1966, 49, 19071910. 
378 H. Sun, S. Gao, X. Li, C. Li and B. Wang, Chin. J. Oceanol. Limnol., 2013, 31, 464-470.

379 H. Seya, K. Nozawa, S. Udagawa, S. Nakajima and K. Kawai, Chem. Pharm. Bull., 1986, 34, 2411-2416.

380 P. G. Mantle and C. M. Weedon, Phytochemistry, 1994, 36, 1209-1217.

381 Y. Fan, Y. Wang, P. Liu, P. Fu, T. Zhu, W. Wang and W. Zhu, J. Nat. Prod., 2013, 76, 1328-1336.

382 L.-H. Meng, X.-M. Li, C.-T. Lv, C.-S. Li, G.-M. Xu, C.-G. Huang and B.-G. Wang, J. Nat. Prod., 2013, 76, 2145-2149.

383 CAS Registry Number: 1235379-39-1, Ambinter Stock Screening Collection, Ambinter, Amb15769954, 21 Feb 2014.

384 CAS Registry Number: 1235379-39-1, Analyticon Discovery MEGx Catalog, AnalytiCon Discovery GmbH, NP-002355, NP-003261, 29 Jan 2014.

385 CAS Registry Number: 1235379-39-1, K13.052.753, Aurora Screening Library, Aurora Fine Chemicals LLC, 3 Jul 2013.

386 M. L. Wang, C. H. Lu, Q. Y. Xu, S. Y. Song, Z. Y. Hu and Z. H. Zheng, Molecules, 2013, 18, 5723-5735.

387 X. Huang, X. Sun, B. Ding, M. Lin, L. Liu, H. Huang and Z. She, Planta Med., 2013, 79, 1572-1575.

388 K. Otoguro, K. Shiomi, Y. Yamaguchi, N. Arai, T. Sunazuka, R. Masuma, Y. Iwai and S. Omura, J. Antibiot., 2000, 53, 5057.

389 J. Yang, R. Huang, S. Qiu, Z. She and Y. Lin, Nat. Prod. Res., 2013, 27, 1902-1905.

390 Y. Hemberger, J. Xu, V. Wray, P. Proksch, J. Wu and G. Bringmann, Chem.-Eur. J., 2013, 19, 15556-15564.

391 D. Rönsberg, A. Debbab, A. Mándi, V. Wray, H. Dai, T. Kurtán, P. Proksch and A. H. Aly, Tetrahedron Lett., 2013, 54, 3256-3259.

392 W. J. McGahren, G. A. Ellestad, G. O. Morton, M. P. Kunstmann and P. Mullen, J. Org. Chem., 1973, 38, 3542-3544.

393 Z. Huang, J. Yang, F. Lei, Z. She and Y. Lin, Chem. Nat. Compd., 2013, 49, 27-30.

394 J. X. Yang, S. Qiu, Z. She and Y. Lin, Chem. Nat. Compd., 2013, 49, 31-33.

395 J. X. Yang, S. Qiu, Z. She and Y. Lin, Chem. Nat. Compd., 2013, 49, 246-248.

396 M. M. Wagenaar and J. Clardy, J. Nat. Prod., 2001, 64, 10061009.

397 V. Rukachaisirikul, U. Sommart, S. Phongpaichit, J. Sakayaroj and K. Kirtikara, Phytochemistry, 2008, 69, 783-787.

398 S. Cao, D. W. McMillin, G. Tamayo, J. Delmore, C. S. Mitsiades and J. Clardy, J. Nat. Prod., 2012, 75, 793797.

399 B. Ding, J. Yuan, X. Huang, W. wWn, X. Zhu, Y. Liu, H. Li, Y. Lu, L. He, H. Tan and Z. She, Mar. Drugs, 2013, 11, 49614972.

400 Y. Shiono, T. Sasaki, F. Shibuya, Y. Yasuda, T. Koseki and U. Supratman, Nat. Prod. Commun., 2013, 8, 1735-1737.

401 J. Wang, W. Ding, C. Li, S. Huang, Z. She and Y. Lin, Chem. Nat. Compd., 2013, 49, 799-802.
402 Z. Feng and L. Yongcheng, Chin. Sci. Bull., 2006, 51, 14261430.

403 C.-L. Shao, C.-Y. Wang, Y.-C. Gu, M.-Y. Wei, J.-H. Pan, D.-S. Deng, Z.-G. She and Y.-C. Lin, Bioorg. Med. Chem. Lett., 2010, 20, 3284-3286.

404 L. A. Shaala, D. T. A. Youssef, K. L. McPhail and M. Elbandy, Phytochem. Lett., 2013, 6, 183-188.

405 S. P. Gunasekera, R. Ritson-Williams and V. J. Paul, J. Nat. Prod., 2008, 71, 2060-2063.

406 J. I. Jiménez, T. Vansach, W. Y. Yoshida, B. Sakamoto, P. Pörzgen and F. D. Horgen, J. Nat. Prod., 2009, 72, 1573-1578.

407 E. Mevers, T. Byrum and W. H. Gerwick, J. Nat. Prod., 2013, 76, 1810-1814.

408 C. C. Thornburg, E. S. Cowley, J. Sikorska, L. A. Shaala, J. E. Ishmael, D. T. A. Youssef and K. L. McPhail, J. Nat. Prod., 2013, 76, 1781-1788.

409 L. T. Tan, T. Okino and W. H. Gerwick, Mar. Drugs, 2013, 11, 3015-3024.

410 R. Montaser, V. J. Paul and H. Luesch, Org. Lett., 2013, 15, 4050-4053.

411 C. M. Pavlik, C. Y. B. Wong, S. Ononye, D. D. Lopez, N. Engene, K. L. McPhail, W. H. Gerwick and M. J. Balunas, J. Nat. Prod., 2013, 76, 2026-2033.

412 K. Kumagai, M. Tsuda, E. Fukushi and J. Kawabata, Heterocycles, 2013, 87, 2615-2623.

413 R. Watanabe, H. Uchida, T. Suzuki, R. Matsushima, M. Nagae, Y. Toyohara, M. Satake, Y. Oshima, A. Inoue and T. Yasumoto, Tetrahedron, 2013, 69, 10299-10303.

414 C. Tsukano and M. Sasaki, Tetrahedron Lett., 2006, 47, 6803-6807.

415 Y. Tanaka, M. Satake, M. Yotsu-Yamashita and Y. Oshima, Heterocycles, 2013, 87, 2037-2046.

416 B. S. Hwang, E. Y. Yoon, H. S. Kim, W. Yih, J. Y. Park, H. J. Jeong and J.-R. Rho, Bioorg. Med. Chem. Lett., 2013, 23, 3023-3027.

417 H. Uchida, Y. Taira and T. Yasumoto, Rapid Commun. Mass Spectrom., 2013, 27, 1999-2008.

418 J. L. Dahmen and J. D. Leblond, Protist, 2013, 164, 183-194.

419 A. I. Selwood, A. L. Wilkins, R. Munday, F. Shi, L. L. Rhodes and P. T. Holland, Tetrahedron Lett., 2013, 54, 4705-4707.

420 M. Ishibashi, N. Yamaguchi, T. Sasaki and J. Kobayashi, J. Chem. Soc., Chem. Commun., 1994, 1455-1456.

421 Y. Takahashi, T. Kubota, M. Imachi, M. R. Wälchli and J. Kobayashi, J. Antibiot., 2013, 66, 277-279.

422 J. D. Leblond, H. I. Timofte, S. A. Roche and N. M. Porter, Phycol. Res., 2010, 58, 222-229.

423 A. Nagatsu, M. Watanabe, K. Ikemoto, M. Hashimoto, N. Murakami, J. Sakakibara, H. Tokuda, H. Nishino, A. Iwashima and K. Yazawa, Bioorg. Med. Chem. Lett., 1994, 4, 1619-1622.

424 A. H. Banskota, R. Stefanova, P. Gallant and P. J. McGinn, J. Appl. Phycol., 2013, 25, 349-357.

425 A. Arakaki, D. Iwama, Y. Liang, N. Murakami, M. Ishikura, T. Tanaka and T. Matsunaga, Phytochemistry, 2013, 85, 107114. 
426 E. Julianti, H. Oh, H.-S. Lee, D.-C. Oh, K.-B. Oh and J. Shin, Tetrahedron Lett., 2012, 53, 2885-2886.

427 K. Banert, Tetrahedron Lett., 2012, 53, 6443-6445.

428 L. A. Januar and T. F. Molinski, Org. Lett., 2013, 15, 23702373.

429 Q.-X. Wu, M. S. Crews, M. Draskovic, J. Sohn, T. A. Johnson, K. Tenney, F. A. Valeriote, X.-J. Yao, L. F. Bjeldanes and P. Crews, Org. Lett., 2010, 12, 4458-4461.

430 J.-C. Zhao, S.-M. Yu, Y. Liu and Z.-J. Yao, Org. Lett., 2013, 15, 4300-4303.

431 Y. Zhuang, X. Teng, Y. Wang, P. Liu, H. Wang, J. Li, G. Li and W. Zhu, Tetrahedron, 2011, 67, 7085-7089.

432 L. Wang and W. Zhu, Tetrahedron Lett., 2013, 54, 67296731.

433 J. Zhang, L. He, H. Xue and R. Feng, Chin. Chem. Lett., 1990, 1, 223-224.

434 J. Zhang and L. He, Yaoxue Xuebao, 1986, 21, 273-278.

435 M. Tsuda, Y. Kasai, K. Komatsu, T. Sone, M. Tanaka, Y. Mikami and J. Kobayashi, Org. Lett., 2004, 6, 3087-3089.

436 T. Mugishima, M. Tsuda, Y. Kasai, H. Ishiyama, E. Fukushi, J. Kawabata, M. Watanabe, K. Akao and J. Kobayashi, J. Org. Chem., 2005, 70, 9430-9435.

437 Z. Bian, C. C. Marvin and S. F. Martin, J. Am. Chem. Soc., 2013, 135, 10886-10889.

438 K. Kong, J. A. Enquist Jr, M. E. McCallum, G. M. Smith, T. Matsumaru, E. Menhaji-Klotz and J. L. Wood, J. Am. Chem. Soc., 2013, 135, 10890-10893.

439 Y. Sun, L. Tian, J. Huang, H.-Y. Ma, Z. Zheng, A.-L. Lv, K. Yasukawa and Y.-H. Pei, Org. Lett., 2008, 10, 393-396.

440 H. Shigehisa, Y. Suwa, N. Furiya, Y. Nakaya, M. Fukushima, Y. Ichihashi and K. Hiroya, Angew. Chem., Int. Ed., 2013, 52, 3646-3649.

441 Q. Li, Y.-S. Xu, G. A. Ellis, T. S. Bugni, Y. Tang and R. P. Hsung, Tetrahedron Lett., 2013, 54, 5567-5572.

442 Z.-J. Lin, Z.-Y. Lu, T.-J. Zhu, Y.-C. Fang, Q.-Q. Gu and W.-M. Zhu, Chem. Pharm. Bull., 2008, 56, 217-221.

443 K. Kempf, A. Raja, F. Sasse and R. Schobert, J. Org. Chem., 2013, 78, 2455-2461.

444 J. Xu, J. Kjer, J. Sendker, V. Wray, H. Guan, R. Edrada, W. Lin, J. Wu and P. Proksch, J. Nat. Prod., 2009, 72, 662665.

445 A. M. Beekman and R. A. Barrow, J. Nat. Prod., 2013, 76, 2054-2059.

446 F. Xu, J. Pang, B. Lu, J. Wang, Y. Zhang, Z. She, L. L. P. Vrijmoed, E. B. Gareth Jones and Y. Lin, Chin. J. Chem., 2009, 27, 365-368.

447 R.-A. F. Rarig, M. N. Tran and D. M. Chenoweth, J. Am. Chem. Soc., 2013, 135, 9213-9219.

448 W. P. Frankmolle, G. Knubel, R. E. Moore and G. M. L. Patterson, J. Antibiot., 1992, 45, 1458-1466.

449 I. Bonnard, M. Rolland, C. Francisco and B. Banaigs, Lett. Pept. Sci., 1997, 4, 289-292.

450 N. Maru, O. Ohno and D. Uemura, Tetrahedron Lett., 2010, 51, 6384-6387.

451 F. Boyaud, Z. Mahiout, C. Lenoir, S. Tang, J. WdzieczakBakala, A. Witczak, I. Bonnard, B. Banaigs, T. Ye and N. Inguimbert, Org. Lett., 2013, 15, 3898-3901.
452 B. Adams, P. Poerzgen, E. Pittman, W. Y. Yoshida, H. E. Westenburg and F. D. Horgen, J. Nat. Prod., 2008, 71, 750-754.

453 P. K. Gajula, S. Sharma, R. S. Ampapathi and T. K. Chakraborty, Org. Biomol. Chem., 2013, 11, 257-260.

454 M. Murata, S. Matsuoka, N. Matsumori, G. K. Paul and K. Tachibana, J. Am. Chem. Soc., 1999, 121, 870-871.

455 M. Ebine, M. Kanemoto, Y. Manabe, Y. Konno, K. Sakai, N. Matsumori, M. Murata and T. Oishi, Org. Lett., 2013, 15, 2846-2849.

456 M. A. M. Mondol, J. H. Kim, M. A. Lee, F. S. Tareq, H.-S. Lee, Y.-J. Lee and H. J. Shin, J. Nat. Prod., 2011, 74, 1606-1612.

457 V. T. Salunkhe, S. Bhosale, P. Punde, D. Bhuniya and S. Koul, Tetrahedron Lett., 2013, 54, 2489-2491.

458 E. N. Reddy, A. Krishnaiah and T. P. Rao, Tetrahedron: Asymmetry, 2013, 24, 724-728.

459 S. Das and R. K. Goswami, J. Org. Chem., 2013, 78, 72747280.

460 N. N. Rao and H. M. Meshram, Tetrahedron Lett., 2013, 54, 4544-4546.

461 F. S. Tareq, J. H. Kim, M. A. Lee, H.-S. Lee, Y.-J. Lee, J. S. Lee and H. J. Shin, Org. Lett., 2012, 14, 1464-1467.

462 C. R. Reddy, E. Jithender and K. R. Prasad, J. Org. Chem., 2013, 78, 4251-4260.

463 F. S. Tareq, J. H. Kim, M. A. Lee, H.-S. Lee, Y.-J. Lee, J. S. Lee and H. J. Shin, Org. Lett., 2013, 15, 2071.

464 H. Huang, Y. Yao, Z. He, T. Yang, J. Ma, X. Tian, Y. Li, C. Huang, X. Chen, W. Li, S. Zhang, C. Zhang and J. Ju, J. Nat. Prod., 2011, 74, 2122-2127.

465 S. Tagawa, T. Choshi, A. Okamoto, T. Nishiyama, S. Watanabe, N. Hatae and S. Hibino, Heterocycles, 2013, 87, 357-367.

466 Y. Matsuo, K. Kanoh, T. Yamori, H. Kasai, A. Katsuta, K. Adachi, K. Shin-ya and Y. Shizuri, J. Antibiot., 2007, 60, 251-255.

467 Y. Matsuo, K. Kanoh, H. Imagawa, K. Adachi, M. Nishizawa and Y. Shizuri, J. Antibiot., 2007, 60, 256-260.

468 C.-C. Lin, W. Tantisantisom and S. R. McAlpine, Org. Lett., 2013, 15, 3574-3577.

469 T. Tamaoki, K. Shirahata, T. Iida and F. Tomita, J. Antibiot., 1981, 34, 1525-1530.

470 R. P. Maskey, E. Helmke, O. Kayser, H. H. Fiebig, A. Maier, A. Busche and H. Laatsch, J. Antibiot., 2004, 57, 771-779.

471 T. Magauer, D. J. Smaltz and A. G. Myers, Nat. Chem. Biol., 2013, 5, 886-893.

472 S. Sato, F. Iwata, T. Mukai, S. Yamada, J. Takeo, A. Abe and H. Kawahara, J. Org. Chem., 2009, 74, 5502-5509.

473 O. F. Jeker and E. M. Carreira, Angew. Chem., Int. Ed., 2012, 51, 3474-3477.

474 C. He, C. Zhu, Z. Dai, C.-C. Tseng and H. Ding, Angew. Chem., Int. Ed., 2013, 52, 13256-13260.

475 M. L. Ciavatta, M. P. Lopez-Gresa, M. Gavagnin, R. Nicoletti, E. Manzo, E. Mollo, Y.-W. Guo and G. Cimino, Tetrahedron, 2008, 64, 5365-5369.

476 J. Vannada, L. Niehues, B. König and G. Mehta, Tetrahedron, 2013, 69, 6034-6040.

477 G. K. Poch and J. B. Gloer, J. Nat. Prod., 1989, 52, 257-260. 
478 J. S. Yadav, A. B. Reddy and K. S. Shankar, Synthesis, 2013, 45, 1034-1038.

479 C. Takahashi, A. Numata, Y. Ito, E. Matsumura, H. Araki, H. Iwaki and K. Kushida, J. Chem. Soc., Perkin Trans. 1, 1994, 1859-1864.

480 J.-Y. Dong, H.-P. He, Y.-M. Shen and K.-Q. Zhang, J. Nat. Prod., 2005, 68, 1510-1513.

481 F.-Z. Wang, Z. Huang, X.-F. Shi, Y.-C. Chen, W.-M. Zhang, X.-P. Tian, J. Li and S. Zhang, Bioorg. Med. Chem. Lett., 2012, 22, 7265-7267.

482 J. E. DeLorbe, D. Horne, R. Jove, S. M. Mennen, S. Nam, F.-L. Zhanag and L. E. Overman, J. Am. Chem. Soc., 2013, 135, 4117-4128.

483 K. Trisuwan, V. Rukachaisirikul, Y. Sukpondma, S. Phongpaichit, S. Preedanon and J. Sakayaroj, Chem. Pharm. Bull., 2009, 57, 1100-1102.

484 L. Song, H. Yao, L. Zhu and R. Tong, Org. Lett., 2013, 15, 69.

485 G. Carr, W. Tay, H. Bottriell, S. K. Andersen, A. G. Mauk and R. J. Andersen, Org. Lett., 2009, 11, 2996-2999.

486 S. Y. Jabri and L. E. Overman, J. Am. Chem. Soc., 2013, 135, 4231-4234.

487 S. Y. Jabri and L. E. Overman, J. Org. Chem., 2013, 78, 87668788.

488 J. Orjala and W. H. Gerwick, Phytochemistry, 1997, 45, 10871090.

489 A. Phanumartwiwath, T. W. Hornsby, J. Jamalis, C. D. Bailey and C. L. Willis, Org. Lett., 2013, 15, 5734-5737.

490 G. E. Chlipala, P. H. Tri, N. van Hung, A. Krunic, S. H. Shim, D. D. Soejarto and J. Orjala, J. Nat. Prod., 2010, 73, 784-787.

491 A. Kamal and S. R. Vangala, Org. Biomol. Chem., 2013, 11, 4442-4448.

492 M. Gutierrez, A. R. Pereira, H. M. Debonsi, A. Ligresti, V. Di Marzo and W. H. Gerwick, J. Nat. Prod., 2011, 74, 23132317.

493 Y.-R. Gao, S.-H. Guo, Z.-X. Zhang, S. Mao, Y.-L. Zhang and Y.-Q. Wang, Tetrahedron Lett., 2013, 54, 6511-6513.

494 P. D. Boudreau, T. Byrum, W.-T. Liu, P. C. Dorrestein and W. H. Gerwick, J. Nat. Prod., 2012, 75, 1560-1570.

495 D. Wang, S. Song, Y. Tian, Y. Xu, Z. Miao and A. Zhang, J. Nat. Prod., 2013, 76, 974-978.

496 J. Kobayashi, M. Ishibashi, M. R. Walchli, H. Nakamura, Y. Hirata, T. Sasaki and Y. Ohizumi, J. Am. Chem. Soc., 1988, 110, 490-494.

497 S. Mahapatra and R. G. Carter, J. Am. Chem. Soc., 2013, 135, 10792-10803.

498 S. B. Singh, J. L. Smith, G. S. Sabnis, A. W. Dombrowski, J. M. Schaeffer, M. A. Goetz and G. F. Bills, Tetrahedron, 1991, 47, 6931-6938.

499 H. Wei, T. Itoh, M. Kinoshita, Y. Nakai, M. Kurotaki and M. Kobayashi, Tetrahedron, 2004, 60, 6015-6019.

500 M. Arai, H. Niikawa and M. Kobayashi, J. Nat. Med., 2013, 67, 271-275.

501 S. T. Carey and M. S. R. Nair, J. Nat. Prod., 1979, 42, 231.

502 M. García-Caballero, M. Marí-Beffa, L. Cañedo, M. A. Medina and A. R. Quesada, Biochem. Pharmacol., 2013, 85, 1727-1740.
503 J. H. Sohn, Y.-R. Lee, D.-S. Lee, Y.-C. Kim and H. Oh, J. Microbiol. Biotechnol., 2013, 23, 1206-1211.

504 K. Arai, K. Kimura, T. Mushiroda and Y. Yamamoto, Chem. Pharm. Bull., 1989, 37, 2937-2939.

505 Y. S. Mohammed and M. Luckner, Tetrahedron Lett., 1963, 1953-1958.

506 A. Quilico, Gazz. Chim. Ital., 1948, 78, 111-135.

507 B. S. Gould and H. Raistrick, Biochem. J., 1934, 28, 16401656.

508 M. Isaka, S. Palasarn, P. Rachtawee, S. Vimuttipong and P. Kongsaeree, Org. Lett., 2005, 7, 2257-2260.

509 W. Zhao, Q. Gu and W. Zhu, Huaxue Yanjiu, 2007, 18, 10-13. 510 X. Han, X. Xu, C. Cui and Q. Gu, Zhongguo Yaowu Huaxue Zazhi, 2007, 17, 155-159.

511 Y. Song, H. Dou, W. Gong, X. Liu, Z. Yu, E. Li, R. Tan and Y. Hou, Eur. J. Pharmacol., 2013, 705, 49-60.

512 H. He, W.-D. Ding, V. S. Bernan, A. D. Richardson, C. M. Ireland, M. Greenstein, G. A. Ellestad and G. T. Carter, J. Am. Chem. Soc., 2001, 123, 5362-5363.

513 R. D. Kersten, A. L. Lane, M. Nett, T. K. S. Richter, B. M. Duggan, P. C. Dorrestein and B. S. Moore, ChemBioChem, 2013, 14, 955-962.

514 X.-G. Li, X.-M. Tang, J. Xiao, G.-H. Ma, L. Xu, S.-J. Xie, M.-J. Xu, X. Xiao and J. Xu, Mar. Drugs, 2013, 11, 3875-3890.

515 J. Qian-Cutrone, S. Huang, Y.-Z. Shu, D. Vyas, C. Fairchild, A. Menendez, K. Krampitz, R. Dalterio, S. E. Klohr and Q. Gao, J. Am. Chem. Soc., 2002, 124, 14556-14557.

516 Y. Ding, J. R. de Wet, J. Cavalcoli, S. Li, T. J. Greshock, K. A. Miller, J. M. Finefield, J. D. Sunderhaus, T. J. McAfoos, S. Tsukamoto, R. M. Williams and D. H. Sherman, J. Am. Chem. Soc., 2010, 132, 12733-12740. 517 J. D. Sunderhaus, T. J. McAfoos, J. M. Finefield, H. Kato, S. Li, S. Tsukamoto, D. H. Sherman and R. M. Williams, Org. Lett., 2013, 15, 22-25.

518 J. D. Hackett, J. H. Wisecaver, M. L. Brosnahan, D. M. Kulis, D. M. Anderson, D. Bhattacharya, F. G. Plumley and D. L. Erdner, Mol. Biol. Evol., 2013, 30, 70-78.

519 D.-Q. Liu, S.-C. Mao, X.-Q. Yu, L.-H. Feng and X.-P. Lai, Heterocycles, 2012, 85, 661-666.

520 A.-H. Liu, D.-Q. Liu, T.-J. Liang, X.-Q. Yu, M.-T. Feng, L.-G. Yao, Y. Fang, B. Wang, L.-H. Feng, M.-X. Zhang and S.-C. Mao, Bioorg. Med. Chem. Lett., 2013, 23, 2491-2494.

521 R. Wang, V. J. Paul and H. Luesch, Free Radical Biol. Med., 2013, 57, 141-153.

522 D. E. Williams, C. M. Sturgeon, M. Roberge and R. J. Andersen, J. Am. Chem. Soc., 2007, 129, 5822-5823.

523 N. Kinashi, K. Fujiwara, T. Tsunoda, R. Katoono, H. Kawai and T. Suzuki, Tetrahedron Lett., 2013, 54, 4564-4567.

524 I. Rubinstein and L. J. Goad, Phytochemistry, 1974, 13, 481484.

525 A. D. Kim, Y. Lee, S.-H. Kang, G. Y. Kim, H. S. Kim and J. W. Hyun, Mar. Drugs, 2013, 11, 418-430.

526 G. Aguilar-Santos and M. S. Doty, Drugs Sea, Trans. Symp., ed. H. D. Freudenthal, 1968, pp. 173-176.

527 L. H. A. Cavalcante-Silva, A. C. D. Correia, J. M. Barbosa, B. A. da Silva, B. V. D. Santos, D. P. de Lira, J. C. F. Sousa, 
G. E. C. de Miranda, F. D. Cavalcante and M. S. AlexandreMoreira, Mar. Drugs, 2013, 11, 1553-1564.

528 D. R. Hirschfeld, W. Fenical, G. H. Y. Lin, R. M. Wing, P. Radlick and J. J. Sims, J. Am. Chem. Soc., 1973, 95, 4049-4050.

529 G. S. E. Abou-El-Wafa, M. Shaaban, K. A. Shaaban, M. E. E. El-Naggar, A. Maier, H. H. Fiebig and H. Laatsch, Mar. Drugs, 2013, 11, 3109-3123.

530 E. Ioannou, C. Vagias and V. Roussis, Mar. Drugs, 2013, 11, 1104-1112.

531 V. L. M. Gouveia, A. M. L. Seca, M. C. Barreto, A. I. Neto, A. Kijjoa and A. M. S. Silva, Phytochem. Lett., 2013, 6, 593597.

532 C. de los Reyes, H. Zbakh, V. Motilva and E. Zubía, J. Nat. Prod., 2013, 76, 621-629.

533 N. Penicooke, K. Walford, S. Badal, R. Delgoda, L. A. D. Williams, P. Joseph-Nathan, B. Gordillo-Roman and W. Gallimore, Phytochemistry, 2013, 87, 96-101.

534 O. M. M. Sabry, S. Andrews, K. L. McPhail, D. E. Goeger, A. Yokochi, K. T. LePage, T. F. Murray and W. H. Gerwick, J. Nat. Prod., 2005, 68, 1022-1030.

535 W. H. Gerwick, W. Fenical, N. Fritsch and J. Clardy, Tetrahedron Lett., 1979, 20, 145-148.

536 A. Numata, S. Kanbara, C. Takahashi, R. Fujiki, M. Yoneda, Y. Usami and E. Fujita, Phytochemistry, 1992, 31, 12091213.

537 Y. Kamei, M. Sueyoshi, K.-i. Hayashi, R. Terada and H. Nozaki, J. Antibiot., 2009, 62, 259-263.

538 R. Katsuta, K. Aoki, A. Yajima and T. Nukada, Tetrahedron Lett., 2013, 54, 347-350.

539 Y. Seo, K. E. Park and T. J. Nam, Bull. Korean Chem. Soc., 2007, 28, 1831-1833.

540 K. Kurata, K. Taniguchi, K. Shiraishi, N. Hayama, I. Tanaka and M. Suzuki, Chem. Lett., 1989, 267-270.

541 J. Becker, L. Butt, V. von Kiedrowski, E. Mischler, F. Quentin and M. Hiersemann, Org. Lett., 2013, 15, 5982-5985.

542 H. A. Jung, S. E. Jin, B. R. Ahn, C. M. Lee and J. S. Choi, Food Chem. Toxicol., 2013, 59, 199-206.

543 T.-H. Kwon, H.-J. Suh, I.-K. Lee, B.-S. Yun, T.-W. Kim, D.-I. Hwang, Y.-J. Kim, M.-J. Kim, O.-O. Kwon, C.-G. Kim and N.-H. Park, Eur. Food Res. Technol., 2013, 237, 501-508.

544 J.-S. Yoon, A. K. Yadunandam, S.-J. Kim, H.-C. Woo, H.-R. Kim and G.-D. Kim, J. Nat. Med., 2013, 67, 519-527.

545 J.-Y. Park, J. H. Kim, J. M. Kwon, H.-J. Kwon, H. J. Jeong, Y. M. Kim, D. Kim, W. S. Lee and Y. B. Ryu, Bioorg. Med. Chem., 2013, 21, 3730-3737.

546 E. M. Balboa, E. Conde, A. Moure, E. Falqué and H. Domínguez, Food Chem., 2013, 138, 1764-1785.

547 K. H. S. Farvin and C. Jacobsen, Food Chem., 2013, 138, 1670-1681.

548 E. Plouguerné, L. M. de Souza, G. L. Sassaki, J. F. Cavalcanti, M. T. V. Romanos, B. A. P. da Gama, R. C. Pereira and E. Barreto-Bergter, Mar. Drugs, 2013, 11, 4628-4640.

549 L. A. Miceli, V. L. Teixeira, H. C. Castro, C. R. Rodrigues, J. F. R. Mello, M. G. Albuquerque, L. M. Cabral, M. A. de
Brito and A. M. T. de Souza, Mar. Drugs, 2013, 11, 41274143.

550 W.-J. Yoon, S.-J. Heo, S.-C. Han, H.-J. Lee, G.-J. Kang, E.-J. Yang, S.-S. Park, H.-K. Kang and E.-S. Yoo, Food Chem. Toxicol., 2012, 50, 3273-3279.

551 W.-J. Yoon, K.-N. Kim, S.-J. Heo, S.-C. Han, J. Kim, Y.-J. Ko, H.-K. Kang and E.-S. Yoo, Biochem. Biophys. Res. Commun., 2013, 434, 892-897.

552 B.-G. Park, S. Oh, D. Kwon, Y. Cui, J. Ham, W.-S. Shin and S. Lee, Bull. Korean Chem. Soc., 2013, 34, 3121-3124.

553 S. L. Midland, R. M. Wing and J. J. Sims, J. Org. Chem., 1983, 48, 1906-1909.

554 K. E. Park, Y. A. Kim, H. A. Jung, H. J. Lee, J.-W. Ahn, B.-J. Lee and Y. Seo, J. Korean Chem. Soc., 2004, 48, 394-398.

555 R. K. Ko, M.-C. Kang, S. S. Kim, T. H. Oh, G.-O. Kim, C.-G. Hyun, J. W. Hyun and N. H. Lee, Nat. Prod. Commun., 2013, 8, 427-428.

556 J. I. Lee, M. K. Kwak, H. Y. Park and Y. Seo, Nat. Prod. Commun., 2013, 8, 431-432.

557 M. Guyot, M. Morel and C. Belaud, J. Chem. Res., Synop., 1983, 188-189.

558 M. H. Moghadam, J. Firouzi, S. Saeidnia, H. Hajimehdipoor, S. Jamili, A. Rustaiyan and A. R. Gohari, Daru, J. Pharm. Sci., 2013, 21-24.

559 S. R. Kumar, M. Hosokawa and K. Miyashita, Mar. Drugs, 2013, 11, 5130-5147.

560 J. B. Gallé, B. Attioua, M. Kaiser, A. M. Rusig, A. Lobstein and C. Vonthron-Sénécheau, Mar. Drugs, 2013, 11, 599-610.

561 C. Francisco, G. Combaut, J. Teste and M. Prost, Phytochemistry, 1978, 17, 1003-1005.

562 S. Urban and M. Timmers, Nat. Prod. Commun., 2013, 8, 715-719.

563 M. Kitamura, P. J. Schupp, Y. Nakano and D. Uemura, Tetrahedron Lett., 2009, 50, 6606-6609.

564 N. Maru, T. Inuzuka, K. Yamamoto, M. Kitamura, P. J. Schupp, K. Yamada and D. Uemura, Tetrahedron Lett., 2013, 54, 4385-4387.

565 W. M. Abdel-Mageed, R. Ebel, F. A. Valeriote and M. Jaspars, Tetrahedron, 2010, 66, 2855-2862.

566 M. T. Holmes and R. Britton, Chem.-Eur. J., 2013, 19, 12649-12652.

567 D. J. Shepherd, P. A. Broadwith, B. S. Dyson, R. S. Paton and J. W. Burton, Chem.-Eur. J., 2013, 19, 12644-12648.

568 J. G. Hall and J. A. Reiss, Aust. J. Chem., 1986, 39, 1401-1409. 569 S. G. Smith, R. S. Paton, J. W. Burton and J. M. Goodman, J. Org. Chem., 2008, 73, 4053-4062.

570 B. S. Dyson, J. W. Burton, T. I. Sohn, B. Kim, H. Bae and D. Kim, J. Am. Chem. Soc., 2012, 134, 11781-11790.

571 R. Brkljača and S. Urban, Nat. Prod. Commun., 2013, 8, 729732.

572 M. L. Ciavatta, S. Wahidulla, L. D'Souza, G. Scognamiglio and G. Cimino, Tetrahedron, 2001, 57, 617-623.

573 B. S. Underwood, J. Tanuwidjaja, S.-S. Ng and T. F. Jamison, Tetrahedron, 2013, 69, 5205-5220.

574 C. P. Manríquez, M. L. Souto, J. A. Gavin, M. Norte and J. J. Fernández, Tetrahedron, 2001, 57, 3117-3123. 
575 X. D. Li, F. P. Miao, X. R. Liang, B. G. Wang and N. Y. Ji, RSC Adv., 2013, 3, 1953-1956.

576 T. Kamada and C. S. Vairappan, Nat. Prod. Commun., 2013, 8, 287-288.

577 L. Shide, A. Olbrich, R. Mayer and G. Rücker, Planta Med., 1987, 53, 556-558.

578 X. Xu, L. Yin, L. Gao, J. Gao, J. Chen, J. Li and F. Song, Mar. Drugs, 2013, 11, 842-847.

579 X. Xu, L. Yin, Y. Wang, S. Wang and F. Song, Nat. Prod. Res., 2013, 27, 723-726.

580 E. K. Olsen, E. Hansen, J. Isaksson and J. H. Andersen, Mar. Drugs, 2013, 11, 2769-2784.

581 W.-S. Sun, S. Su, R.-X. Zhu, G.-Z. Tu, W. Cheng, H. Liang, X.-Y. Guo, Y.-Y. Zhao and Q.-Y. Zhang, Tetrahedron Lett., 2013, 54, 3617-3620.

582 D. Iliopoulou, N. Mihopoulos, C. Vagias, P. Papazafiri and V. Roussis, J. Org. Chem., 2003, 68, 7667-7674.

583 A. E. Leung, M. Blair, C. M. Forsyth and K. L. Tuck, Org. Lett., 2013, 15, 2198-2201.

584 S. J. Rochfort and R. J. Capon, Aust. J. Chem., 1996, 49, 1926.

585 X.-c. Huang, Y.-L. Sun, A. A. Salim, Z.-S. Chen and R. J. Capon, Biochem. Pharmacol., 2013, 85, 1257-1268.

586 D. Mikami, H. Kurihara, S. M. Kim and K. Takahashi, Mar. Drugs, 2013, 11, 4050-4057.

587 M. Francavilla, M. Franchi, M. Monteleone and C. Caroppo, Mar. Drugs, 2013, 11, 3754-3776.

588 L. Mata, E. Wright, L. Owens, N. Paul and R. de Nys, J. Appl. Phycol., 2013, 25, 1963-1973.

589 J. W. Blunt, B. R. Copp, R. A. Keyzers, M. H. G. Munro and M. R. Prinsep, Nat. Prod. Rep., 2012, 29, 144-222.

590 T. F. Molinski, R. Biegelmeyer, E. P. Stout, X. Wang, M. L. C. Frota and A. T. Henriques, J. Nat. Prod., 2013, 76, 374-381.

591 R. Huang, Y. Peng, X. Zhou, X. Yang and Y. Liu, Nat. Prod. Res., 2013, 27, 1537-1541.

592 T. N. Makarieva, P. S. Dmitrenok, A. M. Zakharenko, V. A. Denisenko, A. G. Guzii, R. Li, C. K. Skepper, T. F. Molinksi and V. A. Stonik, J. Nat. Prod., 2007, 70, 1991-1998.

593 J. Ko and T. F. Molinski, J. Org. Chem., 2013, 78, 498-505.

594 F. Farokhi, P. Grellier, M. Clément, C. Roussakis, P. M. Loiseau, E. Genin-Seward, J. M. Kornprobst, G. Barnathan and G. Wielgosz-Collin, Mar. Drugs, 2013, 11, 1304-1315.

595 P. L. Katavic, K. W. L. Yong, J. N. Herring, M. A. Deseo, J. T. Blanchfield, V. Ferro and M. J. Garson, Tetrahedron, 2013, 69, 8074-8079.

596 A. Cutignano, G. Nuzzo, D. D'Angelo, E. Borbone, A. Fusco and A. Fontana, Angew. Chem., Int. Ed., 2013, 52, 9256-9260.

597 X. Luo, F. Li, J. Hong, C.-O. Lee, C. J. Sim, K. S. Im and J. H. Jung, J. Nat. Prod., 2006, 69, 567-571.

598 R. Towada, Y. Kurashina and S. Kuwahara, Tetrahedron Lett., 2013, 54, 6878-6881.

599 N. Tanaka, M. Asai, A. Takahashi-Nakaguchi, T. Gonoi, J. Fromont and J. Kobayashi, Org. Lett., 2013, 15, 25182521.
600 K. Horikawa, T. Yagyu, Y. Yoshioka, T. Fujiwara, A. Kanamoto, T. Okamoto and M. Ojika, Tetrahedron, 2013, 69, 101-106.

601 A. S. Reddy and P. Srihari, Tetrahedron Lett., 2013, 54, 63706372.

602 B.-K. Choi, B.-Y. Cha, T. Yagyu, J.-T. Woo and M. Ojika, Bioorg. Med. Chem., 2013, 21, 1804-1810.

603 Y. Hitora, K. Takada, S. Okada and S. Matsunaga, Tetrahedron, 2011, 67, 4530-4534.

604 Y. Hitora, K. Takada and S. Matsunaga, Tetrahedron, 2013, 69, 11070-11073.

605 Y. Inokuma, S. Yoshioka, J. Ariyoshi, T. Arai, Y. Hitora, K. Takada, S. Matsunaga, K. Rissanen and M. Fujita, Nature, 2013, 501, 262.

606 T. Shirouzu, K. Watari, M. Ono, K. Koizumi, I. Saiki, C. Tanaka, R. W. M. van Soest and T. Miyamoto, J. Nat. Prod., 2013, 76, 1337-1342.

607 Y.-J. Lee, S.-J. Yoo, J. S. Kang, J. Yun, H. J. Shin, J. S. Lee and H.-S. Lee, Lipids, 2013, 48, 87-91.

608 E. J. Mejia, L. B. Magranet, N. J. De Voogd, K. TenDyke, D. Qiu, Y. Y. Shen, Z. Zhou and P. Crews, J. Nat. Prod., 2013, 76, 425-432.

609 N. Legrave, S. Hamrouni-Buonomo, M. Dufies, V. Guérineau, J. Vacelet, P. Auberger, P. Amade and M. Mehiri, Mar. Drugs, 2013, 11, 2282-2292.

610 S. Ohta, T. Ogawa, E. Ohta, T. Ikeuchi, K. Kamemura and S. Ikegami, Nat. Prod. Res., 2013, 27, 1842-1847.

611 T. Akiyama, K. Takada, T. Oikawa, N. Matsuura, Y. Ise, S. Okada and S. Matsunaga, Tetrahedron, 2013, 69, 65606564.

612 N. Aoki, K. Yamamoto, T. Ogawa, E. Ohta, T. Ikeuchi, K. Kamemura, S. Ikegami and S. Ohta, Nat. Prod. Res., 2013, 27, 117-122.

613 W. M. Alarif, A. Abdel-Lateff, S. S. Al-Lihaibi, S.-E. N. Ayyad and F. A. Badria, Z. Naturforsch., C: J. Biosci., 2013, 68, 7075.

614 H. Kim, J. Chin, H. Choi, K. Baek, T.-G. Lee, S. E. Park, W. Wang, D. Hahn, I. Yang, J. Lee, B. Mun, M. Ekins, S.-J. Nam and H. Kang, Org. Lett., 2013, 15, 100-103.

615 H. Kim, J. Chin, H. Choi, K. Baek, T.-G. Lee, S. E. Park, W. Wang, D. Hahn, I. Yang, J. Lee, B. Mun, M. Ekins, S.-J. Nam and H. Kang, Org. Lett., 2013, 15, 5614.

616 B. S. Hwang, K. Lee, C. Yang, E. J. Jeong and J.-R. Rho, J. Nat. Prod., 2013, 76, 2355-2359.

617 I. H. Hwang, J. Oh, A. Kochanowska-Karamyan, R. J. Doerksen, M. Na and M. T. Hamann, Tetrahedron Lett., 2013, 54, 3872-3876.

618 P. V. Kiem, N. X. Nhiem, N. V. Quang, C. V. Minh, N. H. Nam, N. T. Cuc, H. L. T. Anh, B. H. Tai, P. H. Yen, N. X. Cuong, N. P. Thao, N. T. Hoai, N. Y. Kim, S. J. Park and K. S. Hyun, Nat. Prod. Commun., 2013, 8, 1751-1752.

619 G. Chianese, F. Scala, B. Calcinai, C. Cerrano, H. A. Dien, M. Kaiser, D. Tasdemir and O. Taglialatela-Scafati, Mar. Drugs, 2013, 11, 3297-3308.

620 J. S. Oh, B. S. Hwang, O.-H. Kang, D.-Y. Kwon and J.-R. Rho, Mar. Drugs, 2013, 11, 4407-4418. 
621 S. P. Gunasekera, M. Gunasekera, R. E. Longley and G. K. Schulte, J. Org. Chem., 1990, 55, 4912-4915.

622 C. Ruiz, K. Valderrama, S. Zea and L. Castellanos, Mar. Biotechnol., 2013, 15, 571-583.

623 S. Di Micco, A. Zampella, M. V. D'Auria, C. Festa, S. De Marino, R. Riccio, C. P. Butts and G. Bifulco, Beilstein J. Org. Chem., 2013, 9, 2940-2949.

624 J. Zhang, X. Tang, J. Li, P. Li, N. J. de Voogd, X. Ni, X. Jin, X. Yao, P. Li and G. Li, J. Nat. Prod., 2013, 76, 600-606.

625 P. Jumaryatno, L. K. Lambert, J. N. A. Hooper, J. T. Blanchfield and M. J. Garson, Nat. Prod. Commun., 2013, 8, 725-728.

626 C. Festa, S. De Marino, M. V. D'Auria, O. TaglialatelaScafati, E. Deharo, S. Petek and A. Zampella, Tetrahedron, 2013, 69, 3706-3713.

627 C. Festa, C. D'Amore, B. Renga, G. Lauro, S. De Marino, M. V. D'Auria, G. Bifulco, A. Zampella and S. Fiorucci, Mar. Drugs, 2013, 11, 2314-2327.

628 S.-J. Piao, Y.-L. Song, W.-H. Jiao, F. Yang, X.-F. Liu, W.-S. Chen, B.-N. Han and H.-W. Lin, Org. Lett., 2013, 15, 3526-3529.

629 T. Kubota, Y. Ishiguro, A. Takahashi-Nakaguchi, J. Fromont, T. Gonoi and J. Kobayashi, Bioorg. Med. Chem. Lett., 2013, 23, 244-247.

630 B. Yang, H. Tao, X. Zhou, X.-P. Lin and Y. Liu, Nat. Prod. Res., 2013, 27, 433-437.

631 M. Kimura, T. Wakimoto and I. Abe, Tetrahedron Lett., 2013, 54, 114-116.

632 Y. Imae, K. Takada, S. Okada, Y. Ise, H. Yoshimura, Y. Morii and S. Matsunaga, J. Nat. Prod., 2013, 76, 755-758.

633 Y. Nakao, S. Kawatsu, C. Okamoto, M. Okamoto, Y. Matsumoto, S. Matsunaga, R. van Soest and N. Fusetani, J. Nat. Prod., 2008, 71, 469-472.

634 J. A. Lewis, R. N. Daniels and C. W. Lindsley, Org. Lett., 2008, 10, 4545-4548.

635 M. J. Martin, L. Coello, R. Fernández, F. Reyes, A. Rodríguez, C. Murcia, M. Garranzo, C. Mateo, F. Sánchez-Sancho, S. Bueno, C. de Eguilior, A. Francesch, S. Munt and C. Cuevas, J. Am. Chem. Soc., 2013, 135, 10164-10171.

636 C. A. Bewley, C. Debitus and D. J. Faulkner, J. Am. Chem. Soc., 1994, 116, 7631-7636.

637 E. W. Schmidt and D. J. Faulkner, Tetrahedron, 1998, 54, 3043-3056.

638 T. Hoffmann, S. Müller, S. Nadmid, R. Garcia and R. Müller, J. Org. Chem., 2013, 135, 16904-16911.

639 J.-K. Woo, J.-E. Jeon, C.-K. Kim, C.-J. Sim, D.-C. Oh, K.-B. Oh and J. Shin, J. Nat. Prod., 2013, 76, 1380-1383.

640 M. Kita, B. Gise, A. Kawamura and H. Kigoshi, Tetrahedron Lett., 2013, 54, 6826-6828.

641 E. Avilés and A. D. Rodríguez, Tetrahedron, 2013, 69, 1079710804.

642 A. Napolitano, M. Rodriquez, I. Bruno, S. Marzocco, G. Autore, R. Riccio and L. Gomez-Paloma, Tetrahedron Lett., 2003, 59, 10203-10211.

643 M. Pelay-Gimeno, A. Meli, J. Tulla-Puche and F. Albericio, J. Med. Chem., 2013, 56, 9780-9788.
644 S. Matsunaga and N. Fusetani, J. Org. Chem., 1995, 60, 1177-1181.

645 R. A. Espiritu, N. Matsumori, M. Murata, S. Nishimura, H. Kakeya, S. Matsunaga and M. Yoshida, Biochemistry, 2013, 52, 2410-2418.

646 A. Sinisi, B. Calcinai, C. Cerrano, H. A. Dien, A. Zampella, C. D'Amore, B. Renga, S. Fiorucci and O. TaglialatelaScafati, Beilstein J. Org. Chem., 2013, 9, 1643-1651.

647 R. Ueoka, Y. Ise, S. Ohtsuka, S. Okada, T. Yamori and S. Matsunaga, J. Am. Chem. Soc., 2010, 132, 17692-17694.

648 T. Kuranaga, Y. Sesoko, K. Sakata, N. Maeda, A. Hayata and M. Inoue, J. Am. Chem. Soc., 2013, 135, 5467-5474.

649 H. Li, J. J. Bowling, F. R. Fronczek, J. Hong, S. V. Jabba, T. F. Murray, N.-C. Ha, M. T. Hamann and J. H. Jung, Biochim. Biophys. Acta, 2013, 1830, 2591-2599.

650 T. Amagata, T. A. Johnson, R. H. Cichewicz, K. Tenney, S. L. Mooberry, J. Media, M. Edelstein, F. A. Valeriote and P. Crews, J. Med. Chem., 2008, 51, 7234-7242.

651 A. Randazzo, C. Debitus and L. Gomez-Paloma, Tetrahedron, 2001, 57, 4443-4446.

652 B. D. Williams and A. B. Smith III, Org. Lett., 2013, 15, 45844587.

653 B. Pfeiffer, S. Speck-Gisler, L. Barandun, U. Senft, C. de Groot, I. Lehmann, W. Ganci, J. Gertsch and K. H. Altmann, J. Org. Chem., 2013, 78, 2553-2563.

654 T. Sirirak, L. Brecker and A. Plubrukarn, Nat. Prod. Res., 2013, 27, 1213-1219.

655 J. Kobayashi, K. Kondo, M. Ishibashi, M. R. Walchli and T. Nakamura, J. Am. Chem. Soc., 1993, 115, 6661-6665.

656 K. Kondo, M. Ishibashi and J. Kobayashi, Tetrahedron, 1994, 50, 8355-8362.

657 K. Nozawa, M. Tsuda, N. Tanaka, T. Kubota, E. Fukushi, J. Kawabata and J. Kobayashi, Tetrahedron Lett., 2013, 54, 783-787.

658 A. Sinisi, B. Calcinai, C. Cerrano, H. A. Dien, A. Zampella, C. D'Amore, B. Renga, S. Fiorucci and O. TaglialatelaScafati, Bioorg. Med. Chem., 2013, 21, 5332-5338.

659 R. Sakai, K. Suzuki, K. Shimamoto and H. Kamiya, J. Org. Chem., 2004, 69, 1180-1185.

660 M. Sakai, Y. Ishikawa, S. Takamizawa and M. Oikawa, Tetrahedron Lett., 2013, 54, 5911-5912.

661 T. Nishi, T. Kubota, J. Fromont, T. Sasaki and J. Kobayashi, Tetrahedron, 2008, 64, 3127-3132.

662 S. G. Davies, P. M. Roberts, R. S. Shah and J. E. Thomson, Tetrahedron Lett., 2013, 54, 6423-6426.

663 N. L. Seagraves and P. Crews, J. Nat. Prod., 2005, 68, 118121.

664 T. Okaki, R. Fujimura, M. Sekiguchi, D. Zhou, K. Sugimoto, D. Minato, Y. Matsuya, A. Kato, I. Adachi, Y. Tezuka, R. A. Saporito and N. Toyooka, Eur. J. Org. Chem., 2013, 14, 2841-2848.

665 R. Sakai, T. Higa, C. W. Jefford and G. Bernardinelli, J. Am. Chem. Soc., 1986, 108, 6404-6405.

666 G. Kallifatidis, D. Hoepfner, T. Jaeg, E. A. Guzmán and A. E. Wright, Mar. Drugs, 2013, 11, 3500-3516.

667 K. Eguchi, Y. Fujiwara, A. Hayashida, H. Horlad, H. Kato, H. Rotinsulu, F. Losung, R. E. P. Mangindaan, N. J. de 
Voogd, M. Takeya and S. Tsukamoto, Bioorg. Med. Chem., 2013, 21, 3831-3838.

668 T. Kubota, Y. Kamijyo, A. Takahashi-Nakaguchi, J. Fromont, T. Gonoi and J. Kobayashi, Org. Lett., 2013, 15, 610-612.

669 J. I. Jiménez, G. Goetz, C. M. S. Mau, W. Y. Yoshida, P. J. Scheuer, R. T. Williamson and M. Kelly, J. Org. Chem., 2000, 65, 8465-8469.

670 W. P. Unsworth, K. A. Gallagher, M. Jean, J. P. Schmidt, L. J. Diorazio and R. J. K. Taylor, Org. Lett., 2013, 15, 262265.

671 V. Damodaran, J. L. Ryan and R. A. Keyzers, J. Nat. Prod., 2013, 76, 1997-2001.

672 Y. Takekawa, S. Matsunaga, R. W. M. van Soest and N. Fusetani, J. Nat. Prod., 2006, 69, 1503-1505.

673 J. M. Langenhan, E. Mullarky, D. K. Rogalsky, J. R. Rohlfing, A. E. Tjaden, H. M. Werner, L. M. Rozal and S. A. Loskot, J. Org. Chem., 2013, 78, 1670-1676.

674 T. Kubota, K. Kura, J. Fromont and J. Kobayashi, Tetrahedron, 2013, 69, 96-100.

675 S. Khokhar, Y. Feng, M. R. Campitelli, R. J. Quinn, J. N. A. Hooper, M. G. Ekins and R. A. Davis, J. Nat. Prod., 2013, 76, 2100-2105.

676 E. Dumdei and R. J. Andersen, J. Nat. Prod., 1993, 56, 792794.

677 E. Dickson, B. R. Copp and D. Barker, Tetrahedron Lett., 2013, 54, 5239-5242.

678 Y.-J. Lee, D.-G. Lee, H. S. Rho, V. B. Krasokhin, H. J. Shin, J. S. Lee and H.-S. Lee, J. Heterocycl. Chem., 2013, 50, 1400-1404.

679 K. Imada, E. Sakai, H. Kato, T. Kawabata, S. Yoshinaga, T. Nehira, H. Terasawa and S. Tsukamoto, Tetrahedron, 2013, 69, 7051-7055.

680 B. Bao, Q. Sun, X. Yao, J. Hong, C.-O. Lee, C. J. Sim, K. S. Im and J. H. Jung, J. Nat. Prod., 2005, 68, 711-715.

681 G. D. Kim, O. J. Cheong, S. Y. Bae, J. Shin and S. K. Lee, Mar. Drugs, 2013, 11, 1087-1103.

682 D. T. A. Youssef, L. A. Shaala and H. Z. Asfour, Mar. Drugs, 2013, 11, 1061-1070.

683 F. Russell, D. Harmody, P. J. McCarthy, S. A. Pomponi and A. E. Wright, J. Nat. Prod., 2013, 76, 1989-1992.

684 R. Momose, N. Tanaka, J. Fromont and J. Kobayashi, Org. Lett., 2013, 15, 2010-2013.

685 N. Tanaka, R. Momose, Y. Takahashi, T. Kubota, A. Takahashi-Nakaguchi, T. Gonoi, J. Fromont and J. Kobayashi, Tetrahedron Lett., 2013, 54, 4038-4040.

686 R. A. Davis, S. Duffy, S. Fletcher, V. M. Avery and R. J. Quinn, J. Org. Chem., 2013, 78, 9608-9613.

687 N. K. Utkina, A. E. Makarchenko, V. A. Denisenko and P. S. Dmitrenok, Tetrahedron Lett., 2004, 45, 7491-7494.

688 N. K. Utkina, A. E. Makarchenko and V. A. Denisenko, J. Nat. Prod., 2005, 68, 1424-1427.

689 D. H. Nadkarni, S. Murugesan and S. E. Velu, Tetrahedron, 2013, 69, 4105-4113.

690 Y. Zou and M. T. Hamann, Org. Lett., 2013, 15, 1516-1519. 691 C.-D. Pham, R. Hartmann, W. E. G. Müller, N. de Voogd, D. Lai and P. Proksch, J. Nat. Prod., 2013, 76, 103-106.
692 X. Fu, J. R. Barnes, T. Do and F. J. Schmitz, J. Nat. Prod., 1997, 60, 497-498.

693 J. Das, A. Bhan, S. S. Mandal and C. J. Lovely, Bioorg. Med. Chem. Lett., 2013, 23, 6183-6187.

694 A. G. Guzii, T. N. Makarieva, Y. V. Korolkova, Y. A. Andreev, I. V. Mosharova, K. M. Tabakmaher, V. A. Denisenko, P. S. Dmitrenok, E. K. Ogurtsova, A. S. Antonov, H.-S. Lee and E. V. Grishin, Tetrahedron Lett., 2013, 54, 1247-1250.

695 T. N. Makarieva, E. K. Ogurtsova, Y. V. Korolkova, Y. A. Andreev, I. V. Mosharova, K. M. Tabakmakher, A. G. Guzii, V. A. Denisenko, P. S. Dmitrenok, H.-S. Lee, E. V. Grishin and V. Stonik, Nat. Prod. Commun., 2013, 8, 1229-1232.

696 K. M. Tabakmakher, V. A. Denisenko, A. G. Guzii, P. S. Dmitrenok, S. A. Dyshlovoy, H. S. Lee and T. N. Makarieva, Nat. Prod. Commun., 2013, 8, 1399-1402.

697 K. Inaba, H. Sato, M. Tsuda and J. Kobayashi, J. Nat. Prod., 1998, 61, 693-695.

698 M. Yamaguchi, M. Miyazaki, M. P. Kodrasov, H. Rotinsulu, F. Losung, R. E. P. Mangindaan, N. J. de Voogd, H. Yokosawa, B. Nicholson and S. Tsukamoto, Bioorg. Med. Chem. Lett., 2013, 23, 3884-3886.

699 N. Tanaka, T. Kusama, A. Takahashi-Nakaguchi, T. Gonoi, J. Fromont and J. Kobayashi, Tetrahedron Lett., 2013, 54, 3794-3796.

700 N. Tanaka, T. Kusama, A. Takahashi-Nakaguchi, T. Gonoi, J. Fromont and J. Kobayashi, Org. Lett., 2013, 15, 32623265.

701 E. A. Santalova, V. A. Denisenko and P. S. Dmitrenok, Chem. Nat. Compd., 2013, 49, 75-78.

702 K. Hirano, T. Kubota, M. Tsuda, K. Watanabe, J. Fromont and J. Kobayashi, Tetrahedron, 2000, 56, 8107-8110.

703 S. Saha, C. V. R. Reddy, T. Chiranjeevi, U. Addepally, T. S. C. Rao and B. Patro, Bioorg. Med. Chem. Lett., 2013, 23, 1013-1016.

704 T. D. Tran, N. B. Pham, G. Fechner, J. N. A. Hooper and R. J. Quinn, J. Nat. Prod., 2013, 76, 516-523.

705 Y.-J. Lee, S. Han, H.-S. Lee, J. S. Kang, J. Yun, C. J. Sim, H. J. Shin and J. S. Lee, J. Nat. Prod., 2013, 76, 1731-1736.

706 H. Niemann, W. Lin, W. E. G. Müller, M. Kubbutat, D. Lai and P. Proksch, J. Nat. Prod., 2013, 76, 121-125.

707 K. Kunze, H. Niemann, S. Ueberlein, R. Schulze, H. Ehrlich, E. Brunner, P. Proksch and K.-H. van Pée, Mar. Drugs, 2013, 11, 1271-1287.

708 F. Yang, R.-H. Ji, J. Li, J.-H. Gan and H.-W. Lin, Nat. Prod. Commun., 2013, 8, 1713-1714.

709 Z.-B. Zhao, J.-Z. Sun, S.-C. Mao and Y.-W. Guo, J. Asian Nat. Prod. Res., 2013, 15, 198-202.

710 A. N. E.-S. Hamed, W. Wätjen, R. Schmitz, Y. Chovolou, R. Edrada-Ebel, D. T. A. Youssef, M. S. Kamel and P. Proksch, Nat. Prod. Commun., 2013, 8, 289-292.

711 L. Du, Y.-D. Zhou and D. G. Nagle, J. Nat. Prod., 2013, 76, 1175-1181.

712 A. E. Wright, S. A. Rueth and S. S. Cross, J. Nat. Prod., 1991, 54, 1108-1111.

713 T. Kamishima, T. Kikuchi and T. Katoh, Eur. J. Org. Chem., 2013, 21, 4558-4563. 
714 W.-H. Jiao, X.-J. Huang, J.-S. Yang, F. Yang, S.-J. Piao, H. Gao, J. Li, W.-C. Ye, X.-S. Yao, W.-S. Chen and H.-W. Lin, Org. Lett., 2012, 14, 202-205.

715 B. Schmalzbauer, J. Herrmann, R. Muller and D. Menche, Org. Lett., 2013, 15, 964-967.

716 A. Yegdaneh, S. Putchakarn, S. Yuenyongsawad, A. Ghannadi and A. Plubrukarn, Nat. Prod. Commun., 2013, 8, 1355-1357.

717 W. Balansa, R. Islam, D. F. Gilbert, F. Fontaine, X. Xiao, H. Zhang, A. M. Piggott, J. W. Lynch and R. J. Capon, Bioorg. Med. Chem., 2013, 21, 4420-4425.

718 H. Yamazaki, T. Nakazawa, D. A. Sumilat, O. Takahashi, K. Ukai, S. Takahashi and M. Namikoshi, Bioorg. Med. Chem. Lett., 2013, 23, 2151-2154.

719 H.-S. Park, S. Y. Park, C. J. Sim and J.-R. Rho, Chem. Pharm. Bull., 2008, 56, 1198-1200.

720 H. Zhang, J. M. Major, R. J. Lewis and R. J. Capon, Org. Biomol. Chem., 2008, 6, 3811-3815.

721 S.-H. Lee, J.-E. Jeon, C.-H. Ahn, S.-C. Chung, J. Shin and K.-B. Oh, Appl. Microbiol. Biotechnol., 2013, 97, 31413148.

722 G. R. Pettit, Y. Tang, Q. Zhang, G. T. Bourne, C. A. Arm, J. E. Leet, J. C. Knight, R. K. Pettit, J.-C. Chapuis, D. L. Doubek, F. J. Ward, C. Weber and J. N. A. Hooper, J. Nat. Prod., 2013, 76, 420-424.

723 A. Patra, C. W. J. Chang, P. J. Scheuer, G. D. van Duyne, G. K. Matsumoto and J. Clardy, J. Am. Chem. Soc., 1984, 106, 7981-7983.

724 I. T. Sandoval, E. J. Manos, R. M. Van Wagoner, R. G. C. Delacruz, K. Edes, D. R. Winge, C. M. Ireland and D. A. Jones, Chem. Biol., 2013, 20, 753-763.

725 D. Green, I. Goldberg, Z. Stein, M. Ilan and Y. Kashman, Nat. Prod. Lett., 1992, 1, 193-199.

726 J. Peng, K. Walsh, V. Weedman, J. D. Bergthold, J. Lynch, K. L. Lieu, I. A. Braude, M. Kelly and M. T. Hamann, Tetrahedron, 2002, 58, 7809-7819.

727 C. Wang, D. Wang and S. Gao, Org. Lett., 2013, 15, 44024405.

728 A. J. Singh, J. D. Dattelbaum, J. J. Field, Z. Smart, E. F. Woolly, J. M. Barber, R. Heathcott, J. H. Miller and P. T. Northcote, Org. Biomol. Chem., 2013, 11, 8041-8051.

729 E. Avilés, A. D. Rodríguez and J. Vicente, J. Org. Chem., 2013, 78, 11294-11301.

730 N. X. Nhiem, N. V. Quang, C. V. Minh, D. T. T. Hang, H. L. T. Anh, B. H. Tai, P. H. Yen, N. T. Hoai, D. C. Thung and P. V. Kiem, Nat. Prod. Commun., 2013, 8, 1209-1212.

731 J.-E. Jeon, L. Liao, H. Kim, C. J. Sim, D.-C. Oh, K.-B. Oh and J. Shin, J. Nat. Prod., 2013, 76, 1679-1685.

732 F. Lefranc, G. Nuzzo, N. A. Hamdy, I. Fakhr, L. M. Y. Banuls, G. Van Goietsenoven, G. Villani, V. Mathieu, R. van Soest, R. Kiss and M. L. Ciavatta, J. Nat. Prod., 2013, 76, 15411547.

733 C. Audoin, D. Bonhomme, J. Ivanisevic, M. de la Cruz, B. Cautain, M. C. Monteiro, F. Reyes, L. Rios, T. Perez and O. P. Thomas, Mar. Drugs, 2013, 11, 1477-1489.

734 J. Li, L. Du, M. Kelly, Y.-D. Zhou and D. G. Nagle, J. Nat. Prod., 2013, 76, 1492-1497.
735 J. Daoust, M. Chen, M. Wang, D. E. Williams, M. A. G. Chavez, Y. A. Wang, C. E. Merchant, A. Fontana, T. J. Kieffer and R. J. Andersen, J. Org. Chem., 2013, 78, 8267-8273.

736 W. Balansa, R. Islam, F. Fontaine, A. M. Piggott, H. Zhang, X. Xiao, T. L. Webb, D. F. Gilbert, J. W. Lynch and R. J. Capon, Org. Biomol. Chem., 2013, 11, 4695-4701.

737 W. Wang, B. Mun, Y. Lee, M. V. Reddy, Y. Park, J. Lee, H. Kim, D. Hahn, J. Chin, M. Ekins, S.-J. Nam and H. Kang, J. Nat. Prod., 2013, 76, 170-177.

738 Y.-M. Fuh, M.-C. Lu, C.-H. Lee and J.-H. Su, Nat. Prod. Commun., 2013, 8, 571-572.

739 D. Hahn, D. H. Won, B. Mun, H. Kim, C. Han, W. Wang, T. Chun, S. Park, D. Yoon, H. Choi, S.-J. Nam, M. Ekins, J. Chin and H. Kang, Bioorg. Med. Chem. Lett., 2013, 23, 2336-2339.

740 L. Harinantenaina, P. J. Brodie, J. Maharavo, G. Bakary, K. TenDyke, Y. Shen and D. G. I. Kingston, Bioorg. Med. Chem., 2013, 21, 2912-2917.

741 L. P. P. Cano, S. A. Bartolotta, N. A. Casanova, G. E. Siless, E. Portmann, L. Schejter, J. A. Palermo and M. A. Carballo, Steroids, 2013, 78, 982-986.

742 T.-R. Su, K.-J. Liang, M.-Y. Chiang, M.-C. Lu, Y.-J. Wu and J.-H. Su, Nat. Prod. Commun., 2013, 8, 1535-1536.

743 Z.-B. Cheng, H. Xiao, C.-Q. Fan, Y.-N. Lu, G. Zhang and S. Yin, Steroids, 2013, 78, 1353-1358.

744 X. C. Nguyen, A. Longeon, V. C. Pham, F. Urvois, C. Bressy, T. T. V. Trinh, H. N. Nguyen, V. K. Phan, V. M. Chau, J.-F. Briand and M.-L. Bourguet-Kondracki, J. Nat. Prod., 2013, 76, 1313-1318.

745 R. A. Keyzers, J. Daoust, M. T. Davies-Coleman, R. van Soest, A. Balgi, E. Donohue, M. Roberge and R. J. Andersen, Org. Lett., 2008, 10, 2959-2962.

746 R. Forestieri, E. Donohue, A. Balgi, M. Roberge and R. J. Andersen, Org. Lett., 2013, 15, 3918-3921.

747 Z. Lu, M. Koch, M. K. Harper, T. K. Matainaho, L. R. Barrows, R. M. Van Wagoner and C. M. Ireland, J. Nat. Prod., 2013, 76, 2150-2152.

748 D.-Q. Xue, S.-C. Mao, X.-Q. Yu and Y.-W. Guo, Biochem. Syst. Ecol., 2013, 49, 101-106.

749 S. S. Afiyatullov, A. I. Kalinovsky, A. S. Antonov, L. P. Ponomarenko, P. S. Dmitrenok, D. L. Aminin, V. B. Krasokhin, V. M. Nosova and A. V. Kisin, J. Nat. Prod., 2007, 70, 1871-1877.

750 S. A. Kolesnikova, E. G. Lyakhova, A. I. Kalinovsky, M. A. Pushilin, S. S. Afiyatullov, E. A. Yurchenko, S. A. Dyshlovoy, C. V. Minh and V. A. Stonik, J. Nat. Prod., 2013, 76, 1746-1752.

751 J. Colorado, D. Muñoz, D. Marquez, M. E. Marquez, J. Lopez, O. P. Thomas and A. Martinez, Molecules, 2013, 18, 2598-2610.

752 S. Ahmed, A. Ibrahim and A. S. Arafa, Tetrahedron Lett., 2013, 54, 2377-2381.

753 R. Huang, Y. Peng, X. Zhou, M. Fu, S. Tian and Y. Liu, Nat. Prod. Res., 2013, 27, 319-322.

754 N. Cachet, L. Loffredo, O. O. Vicente and O. P. Thomas, Phytochem. Lett., 2013, 6, 205-208. 
755 S.-H. Qi, G.-C. Su, Y.-F. Wang, Q.-Y. Liu and C.-H. Gao, Chem. Pharm. Bull., 2009, 57, 87-88.

756 S.-H. Qi, G.-C. Su, Y.-F. Wang, Q.-Y. Liu and C.-H. Gao, Chem. Pharm. Bull., 2013, 61, 887.

757 A. Berndt, M. Gruner, A. W. Schmidt and H.-J. Knölker, Synlett, 2013, 24, 2102-2106.

758 S. Kodani, K. Sato, T. Higuchi, B. E. Casareto and Y. Suzuki, Nat. Prod. Res., 2013, 27, 1859-1862.

759 H.-M. Chung, J.-H. Su, T.-L. Hwang, J.-J. Li, J.-J. Chen, Y.-H. Chen, Y.-C. Chang, Y.-D. Su, Y.-H. Chen, L.-S. Fang, J.-H. Sheu, W.-H. Wang and P.-J. Sung, Tetrahedron, 2013, 69, 2740-2744.

760 H.-M. Chung, W.-H. Wang, T.-L. Hwang, Y.-C. Wu and P.-J. Sung, Nat. Prod. Commun., 2013, 8, 1037-1040.

761 D. Chen, W. Chen, D. Liu, L. van Ofwegen, P. Proksch and W. Lin, J. Nat. Prod., 2013, 76, 1753-1763.

762 Y.-J. Xio, J.-H. Su, B.-W. Chen, Y.-J. Tseng, Y.-C. Wu and J.-H. Sheu, Mar. Drugs, 2013, 11, 3735-3741.

763 Y.-J. Tseng, Y.-S. Lee, S.-K. Wang, J.-H. Sheu and C.-Y. Duh, Mar. Drugs, 2013, 11, 2501-2509.

764 B. Yang, S. Liao, X. Lin, J. Wang, J. Liu, X. Zhou, X. Yang and Y. Liu, Mar. Drugs, 2013, 11, 4741-4750.

765 E. R. Wagner, R. D. Moss, R. M. Brooker, J. P. Heeschen, W. J. Potts and M. L. Dilling, Tetrahedron Lett., 1965, 4233-4239.

766 P. Georgantea, E. Ioannou, C. Vagias and V. Roussis, Tetrahedron Lett., 2013, 54, 6920-6922.

767 Y.-F. Lin, C.-Y. Kuo, Z.-H. Wen, Y.-Y. Lin, W.-H. Wang, J.-H. Su, J.-H. Sheu and P.-J. Sung, Molecules, 2013, 18, 8160-8167.

768 L. Li, C.-Y. Wang, C.-L. Shao, L. Han, X.-P. Sun, J. Zhao, Y.-W. Guo, H. Huang and H.-S. Guan, J. Asian Nat. Prod. Res., 2009, 11, 851-855.

769 N. P. Thao, N. H. Nam, N. X. Cuong, T. H. Quang, P. T. Tung, L. D. Dat, D. Chae, S. Kim, Y.-S. Koh, P. V. Kiem, C. V. Minh and Y. H. Kim, Bioorg. Med. Chem. Lett., 2013, 23, 228-231.

770 H.-Y. Fang, C.-H. Hsu, C.-H. Chao, Z.-H. Wen, Y.-C. Wu, C.-F. Dai and J.-H. Sheu, Mar. Drugs, 2013, 11, 1853-1865.

771 T.-C. Tsai, Y.-J. Wu, J.-H. Su, W.-T. Lin and Y.-S. Lin, Mar. Drugs, 2013, 11, 114-123.

772 K.-H. Chen, C.-F. Dai, M.-C. Lu, J.-J. Li, J.-J. Chen, Y.-C. Chang, Y.-D. Su, W.-H. Wang and P.-J. Sung, Mar. Drugs, 2013, 11, 3372-3380.

773 L.-C. Hu, J.-H. Su, M. Y.-N. Chiang, M.-C. Lu, T.-L. Hwang, Y.-H. Chen, W.-P. Hu, N.-C. Lin, W.-H. Wang, L.-S. Fang, Y.-H. Kuo and P.-J. Sung, Mar. Drugs, 2013, 11, 1999-2012.

774 A. Ma, Z. Deng, L. van Ofwegen, M. Bayer, P. Proksch and W. Lin, J. Nat. Prod., 2008, 71, 1152-1160.

775 C.-C. Su, B.-S. Wong, C. Chin, Y.-J. Wu and J.-H. Su, Int. J. Mol. Sci., 2013, 14, 4317-4325.

776 Y.-S. Lin, C.-H. Chen, C.-C. Liaw, Y.-C. Chen, Y.-H. Kuo and Y.-C. Shen, Tetrahedron, 2009, 65, 9157-9164.

777 L.-C. Hu, W.-H. Yen, J.-H. Su, M. Y.-N. Chiang, Z.-H. Wen, W.-F. Chen, T.-J. Lu, Y.-W. Chang, Y.-H. Chen, W.-H. Wang, Y.-C. Wu and P.-J. Sung, Mar. Drugs, 2013, 11, 2154-2167.
778 W.-H. Yen, Y.-D. Su, Y.-C. Chang, Y.-H. Chen, Y.-H. Chen, C.-F. Dai, Z.-H. Wen, J.-H. Su and P.-J. Sung, Tetrahedron Lett., 2013, 54, 2267-2270.

779 H.-F. Lin, H.-J. Su, N.-L. Lee and J.-H. Su, Nat. Prod. Commun., 2013, 8, 1363-1364.

780 D. Lai, Z. Geng, Z. Deng, L. van Ofwegen, P. Proksch and W. Lin, J. Agric. Food Chem., 2013, 61, 4585-4592.

781 J. Yin, M. Zhao, M. Ma, Y. Xu, Z. Xiang, Y. Cai, J. Dong, X. Lei, K. Huang and P. Yan, Mar. Drugs, 2013, 11, 455-465.

782 M. Zhao, X. Li, F. Zhao, S. Cheng, Z. Xiang, J. Dong, K. Huang and P. Yan, Chem. Pharm. Bull., 2013, 61, 13231328.

783 M. Zhao, J. Yin, W. Jiang, M. Ma, X. Lei, Z. Xiang, J. Dong, K. Huang and P. Yan, Mar. Drugs, 2013, 11, 1162-1172.

784 C. B. Rao, C. Satyanarayana, D. S. Rao, D. V. Rao, E. Fahy and D. J. Faulkner, J. Nat. Prod., 1993, 56, 2003-2007.

785 F. Cao, J. Zhou, K.-X. Xu, M.-Q. Zhang and C.-Y. Wang, Nat. Prod. Commun., 2013, 8, 1675-1678.

786 S.-K. Wang, M.-K. Hsieh and C.-Y. Duh, Mar. Drugs, 2013, 11, 4318-4327.

787 Z. Xi, W. Bie, W. Chen, D. Liu, L. van Ofwegen, P. Proksch and W. Lin, Mar. Drugs, 2013, 11, 3186-3196.

788 R. F. Abou El-Ezz, S. A. Ahmed, M. M. Radwan, N. A. Ayoub, M. S. Afifi, S. A. Ross, P. T. Szymanski, H. Fahmy and S. I. Khalifa, Tetrahedron Lett., 2013, 54, 989-992.

789 C.-X. Zhang, X.-X. He, J. Zhang, Q. Guo, L.-F. Lei, J.-Y. Su and L.-M. Zeng, Nat. Prod. Res., 2013, 27, 782-786.

790 Z. Xi, W. Bie, W. Chen, D. Liu, L. van Ofwegen, P. Proksch and W. Lin, Helv. Chim. Acta, 2013, 96, 2218-2227.

791 P. C. Yan, Y. Lv, L. van Ofwegen, P. Proksch and W. Lin, Org. Lett., 2010, 12, 2484-2487.

792 P. Yan, Z. Deng, L. van Ofwegen, P. Proksch and W. Lin, Mar. Drugs, 2010, 8, 2837-2848.

793 P. Yan, Z. Deng, L. van Ofwegen, P. Proksch and W. Lin, Chem. Pharm. Bull., 2010, 58, 1591-1595.

794 L.-M. Zeng, W.-J. Lan, J.-Y. Su, G.-W. Zhang, X.-L. Feng, Y.-J. Liang and X.-P. Yang, J. Nat. Prod., 2004, 67, 19151918.

795 P. Yan, Z. Deng, L. van Ofwegen, P. Proksch and W. Lin, Chem. Biodiversity, 2011, 8, 1724-1734.

796 X.-H. Yan, M. Gavagnin, G. Cimino and Y.-W. Guo, Tetrahedron Lett., 2007, 48, 5313-5316.

797 R. Jia, T. Kurtan, A. Mandi, X.-H. Yan, W. Zhang and Y.-W. Guo, J. Org. Chem., 2013, 78, 3113-3119.

798 W.-J. Lan, S.-L. Wang and H.-J. Li, Nat. Prod. Commun., 2009, 4, 1193-1196.

799 Y.-F. Li, L.-L. He, H.-L. Liu, L.-F. Liang, H.-B. Zhang and Y.-W. Guo, J. Asian Nat. Prod. Res., 2013, 15, 566-573.

800 P. Yan, Z. Deng, L. van Ofwegen, P. Proksch and W. Lin, Chem. Pharm. Bull., 2010, 58, 1591-1595.

801 M.-E. F. Hegazy, T. A. Mohamed, F. F. Abdel-Latif, M. S. Alsaid, A. A. Shahat and P. W. Pare, Phytochem. Lett., 2013, 6, 383-386.

802 L.-F. Liang, T. Kurtan, A. Mandi, L.-G. Yao, J. Li, W. Zhang and Y.-W. Guo, Org. Lett., 2013, 15, 274-277.

803 L.-F. Liang, L.-X. Gao, J. Li, O. Taglialatela-Scafati and Y.-W. Guo, Bioorg. Med. Chem., 2013, 21, 5076-5080. 
804 L.-F. Liang, L.-F. Lan, O. Taglialatela-Scafati and Y.-W. Guo, Tetrahedron, 2013, 69, 7381-7386.

805 C. Zhang, J. Li, J. Su, Y. Liang, X. Yang, K. Zheng and L. Zeng, J. Nat. Prod., 2006, 69, 1476-1480.

806 J. A. Toth, B. J. Burreson, P. J. Scheuer, J. Finer-Moore and J. Clardy, Tetrahedron, 1980, 36, 1307-1309.

807 R. Jia, Y.-W. Guo, E. Mollo and G. Cimino, Helv. Chim. Acta, 2005, 88, 1028-1033.

808 C. Li, M. Jiang, M.-P. La, T.-J. Li, H. Tang, P. Sun, B.-S. Liu, Y.-H. Yi, Z. Liu and W. Zhang, Mar. Drugs, 2013, 11, 15651582.

809 J.-F. Sun, Z. Han, X.-F. Zhou, B. Yang, X. Lin, J. Liu, Y. Peng, X.-W. Yang and Y. Liu, Tetrahedron, 2013, 69, 871-880.

810 C.-C. Liaw, Y.-C. Lin, Y.-S. Lin, C.-H. Chen, T.-L. Hwang and Y.-C. Shen, Mar. Drugs, 2013, 11, 2042-2053.

811 B.-W. Chen, S.-Y. Wang, C.-Y. Huang, S.-L. Chen, Y.-C. Wu and J.-H. Sheu, Tetrahedron, 2013, 69, 2296-2301.

812 Y.-S. Cai, L.-G. Yao, A. Di Pascale, C. Irace, E. Mollo, O. Taglialatela-Scafati and Y.-W. Guo, Tetrahedron, 2013, 69, 2214-2219.

813 T. Miyamoto, K. Yamada, N. Ikeda, T. Komori and R. Higuchi, J. Nat. Prod., 1994, 57, 1212-1219.

814 C.-J. Tai, J.-H. Su, C.-Y. Huang, M.-S. Huang, Z.-H. Wen, C.-F. Dai and J.-H. Sheu, Mar. Drugs, 2013, 11, 788-799.

815 Y.-N. Lee, C.-J. Tai, T.-L. Hwang and J.-H. Sheu, Mar. Drugs, 2013, 11, 2741-2750.

816 M. Ochi, K. Yamada, K. Kataoka, H. Kotsuki and K. Shibata, Chem. Lett., 1992, 155-158.

817 T.-H. Chen, M.-C. Lu, Y.-C. Chang, Y.-D. Su, Y.-H. Chen, N.-C. Lin, L.-S. Fang, Y.-C. Wu and P.-J. Sung, Mar. Drugs, 2013, 11, 4585-4593.

818 F.-Y. Shih, T.-H. Chen, M.-C. Lu, W.-F. Chen, Z.-H. Wen, Y.-H. Kuo and P.-J. Sung, Int. J. Mol. Sci., 2013, 14, 2178121789.

819 M.-C. Lin, B.-W. Chen, C.-Y. Huang, C.-F. Dai, T.-L. Hwang and J.-H. Sheu, J. Nat. Prod., 2013, 76, 1661-1667.

820 T.-T. Li, X.-L. Tang, C.-L. Chen, X.-W. Zhang, R.-C. Wu, H.-Y. Zhu, P.-L. Li and G.-Q. Li, Helv. Chim. Acta, 2013, 96, 1188-1196.

821 Y.-J. Tseng, S.-K. Wang and C.-Y. Duh, Mar. Drugs, 2013, 11, 3288-3296.

822 G. Zhang, X. Tang, C. Cheng, K. Gong, X. Zhang, H. Zhu, R. Wu, P. Li and G. Li, Steroids, 2013, 78, 845-850.

823 H.-Y. Zhao, C.-L. Shao, Z.-Y. Li, L. Han, F. Cao and C.-Y. Wang, Molecules, 2013, 18, 3458-3466.

824 K.-K. Gong, X.-L. Tang, G. Zhang, C.-L. Cheng, X.-W. Zhang, P.-L. Li and G.-Q. Li, Mar. Drugs, 2013, 11, 4788-4798.

825 L.-L. Sun, C.-L. Shao, H. Hang, Z.-Y. Guo, Q. Xing and C.-Y. Wang, Nat. Prod. Res., 2013, 27, 1159-1166.

826 M. Shaaban, K. A. Shaaban and M. A. Ghani, Steroids, 2013, 78, 866-873.

827 A. Umeyama, N. Shoji, M. Ozeki and S. Arihara, J. Nat. Prod., 1996, 59, 894-895.

828 A. I. Elshamy, A. F. Abdel-Razik, M. I. Nassar, T. K. Mohamed, M. A. Ibrahim and S. M. El-Kousy, Nat. Prod. Res., 2013, 27, 1250-1254.
829 M. Shaaban, M. A. Ghani and K. A. Shaaban, Z. Naturforsch., B: J. Chem. Sci., 2013, 68, 939-945.

830 P. Wang, H. Tang, B.-S. Liu, T.-J. Li, P. Sun, W. Zhu, Y.-P. Luo and W. Zhang, Steroids, 2013, 78, 951-958.

831 T.-F. Liu, X. Lu, H. Tang, M.-M. Zhang, P. Wang, P. Sun, Z.-Y. Liu, Z.-L. Wang, L. Li, Y.-C. Rui, T.-J. Li and W. Zhang, Steroids, 2013, 78, 108-114.

832 L.-F. Liang, X.-J. Wang, H.-Y. Zhang, H.-L. Liu, J. Li, L.-F. Lan, W. Zhang and Y.-W. Guo, Bioorg. Med. Chem. Lett., 2013, 23, 1334-1337.

833 S.-K. Wang, S.-Y. Puu and C.-Y. Duh, Mar. Drugs, 2013, 11, 571-580.

834 Z. Wang, H. Tang, P. Wang, W. Gong, M. Xue, H. Zhang, T. Liu, B. Liu, Y. Yi and W. Zhang, Mar. Drugs, 2013, 11, 775-787.

835 N. P. Thao, N. H. Nam, N. X. Cuong, B. H. Tai, T. H. Quang, N. T. T. Ngan, B. T. T. Luyen, S. Y. Yang, C. H. Choi, S. Kim, D. Chae, Y.-S. Koh, P. V. Kiem, C. V. Minh and Y. H. Kim, Bull. Korean Chem. Soc., 2013, 34, 949-952.

836 L.-L. Sun, X.-M. Fu, X.-B. Li, Q. Xing and C.-Y. Wang, Nat. Prod. Res., 2013, 27, 2006-2011.

837 W.-H. Yen, W.-F. Chen, C.-H. Cheng, C.-F. Dai, M.-C. Lu, J.-H. Su, Y.-D. Su, Y.-H. Chen, Y.-C. Chang, Y.-H. Chen, J.-H. Sheu, C.-S. Lin, Z.-H. Wen and P.-J. Sung, Molecules, 2013, 18, 2895-2903.

838 J. Zhang, X.-J. Liao, K.-L. Wang, Z. Deng and S.-H. Xu, Steroids, 2013, 78, 396-400.

839 C.-H. Chao, Y.-C. Wu, Z.-H. Wen and J.-H. Sheu, Mar. Drugs, 2013, 11, 136-145.

840 C.-Y. Huang, C.-C. Liaw, B.-W. Chen, P.-C. Chen, J.-H. Su, P.-J. Sung, C.-F. Dai, M. Y. Chiang and J.-H. Sheu, J. Nat. Prod., 2013, 76, 1902-1908.

841 J. Zhang, L.-C. Li, K.-L. Wang, X.-J. Liao, Z. Deng and S.-H. Xu, Bioorg. Med. Chem. Lett., 2013, 23, 1079-1082.

842 M. Jiang, P. Sun, H. Tang, B.-S. Liu, T.-J. Li, C. Li and W. Zhang, J. Nat. Prod., 2013, 76, 764-768.

843 S. Qi, S. Zhang, J. Huang, Z. Xiao, J. Wu and Q. Li, Magn. Reson. Chem., 2005, 43, 266-268.

844 C.-H. Chao, C.-H. Hsieh, S.-P. Chen, C.-K. Lu, C.-F. Dai and J.-H. Sheu, Tetrahedron Lett., 2006, 47, 5889-5891.

845 K. Ota and H. Miyaoka, Chem. Commun., 2013, 49, 81488150.

846 H. Takamura, K. Iwamoto, E. Nakao and I. Kadota, Org. Lett., 2013, 15, 1108-1111.

847 J. S. Clark, R. Berger, S. T. Hayes, H. M. Senn, L. J. Farrugia, L. H. Thomas, A. J. Morrison and L. Gobbi, J. Org. Chem., 2013, 78, 673-696.

848 M. J. Palframan and G. Pattenden, Tetrahedron Lett., 2013, 54, 6822-6825.

849 M. J. Palframan and G. Pattenden, Tetrahedron Lett., 2013, 54, 324-328.

850 H. Kikuchi, Y. Tsukitani, Y. Yamada, K. Iguchi, S. A. Drexler and J. Clardy, Tetrahedron Lett., 1982, 23, 1063-1066.

851 H.-P. Lee, S.-Y. Huang, Y.-Y. Lin, H.-M. Wang, Y.-H. Jean, S.-F. Wu, C.-Y. Duh and Z.-H. Wen, Mar. Drugs, 2013, 11, 99-113. 
852 W.-H. Yen, L.-C. Hu, J.-H. Su, M.-C. Lu, W.-H. Twan, S.-Y. Yang, Y.-C. Kuo, C.-F. Weng, C.-H. Lee, Y.-H. Kuo and P.-J. Sung, Molecules, 2012, 17, 14058-14066.

853 K.-J. Huang, Y.-C. Chen, M. El-Shazly, Y.-C. Du, J.-H. Su, C.-W. Tsao, W.-H. Yen, W.-B. Chang, Y.-D. Su, Y.-T. Yeh and M.-C. Lu, Molecules, 2013, 18, 2924-2933.

854 Y. Kashman, M. Bodner, Y. Loya and Y. Benayahu, Isr. J. Chem., 1977, 16, 1-3.

855 W.-L. Hsu, S.-J. Chiu, Y.-T. Tsai, C.-M. Chang, J.-Y. Wang, E. T. Wang, M.-F. Hou, C.-Y. Huang, J.-H. Sheu and W.-C. Chang, Molecules, 2013, 18, 7023-7034.

856 C.-Y. Kao, J.-H. Su, M.-C. Lu, T.-L. Hwang, W.-H. Wang, J.-J. Chen, J.-H. Sheu, Y.-H. Kuo, C.-F. Weng, L.-S. Fang, Z.-H. Wen and P.-J. Sung, Mar. Drugs, 2011, 9, 1319-1331.

857 C.-Y. Lin, M.-C. Lu, J.-H. Su, C.-L. Chu, D. Shiuan, C.-F. Weng, P.-J. Sung and K.-J. Huang, Mar. Drugs, 2013, 11, 1336-1350.

858 S. A. Look, W. Fenical, G. K. Matsumoto and J. Clardy, J. Org. Chem., 1986, 51, 5140-5145.

859 D. R. Day, S. Jabaiah, R. S. Jacobs and R. D. Little, Mar. Drugs, 2013, 11, 3258-3271.

860 T. Higa, J. Tanaka, Y. Tsukitani and H. Kikuchi, Chem. Lett., 1981, 1647-1650.

861 C. Ishikawa, J. Tanaka, H. Katano, M. Senba and N. Mori, Mar. Drugs, 2013, 11, 3410-3424.

862 C. Schneider, M. L. Manier, D. L. Hachey and A. R. Brash, Lipids, 2002, 37, 217-221.

863 E. Reina, F. A. Ramos, L. Castellanos, M. Aragon and L. F. Ospina, J. Pharm. Pharmacol., 2013, 65, 1643-1652.

864 S.-L. Wu, J.-H. Su, C.-Y. Huang, C. J. Tai, P.-J. Sung, C.-C. Liaw and J.-H. Sheu, Mar. Drugs, 2012, 10, 1203-1211.

865 B.-W. Chen, Y.-C. Wu, M. Y. Chiang, J.-H. Su, W.-H. Wang, T.-Y. Fan and J.-H. Sheu, Tetrahedron, 2009, 65, 7016-7022.

866 Y.-H. Chen, T.-L. Hwang, Y.-D. Su, Y.-C. Chang, P.-H. Hong, L.-C. Hu, W.-H. Yen, H.-Y. Hsu, S.-J. Huang, Y.-H. Kuo and P.-J. Sung, Chem. Pharm. Bull., 2012, 60, 160-163.

867 S.-L. Wu, J.-H. Su, C.-Y. Huang, C.-J. Tai, P.-J. Sung, C.-C. Liaw and J.-H. Sheu, Mar. Drugs, 2013, 11, 5087-5088.

868 M. R. Prinsep and M. Dumté, Nat. Prod. Commun., 2013, 8, 693-694.

869 A. R. Carroll, S. Duffy, M. Sykes and V. M. Avery, Org. Biomol. Chem., 2011, 9, 604-609.

870 F. A. Khan and S. Ahmad, Tetrahedron Lett., 2013, 54, 29962998.

871 Y. Kamano, H. Zhang, Y. Ichihara, H. Kizu, K. Komiyama and G. R. Pettit, Tetrahedron Lett., 1995, 36, 2783-2784.

872 G. S. M. Figueiredo, R. S. Zardo, B. V. Silva, F. A. Violante, A. C. Pinto and P. D. Fernandes, Pharmacol, Biochem. Behav., 2013, 103, 431-439.

873 K. Konoki, T. Onoda, R. Watanabe, Y. Cho, S. Kaga, T. Suzuki and M. Yotsu-Yamashita, Mar. Drugs, 2013, 11, 300-315.

874 H. Kawashima, M. Ohnishi and S. Ogawa, J. Oleo Sci., 2013, 62, 465-470.

875 E. Villaverde-de-Sáa, C. Valls-Cantenys, J. B. Quintana, R. Rodil and R. Cela, J. Chromatogr. A, 2013, 85-94.
876 M. Carbone, M. L. Ciavatta, J.-R. Wang, I. Cirillo, V. Mathieu, R. Kiss, E. Mollo, Y.-W. Guo and M. Gavagnin, J. Nat. Prod., 2013, 76, 2065-2073.

877 C. M. Ireland, J. E. Biskupiak, G. J. Hite, M. Rapposch, P. J. Scheuer and J. R. Ruble, J. Org. Chem., 1984, 49, 559561.

878 S. Jaisamut, S. Prabpai, C. Tancharoen, S. Yuenyongsawad, S. Hannongbua, P. Kongsaeree and A. Plubrukarn, J. Nat. Prod., 2013, 76, 2158-2161.

879 K. C. Tan, T. Wakimoto, K. Takada, T. Ohtsuki, N. Uchiyama, Y. Goda and I. Abe, J. Nat. Prod., 2013, 76, 1388-1391.

880 S. Smith and G. M. Timms, J. Chem. Soc., 1937, 396-401. 881 T. Wakimoto, K. C. Tan and I. Abe, Toxicon, 2013, 72, 1-4. 882 M. Carbone, C. Muniain, F. Castelluccio, O. Iannicelli and M. Gavagnin, Biochem. Syst. Ecol., 2013, 49, 172-175.

883 K. E. Clark, A. Capper, G. Della Togna, V. J. Paul, L. I. Romero, T. Johns, L. Cubilla-Rios and T. L. Capson, Nat. Prod. Commun., 2013, 8, 1537-1540.

884 I. W. Mudianta, V. L. Challinor, A. E. Winters, K. L. Cheney, J. J. De Voss and M. J. Garson, Beilstein J. Org. Chem., 2013, 9, 2925-2933.

885 P. Ciminiello, C. Dell'Aversano, E. Fattorusso, M. Forino, S. Magno, S. Ianaro and M. Di Rosa, Eur. J. Org. Chem., 2001, 49-53.

886 P. Ciminiello, C. Dell'Aversano, E. Fattorusso, M. Forino, S. Magno, F. U. Santelia, V. I. Moutsos, E. N. Pitsinos and E. A. Couladouros, Tetrahedron, 2006, 62, 7738-7743.

887 D. H. Dethe and A. Ranjan, RSC Adv., 2013, 3, 23692-23703. 888 Y. Nakao, W. Y. Yoshida, Y. Takada, J. Kimura, L. Yang, S. L. Mooberry and P. L. Scheuer, J. Nat. Prod., 2004, 67, 1332-1340.

889 Y. Takada, M. Umehara, Y. Nakao and J. Kimura, Tetrahedron Lett., 2008, 49, 1163-1165.

890 M. Umehara, T. Negishi, Y. Maehara, Y. Nakao and J. Kimura, Tetrahedron, 2013, 69, 3045-3053.

891 Y. Kato and P. J. Scheuer, J. Am. Chem. Soc., 1974, 96, 22452246.

892 Y. Hanaki, M. Kikumori, S. Ueno, H. Tokuda, N. Suzuki and K. Irie, Tetrahedron, 2013, 69, 7636-7645.

893 D. S. Dalisay, E. W. Rogers, A. S. Edison and T. F. Molinski, J. Nat. Prod., 2009, 72, 732-738.

894 W. Tantisantisom, D. M. Ramsey and S. R. McAlpine, Org. Lett., 2013, 15, 4638-4641.

895 M. T. Hamann and P. J. Scheuer, J. Am. Chem. Soc., 1993, 115, 5825-5826.

896 R. Salazar, H. Cortés-Funes, E. Casado, B. Pardo, A. LópezMartín, C. Cuadra, J. Tabernero, C. Coronado, M. Garciá, A. S. Matos-Pita, B. Miguel-Lillo, M. Cullell-Young, J. L. Iglesias Dios and L. Paz-Ares, Cancer Chemother. Pharmacol., 2013, 72, 75-83.

897 M. Serova, A. de Gramont, I. Bieche, M. E. Riveiro, C. M. Galmarini, M. Aracil, J. Jimeno, S. Faivre and E. Raymond, Mar. Drugs, 2013, 11, 944-959.

898 K. V. Rao, M.-K. Na, J. C. Cook, J. Peng, R. Matsumoto and M. T. Hamman, J. Nat. Prod., 2008, 71, 772-778. 
899 M. A. Albadry, K. M. Elokely, B. Wang, J. J. Bowling, M. F. Abdelwahab, M. H. Hossein, R. J. Doerksen and M. T. Hamann, J. Nat. Prod., 2013, 76, 178-185.

900 The error has been noted by the lead author and a correction will be forthcoming (M. Hamann, pers. commun.).

901 K. Yamada, M. Ojika, T. Ishigaki, Y. Yoshida, H. Ekimoto and M. Arakawa, J. Am. Chem. Soc., 1993, 115, 11020-11021.

902 M. Kita, Y. Hirayama, K. Yoneda, K. Yamagishi, T. Chinen, T. Usui, E. Sumiya, M. Uesugi and H. Kigoshi, J. Am. Chem. Soc., 2013, 135, 18089-18095.

903 M. Ojika, H. Kigoshi, Y. Yoshida, T. Ishigaki, M. Nisiwaki, I. Tsukada, M. Arakawa, H. Ekimoto and K. Yamada, Tetrahedron, 2007, 63, 3138-3167.

904 O. Ohno, M. Morita, K. Kitamura, T. Teruya, K. Yoneda, M. Kita, H. Kigoshi and K. Suenaga, Bioorg. Med. Chem. Lett., 2013, 23, 1467-1471.

905 Y. Nakamura, H. Kato, T. Nishikawa, N. Iwasaki, Y. Suwa, H. Rotinsulu, F. Losung, W. Maarisit, R. E. P. Mangindaan, H. Morioka, H. Yokosawa and S. Tsukamoto, Org. Lett., 2013, 15, 322-325.

906 C.-D. Pham, H. Weber, R. Hartmann, V. Wray, W. Lin, D. Lai and P. Proksch, Org. Lett., 2013, 15, 2230-2233.

907 K. E. Rudolph, M. S. Liberio, R. A. Davis and A. R. Carroll, Org. Biomol. Chem., 2013, 11, 261-270.

908 J. L. Li, E. La Kim, H. Wang, J. Hong, S. Shin, C.-K. Lee and J. H. Jung, Bioorg. Med. Chem. Lett., 2013, 23, 4701-4704.

909 M. Menna, A. Aiello, F. D'Aniello, C. Imperatore, P. Luciano, R. Vitalone, C. Irace and R. Santamaria, Eur. J. Org. Chem., 2013, 3241-3246.

910 N. Bontemps, F. Gattacceca, C. Long, O. P. Thomas and B. Banaigs, J. Nat. Prod., 2013, 76, 1801-1805.

911 B. R. Copp, J. Tompa, A. Tahir and C. M. Ireland, J. Org. Chem., 1998, 63, 8024-8026.

912 H. K. H. Fong and B. R. Copp, Mar. Drugs, 2013, 11, $274-$ 299.

913 N. Matsumori, Y. Hiradate, H. Shibata, T. Oishi, S. Shimma, M. Toyoda, F. Hayashi, M. Yoshida, M. Murata and M. Morisawa, Org. Lett., 2013, 15, 294-297.

914 M. Yoshida, M. Murata, K. Inaba and M. Morisawa, Proc. Natl. Acad. Sci. U. S. A., 2002, 99, 14831-14836.

915 T. V. K. Reddy, B. L. A. P. Devi, R. B. N. Prasad, P. Sujitha and C. G. Kumar, Eur. J. Med. Chem., 2013, 67, 384-389.

916 A. Aiello, E. Fattorusso, A. Giordano, M. Menna, C. Navarrete and E. Muñoz, Tetrahedron, 2009, 65, 43844388.

917 J. N. Kumar, P. R. Reddy, B. Das, C. G. Kumar and P. Sujitha, Bioorg. Med. Chem. Lett., 2013, 23, 5192-5194.

918 J. N. Kumar and B. Das, Tetrahedron Lett., 2013, 54, 38653867.

919 M. L. Ciavatta, E. Manzo, G. Nuzzo, G. Villani, M. Varcamonti and M. Gavagnin, Tetrahedron, 2010, 66, 7533-7538.

920 T. B. Parsons, N. Spencer, C. W. Tsang and R. S. Grainger, Chem. Commun., 2013, 49, 2296-2298.

921 D. R. Appleton and B. R. Copp, Tetrahedron Lett., 2003, 44, 8963-8965.
922 K. Takamura, H. Matsuo, A. Tanaka, J. Tanaka, T. Fukuda, F. Ishibashi and M. Iwao, Tetrahedron, 2013, 69, 2782-2788.

923 W. Y. Yoshida, K. K. Lee, A. R. Carroll and P. J. Scheuer, Helv. Chim. Acta, 1992, 75, 1721-1725.

924 H. Jin, P. Zhang, K. Bijian, S. Ren, S. Wan, M. A. AlaouiJamali and T. Jiang, Mar. Drugs, 2013, 11, 1427-1439.

925 T. H. Trieu, J. Dong, Q. Zhang, B. Zheng, T.-Z. Meng, X. Lu and X.-X. Shi, Eur. J. Org. Chem., 2013, 3271-3277.

926 J. D. Panarese and S. P. Waters, Org. Biomol. Chem., 2013, 11, 3428-3431.

927 W. Wang, S.-J. Nam, B.-C. Lee and H. Kang, J. Nat. Prod., 2008, 71, 163-166.

928 L. Peng, F.-M. Zhang, B.-M. Yang, X.-B. Zhang, W.-X. Liu, S.-Y. Zhang and Y.-Q. Tu, Tetrahedron Lett., 2013, 54, 6514-6516.

929 H. Fuwa, K. Sekine and M. Sasaki, Org. Lett., 2013, 15, 39703973.

930 B. C. M. Potts, D. J. Faulkner, J. A. Chan, G. C. Simolike, P. Offen, M. E. Hemling and T. A. Francis, J. Am. Chem. Soc., 1991, 113, 6321-6322.

931 A. N. Pearce, E. W. Chia, M. V. Berridge, E. W. Maas, M. J. Page, J. L. Harper, V. L. Webb and B. R. Copp, Tetrahedron, 2008, 64, 5748-5755.

932 L. P. P. Liew, M. Kaiser and B. R. Copp, Bioorg. Med. Chem. Lett., 2013, 23, 452-454.

933 A. N. Pearce, E. W. Chia, M. V. Berridge, G. R. Clark, J. L. Harper, L. Larsen, E. W. Maas, M. J. Page, N. B. Perry, V. L. Webb and B. R. Copp, J. Nat. Prod., 2007, 70, 936-940.

934 C. F. C. Lam, N. Pearce, S. H. Tan, M. Kaiser and B. R. Copp, Mar. Drugs, 2013, 11, 3472-3499.

935 A. M. Seldes, M. F. Rodriguez Brasco, L. Hernandez Franco and J. A. Palermo, Nat. Prod. Res., 2007, 21, 555-563.

936 S. B. Bharate, R. R. Yadav, S. I. Khan, B. L. Tekwani, M. R. Jacob, I. A. Khan and R. A. Vishwakarma, MedChemComm, 2013, 4, 1042-1048.

937 M. J. McKay, A. R. Carroll and R. J. Quinn, J. Nat. Prod., 2005, 68, 1776-1778.

938 A. K. Pandey, R. Sharma, R. Shivahare, A. Arora, N. Rastogi, S. Gupta and P. M. S. Chauhan, J. Org. Chem., 2013, 78, 1534-1546.

939 J. Kobayashi, J.-F. Cheng, Y. Kikuchi, M. Ishibashi, S. Yamamura, Y. Ohizumi, T. Ohta and S. Nozoe, Tetrahedron Lett., 1990, 31, 4617-4620.

940 L. V. Frolova, I. V. Magedov, A. E. Romero, M. Karki, I. Otero, K. Hayden, N. M. Evdokimov, L. M. Y. Banuls, S. K. Rastogi, W. R. Smith, S.-L. Lu, R. Kiss, C. B. Shuster, E. Hamel, T. Betancourt, S. Rogelj and A. Kornienko, J. Med. Chem., 2013, 56, 6886-6900.

941 H. Kang and W. Fenical, J. Org. Chem., 1997, 62, 3254-3262. 942 J. W. Bin, I. L. K. Wong, X. Hu, Z. X. Yu, L. F. Xing, T. Jiang, L. M. C. Chow and W. S. Biao, J. Med. Chem., 2013, 56, 90579070.

943 T. H. Won, J.-e. Jeon, S.-H. Kim, S.-H. Lee, B.-J. Rho, D.-C. Oh, K.-B. Oh and J. Shin, J. Nat. Prod., 2012, 75, 2055-2061. 
944 C.-H. Ahn, T. H. Won, H. Kim, J. Shin and K.-B. Oh, Bioorg. Med. Chem. Lett., 2013, 23, 4099-4101.

945 K. Suwanborirux, K. Charupant, S. Amnuoypol, A. Kubo and N. Saito, J. Nat. Prod., 2002, 65, 935-937.

946 M. Tsujimoto, W. Lowtangkitcharoen, N. Mori, W. Pangkruang, P. Putongking, K. Suwanborirux and N. Saito, Chem. Pharm. Bull., 2013, 61, 1052-1064.

947 J. Sikorska, A. M. Hau, C. Anklin, S. Parker-Nance, M. T. Davies-Coleman, J. E. Ishmael and K. L. McPhail, J. Org. Chem., 2013, 78, 2812.

948 J. L. Li, B. Xiao, M. Park, E. S. Yoo, S. Shin, J. Hong, H. Y. Chung, H. S. Kim and J. H. Jung, J. Nat. Prod., 2013, 76, 815 .

949 G.-Y. Zhang, H.-H. Ren, Y.-B. Zhang, L.-Q. Ma, Y.-L. Yang and S. Wang, Biochem. Syst. Ecol., 2013, 51, 203-206.

950 N. P. Thao, N. X. Cuong, B. T. T. Luyen, N. H. Nam, P. V. Cuong, N. V. Thanh, N. X. Nhiem, T. T. H. Hanh, E.-J. Kim, H.-K. Kang, P. V. Kiem, C. V. Minh and Y. H. Kim, Chem. Pharm. Bull., 2013, 61, 1044-1051.

951 N. P. Thao, N. X. Cuong, B. T. T. Luyen, T. H. Quang, T. T. H. Hanh, S. Kim, Y.-S. Koh, N. H. Nam, P. V. Kiem, C. V. Minh and Y. H. Kim, Mar. Drugs, 2013, 11, 2917-2926.

952 R. S. Popov, N. V. Ivanchina, A. A. Kicha, T. B. Malyarenko, A. I. Kalinovskii and P. S. Dmitrenok, Chem. Nat. Compd., 2013, 49, 286-290.

953 Z. Li, G. Chen, X. Lu, H. Wang, B. Feng and Y. Pei, Nat. Prod. Res., 2013, 27, 1816-1822.

954 Z.-R. Zou, Y.-H. Yi, H.-M. Wu, J.-H. Wu, C.-C. Liaw and H.-K. Lee, J. Nat. Prod., 2003, 66, 1055-1060.

955 A. S. Silchenko, A. I. Kalinovsky, S. A. Avilov, P. V. Andryjaschenko, P. S. Dmitrenok, E. A. Martyyas, V. I. Kalinin, P. Jayasandhya, G. C. Rajan and K. P. Padmakumar, Nat. Prod. Commun., 2013, 8, 301-310.

956 A. S. Silchenko, A. I. Kalinovsky, S. A. Avilov, P. V. Andryjashchenko, P. S. Dmitrenok, V. I. Kalinin, S. Taboada and C. Avila, Biochem. Syst. Ecol., 2013, 51, 4549.

957 A. S. Silchenko, A. I. Kalinovsky, S. A. Avilov, P. V. Andryjashchenko, P. S. Dmitrenok, E. A. Martyyas and V. I. Kalinin, Nat. Prod. Commun., 2013, 8, 1053-1058.

958 A. S. Silchenko, A. I. Kalinovsky, S. A. Avilov, P. V. Andryjaschenko, P. S. Dmitrenok, E. A. Yurchenko, I. Y. Dolmatov, V. I. Kalinin and V. A. Stonik, Nat. Prod. Commun., 2013, 8, 1527-1534.

959 N. P. Thao, N. X. Cuong, B. T. T. Luyen, N. V. Thanh, N. X. Nhiem, Y.-S. Koh, B. M. Ly, N. H. Nam, P. V. Kiem, C. V. Minh and Y. H. Kim, J. Nat. Prod., 2013, 76, 1764-1770.

960 N. P. Thao, L. D. Dat, N. T. Ngoc, V. A. Tu, T. T. H. Hanh, P. T. T. Huong, N. X. Nhiem, B. H. Tai, N. X. Cuong, N. H. Nam, P. V. Cuong, S. Y. Yang, S. Kim, D. Chae, Y.-S. Koh, P. V. Kiem, C. V. Minh and Y. H. Kim, Bioorg. Med. Chem. Lett., 2013, 23, 1823-1827.

961 S. De Marino, M. Iorizzi, F. Zollo, C. D. Amsler, S. P. Greer and J. B. McClintock, Eur. J. Org. Chem., 2000, 4093-4098.
962 G. Xiao and B. Yu, Chem.-Eur. J., 2013, 7708-7712.

963 N. V. Palyanova, T. M. Pankova, M. V. Starostina, A. A. Kicha, N. V. Ivanchina and V. A. Stonik, Mar. Drugs, 2013, 11, 1440-1455.

964 F.-J. Wu, Y. Xue, Q.-J. Tang, J. Xu, L. Du, C.-H. Xue, K. Takahashi and Y.-M. Wang, J. Oleo Sci., 2013, 62, 717727.

965 J. S. Yoo, T. Park, G. Bang, C. Lee, J.-R. Rho and Y. H. Kim, J. Mass Spectrom., 2013, 48, 164-171.

966 N. V. Ivanchina, A. A. Kicha, T. V. Malyarenko, A. I. Kalinovsky, P. S. Dmitrenok and V. A. Stonik, Steroids, 2013, 78, 1183-1191.

967 H. Nan, H. Lin, Z. Qian and H. Yin, Heterocycles, 2013, 87, 1093-1098.

968 H. Wang, M.-Y. Li, T. Satyanandamurty and J. Wu, Planta Med., 2013, 79, 666-672.

969 M. G. Ponnapalli, M. Ankireddy, S. C. V. A. R. Annam, S. Ravirala, S. Sukki and V. R. Tuniki, Tetrahedron Lett., 2013, 54, 2942-2945.

970 C.-L. Cheng, Z.-Z. Wang, P.-L. Li, X.-W. Zhang, R.-C. Wu, H.-Y. Zhu, X.-L. Tang and G.-Q. Li, Chin. Chem. Lett., 2013, 24, 1080-1082.

971 H. Chen, J. Zhang, M.-Y. Li, T. Satyanandamurty and J. Wu, Chem. Biodiversity, 2013, 10, 612-620.

972 Y.-B. Wu, Z.-Y. Ni, C.-H. Huo, J. Su, M. Dong, F. Sauriol, Q.-W. Shi, Y.-C. Gu and H. Kiyota, Biosci., Biotechnol., Biochem., 2013, 77, 736-740.

973 K. Toume, K. Kamiya, M. A. Arai, N. Mori, S. K. Sadhu, F. Ahmed and M. Ishibashi, Org. Lett., 2013, 15, 6106-6109.

974 J. Li, M.-Y. Li, T. Bruhn, F. Z. Katele, Q. Xiao, P. Pedpradab, J. Wu and G. Bringmann, Org. Lett., 2013, 15, 3682-3685.

975 J. Li, M.-Y. Li, Q. Xiao, P. Pedpradab and J. Wu, Phytochem. Lett., 2013, 6, 482-485.

976 S. Homhual, H.-J. Zhang, N. Bunyapraphatsara, T. P. Kondratyuk, B. D. Santarsiero, A. D. Mesecar, A. Herunsalee, W. Chaukul, J. M. Pezzuto and H. H. S. Fong, Planta Med., 2006, 72, 255-260.

977 J. Chen, C.-S. Jiang, W.-Q. Ma, L.-X. Gao, J.-X. Gong, J.-Y. Li, J. Li and Y.-W. Guo, Bioorg. Med. Chem. Lett., 2013, 23, 5061-5065.

978 K. Li, C. O. Brant, M. Huertas, S. K. Hur and W. Li, Org. Lett., 2013, 15, 5924-5927.

979 M. Adachi, T. Imazu, M. Isobe and T. Nishikawa, J. Org. Chem., 2013, 78, 1699-1705.

980 M. Yotsu-Yamashita, Y. Abe, Y. Kudo, R. Ritson-Williams, V. J. Paul, K. Konoki, Y. Cho, M. Adachi, T. Imazu, T. Nishikawa and M. Isobe, Mar. Drugs, 2013, 11, 27992813.

981 Y. L. Mak, J. J. Wu, W. H. Chan, M. B. Murphy, J. C. W. Lam, L. L. Chan and P. K. S. Lam, Anal. Bioanal. Chem., 2013, 405, 3331-3340.

982 http://www.marinespecies.org, accessed June 2014. 